Firm Characteristics, Business Environment, and Performance of Non-Traditional Agricultural SME Exporters in Ghana

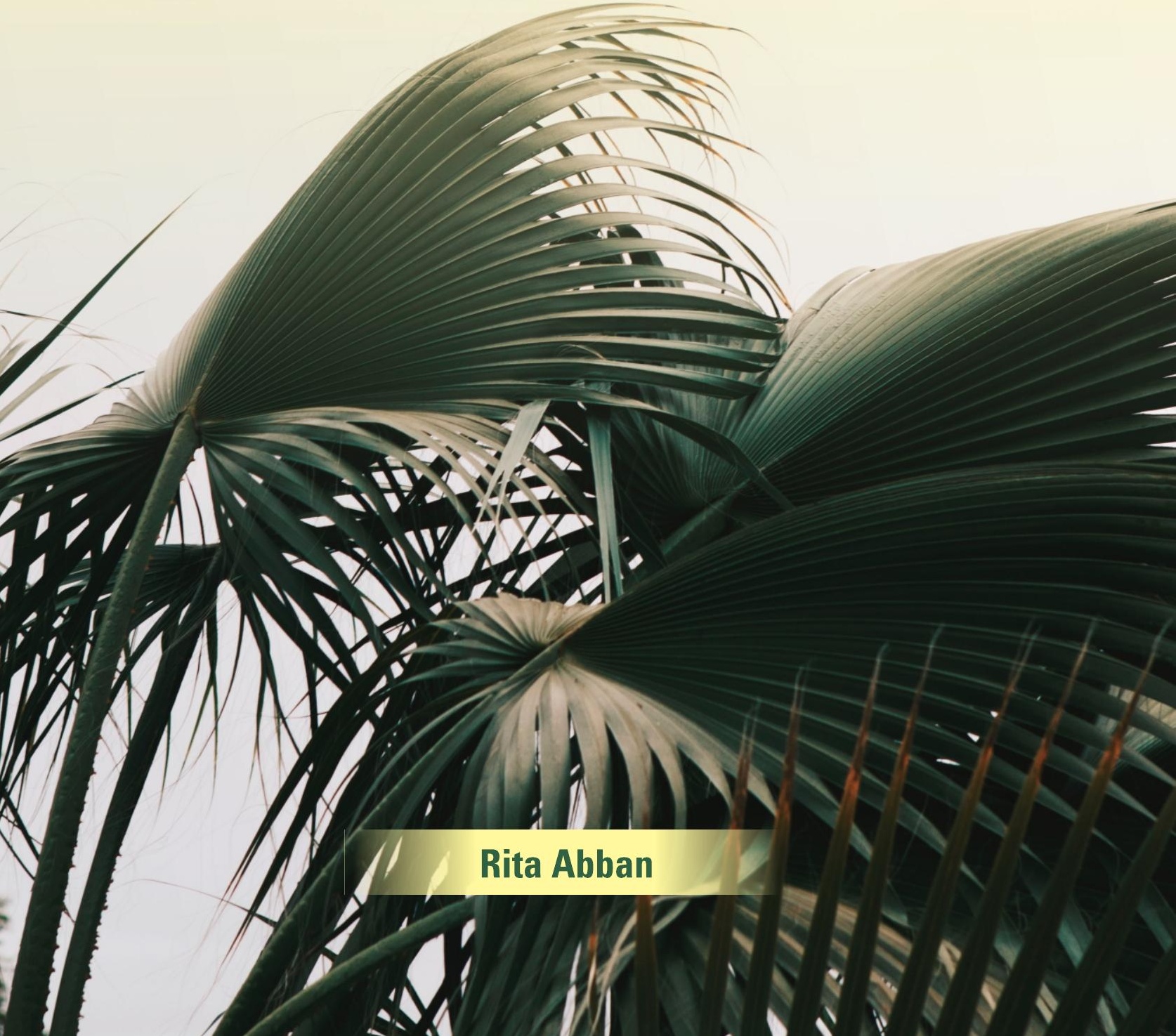




\section{PROPOSITIONS}

1. Irrespective of SME characteristics, channel choice and export institutions are major determinants of export performance of Non-traditional agricultural exports (NTAE-) SMEs in Ghana.

(this thesis)

2. CEOs of NTAE SMEs in Ghana should strengthen their networks through intensive contacts with export associations and institutions.

(this thesis)

3. For the effective implementation of agricultural innovations, an enabling environment needs to be sustained by all stakeholders in agri supply chains.

4. Better organization of and government support for the rural poor will ensure equitable development.

5. If not properly harnessed, knowledge can be as destructive as weapons of war.

6. Patience and understanding, but also creativity, is needed to move mountains.

\section{Propositions belonging to the PhD thesis, entitled}

Firm Characteristics, Business Environment and Performance of

Non-Traditional Agricultural SME Exporters in Ghana.

\section{Rita Abban}

Wageningen, 21 January 2020 
Firm Characteristics, Business Environment, and Performance of Non-Traditional Agricultural SME Exporters in Ghana 


\section{Thesis Committee}

\section{Promotors}

Prof. Dr S.W.F. (Onno) Omta

Emeritus Professor of Management Studies

Wageningen University \& Research

Prof. Dr J.B.K. Aheto

Emeritus Professor Faculty of Business and Management

Pentecost University College, Accra, Ghana

\section{Co-promotor}

Dr V.E. Scholten

Assistant Prof., Director of the Delft Centre for Entrepreneurship

Delft University of Technology, the Netherlands

\section{Other Members}

Prof. Dr Vincenzo Fogliano, Wageningen University \& Research

Prof. Dr Xavier Gellynck, Ghent University, Belgium

Dr Otto Kroesen, Delft University of Technology

Dr Haki Pamuk, Wageningen University \& Research

This research was conducted under the auspices of the Wageningen School of Social Sciences (WASS) 


\title{
Firm Characteristics, Business Environment, and Performance of Non-Traditional Agricultural SME Exporters in Ghana
}

\section{Rita Abban}

\author{
Thesis \\ submitted in fulfilment of the requirements for the degree of doctor \\ at Wageningen University \\ by the authority of the Rector Magnificus \\ Prof. Dr A.P.J. Mol, \\ in the presence of the \\ Thesis Committee appointed by the Academic Board \\ to be defended in public \\ on Tuesday 21 January, 2020 \\ at $4 \mathrm{pm}$ in the Aula.
}


Rita Abban

Firm Characteristics, Business Environment, and Performance of

Non-Traditional Agricultural SME Exporters in Ghana

212 pages

PhD thesis, Wageningen University, Wageningen, NL (2020)

With references, with summary in English

ISBN: 978-94-6395-101-2

DOI: https://doi.org/10.18174/498974 


\section{Acknowledgements}

Words are often not enough to express my gratitude and to acknowledge the support of so many people.

To my supervisors, I acknowledge each of you in a unique way. The journey to a PhD took a positive turn when I met Emeritus Professor Dr. S.W.F. (Onno) Omta, sometime in April 2007. He remained a pillar of support and a mentor throughout the entire journey. Special thanks to Dr. Victor Scholten who contributed in a number of ways and to Dr. Gerben van der Velde, I remain deeply grateful, you came in at a time to make that difference. To Emeritus Professor Dr. John B.K. Aheto, you were always there for me, through thick and thin, even when I was in despair you encouraged me. Your guidance is immeasurable.

Working at the Wageningen School of Social Sciences (WASS) provided a number of opportunities which I explored and benefited from. My work as an assistant lecturer (Corporate Financial Management and Financial Business Management courses) was made more enjoyable with the free rides I hitched with Dr. Harry Bremmers. I recall the with extreme gratitude and appreciation, the trips from the office to the Atlas Building for lectures and the small chats we had on my PhD progress, advice, and suggestions on teaching techniques. Dr. Miranda Meuwissen was a joy to be with, as she had some jokes now and then when I discussed an experience during my class. I had the opportunity to discuss reviews of my paper and work with Professor Gertjan Hofstede, Dr. Jack Peerlings and Professor Aad van Tilburg. I gained a lot of experience working directly with Dr. Frances Fortuin, Dr. Jos Bijman and Dr. Nel Wognum, in working groups critiquing thesis of other $\mathrm{PhD}$ candidates before their defense. I also learned a lot from comments made during working group sessions from other Professors including Jacques Trienekens, Paul van Beek, Emiel Wubben, Geoffrey Hagelaar, Vincent Blok, Ron Kemp, Wim Hulsink, Domenico Dentoni, Anna Sabidussi, and Maarten Batterink.

I say a big thank you to the Management Studies Group (MST) as a whole and in particular, Leonie van Scherrenburg, Ina Versteeg, Janna van Hoek and Jeanette Lubbers. Marcella Haan, Eveline Vaane, Dr. Irina Bezlepkina, Dr. Dries Hegger, and all administrative staff.

To my other MST colleagues (and those from other Groups), most of whom have graduated, I say thank you for letting me share in your company and counsel. Gumataw Abebe, Djalalou-Dine Arinloye, I remember our study times and debates, Zhen Liu, 
Andrei Cechin, Mark Wever, Mersiha Tepic, Etriya Etriya, Hanieh, Khodaei, Jose-Jaime Coronado, Rannia Nijhoff-Savvaki, Ekaterina Grekova, Daniela Pozobon, Guang-qian, Peng, Xia Zhao, Huliang Lu, Grwambi Bukelwa, Workneh Tessema, Adane Tufa, Misery Sikwela, Krisztian Kovacs, Essegbemon Akpo, and Alphonse Singbo.

To my "family" and friends I lived with in Amsterdam, thank you for being there for me. Eddy Adusei, Alhaji Moro and Sophia Oubda, Matilda Esson, Fr. Muge, Fr. Koos, Fr. Timmerman, Fr. Affum and parishioners of All Saints Catholic Church.

I cannot forget my 'unofficial supervisor' who helped me along the way. I am deeply indebted to Professor Dr. Kofi Awusabo-Asare of the University of Cape-Coast-UCC (Department of Population and Health). Professor Dr. Esi Abbam Elliot of Suffolk University (Department of Marketing) thank you for believing in me. To Professor Dr. Emmanuel Kojo Sakyi of the University of Ghana (UG) (Department of Public Administration and Health Service Management), I say thank you for your assistance during fieldwork. To all others who helped me in fieldwork, data collection, data entry and analysis, I am grateful to you. I mention, Mr. Samuel Kwasi-Kwakye Quachey (QComputer Solutions), Mr. Felix Larry Essilfie and Mr. Joseph Clottey both of UG (Department of Agricultural Economics and Agribusiness), Mr. Kenneth Nartey and Mr. Emmanuel Darkwa both of Dodowa Health Research Center, Mr. Mawutor Anku of the Ministry of Finance and Economic Planning, Ms. Delali Kpestsigo of UCC (Department of Population and Health), Mr. Emmanuel Abbey of UG (Department of Economics) and Mr. Paul Ntifo of UG (HR Division-Registrar's Office).

I acknowledge the assistance provided by the Ghana Export Promotion Authority. I wish to especially mention Mrs. Agnes Gifty Adjei-Sam, Mr. Seidu Saaka, and Mr. Emmanuel Quao. I am grateful to the various Associations, government institutions and the NonTraditional Agricultural Export Small and Medium Enterprises (NTAE SMEs) respondents who participated in the pilot study and the fieldwork. I cannot mention all of you by name but I acknowledge your key inputs.

I am grateful to the University of Cape-Coast, School of Business, especially, (former Dean) Professor Edward Marfo Yiadom of the Department of Accounting, Dr. Mohammed Anokye Adam, Dr. Samuel K. Agyei, and Dr. Siaw Frimpong all of the Department of Finance, and Mr. Daniel Ofori of the Department of Marketing and Supply Chain Management for a comprehensive review and analysis of my thesis and a mock defense to prepare me. 
My inspiration to undertake a $\mathrm{PhD}$ started several years ago from my relationship with my late father, Professor Dr. Abban, who always challenged me to stand up and stand out in keeping with sound ethical principles and moral values ("aim to be among the top three"). I used to enjoy reciting his titles every now and then: Veteran Gold Coast Army (WWII), Physician Specialist, Specialist Psychiatrist, Pharmacologist, Specialist Tropical Medicine \& Sickle Cell, Past Grand Advisor, Supreme Physician, Past Supreme Knight Noble Order of the Knights of Marshall, Founding member West African College of Physicians and Surgeons, etc. etc. I also realized very early from my work experience that the title Doctor mattered especially in opening the door(s) to a whole new level in the world of key decision makers.

The one person who looks up to me, and who I could not let down is my daughter-AnneMarie (Chups). Thank you for your patience in putting up with me during this journey. To the rest of my family thank you for the understanding and experience, it was an endurance with very many lessons learnt. To my friends who supported me, and to any person(s) whom I may have left out inadvertently, know that I am grateful in no small way. 
To

Anne-Marie Abban-Demitrus

And in honour of

PTE. WWII (Sir Knight) Professor Dr. Frank A. Abban (deceased) 


\section{Table of Contents}

$\begin{array}{lll}\text { Chapter } 1 \quad \text { General Introduction } & 1\end{array}$

1.1 Preface 2

1.2 Introduction 2

$\begin{array}{lll}1.3 & \text { Problem statement and Objectives } & 7\end{array}$

1.4 Research Questions 8

1.5 Theoretical Framework 9

$\begin{array}{lll}1.6 & \text { Outline of the Thesis } & 12\end{array}$

Chapter 2 Perspectives on Agriculture and Agribusiness in Sub-Saharan Africa $\quad 15$

$\begin{array}{lll}2.1 & 16\end{array}$

2.2 Overview of Initiatives in Agriculture and Agribusiness $\begin{array}{ll}\text { in Africa } & 17\end{array}$

2.3 Context and Research Methods 19

2.4 Findings 24

2.5 Conclusions and Recommendations 27

Chapter 3 Ele Agbe in search for a new light in Ghana's shea sector 31

3.1 Background $\quad 32$

3.2 Introduction $\quad 32$

3.3 Company Background 33

3.4 Current Management Structure 33

3.5 Key Success Factors 34

$3.6 \quad$ Strategic Issues for Ele Agbe 36

3.7 Conclusions and Recommendations 38

Chapter 4 Internal Capabilities and Export Performance of SMEs in Ghana's Non-Traditional Agricultural Export Sector 39

$\begin{array}{lll}4.1 & \text { Introduction } & 40\end{array}$

4.2 Theoretical background and framework 41

4.3 Export in Developing Countries 43

4.4 Research Design 46

$\begin{array}{lll}4.5 & \text { Research Methods } & 48\end{array}$

4.6 Results/Data Analysis $\quad 50$

4.7 Conclusions and Recommendations 58 
Chapter 5 Connecting the Dots: A Multiple Case Study of the Network Relationships of Small and Medium-Sized Enterprises (SMEs) in the Non Traditional Agricultural Export (NTAE) Sector of Ghana 61

5.1 Background 62

5.2 Review of Relevant Studies and Research Model 64

5.3 Context and Research Methods 70

$\begin{array}{lll}5.4 & \text { Findings } & 75\end{array}$

$\begin{array}{lll}5.5 & \text { Conclusions and Recommendations } & 79\end{array}$

Chapter 6 Non-Traditional Agricultural Export Performance in Ghana. Exporting SMEs' Characteristics, $\begin{array}{lr}\text { Channel Choice and Institutions } & 81\end{array}$

$\begin{array}{lll}6.1 & \text { Introduction } & 82\end{array}$

6.2 The NTAE-SME Sector in Ghana 86

6.3 Conceptual Framework and Hypotheses 87

6.4 Research Methods 95

$\begin{array}{lll}6.5 & \text { Results/Data Analysis } & 102\end{array}$

6.6 Conclusions and Recommendations 107

Chapter $7 \quad$ General Discussions and Conclusions 111

$\begin{array}{lll}7.1 & 112\end{array}$

7.2 Answers to the research questions 113

7.3 Theoretical and methodological contributions 119

$\begin{array}{ll}7.4 & \text { Policy and managerial implications } \\ 7.5 & 121\end{array}$

$\begin{array}{ll}7.5 & \text { Limitations and further research }\end{array}$

$\begin{array}{ll}\text { Appendices } & 125\end{array}$

$\begin{array}{ll}\text { Summary } & 165\end{array}$

$\begin{array}{ll}\text { References } & 173\end{array}$

Completed Training and Supervision Plan 195

Funding 196

About the Author 197 


\section{List of Tables}

\section{Chapter 2}

$2.1 \quad$ Number of respondents (per country/case) 20

2.2 Profile of respondents 22

2.3 Key Questions 23

\section{Chapter 4}

4.1 Company characteristics (location, audits, and financial assets) 51

4.2 Vision of the SME CEOs 52

4.3 Average Variance Extracted (AVE) and Correlations 55

4.4 PLS SEM estimates for factors that are linked to export performance of SMEs in Ghana $\quad 56$

\section{Chapter 5}

$\begin{array}{lll}5.1 & \text { Key questions } & 72\end{array}$

\section{Chapter 6}

6.1a Independent variables: items, factor loadings, VIF, Cronbach alpha, mean and standard deviations and measurement scales

6.1b Dependent and control variables: items, means and standard deviations and measurement scales 98

6.2 Average Variance Extracted (AVE) and Correlations 101

6.3 Sample Characteristics (location, size, product type and CEO gender and education) 102

6.4a Outer Model: SME characteristics (including p values) 104

6.4b Outer model: Export mode and institutions (services and finance) (including $\mathrm{p}$ values) 105

6.5 PLS SEM estimates for the internal and external environmental factors related to export performance of NTAE SMEs in Ghana 106 


\section{List of Figures}

\section{Chapter 1}

1.1 NTAE Performance by sub-sector, 2007 and 2016

$\begin{array}{lll}1.2 & \text { Theories applied in the study } & 10\end{array}$

$\begin{array}{lll}1.3 & \text { Outline of the thesis } & 14\end{array}$

\section{Chapter 2}

2.1 Government commitment to agriculture and agribusiness 26

\section{Chapter 4}

4.1 Conceptual Model: Relationship between the independent constructs and the dependent constructs of Export Performance 46

4.2 Map of Ghana $2019 \quad 46$

\section{Chapter 5}

5.1 Research Model

Chapter 6

6.1 Conceptual Model 


\section{Abbreviations}

AGI

AGOA

Association of Ghanaian Industries

AJEMS

Africa Growth Opportunities Act

AJOM

African Journal of Economic and Management Studies

AU

Africa Journal of Management

AUC

African Union

AVE

African Union Commission

AWEP

Average Variance Extracted

BOG

Africa Women's Entrepreneurship Program

CA

Bank of Ghana

CAADP Comprehensive Africa Agriculture Development Programme

$\mathrm{CEO}$

Chief Executive Officer

CSOs

Civil Society Organisations

ERP

Economic Recovery Programme

EU

European Union

FAGE

FL

Federation of the Association of Ghanaian Exporters

FNGO

Fornell-Larcker

GCEPS

Financial Non-Governmental Organisation

GDP

Ghana Customs Excise and Preventive Service

GEPA

Gross Domestic Product

GSS

Ghana Export Promotion Authority

IMF

Ghana Statistical Service

IFAMR

International Monetary Fund

IP

International Food and Agribusiness Management Review

ITJE Intellectual Property

JME International Journal of Technology and Entrepreneurship Journal of Management and Entrepreneurship

LT

Letters of Credit

MDG

Long-term

ME

Millennium Development Goal

MSME

Merchandise Export

MT

Micro, Small and Medium Enterprises

Management Team 
NEPAD New Partnerships for Africa's Development

NGO Non-Governmental Organisation

NTAE Non-Traditional Agricultural Export

NTE Non-Traditional Export

OAU Organisation of African Unity

PHL Post-Harvest Losses

PLS Partial Least Squares

RBV Resource Based View

RECs Regional Economic Communities

SAP Structural Adjustment Programme

SCM Supply Chain Management

SD Standard Deviation

SDGs Sustainable Development Goals

SEM Structural Equation Model

SME Small and Medium Enterprises

SPEG Sea Freight Pineapple Exporters of Ghana

SSA Sub-Saharan Africa

SSC South-South Cooperation

ST Short-term

UNCG United Nations Communications Group

US United States

USAID United States Agency for International Development

USD United States Dollar

VEPEAG Vegetable Producers and Exporters Association of Ghana

VIF

Value Inflation Factor

VRIN

Valuable, Rare, Inimitable, Non-Substitutable

VRIO

Valuable, Rare, Imperfectly Imitable, Organization

WDR

World Development Report 
CHAPTER 1

General Introduction 


\section{CHAPTER 1}

\section{General Introduction}

\subsection{Preface}

For most Sub-Sahara African (SSA) economies, the most important means of generating foreign exchange revenues have been traditional agricultural products and minerals. These products have to a large extent been exported in their raw form, with little added value. The result is thought to have negatively affected the development and status of micro, small, and medium sized enterprises/farmers. African Union (AU) member states have sought to improve or reverse this trend by committing themselves towards more effective agriculture and agribusiness policies. To this end, diversification of exports to include non-traditional agricultural exports (NTAEs) ${ }^{1}$ has become relevant over the past 3 decades. What is becoming obvious is that the overarching policies at AU and state levels have not been synchronized with micro level policies both/each of which could strengthen agri supply chains within the NTAE sector. NTAE small and medium enterprises (SMEs) can benefit from the growing export opportunities due to international demand for alternative products. To achieve this the provision of services through the role of government become vital to NTAE SME entrepreneurial behaviour, and how they respond to logistics and government support. Thus, the interactions between entrepreneurial behaviour and contextual factors are important areas which need to be investigated. In addition, the discussions provide information on interventions in the NTAE sector likely to support Ghana's Global Agenda 2030 and the attainment of sustainable development goals (SDGs). The thesis provides insights into how selected NTAE SMEs in Ghana respond to government stimulus, as these will have implications for policy makers and practitioners.

\subsection{Introduction}

Agriculture has been and still is the backbone of the economy of many developing countries. As the main source of foreign exchange, agriculture has received increasing attention from governments and international development partners, for the entire value chain, particularly high value commodities (Babu et al., 2015). For Sub-Saharan Africa (SSA), agriculture is thought to show the fastest growth (Livingston et al., 2011). This accounts for the growth in the economies of countries such as Ethiopia (8.5\%), which is

\footnotetext{
${ }^{1}$ NTAEs include horticultural products, tubers, wood, apparel among others. See Section 1.2 NTAE Sector pp4.
} 
the fastest growing economy (per GDP growth \%) in SSA, followed by Rwanda (7.8\%) and Ghana (7.6\%) IMF (2019²). In 2017, Ghana was considered to be one of the best performing countries in Africa being about 30 percentage points away from the frontier ${ }^{3}$. The growth is backed by agriculture which is still an economic mainstay of many SSA countries, employing about $60 \%$ of the workforce, and, contributing an average of $30 \%$ to the gross domestic product (Thornton et al., 2011, pp118). Agricultural exports from Africa formed $12 \%$ of world trade. Out of this, agricultural products (added value agricultural products - semi/processed) made up $10 \%$ of the $12 \%$. These agricultural exports are "high value cash-crops such as cocoa, tea, cotton, and oranges" (Livingston et al., 2011, pp6). Ghana's traditional exports are cocoa, gold, and, timber which accounted for $62.6 \%$ of merchandise exports ${ }^{4}$ in 2017 (Bank of Ghana-BOG, 2017).

Agriculture in Ghana is based on small holder farming of arable land under irrigation (Martey et al., 2012, pp2132). Around the 1960s, 70\% of agricultural holdings were managed by small farmers (mainly family businesses), and government agricultural holdings were not more than 10\% (Oppong et al., 2014, pp79). Ghana was at the time, the world's largest producer of cocoa, which contributed $45 \%$ of foreign exchange earnings. The proportion gradually dropped to $35 \%$ in the 1990 s and to $25 \%-30 \%$ around 2010 (Essegbey \& Ofori-Gyamfi, 2012; Quarmine et al., 2012). In 2016 and 2017 cocoa contributed $23.2 \%$ and $19.1 \%$ respectively, to Ghana's foreign exchange earnings (BOG, 2017). The fall in the share of export earnings could be attributable to a drop in production and market prices. As Aryeetey \& Mckay (2007) suggest, this may have been caused by negative export policy(s) in the 1970's leading to high taxes on cocoa and overvalued exchange rates. This drove farmers to change to the production of other crops or other activities. The trend was reversed in the 1980s with the inclusion of non-traditional exports $\left(\mathrm{NTEs}^{5}\right)$ - mostly agricultural or processed agricultural products, including pineapples, yams, wood products, cocoa products, canned tuna, and oil palm products which increased revenue contribution to trade (Aryeetey \& Mckay, 2007, pp155). In the 1980s, the then government introduced policies to diversify exports in order to increase revenues (Egyir et al., 2012). These policy interventions which included the Economic

\footnotetext{
${ }^{2}$ In: Business News March 1, 2019. See References pp173.

${ }^{3}$ Frontier is explained as the best performing country in the world, i.e. New Zealand-86.6 (Ghana57.2) -based on 2017 World Development Indicators, https://databank.worldbank.org/data/reports.aspx?source=2\&series=IC.BUS.DFRN.XQ

${ }^{4}$ Merchandise exports are cocoa beans and cocoa bean products, gold, timber and timber products, crude oil. Other exports are non-traditional agricultural exports and minerals: aluminium alloys, bauxite, diamond, and, manganese (BOG, 2017, pp16-17)

${ }^{5}$ NTEs also include aluminum, base metal, plastics and chemicals.
} 
Recovery Programme (ERP) and Structural Adjustment Programme (SAP) promoted non-traditional agricultural exports (NTAEs). Changes in the global market for agricultural commodities in the 1990s, led to rising importance of NTAEs, especially horticultural products, from many African countries, including Ghana. The export of fresh fruits and vegetables rose by 243\% between 1980 and 2005 (Ouma et al., 2013). BOG (2017) annual report statistics show non-traditional exports in 2015, 2016, and 2017 was USD $\$ 2.24$ billion (21.8\% of total exports), USD $\$ 2.05$ billion (18.4\% of total exports), and USD $\$ 2.06$ billion (14.9\% of total exports) respectively. The increases in agricultural component of NTE was partly due to opportunities for value addition (through processing and creating new products). However, small businesses and smallholder farmers were increasingly marginalized as a result of the adverse effects of globalization, unfair competition, specialized requirements for innovation, food safety and quality (Banson, 2015).

There are no statistics immediately available on Africa's total NTAE products/exports as either a share of global trade or export volumes. However, the Food and Agricultural Organisation-FAO, 2004 studies make mention of the increasingly important role of developing countries to world trade in NTAEs. Developing countries accounted for $56 \%$ of NTAE world trade in 2001. This percentage includes Africa although Africa's portion/contribution is not identified. It should be observed that in terms of international trade and export data "retail sales and export values are not strictly comparable due to differences in data collection methods" (Willer \& Lernoud, 2017, pp69). Cote d'Ivoire and Ghana held $17 \%$ and $3.8 \%$ of world pineapple trade in 2001 (FAO, 2004) which shows good performance for this sub-sector product. Situating the NTAE performance of Ghana in the context of the Africa region is however a challenge for the reasons presented.

\section{NTAE Sector}

The NTAE sector includes exotic fruits, vegetables, tubers, processed and semi-processed wood, apparel, rubber and agricultural products. Cocoa paste, canned tuna, veneer, cocoa butter, sheanut butter and pineapples are among the leading NTAE products (Abban et al., 2013; Hinson, 2011). Figure 1.1 shows a remarkable export growth of the NTAE sector (Ghana Export Promotion Authority-GEPA 2018 Statistics) from 2007 to $2016^{6}$. In 2007 , total NTAE revenues amounted to USD $\$ 898$ million, while in 2016 , the total revenue

\footnotetext{
${ }^{6}$ GEPA 2018 Statistics on NTAE Performance per Sub-Sector (year by year) can be found in Appendix 5, pp137.
} 
from NTAEs had risen to USD \$2 billion. This represents an increase of $223 \%$. The overall performance does not reflect the sub-sector performance also in terms of weight/volume. For example, the performance of cereals alone (rice, maize seed, cereals, and maize) dropped 65\% from 6.5 thousand $\mathrm{kg}$ in 2007 to 2.26 thousand $\mathrm{kg}$ in 2016, although the revenues fell by $26 \%$ from USD \$ 1.47 million in 2007 to USD \$ 1.09 million in 2016 . Figure 1.1 presents a comparison of aggregated values in United States dollars for 2007 and 2016.

Figure 1.1 NTAE Performance by Sub-Sector, 2007 and 2016

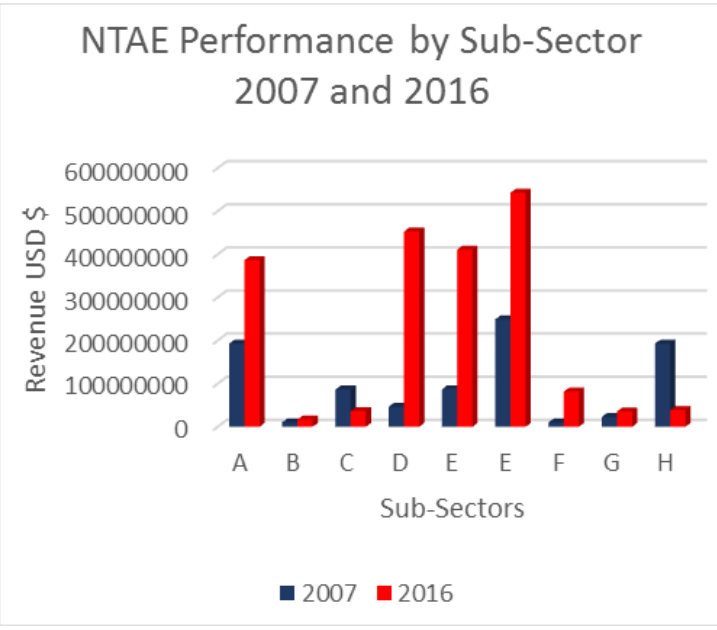

\begin{tabular}{|c|c|}
\hline $\mathbf{A}$ & $\begin{array}{l}\text { cereals, coffee, tea, mate, spices, prepared } \\
\text { cereals and tubers, prepared food and } \\
\text { beverages, sugar and sugar confectionery }\end{array}$ \\
\hline B & $\begin{array}{l}\text { dairy products (raw), animal feed, dairy } \\
\text { products (processed) }\end{array}$ \\
\hline $\mathrm{C}$ & fish and seafood, meat and meat offal \\
\hline D & $\begin{array}{l}\text { horticultural products, vegetable saps and } \\
\text { extracts }\end{array}$ \\
\hline $\mathbf{E}$ & $\begin{array}{l}\text { oil seeds and nuts, animal or vegetable } \\
\text { oils, essential oils }\end{array}$ \\
\hline $\mathbf{F}$ & other agricultural products, cocoa products \\
\hline G & $\begin{array}{l}\text { medicaments, tobacco and tobacco } \\
\text { substitutes }\end{array}$ \\
\hline $\mathbf{H}$ & $\begin{array}{l}\text { footwear and headgear, textile and } \\
\text { garments }\end{array}$ \\
\hline I & $\begin{array}{l}\text { handicrafts, leather articles, travel goods, } \\
\text { wood products }\end{array}$ \\
\hline
\end{tabular}

Source: GEPA Annual Report 2018

Discussions in the literature on Ghana's NTAE sector suggest, horticultural products, such as pineapple, papaya, mango and chilies, were given attention right from the 1980s (Egyir et al., 2012). For this reason, horticultural exports experienced substantial growth over the past three decades. Fresh fruits and vegetables made significant contributions to growth of Ghana's agricultural sector (Kleeman et al., 2014). The export of pineapples, rose significantly in the 1980s but dipped in 2004 because of the shift in pineapple variety demand on the global market from smooth cayenne to MD2 (Kleeman et al., 2014, pp 80). This shows that market information to pineapple exporters was either inadequate or not acted upon. In Ghana's shea sector (see Appendix 9 for recent developments), exporters of processed products are innovative in developing new product lines; however expansion appears inhibited by lack of a regulated shea sector, "non-existent working policy for shea and breaks or gaps in the shea supply chain" (Abban et al., 2014, pp65). These two cases suggest that there are sub-sector peculiarities (such as, different levels of market 
information, different regulatory frameworks) to exporting of NTAEs. This is in spite of the government export incentive packages (retention of export earnings, income tax rebates) introduced in the 1980s and 1990s (Kuada, 2000).

\section{SMEs in the NTAE sector}

The NTAE sector is dominated by small and medium enterprises (SMEs) who contribute to $70 \%$ of GDP, over $80 \%$ of employment and make up $90 \%$ of Ghanaian businesses (Abor et al., 2014). As a consequence, NTAE SMEs are important for government, because of their contribution to reach socio-economic objectives (Quaye et al., 2014). SMEs can be classified in terms of their assets/employees: Micro: $\leq$ \$US10,000/1-5 employees;

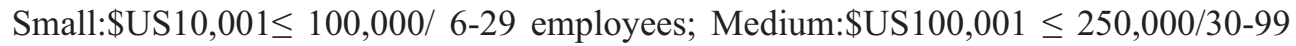
employees (Abban et al., 2013; Abor \& Quartey, 2010). SMEs play an important role in the NTAE sector, though they appear not to have been performing well. This is in spite of various assistance programmes, incentive schemes, and, technical support from governmental and non-governmental organisations (NGOs), and multilateral agencies ${ }^{7}$ made available to them (Boansi et al., 2014; Oppong et al., 2014). Some reasons advanced for not performing well are that SMEs face peculiar problems. These include deficiencies arising from their limited resources and limited range of their technological competencies (Mahmoud, 2011). Institutional problems are considered as another factor affecting SMEs. The public incentive schemes and programmes are still considered sub-optimal in their net effect on export operations (Buatsi, 2000, pp15). On the one hand, exporters may not be knowledgeable about export financing and experience difficulties in obtaining finance. On the other hand, it is also true that financial institutions lack in-depth knowledge of export sector operations. For this reason, financial institutions are not well equipped to assist SME exporters (Buatsi, 2000). Quartey et al. (2017) discuss the limited access to credit of SMEs in Ghana and indicate that the problems originate from commercial or equity banks (lack of understanding of the agriculture sector), institutional imperfections (incongruent regulations; lack of policies) and also the SMEs themselves (limited capacities/skills). Besides these, there are other factors that may hinder SMEs operating in the NTAE sector. For example, Ghanaian companies especially the SMEs are thought to have "no concept of the importance of the internet for export marketing" (Hinson, 2010, pp338). The internet is believed to have the potential of impacting business operations through information acquisition, market access, and, export promotion,

\footnotetext{
${ }^{7}$ Multilateral agencies obtain their funding from multiple governments and spend it on projects in various countries.
} 
although the associated costs of these may be an impediment to NTAE SMEs (Hinson \& Abor 2005, pp236).

\subsection{Problem Statement and Objectives}

For Sub-Saharan economies to develop more fully their agricultural sector, there is the need for them to exploit opportunities provided by their vast and varied resources, and, not limit themselves to a narrow core of resources. Some ways to do this are through diversification, innovation and value added. While agriculture is proven to be the backbone of many African economies, "agricultural diversification and production of high value crops" showcase the importance of the NTAE sector, and, illustrate its potential for development (Dolan \& Humphrey, 2000, pp148). This cannot be done without a critical assessment of the NTAE SMEs and the environment in which they operate. Identifying the enabling factors that may impact their export performance is therefore important (Buatsi, 2000).

There is a pile of literature on Ghana's export and SMEs, mostly on finance, internet use, marketing, environment and resources (Ansong \& Agyeman, 2016; Yeboah, 2015; Adomako \& Danso, 2014; Adu-Gyamfi \& Kornelieussen, 2014; Obeng et al., 2014; Quaye et al., 2014; Yamoah et al., 2014; Mahmoud, 2011; Boateng et al., 2011; Aryeetey \& Ahene, 2005) and a growing amount of literature on NTEs and SMEs (Boso et al., 2016; Abor et al., 2014; Hinson, 2010; Hinson \& Soerensen, 2005; Hinson \& Abor, 2005; Kuada, 2000; Buatsi, 2000) and some research on NTAE sub-sectors (Banahene et al., 2016; Abban et al., 2014; Ouma et al., 2013; Melle \& Buschmann, 2013; Taylor \& Owusu, 2012; Takane, 2004) but a theoretical gap still exists that needs to be explored to identify which factors at the NTAE SME level, and, at the level of the SME's environment stimulate or hinder NTAE performance. The findings will explain further which resources and networks are most relevant for the NTAE sector. Specifically criticisms of the RBV suggest that resources alone do not fully explain performance thereby constituting a theoretical gap. The unexplained link can be better explained by application of other theoretical concepts. For this reason, the network and supply chain management theories are used together with the RBV to explain the gap, and, better link resources and networks to performance. This study intends to contribute to the literature by proposing which factors, resources, supply chains and networks at the NTAE SME level, and, the business environment affect NTAE performance. The study makes use of a mixed method of analysis dwelling extensively on a qualitative approach with statistical applications. The 
contribution will inform whether the findings are consistent with theories on exporting SMEs in general, are peculiar to Ghana's NTAE sector, or, lead to new theoretical insights.

While there are challenges to export growth and difficulties for individual NTAE SMEs, some NTAE SMEs are exporting more successfully than others. In this thesis, this will be analysed using the theoretical insights of the Resource Based View (RBV), Network theory, and, Supply Chain Management (SCM), although these theories do not fully apply to the NTAE SME context in Ghana. The contextual factors of NTAE SMEs in developing countries, their internal capabilities, the logistic/chain characteristics and the relationship (positive/negative) to government support are often not addressed in the literature. In discussing these factors we follow Buatsi (2000) who divides the underlying factors determining the ability to export to be attributable to "sources within the firm" and "sources outside the firm".

The overall objectives of this study is to identify the internal and external factors that facilitate or hinder NTAE SME export performance. This knowledge is used to provide suggestions towards a more effective policy framework, to support NTAE SMEs operations. The study is also considered important to the current discussions related to Ghana's Global Agenda 2030, and, the possibilities to reach the sustainable development goals (SDGs). Specifically, development goal 1 - no poverty, goal 2 -zero hunger, goal 8 decent work and economic growth, goal 9 - industry, innovation and infrastructure, and, goal 12 - responsible consumption and production (UNCG, 2017).

\subsection{Research Questions}

This thesis addresses the following central research question and sub-questions:

The central research question is:

Within the theoretical context of the Resource Based View (RBV), Supply Chain Management (SCM), and network theories, which characteristics (specifically internal capabilities, resources, and, network relationships) of NTAE SMEs and their business environment, are positively related to their export performance?

The sub-questions to be addressed are:

1. Which of the firms' internal capabilities are most relevant to NTAE SMEs export performance?

2. What are the challenges that confront exporting NTAE SMEs and what could be done to improve the situation? 
3. What combination of the firm resources and network relationships are positively linked to NTAE SMEs performance?

Each sub-question is not specifically linked to one chapter. The results of 2 or 3 chapters are used to answer the research questions in Chapter 7. The results of the Chapters 3 and 4 are used to answer sub-research question 1 on the internal capabilities relevant to NTAE SMEs export performance. The results of the Chapters 1,2 and 6, are used to answer the sub-research question 2 on the challenges confronting exporting NTAE SMEs, and, how the situation could be improved. While the results of the Chapters 5 and 6 are used to answer the sub-research question 3, on the combination of firm resources and network relationships that may positively affect NTAE SME performance.

\subsection{Theoretical Framework}

This study is mainly based on the Resource Based View (RBV) of the firm, network (relationships) analysis, and, Supply Chain Management (SCM) (export linkages) as presented in Figure 1.2. The resource based view (RBV) is an approach that facilitates the study of a firm's capabilities and ability to exploit opportunities. Originally attributed to Wernerfelt (1984), the RBV looks at resources and products of the firm as two sides of the same coin. Unlike products, there is the attribution of resources as a broader set of resources. This can be traced back to Penrose (1959). Within the context of this study, RBV has been used to explain the SMEs entrepreneurial strategy, innovation and supply capacities (Schumpeter, 1942; Gashi et al., 2014; Barassa et al., 2016). A key attribute of $\mathrm{RBV}$ is to provide the premise for explaining and investigating various theories of, or, related to the firm. Most importantly, and, related to this study is the reference to RBV to discuss the environment of the firm. The focus is on intra and inter firm activities and relationships with respect to networks and actors in the firm's supply chain.

The RBV suggests that the resource base of the firm determines the networks available to the firm, and, how access to resources and opportunities in another network may prove advantageous to the firm (Granovetter, 1973, 1983). The study contributes to the perspective of supply chain as complex or interacting networks confronting the firm, (Christopher \& Peck, 2004) for which the firm resource(s) determines performance. The network theory is linked to the SCM of the firm, because it helps in determining the actors that can be found upstream and downstream of a firms' supply chain, and, how these actors interact throughout the chain. This is because chain actors act differently at each stage of the supply chain (Hugos, 2018). 


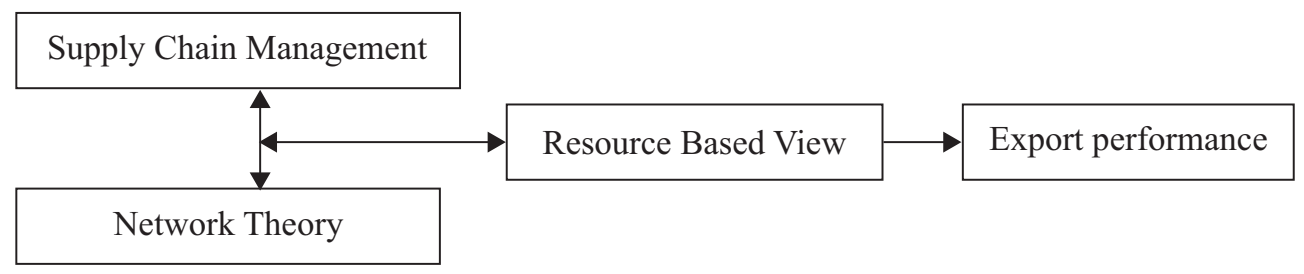

Figure 1.2 Theories applied in the study

The application of RBV to this study is supported by literature. RBV has been used to explain determinants of a firm's internationalization process (Barney, 1991; Wernerfelt, 1984) which makes it relevant to our study context. In particular the RBV theory focuses on the internal determinant factors "that have a potential effect on exporting (resources and capabilities)" (Galati et al., 2014, pp105). The RBV theory has been used in several studies to explain or discuss factors that determine firm behaviour in export markets, or export success (Galati et al., 2014). In combining RBV with export research, it is evident that a "firm's resources are closely related to its export performance" (Chung et al., 2019, pp5-6). These views are also supported by Makri et al. (2017) who argue that application of the RBV has contributed to theoretical development, and, logical rigor of export related studies. This makes the RBV very useful to this study.

However, there have been criticisms of RBV in the literature which cannot be overlooked. These have been related to description/definition of RBV, assumptions, and, applications (Hoopes et al., 2003; Armstrong \& Shimizu, 2007; Sanchez, 2008; Seoudi, 2009). More recently, Shafeey \& Trott (2014) discussed extensively the schools of thought and the criticisms of the RBV. While the schools of thought have discussed RBV in terms of resources, dynamic capabilities and core competencies, these have not been distinctly addressed in the literature. In addition, the RBV theory is developed on the valuable (V), rare (R), imperfectly imitable (I), and organization (O), known as the VRIO framework. This is thought to explain resource based competition (competitive advantage and performance) of the firm. Shafeey \& Trott (2014, pp3) argue that the RBV based on fundamental, conceptual, and, theoretical criticisms of VRIO, "does not adequately address the notion of resource-based competition, and its claim to be a general view of resources is unwarranted theoretically and unsupported empirically". In other words, RBV does not (on its own) adequately explain firm (export) performance. The argument about this theoretical gap buttresses earlier assertions such as Sirmon et al. (2007), that the findings on RBV based research have been mixed. This suggests an unexplained link between resources and performance. To strengthen the resources and performance link would therefore require the application of other theories that facilitate the use and 
application of resources, such as network and supply chain management theories. Business and strategic management literature considers RBV as one of the significant perception approaches, given the complicated external business environment of the firm. RBV contributes extensively to discussion of internationalization issues (Khalefa, 2018). At the center of most discussions on internationalization in the literature is network theory.

Network theory is about making use of knowledge and information from two or more business connected relationships. Businesses are based on one or more networks relating to suppliers, buyers, government, distributors, and customers, among others (supply chain). Networks support the structures that facilitate or determine the degree of internationalisaton. In addition, the network relationships are facilitated by actors, either organisations or individuals, with a large number of social relationships - called network structures (Mitgwe, 2006; Hakansson \& Snehota, 1995; Johanson \& Mattsson, 1987). To analyse the network structures the context also needs to be established. There are 3 key factors that determine network structures namely actors, resources and activities/ operations (chains) (Axelsson \& Easton, 2016; Hakansson, 2015). While the actors manage the resources and chains, the nature of the resources and chains also determine the type of actors. The type of actors determines the type of networks that are likely (to be found in a firm's supply chain) to facilitate internationalization. The literature discusses network structural and relational embeddedness to include: network density, network complexity, weak and strong ties, bridging and bonding ties, trust and contracts (Leeds, 1964; Granovetter, 1983, 1973; Gulati, 1988; Burt, 1992; Kawachi, Kennedy, Lochner \& Prothow-Smith, 1997; Long, 2001; Newman, 2003; Woolthuis, Hillebrand \& Nooteboom, 2005; Bhagavatula, 2009). Although these discussions are generally related to the firm's social, local, international and governmental networks, it is only networks of importance and value that need to be considered by the firm (Hakansson \& Snehota, 1995; Costa e Silva et al., 2012; Yamin \& Kurt, 2018; Khalefa, 2018) in relation to its activities/operations (chains).

Chin et al. (2015) describe a supply chain as a complex network of actors in both upstream and downstream processes. Their activities, either directly or indirectly, spans from production to delivery of products or services to the ultimate consumer. Managing networks in the supply chain is thought to be complex because of there are several activities, sub-systems, relationships and operations. To achieve the objective of a supply chain in the short term (reduce cost and increase productivity), and, long term (reaching customer satisfaction and profit) also requires the optimal use of a firm's resources and capabilities (Chandra \& Kumar, 2000; Tan, 2002; Li et al., 2005; Chin et al., 2015). It is the 
firms that capitalize on strategic opportunities in their supply chains by appropriating the benefits (knowledge, experience and information) of their networks that are better able to sustain competitive advantage and performance (Hult et al., 2007; Reyes et al., 2015).

These theoretical concepts provide a brief description of the relevance of the theories used and how these theories are related to the study context. Further discussions on the theories are presented in the Chapters 4 to 6 . Chapter 4 discusses the internal capabilities of the firm (resources and capabilities) and its export chains in relation to export performance. Chapter 5 focuses on the role of networks and supply chains in reaching higher export performance, while Chapter 6 combines empirical analysis on resources, capabilities, and networks in the firm's supply chains linked to export performance. The outline of the thesis details further how these theories and concepts are explained and applied.

\section{Contributions to the literature}

The study conceptualizes RBV (firm and CEO characteristics) and networks as a part of the firm's internal capabilities. The supply chain (export mode) and interactions with institutions (services and finance) are conceptualized as part of the firm's external environment. In doing so, the issues, networks, and, resources relevant to the upstream related processes and downstream related processes are easily identified. Specific insights are provided in this thesis about the relevant actors in NTAE SME supply chain and networks, and, how these (combined with resources) relate to export performance. The plethora of studies on SMEs in Ghana earlier mentioned, have focused on exports, finance, NTEs, or, some sub sector other than the NTAE sector. The study adds to the understanding of which factors are most relevant to NTAE SMEs for export performance. It provides some evidence on which combination of networks and resources are relevant to upstream processes and downstream processes. The thesis also offers empirical analysis of factors that impact export performance of NTAE SMEs.

\subsection{Outline of the Thesis}

The outline of the thesis is presented in Figure 1.3. There was need to first obtain some insights through an overview of Africa's agriculture and agribusiness as presented in Chapter 2. A qualitative exploratory study was conducted based on the views of experts (government officials and decision makers) actively contributing to the formulation and/or implementation of the policies in respective African countries. Their contributions are in relation to agri supply chains, and/or support to respective governments to meet targets related to agricultural development. These general perceptions (based on questionnaires-Table 2.3) are useful in providing some ideas of the nature of the 
environment for agri supply chains, and, in particular, macro level support to exporting SMEs, and, within the context of Ghanaian NTAE SMEs sector.

The perspectives in Chapter 2 are narrowed down to the challenges, actors, and strategies adopted in the Ghanaian shea industry in Chapter 3. The shea industry is a sub-sector of the NTAE sector and is randomly selected as a pilot study. The aim is to find out if the perspectives of the experts in Chapter 2 are similar to those of an NTAE SME exporter. Chapter 3 applies a phenomenological approach to a qualitative analysis applied on a "best in class" SME. This is through an on-site interview with the CEO of Ele Agbe, a multiple award winning SME operating in Ghana's shea sector (an NTAE sub-sector). General questions were asked to identify possible relevant factors and networks in an SME's environment. The findings are used to compare/contrast discussions on the NTAE SMEs in the subsequent chapters to determine whether there is consistency in the results.

The empirical analysis are presented in Chapters 4 and 6, based on the structured on-site interviews of the CEOs/top management of 152 exporting NTAE SMEs in Ghana. In Chapter 4, the RBV approach is used to analyse the research model on internal capabilities (human and physical capital, social and management team networks) of the participating SMEs related to the export performance as perceived by the CEOs. This study helps to identify which internal capabilities that are relevant to NTAE SME export performance need to be sustained or further developed. While a number of studies exist that relate the internal capabilities of firms to exporting, these have mostly been conducted in developed countries (He et al., 2013; Morgan et al., 2012). Only few studies (Adu-Gyamfi \& Korneliussen, 2013; Buatsi, 2000), have focused on internal and external barriers, and, the antecedents of export performance in Ghana, but these were not conducted in the NTAE sector.

Chapter 5, is a qualitative study of the network relationships of ten NTAE SMEs with relevant actors and institutions to investigate what the SMEs can do to improve these relationships. Studies on networks of SMEs in Ghana have been linked to entrepreneurial or marketing orientation of firms (Boso et al., 2013; Acquaah, 2012). These studies were undertaken with the purpose of determining what kind of networks could be relevant to improve SMEs export performance. Following this, Chapter 6 provides an empirical analysis of 152 NTAE SMEs in Ghana. The RBV, supply chain, and, network theories are referenced and related to the (internal and external factors) study model. The analyses are used to propose which factors are positively related to export performance and support policy interventions. Finally Chapter 7 discusses the main conclusions, explores their implications, and, presents recommendations for policy makers and practitioners. 


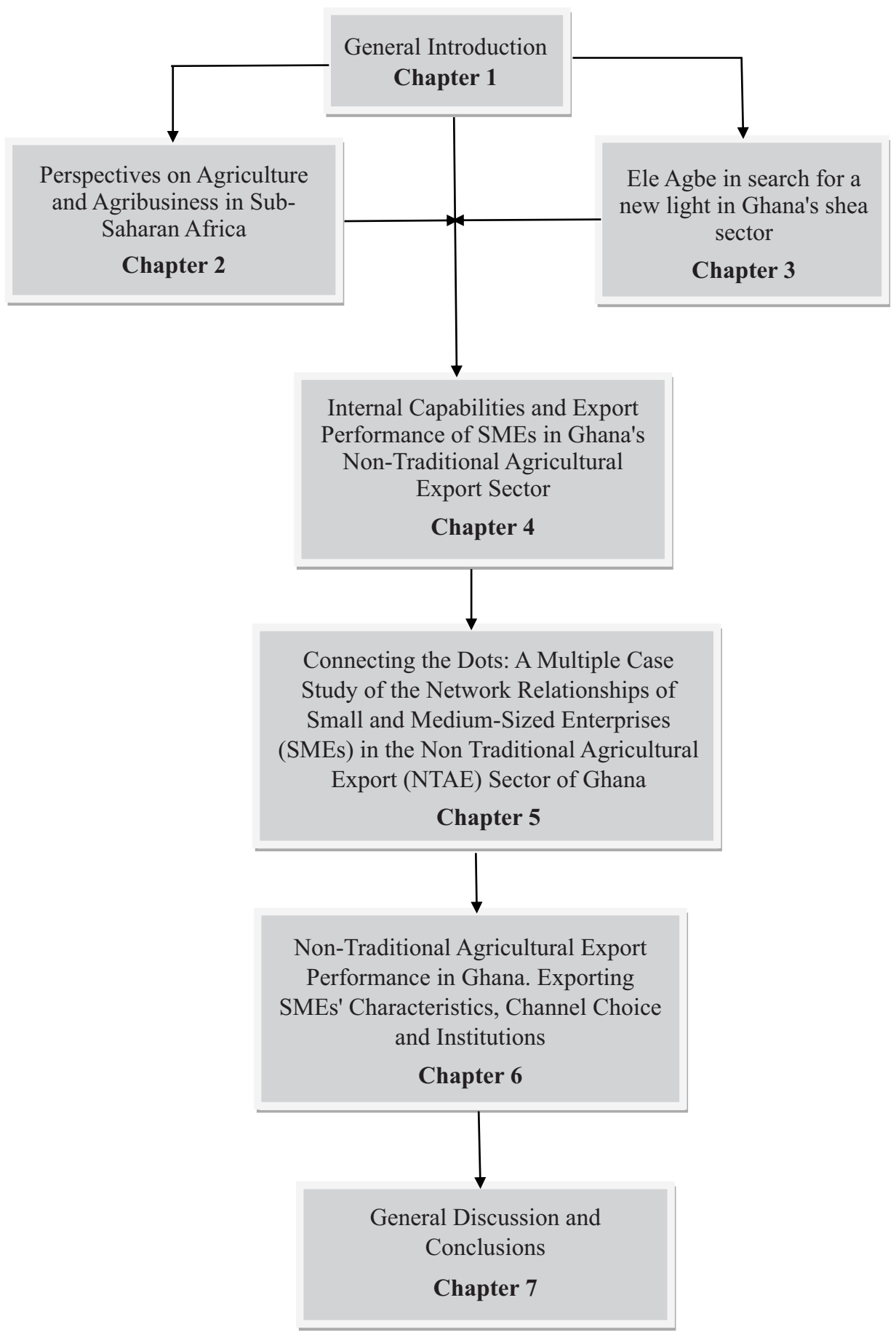

Figure 1.3 Outline of the Thesis 


\section{CHAPTER 2}

\section{Perspectives on Agriculture and Agribusiness in Sub-Saharan Africa}

\section{Chapter based on:}

Abban, R., Aheto, J.B.K., Omta, S.W.F. \& Scholten, V.E. (forthcoming). Some Perspectives on Agriculture and Agribusiness in Sub-Saharan Africa. International Journal of Technology and Entrepreneurship (IJTE).

Accepted: August 13, 2019. 


\section{CHAPTER 2}

\section{Perspectives on Agriculture and Agribusiness in Sub-Saharan Africa}

\subsection{Introduction}

Agriculture, including agribusiness plays a vital role in Africa for growth and development. On average, agriculture contributes to about $50 \%$ of the continent's productive economic activities. For Sub-Saharan Africa (SSA), agriculture "creates jobs, generates income, produces food and contributes to social stability", and, accounts for " $25 \%$ of SSA's GDP on average" (Schaffnit-Chatterjee, 2014, pp3). Agriculture is believed to account for $70 \%$ of the labour force in SSA out of which an estimated $75 \%$ are rural poor surviving on $\$ 1$ or less per day (Aker, 2010). A more recent publication on SSA suggests that agriculture's share in national gross domestic product (GDP) and total labour force shrank, due to movements into the services sector. However, "rising incomes, rapidly growing "consumption cities", and continued high population growth in rural areas have stimulated agricultural commercialisation" (Ecker, 2018, pp271). In addition, agriculture is thought to receive "increased attention from national governments and international development partners" for which reason(s) "interest in agricultural development should be spread beyond on-farm production to include all aspects of the value chain, particularly for high-value commodities" (Babu et al., 2015, pp1). Bates (2005) suggests that tropical African economies are based on production and export of primary produce such as timber, mineral, and oil, and, agricultural produce such as coffee, tea, cocoa, palm oil, palm kernel oil, cotton seed, groundnuts, sisal and cotton. There is the need for agricultural added-value produce and products to improve revenue generation. Agriculture, commerciali-sation, agribusiness and exports in particular are important to the agri supply chain of African economies dominated by micro, small and medium sized farmers/enterprises.

Agriculture is basically food production for consumption. Agriculture has promoted economic growth amongst several developing countries the world over, although "in African countries, agriculture is widely seen to have performed worse than in Asia and Latin America" (Pretty et al., 2011, pp5). It is for these reasons that agribusiness especially agribusiness export is of relevance to SSA economies to generate additional revenue and diversification of traditional primary produce exports. Agribusiness is seen as the link between agricultural producers (farmers) and consumers. It is the off-farm link in the agricultural value chain. It covers input suppliers, agro-processors, traders, exporters, and, retailers (Roepstorff \&Wiggins, 2011). The idea of agribusiness being a catalyst for 
development is supported by the view that it also creates opportunities in the rural nonfarm economy for the rural poor (World Development Report (WDR), 2008). In Africa, the features of agribusiness are not much different from those of agriculture. It has several and scattered micro, small and medium scale businesses which are predominantly owned, operated, and controlled by women.

Agribusiness is expected to grow faster than on-farm production in Africa especially in the area of food processing and distribution, thereby contributing an increasing proportion to national incomes of SSA economies (Babu et al., 2015). This contrasts with the earlier view of Dineham \& Hine (1984) who suggest that the agribusiness method of agriculture is capital intensive, and, requires use of new technologies to improve yields which may be beyond the small, mostly rural farmers. In general, over the period from the 1980 s to 2010 , all the regions in Africa experienced net agricultural production growth with the greatest increases in North and West Africa (Pretty et al., 2011). The relevance of agriculture and agribusiness for SSA is for the need to sustain economic transformation because unlike east and south-east Asia, SSA "did not participate to the same degree in the Green Revolution of the 1970-80s and has, therefore, not been able to reap the economy-wide rewards", and, neither have "policy priorities set forth in forums such as the Abuja Declaration, Malabo Declaration, and under the Comprehensive Africa Agriculture Development Programme (CAADP)" been met (Sheahan \& Barrett, 2017, pp12).

\subsection{Overview of Initiatives in Agriculture and Agribusiness in Africa}

Within the context of agriculture and agribusiness, African leaders sought to transform the focus of the Organisation of African Unity (OAU) now African Union (AU) to economic development through initiatives such as: "the Lagos Plan of Action (1980); the Final Act of Lagos (1980); the Africa's Priority Programme for Economic Recovery (1986-1990); the African Alternative Framework to Structural Adjustment Programme (1989); the African (Arusha) Charter for Popular Participation and Development (1990); the Abuja Treaty (1991); and the Cairo Agenda (1994), amongst others"(NEPAD, 2012). The inability to achieve the objectives of these initiatives and consensus building led to the establishment of the New Partnerships for Africa's Development(NEPAD) in 2001.

NEPAD was integrated into the African Union (AU) with the creation of the NEPAD Planning and Coordinating Agency in February 2010. NEPAD has the support of the AU and Regional Economic Communities (REC). The framework for NEPAD's agriculture and food security programme area is guided by the Comprehensive Africa Agriculture Development Programme (CAADP) established in July 2003. 
CAADP aims at improving and promoting agriculture and agribusiness across Africa. It aspires to foster active farmer participation in the market economy. The vision was set to accomplish these objectives by 2012. Unfortunately, this has not been achieved largely due to the lack of commitment of member states to meet agreed resource targets for agriculture. The African Union (AU), with a membership of 54 countries committed to the CAADP in July 2003.

The key objectives of CAADP were for AU member countries to invest $10 \%$ of national budget (GDP) in agriculture and to increase agricultural productivity and growth by $6 \%$. As at May 2011, only 26 countries (less than half the AU membership) had signed the CAADP Compact 2007. Earlier, in 2005, six (6) countries (Niger, Ethiopia, Burkina Faso, Chad, Mali, and Malawi) were the only ones to achieve the target of allocating $10 \%$ of national budget to agriculture. In 2010, only 8 nations stated having attained the $10 \%$ target and 10 nations also met the $6 \%$ target. Nineteen countries had agricultural productivity growth between $3 \%-6 \%$ (NEPAD, 2012).

Following the inability of over 50\% of AU members to meet the CAADP targets in 2012 there was the need to review policy directions leading to the June 2014 Malabo Declarations. The objective of the declarations was for commitments specified in actions and processes towards agricultural transformation by 2025 (African Union Commission AUC, 2019). Of relevance to discussing the gap between the actual performance of member countries and benchmark targets for the CAADP are factors related to the agri supply chain (agriculture and agribusiness supply chain).

\section{Agri Supply Chains}

A supply chain can be described as the span of activities from inputs and raw material sources to finish, distribution and outlets. It involves all stages "directly or indirectly in fulfilling a customer request” (Hugos, 2018, pp2). Most actors in SSA agri supply chains are micro, small and medium scale businesses/farmers/entrepreneurs (Kleemann et al., 2014). Also "agricultural production systems are largely based on smallholder farms" (Livingston et al., 2011, pp9). The importance of the agri supply chain arises, because "significant volumes of food are lost after harvest in sub-Saharan Africa (SSA), the value of which is estimated at USD 4 billion for grains alone" (Affognon et al., 2015, pp49). According to Affognon et al. (2015), one of the reasons for this is, imprecise understanding of the working of the agri supply chain by small scale farmers/entrepreneurs. For example, the losses in SSA tomato supply chains were found to be much higher for small scale farmers than for large scale farmers engaging in commercial agriculture (Sibomana et al., 
2016). In addition, supply chains have become increasingly important due to consumer awareness and demand for more information about products including quality, health, farming, distribution, marketing and processing activities and possible value co-creation opportunities (Handayati et al., 2015).

Agri supply chains each have their peculiarities, and, or challenges. These have been discussed in a number of perspectives. Some of these include collaboration between organisations in food supply (Bijman et al., 2006), decision making and planning (Shukla \& Jharkharia, 2013; Tsolakis et al., 2014) and coordination of different function within a supply chain (Handayati et al., 2015). Although "research on coordination-related issues in an agricultural supply chain is in its early development" (Handayati et al., 2015, pp2), and a number of studies exist on specific agri sectors and supply chains, such as, Dolan \& Humphrey, 2000; Whitfield, 2011; Abor et al., 2014; Affognon et al., 2014; Amanor \& Chichava, 2016; Babu et al., 2016; Sheahan \& Barrett, 2017; Ecker, 2018; CAADP 2019 to mention a few, none of these studies discuss the external factors that enable the proper function of the agri supply chains within the context of the African Union initiatives. Four broad thematic areas are identified, namely: public policy, investment financing, political wherewithal and partnership opportunities, and linkages.

This chapter is an exploratory study involving 5 cases (the countries listed in Table 2.1) and is based on the views of 11 experts, responsible officials and decision makers on the four identified external determinant factors to the agri supply chains (agriculture and agribusiness). It attempts to address the following research question: Will the external determinant factors (public policy, investment financing, political wherewithal and partnership opportunities, and linkages) of the agri supply chain within AU member states support initiatives and achieve targets?

\subsection{Context and Research Methods}

The study context was the Agricultural Green Revolution Forum held in 2012 in Arusha, Tanzania. The Forum brought together private and public sector experts, responsible officials and decision makers in AU member countries and provided an opportune platform to correspond with AU member delegates. Specifically participants included African heads of states, ministers, private agribusiness firms, financial institutions, farmers and NGOs to discuss Africa's farming industry, and, the potential of its smallscale farmers/entrepreneurs with the objective to address developments within Africa's 
agriculture sector ${ }^{8}$. The major themes for the forum were: rethinking public-private partnerships, revolutionizing agricultural finance, making markets work and building the foundations for rapid growth in agricultural productivity ${ }^{9}$.

A purposive judgmental sampling approach was used in targeting specific individuals of African countries who held managerial portfolios in their institutions or state. These individuals worked in institutions which were either agriculture based or agriculture related. A total of 30 self-administered questionnaires were distributed. The questionnaires included open ended questions and closed ended questions (drawn on 5 point 'Likert' scales) presented in Table 2.3. Eleven completed self-administered questionnaires were received representing a response rate of $37 \%$. The survey was conducted on-site by the researcher, so explanations and clarifications could be readily given if needed. The distribution of respondents per case (country) is summarised in Table 2.1 below.

Table 2.1 Number of Respondents (per country/case)

\begin{tabular}{|c|l|c|}
\hline Case & Country & No. of Respondents \\
\hline $1,1 \mathrm{a}$ & Tanzania & 4 \\
\hline 2 & Mali & 1 \\
\hline 3 & Mozambique & 1 \\
\hline 4 & Kenya & 3 \\
\hline 5 & Ghana & 11 \\
\hline & TOTAL \\
\hline
\end{tabular}

The 5 cases (in Table 2.1) were chosen to include one success story (Mali), one of the three countries (in addition to Ethiopia and Chad) that had obtained both the CAADP target of $10 \%$ of national budget to agriculture and the CAADP target of $6 \%$ agricultural growth in 2012 .

Description of the respondents

The questionnaires represented the views of the individual respondents for 5 cases namely: Ghana, Tanzania, Zanzibar (1a, part of Tanzania), Kenya, Mozambique and Mali. The relevant background information of the respondents is shown in Table 2.2. About $30 \%$ of the respondents (3) were female and the remaining $70 \%$ of respondents (8) were male. Of the total number of respondents $45 \%$ had core agriculture or agriculture related

\footnotetext{
${ }^{8} \mathrm{http} / / /$ www.africanfarming.net/events/event-news/tanzania-to-welcome-african-green-revolutionforum

${ }^{9} \mathrm{http} / / /$ paepard.blogspot.com/2012/10/african-green-revolution-forum-2012.html
} 
specialisations. All respondents were in senior decision making positions with the average overall work experience being 16.9 years. Where years of experience in the agriculture sector was considered, the shared average experience for respondents was 10.7 years. This included respondents who did not work directly in the agriculture sector. When these respondents were excluded the average experience in the agricultural sector was 13.1 years. On the whole the number of years working in the agriculture sector was assumed to indicate that the respondents were knowledgeable in this area. Out of the respondents $46 \%$ were above 40 years, $36 \%$ did not provide their ages and the remaining $18 \%$ were below 40 years. About $72 \%$ of respondents had worked in their current position for 1 to 5 years, the remaining $18 \%$ had worked in their current position for 6 years and over. Sixty four percent had worked in their current organisation between 1 and 6 years while the remaining $46 \%$ had worked in their current organisation for over 6 years. 


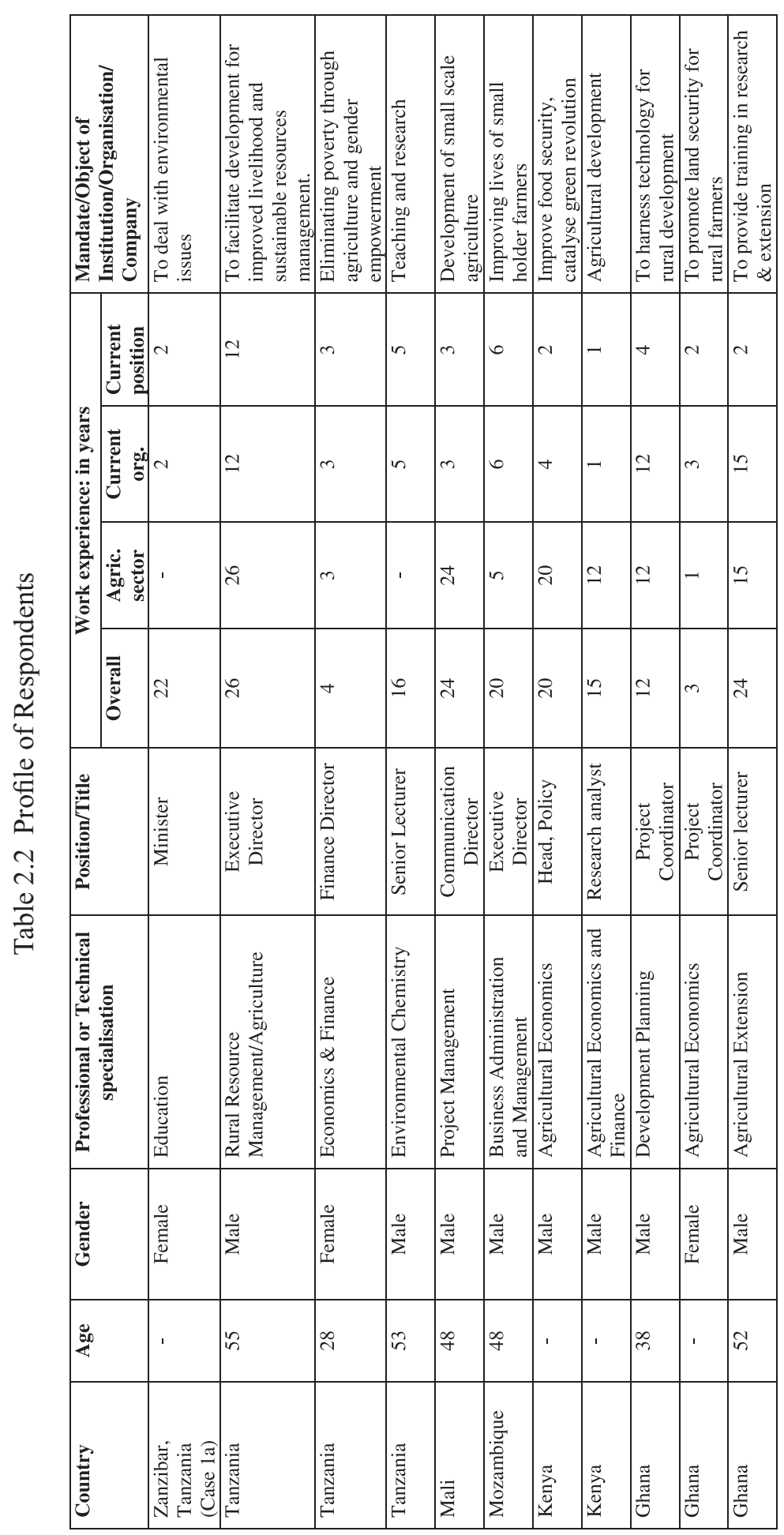




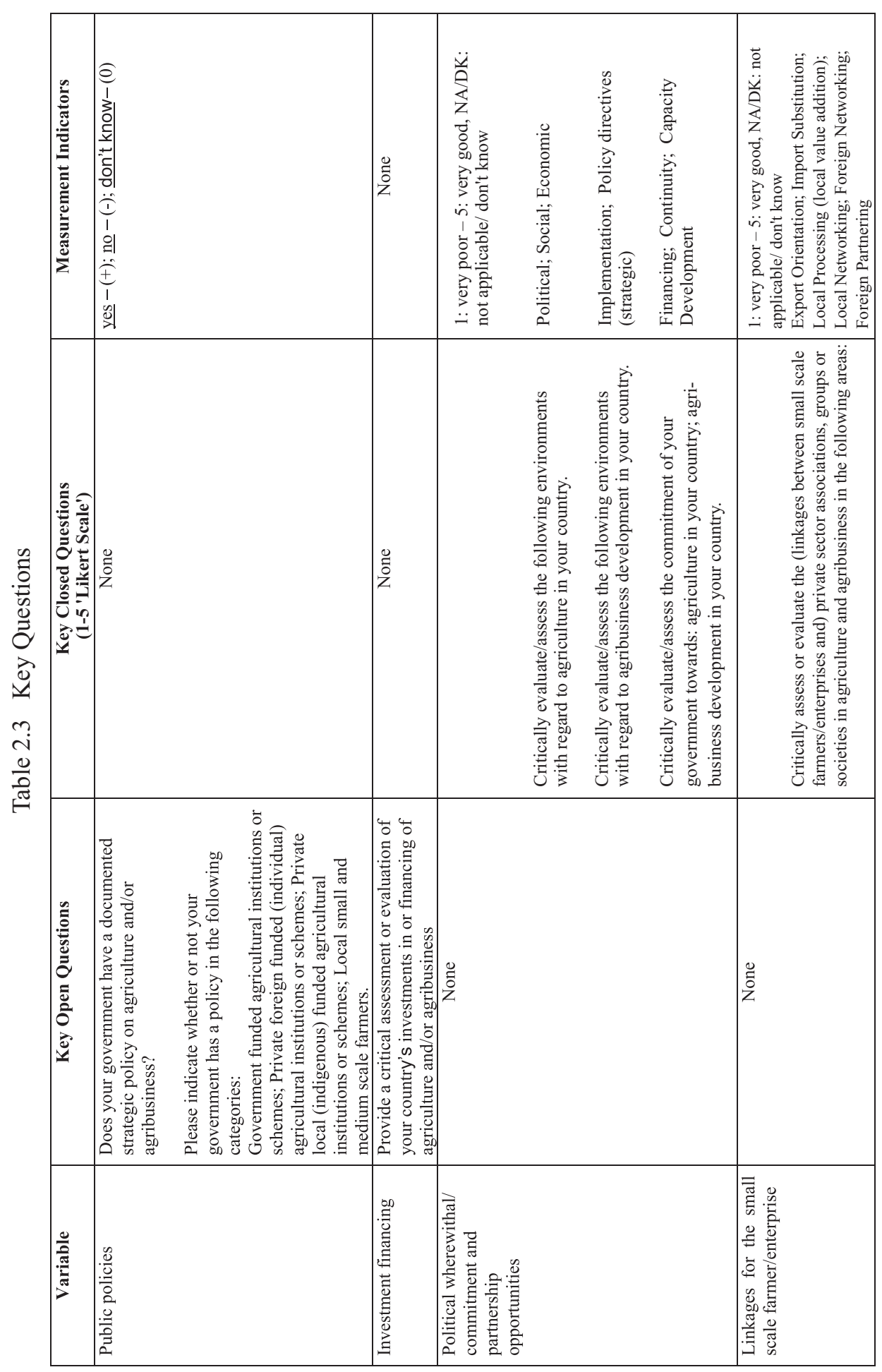




\subsection{Findings}

\section{Public policies}

All respondents except one provided a positive response on the question related to expert knowledge regarding their government's strategic policies on agriculture and agribusiness. The exception was Case 1a -Tanzania (Zanzibar) Environmental Minister who indicated no expert knowledge of agriculture and/or agribusiness government policy, but stated subsequently that the policy on agriculture was "reasonable" (see Table 2.2).

In Case 1-Tanzania, the policy named "Kilimo Kwansa" meaning agriculture first had been implemented. This policy covered agribusiness as well. It was thought however, "...not all senior government officials can interpret it correctly" and "...due to corruption farmers are not benefiting." There was the perception that a top down approach was used in implementing agricultural development policies and therefore the "Kilimo Kwansa" was not "grass-root oriented" or "participatory to rural populace." This of course meant that agribusiness was not positively affected. Case 2-Mali considered the agriculture policy of the government to be good because of developments for small scale farmers, including finance, insurance, and, social security. Case 3-Mozambique expressed a critical view of agriculture land policy and land law, which was thought to be rigid and fraught with delays in land acquisition because most land is state owned offering no security to the farmer. Case 4 -Kenya mentioned a "Vision 2030" strategy document for agriculture. The document detailed investment, priority areas, and timelines required to achieve specific milestones. The objective is to improve "agricultural productivity, support capacity building, and help transform agricultural policies for sustained agricultural growth." This included transforming agricultural products into value added. Case 5-Ghana stated an agricultural sector policy with specific details for various sub-sectors. Within this document were "...cross-cutting issues regarding agribusiness" but "...there are no explicit policy provisions on agribusiness in the broader agriculture policy." The agricultural policy was considered “...not very effective in general”.

Agribusiness is not considered viable in Case 3-Mozambique because of lack of political will, poor marketing and delivery systems, and lack of organisation or co-operation among farmers. This contrasted with Case 2-Mali where agribusiness is considered a good compliment to agriculture for small scale farmers and enabling partnerships between foreigners and nationals. This is not surprising as Mali is one of three countries to have met both the 10\% and 6\% CAADP targets in 2012. Generally not much attention has been given to agribusiness in the other three Cases $(1,4$, and 5) in this study. 
All cases affirmed a government policy for government funded agricultural institutions or schemes. Such government policy existed for private foreign funded (individual) agricultural institutions or schemes in Cases 1,2,3 and 4. In Case 5, Ghana, there was lack of clarity as to the existence or operationalization of such a policy. No policy appeared to exist in Case 5 for private local (indigenous) funded agricultural institutions or schemes, although a government policy existed for private non-governmental organisations (NGOs) for all Cases. All respondents maintained that government policy existed for local small and medium scale farmers/entrepreneurs.

\section{Investment financing}

The consensus for all respondents was that investments in agriculture are woefully low or inadequate. With the exception of Case 2-Mali (which had met the two CAADP targets) the view on agricultural investments was “....inadequate financing - far below the CAADP commitment of $10 \%$ investment in agriculture" for all other cases. Although, there was a general agreement that investments in agriculture were below expectation, there were questions on what is computed as investment financing in agriculture. For example, does putting up additional office blocks and the purchase of saloon cars for officials of the Ministry of Agriculture constitute investments in agriculture? There were also issues on why countries that have met the CAADP targets have not seen enough growth to be classified as middle income countries. For example Case 2-Mali, which has met the two CAADP targets is classified by the World Bank in 2012 listings as a low income country. While case 5-Ghana, which has met the 10\% CAADP target in 2012, is classified as a low middle income country. These indicators and statistics leads to the debate on whether agriculture is being effectively managed in terms of investments and or ease of access to finance by micro, small and medium sized farmers/enterprises in this sector.

\section{Political wherewithal/commitment and partnership opportunities}

Political wherewithal or commitment and partnership opportunities were presented with reference to agriculture and agribusiness. These factors were measured by the perceptions on political, social, and, economic environments as well as implementations, policy directives, financing, continuity, sustainability and capacity building. It was argued that a stable political environment attracts foreign partnerships and builds a positive image to gain confidence in the economy. Almost all respondents rated their countries political environment as average for agriculture. The exceptions was for Case 1-Tanzania where two respondents believed the political environment to be very good or good, and, one respondent in Case 4-Kenya who thought the political environment to be very good. The 
social environment was ranked either average or good by respondents. The result for the economic environment was informative. Most of the respondents thought that the economic environment had average impact on agriculture. In accordance with the classification of Mali by the World Bank as a low income country, the respondent from Case 2-Mali thought the economic environment was poor, although Mali had met CAADP targets. In a similar vein, Case 5-Ghana reported average for the economic environment although Ghana is classified as a middle income country. All the cases considered the environment for agribusiness development to be average. The views on government commitment to agriculture and agribusiness (measured by financing, continuity, and capacity development) were averaged for each country. Using averages makes it easier for comparative analysis. The averaged views measured on 5 point 'Likert scales' are shown in Figure 2.1.

Figure 2.1 Government commitment to agriculture and agribusiness

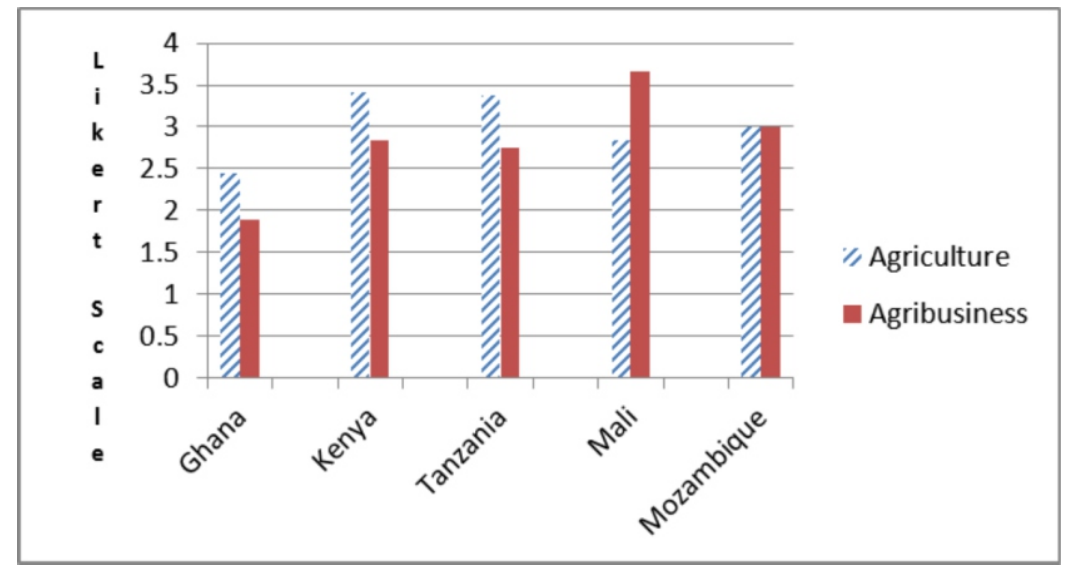

Figure 2.1 shows that more emphasis is put on agriculture than on agribusiness, except for Mozambique and especially Mali. This supports the observation that exports from Africa are generally raw materials, with little or no value added. Value addition is considered a good indicator of agribusiness activity. Value addition attracts more revenue and thereby facilitates development.

\section{Linkages for the Small Scale Farmer/Enterprise}

Questions were put regarding the network linkages of small scale farmers with private sector associations, groups or societies in agriculture and agribusiness. These were done by evaluating: export orientation, import-substitution, local processing (local value addition), local networking, foreign networking and foreign partnering. Agricultural based export orientation among the country cases was average and good in countries 
known for their tourism, that is to say Case 4-Kenya and Case 1-Tanzania. One possible explanation may be that tourism provides some exposure to local business by creating avenues for exporting. Not surprisingly, respondents from these two Cases considered foreign networking and foreign partnering to be good. Value addition was also considered good by them. The other country which considered export orientation, foreign networking, foreign partnering and value addition to be good was Case 2-Mali. An observation for this evaluation is attributable to the substantial investments Case 2 has made in agriculture and agribusiness. This has made Case 2-Mali one of the successful models of CAADP achievements in Africa. Import substitution was generally considered average for each of the country cases. This suggests demand and use of local inputs for production was not high. It may be that local networking needs to be further strengthened in order to provide more linkages between small scale farmers and local industries. An ideal scenario may be stronger local networking for upstream processes and stronger foreign networking for downstream processes. This may reduce transaction costs of production and marketing.

\subsection{Conclusions and Recommendations}

The case study explored external determinant factors in SSA agri supply chains which impact initiatives and state commitments to developing agriculture and agribusiness. The study was based on expert opinions and perceptions from 5 cases of AU member states. The focus was on 2012 CAADP objectives and selected recent literature to answer the research question:

Will the external determinant factors (public policy, investment financing, political wherewithal and partnership opportunities, and linkages) of the agri supply chain within AUmember states support initiatives and achieve targets?

Recent developments on SSA agriculture and agribusiness are well documented in a number of studies, though not all of them are related to AU initiatives. The conclusions drawn are not exhaustive. They are however, relied on to generate some understanding of the current circumstance in SSA. It is interesting to note that public policy within AU member states is inadequate (either in terms of design and or implementation) because the SSA agriculture sector is confronted with a number of challenges such as "insufficient access to efficient inputs, low level of investments in the sector, restrictions related to land policy frameworks and regulations, environmental issues and climate change" (Adenle et al., 2017, pp2) and "opaque national policy, weak governance and lack of social capital, remain as the most important factors" (Adenle et al., 2017, pp9) affecting agriculture. 
While this view may very well hold, some West African countries (Burkina Faso, Chad, Ghana, Guinea and Nigeria) have attained high agricultural GDP growth over 3.5\% with Ghana in particular achieving the millennium development goal MDG-1 (to eradicate extreme poverty and hunger).

In discussion on financing for exporting SMEs looking at the downstream end of the agri supply chain it appears not much has changed since 2012. SMEs are thought to make up $95 \%$ of enterprises worldwide and account for $60 \%$ of employment in the private sector (Quartey et al., 2017). In spite of this, access to finance remains an issue in a number of ways. SMEs in Africa are thought to "lack access to the financial resources needed to expand, grow and transform into higher size thresholds". This is for two reasons: "first, the provision of finance for Africa is generally rated as riskier than for other regions. Second, the provision of finance for small firms is globally rated as riskier than for large firms" (Abor et al., 2017, pp19). The absence of effective policies for agriculture and agribusiness and structured implementation of these policies may also be a cause for challenges in access to finance by SMEs. In some circumstances, interventions by way of foreign investments in African agriculture has not been done with equitable agriculture and agribusiness growth, nor participatory development in mind. This is evident in partnerships such as South South Cooperation (SSC) between Brazil, China and Ghana, Mozambique (Amanor \& Chichava, 2016). Though the pros and cons exist on amount of state investment and degree of involvement in the agribusiness sectors for both Ghana and Mozambique, the objective of the foreign investments (Brazil, China) "reflect the dominant trends in contemporary agricultural development that promote market penetration, capital accumulation and the integration of smallholders into existing forms of market accumulation" (Amanor \& Chichava, 2016, pp21). The conclusion by most of the Cases requires member states to develop an attractive economic environment with well-structured policies which will ensure that partnerships are mutually beneficial.

An alternative approach to improving SSA agri supply chains suggested by Afognon et al. (2015) is reduction in postharvest losses (PHL) and interventions to mitigate such losses which occur at various points of agri supply chains and which require investments in research on how to counter agro-climatic effects on produce and storage among others. Agri-investments are low although "in SSA, PHL reduction is prioritized in the Africa Union's Comprehensive African Agricultural Development Program (CAADP)" (Afognon et al., 2015, pp49). Strong agricultural development is needed in SSA as "many lack adequate foreign exchange reserves to pay for food imports and infrastructure to store 
and distribute it efficiently" (Van Ittersum et al., 2016, pp14964) which requires effective linkages. To improve linkages Babu et al., (2015, pp27) suggest "strengthening public-private partnerships could be an effective approach to help agribusiness value chains in sub-Saharan Africa become more competitive". Case 2 Mali is an example of how substantial investments in agriculture and agribusiness can help achieve the CAADP targets. All the Cases supported value addition as an important government strategy to build linkages for the MSME/farmer. This would improve export revenue generation from the downstream end of the agri supply chain.

The CAADP biennial review report of June 2019 indicates that following the June 2014 Malabo declaration on CAADP targets, AU member states reaffirmed their commitment. Currently, $85 \%$ of member states representing 47 out of $55 \mathrm{AU}$ member states submitted data for biennial review, although not all required data was submitted. However, 36\% (20) of AU member states were found to be on track in meeting target and Malabo Commitments by 2025. Although more effort is required, the discussions and research identifying areas for improvement which are linked to the external determinant factors (public policy, investment financing, political wherewithal and partnership opportunities, and linkages) identified in this study suggests that these factors will support state initiatives and targets. What may appear lacking for these factors are improved structures and ways of implementation.

\section{Limitations}

Although a strong point of the present study is that it focuses on the views of officials and decision makers that are actively contributing to the formulation and/or implementation of the policies concerned, the reader should keep in mind that the views and opinions presented in this chapter are those of the respondents, and that, of course, other views and evaluations exist. Further research could provide a more extensive overview over the different opinions and views.

In the next chapter through a case study of a Ghanaian NTAE SME, agricultural/ agribusiness structures (if any) that prevailed around the period of the Malabo declaration is discussed. The discussion includes the views of the NTAE SME on the implementation. 


\section{CHAPTER 3}

\section{ELE AGBE in search for a new light in Ghana's shea sector}

\section{Chapter based on:}

Abban, R., Omta, S.W.F., Aheto, J.B.K. \& Scholten, V. (2014). Ele Agbe in search of a new light in Ghana's shea sector. International Food and Agribusiness Management Review, 17 (sp. issue B), pp 63-68.

Published: June 17, 2014. 


\section{CHAPTER 3}

\section{Ele Agbe in search for a new light in Ghana's shea sector}

\subsection{Background}

The efforts of AU member states to improve commitment to the development of agriculture and agribusiness led to the Malabo declaration of June 2014 (AUC, 2019) which set out prioritization of policies (Sheahan \& Barrett, 2017). The state macro policies were however individually determined. The Malabo declaration resulted from the inability of more than half of the AU member states to meet CAADP targets suggesting either macro and/or micro policies were misaligned or non-existent at state level. This may in part explain the low results of export diversification strategies such as the promotion of non-traditional agricultural exports (NTAEs) for most Sub-Saharan Africa economies including Ghana over the preceding decades. In Ghana, the promotion of NTAEs also had effect for small NTAE companies. This chapter presents a case study of Ele Agbe, a small company in Ghana's shea sector.

\subsection{Introduction}

In 2013, Ele Agbe, a small private limited company, is one of the leading names in Ghana's shea processing sector. Ele Agbe, which has been in export for 14 years, initially operated with staff strength of 6 full time workers and 150 casual workers (wood carvers). Now, the company has a staff strength of 10 full time workers and about 300 casual workers for harvesting ${ }^{10}$. The company has remained sustainable through strong marketing and innovation in diversifying its products based on consumer needs/expectations in both domestic and international markets. In the past five years, 20 new product lines have been introduced by the company to include shea varieties of soap, lotion bars and lip balm. Other shea products available are body oil, hair pomade and cream for babies. Ele Agbe's success may be attributable in part to its networks and management drive. For example, the company has several international recognitions. Ele Agbe's CEO is the President of the Africa Women's Entrepreneurship Program (AWEP) in Ghana. With an optimistic view of its potential, Ele Agbe remains inhibited by the seeming lack of a regulated shea sector and breaks in the shea supply chain. The company now needs to consider which of its firm and business networks it can leverage on to achieve its potential given both its internal and external environment. The company is studied based on a face-to-face semi-structured

\footnotetext{
10 The 300 casual workers are shea pickers contracted seasonally on a daily basis during harvesting. Source: https://ghananuts.org/products_shea.htm
} 
interview with the CEO and observations of the work processes (see footnote 14). The focus of these questions is mainly on the opportunities and challenges that confront the shea sector. The findings are compared with views of other shea companies obtained during pilot fieldwork. (see footnotes 15 and 16)

\subsection{Company Background}

Ele Agbe, an $\mathrm{SME}^{11}$, was established in 1996 and started full operation in 1998 focusing mainly in ornamental beads, original jewelry designs and handmade home décor and started exporting in 1999. Shea butter products were introduced to its export product lines sometime in 2004. The expansion was made possible through the use of retained earnings (equity) of $\$ 400$ to launch a range of Shea butter products to front the marketing of the rural women producers for sustainable livelihood. The vision of Ele Agbe is to satisfy demand in local value-added products, and, create jobs for rural-urban women and youth, and, earn living (income) by targeting both domestic and international markets. The leadership (CEO) drive to achieve this vision is from 18 years of export experience, and, to a high extent, based on previous work in another company, self-learning and feedback from buyers. Other motivating factors are the high involvement of the CEO in export trade and how frequent she travels abroad.

The company targets the domestic market and sub-regional markets through international trade fairs and exhibitions, and the international market, mainly the USA, Japan, and, occasional orders from the UK. The quality of the products is very high and meets international quality standards and fair trade practices as indicated by the (international) buyers and inspection bodies of the different countries.

\subsection{Current Management Structure}

The company has one top level manager (CEO), four middle level and five junior level staff. Reporting is centralized around the CEO and the middle level staff are engaged in supervisory work of the casual workers. These casual workers are mainly shea pickers represented by an association. The casuals are engaged seasonally during shea harvesting and processing. The junior staffs are mostly engaged in mixing, packaging and labeling of products.

\footnotetext{
${ }^{11}$ SMEs are defined in terms of assets/employees as follows: Micro: $\leq$ \$US10,000/1-5 employees; Small:\$US10,001 $\leq$ 100,000/ 6-29 employees; Medium:\$US100,001 $\leq$ 250,000/30-99 employees (Abban et al., 2013; Abor \& Quarey 2010)
} 
The company has a weak board ${ }^{12}$ and low internal controls although management is expedient in meeting regulatory and monitoring requirements. The work processes neither allow for a distinct separation of functions, nor, checks and balances, as a result of overreliance on directives of the CEO. This centralized structure for a small company has been effective in carrying out timely export orders especially as a result of the familial work rapport established with casuals/contractors who provide input supplies.

\subsection{Key Success Factors}

Entrepreneurship, product chain characteristics, and, social capital are the driving forces for the business sustainability and export performance of the company. These, coupled with direct linkages forged by the CEO with World leaders and renowned personalities, on developing economy projects have stood Ele Agbe in the limelight. For example, the CEO (and President of AWEP) was selected as one of the successful women entrepreneurs making positive impact to represent their sector of operation in Washington DC. This was the initiative of the AWEP as a support to boost trade under the Africa Growth Opportunities Act (AGOA) ${ }^{13}$ in Africa. The AWEP was initiated by former US Secretary of State, Hillary Clinton. The CEO also had opportunity to join the Cherie Blaire Foundation Mentoring Programme 2012. Her final blog gave her the opportunity to meet Cherie Blaire and develop a business linkage. These 2 programmes were instrumental in boosting the image of the company worldwide.

The outcome is in line with the company's vision to support sustainable jobs for ruralurban women and youth, which it does through its community business based model for shea-pickers and processors. The company has developed bonds with over 300 shea pickers and processors belonging to about 10 groups or associations, which provide upstream input supplies of raw shea butter. The community business model concept provides the shea pickers and processors with ready access to market for their produce at competitive prices. The women and youth are also taught to apply fair trade practices and quality standards as part of their work.

Although the company has not yet registered its trade secret as intellectual property, it has closely guarded it. It has an agent in the United States who provides other input supplies

\footnotetext{
${ }^{12}$ The board has 3 members: the CEO, a business partner, and her daughter as (Board/Company) Secretary. The board is regarded as weak, because the board membership is not consistent with the Cadbury's Code on good corporate governance, which provides recommendations on board size (5-7 members) and composition (Professional background/relationships).

${ }^{13}$ The AGOA is a US initiative to promote exports of developing economies.
} 
(oils, fragrance) not available locally. The quantity mix of various inputs and the processing forms a part of the trade secret that gives Ele Agbe the competitive edge in its final products. The strong network alliance by the company with its suppliers and buyers has developed a formidable bond. This creates a buffer for the company in the face of an unregulated and seasonal shea sector and strong competition. Ele Agbe does not limit itself to work relations but also considers the welfare and concerns of its suppliers. Strong competition comes from large companies (local and foreign) including their agents that buy huge volumes of unprocessed sheanuts. The price offered by these large companies, though low, is higher than local market prices and therefore distorts local markets. Also shea pickers are rationally attracted by the better prices offered by the large companies for their work. Indigenous shea processors process the sheanuts into shea butter using local methods. To compete with large companies, indigenous businesses are compelled to move to farm gate locations to directly buy shea from the farmers increasing their transportation costs. Regulating prices as is done in the cocoa industry, would therefore help indigenous businesses in the shea industry.

The ability of Ele Agbe to integrate its shea supply chain ${ }^{14}$ from upstream shea pickers to downstream bulk buyers has enabled the company to spread risk and costs of production in a way that harnesses its driving force of:

- Fair trade practices and quality standards acquired under a USAID programme applied in all contract dealings downstream and upstream.

- Operation of one centralized production location ensures effective supervision and guarded trade secret.

- High expansion drive and involvement of staff in decision-making, particularly things that affect them, promotes innovation, and, led to introduction of 20 new products within the past 5 years.

- Strong network and rapport facilitates timely market information from visits to export markets, feedback from buyers and agents which are used to offset constraints arising from frequent changes in regulations of importing country and need for more learning.

\footnotetext{
${ }^{14}$ The claims of the CEO are supported by findings from on-site observation of company processes and interaction with the staff. Staff members shared the view that production costs, especially those for supplies and for transportation has been reduced, while sales had more than doubled over the preceding 3 years.
} 
- Use product differentiation and quality processes as core business strategies to meet market entry requirements and consumer expectations.

- Work executed in small cohesive teams with employees (contractors) able to work in all areas of production.

- Positive business outlook supported by novel products, bold initiatives, and innovation by the CEO.

- Meeting of local regulatory and monitoring requirements and financial audits.

- Complete ownership of business property, equity financing, well-equipped warehousing facility, and application of free-on-board export channel eliminates operational shocks occasioned by fluctuations in debt servicing.

Other general critical key factors include the fact that products of the company are nonperishable and can be held in stock for more than 2 years. This, coupled with the high profile network linkages forged by the $\mathrm{CEO}$, boosts the image of the company as a credible trade partner. The contact networks of the company are very well-known and provide the company with valuable information. The product brand is catching on abroad. The overall impact of these is the increase in export orders for which the company has had to decline some requests because of its small production facility. For example, sales revenue increased over $200 \%$ over the last 3 years.

The CEO is concerned that the lack of a national policy on the shea sector means that there is no way to ensure that quality standards are maintained by all producers/exporters (see Appendix 9, pp163 on recent developments in the shea sector). The activities of foreign companies remain unregulated as they have unlimited access to the shea pickers. They are competing with indigenous companies for the raw shea nuts. The competition drives up prices and limits supply for a product that is seasonal. This practice hampers year-round production of shea products as the demand erodes the possibility for shea stock build-up.

\subsection{Strategic Issues for Ele Agbe}

The company has concretized strategic linkages with leading personalities and appears to have focused less on local strategic linkages with the exception of upstream input suppliers. The company considers it would be beneficial (in terms of downstream linkages) to link up with local shea associations such as the Shea Producers Association and Shea Network to which some known shea exporting companies belong. Such links would help the company identify which other companies within these associations it can partner for group exports. For example, AWEP targets female entrepreneurs. There is an 
advantage to female entrepreneurs to take opportunity from such partnership especially as the export market is already established.

Ele Agbe is taking steps to register its trade secret as a sure way to prevent seepage or industrial pilferage. Next steps include the possible franchising of the trade secret in contract arrangements with shea butter producing associations such as Christian Mothers' Association, Pagsung Sheabutter Association, and Gubdanda Womens' Group. This will help to generate increased revenues from the franchise and from export volumes.

The company's downstream buyers are mostly retail outlets in the US, Japan, and, UK. Management is initiating an arrangement whereby the retail outlets provide links to others who are interested in shea products. This will increase existing market for the products and serve as an incentive to contract arrangement with the shea butter producing associations. The shea butter producing associations will find the venture profitable as higher revenues can be expected. Promoting the welfare arrangements that the company has with its current input suppliers (in the contracts with the shea butter producing associations) suggest that gain from the social setting is assured. This strategy is in line with the company's vision of targeting rural women and the youth.

An analysis of 14 other shea exporting companies ${ }^{15}$ supports the perceptions of Ele Agbe's $\mathrm{CEO}$ on the challenges faced in the shea sector. Some of these companies export to other African countries such as South Africa, Liberia, Sierra-Leone, Nigeria, and, Asian countries such as India, China, and Japan. Since these companies do not mention frequent changes in regulation covering imports as a constraint, Ele Agbe may consider venturing into these other markets.

As part of efforts to regulate the shea sector, government included the shea sector under the Ghana Tree Crop Development Authority bill which was recently passed by Parliament on December 2, 2019 (see Appendix 9, pp163). The bill now awaits Presidential assent to become law and for implementation. Effective communication among shea producers and government will enable beneficial implementation of the policy. In particular, indigenous shea producers ${ }^{16}$ could lobby by the government to formulate a policy either limiting the

\footnotetext{
${ }^{15}$ Analysis was made on similar questions (aside pilot survey questions) asked to shea companies to corroborate or refute assertions made by Ele Agbe company. See Q71c and Q71d of main survey instrument, Appendix 6 pp 138 .

${ }^{16}$ These are general views expressed by indigenous Shea company respondents. The price distortions are caused by large mostly foreign companies. Limiting the export of (raw) sheanuts would reduce scarcity of sheanuts and make it more available locally to shea processors who can then export value added shea products.
} 
proportion of shea nut exports or determining the percentage of a company's exports in sheanut and processed shea. The Ele Agbe company hopes to work to seize this opportunity to make the platform for shea exports more favourable to local companies through advocacy to government.

\subsection{Conclusions and Recommendations}

Ele Agbe appears to have positioned itself for international (especially Japan and US) markets based on the networks developed with leading personalities in these areas. While the social network developed has helped the company with its branding and market penetration, the frequent changes in regulations is costly to the company. The question for the company now is how to sustain its network which is linked solely to the CEO and not the company or its structures? Should more effort not be made on harnessing local social networks and exploiting other network opportunities in the sub-region to reduce costs further? How best should the company expand its business model of operation without compromising its vision? Should the network ties with world personalities used for international markets be the same approach used for the sub-regional markets? The answers to these questions would no doubt help Ele Agbe to come up with a more competitive strategy(s) for exporting.

The concept of developing the capacity of rural women and youth through a franchise of registered trade secret is appealing. This is because it can be scaled up through replication of the business operating model to different communities. It is not clear how viable this may be given the constraints associated with intellectual property registration at national, regional, and, world levels, and, successfully guarded trade secret. The advantages to Ele Agbe include the internal capabilities it has developed and the established networks in the shea export supply chain.

This case study is a presentation of an SME in Ghana, indicating the difficulties of frequent changes in government regulation, the importance of its internal capabilities, how it forms linkages, and, how it functions/operates within its networks. This makes it interesting to investigate further the advantages of the internal capabilities of NTAE SMEs, and how they function/operate within their supply chains and networks. Evaluation and lessons learned will be drawn from further studies presented in the subsequent chapters. 


\section{CHAPTER 4}

\section{Internal Capabilities and Export Performance of SMEs in Ghana's Non-Traditional Agricultural Export Sector}

\section{Chapter based on:}

Abban, R., Scholten, V., Velde van der, G., Omta, S.W.F. \& Aheto, J.B.K. (2018). Internal Capabilities and Export Performance of SMEs in Ghana's Non-Traditional Agricultural Export

Sector. Journal of Management \& Entrepreneurship, 12(3), pp1-29.

Published: March 23, 2019 (in edition July-September 2018) 


\section{CHAPTER 4}

\section{Internal Capabilities and Export Performance of SMEs in Ghana's Non- Traditional Agricultural Export Sector}

\subsection{Introduction}

Small and medium-sized enterprises (SMEs) in Ghana are considered to contribute to economic development through employment, supporting a relatively "even distribution of industrial development in the country, including the rural areas" (Oppong et al., 2014, pp 85 ). In Ghana, SMEs account for about $92 \%$ of all businesses; contribute close to $70 \%$ of gross domestic product (GDP); and provide an estimated $85 \%$ of employment in manufacturing (Abor \& Quartey, 2010). The proportion of non-traditional agricultural export (NTAE) sector, predominantly SMEs, is becoming an important development strategy in low and middle-income countries (LMICs) due to its high-value products (fruits, vegetables and horticultural products), and, its growing importance in the economy of these countries. This is partly because many African countries (including Ghana) adopted "a market-friendly, export-oriented strategy", with non-traditional agricultural products (Ouma et al., 2013, pp227). Between 1980 and 2005, the NTAEs in African countries increased by $243 \%$ and this growth was even higher in the horticulture exports of the sub-sector (Ouma et al., 2013). In general, the export firms in Ghana, have been reasonably studied on aspects such as international experience of exporters and market strategy of firms (Sraha et al., 2017; Acquaah \& Agyapong 2015; Akomea et al., 2014; Hinson et al., 2008), the role of bank finance (Abor et al., 2014); and, the role of market orientation (Mahamoud, 2011), but not much on their entrepreneurial strategy, innovation capacity, and, value chain activities. The non-traditional agricultural export products, especially, require new strategies in the organisation of their value chain (Konig et al., 2013). The impact of any intervention may be limited in part by the lack of a holistic approach that addresses opportunities and challenges in the SME value chain (Devaux et al., 2018). Therefore, this study investigates how exporting SMEs in Ghana develop entrepreneurial strategies and innovate when organizing their value chain activities. This chapter is structured as follows: section 2 discusses theoretical background and framework for the study. It is followed by export in developing countries (an explanation of the concepts and hypothesis development) in section 3. Section 4 explains the research design and section 5 explains the research methods. The results/data analysis are discussed in section 6. Section 7 presents conclusions and recommendations. 


\subsection{Theoretical Background and Framework}

In the Resource Based View (RBV), the resources and the internal capabilities of a firm (human and physical capital, social and management team networks) have been regarded as essential to understanding the performance of firms. Originally developed by Wernerfelt (1984), the RBV of a firm has been described as "the accumulation of valuable, rare, inimitable, and non-substitutable (VRIN) resources" (Lin \& Wu, 2014, pp407). Judicious use of resources, both tangible (land, building, equipment, human) and intangible (team capabilities and capacity), enable a firm to gain higher returns (Lozano et al., 2014, pp6-7; Peteraf, 1993, pp179; Barney, 2001). As a result, firms that build skills and know-how from their resource base are able to leverage "superior resources and capabilities" for "superior profits" and performance (Wolff \& Pett, 2000, pp36). The paradigm has gained interest in the study of the performance of the firms in developing economies in recent years due to its ability to explain firm performance (Fainshmidt et al., 2016). In particular, the scarce resources that are available in developing countries influence their firms' innovative activity, which eventually leads to competitive advantage and performance (Barassa et al., 2017). Various studies that draw on the RBV theory have investigated the factors that largely explain the success of exporting firms and found that an entrepreneurial strategy, the human capital of the firm (international experience and export knowledge), and the organization of the value chain activities were important for their success (Heiss, 2017; Carland et al., 2015; Gashi et al., 2014; Kungwansupaphan \& Siengthai, 2014, 2012). Although few studies focused on agricultural firms, they argue that firms that export agricultural products can differentiate themselves in foreign markets by entering niche markets of non-traditional export products. Export knowledge, entrepreneurial strategy, and, the innovation capacity of the firm are important assets to identify the niches and gain a competitive advantage.

A firm's entrepreneurial strategy reflects its behaviour to develop innovations and take bold decisions regarding investments (Brown et al., 2006). For export firms, this is manifested by the investment they make in physical capital (supply capacity), which, in part, influences the productivity-export relationship (Gashi et al., 2014) and in part builds a firm's resource base. A firm's entrepreneurial strategy reflects its behavior to identify opportunities and take bold decisions regarding investments (Brown et al., 2006). Gashi et al. (2014) have argued that the impact of investment in physical capital (supply capacity) increases productivity and export (in quantities). Furthermore, a firm's internal resources, which include physical capital (supply capacity) and human and organizational capital, is linked to export performance (Heiss, 2017). 
The human capital of a firm reflects its resources in terms of the knowledge and capabilities of the management team and employees. The term, originally coined by Becker (1964), refers to "the skills, knowledge, (experience) and competence", which emanate from the accumulation of education and experience (Kungwansupaphan \& Siengthai, 2014, pp5). The role of human capital is to harness employees' capabilities to the advantage of a firm.

Value-chain concepts are relevant to the emerging philosophy on chain development and relationships. The term "value chain" is variously used and applied in the literatures. (Devaux et al., 2018; Donovan et al., 2015). The value chain activities can be categorised as primary activities and support activities. These activities are integrating functions that cut across the traditional functions of the firm (Christopher, 2011, pp10). Porter (1985, pp 33) states that a "value chain disaggregates a firm into its strategically relevant activities" whose performance leads to competitive advantage. It is "the full range of activities that firms and workers undertake to bring a product from its conception to end use and beyond" (Gerrefi \& Fernandez-Stark, 2016, pp7).

Export performance can be viewed as "the outcome of the firm's export activities" (Abban et al., 2018, pp4). The literature provides for both subjective (relative performance, perceptions on performance) and objective (sales, profits) measures. In the present study we use the perception of the NTAE SME to measure export performance, although a performance measure on real export numbers would have benefits. However the main constraint with real numbers is that it is difficult to compare the numbers across the various products in the different NTAE sectors. More importantly, many respondents did not answer the questions regarding the objective measures of export performance. For these reasons we choose to focus on relative measures of perceived performance (as compared to competitors) ${ }^{17}$. Some studies have "found that subjective approaches (such as the one used in our study) were closely correlated with objective measures" (Aziz \& Yassin, 2010, pp157) and therefore subjective measures can be used in research where objective data are unavailable (Greenlay, 1995; Dess \& Robinson, 1984). There is consensus among researchers that export performance has more than one dimension (Jalali, 2012, pp55). Two dimensions of export performance used in most studies are economic (objective sales, profitability, sales growth, export intensity-proportion of export over total sales, etc.) and/or strategic (subjective - overall export performance, relative overall export

\footnotetext{
${ }^{17}$ However, the use of 'subjective' performance measures can be debated. We go deeper into this point under Section 7.5, the first limitation on page 122.
} 
performance and relative export sales growth, perception of performance, etc.) (Ngo et al., 2016; Hinson et al., 2008; Zou \& Stan, 1998). As a result, the explanations on export performance are varied and contextual in application (Stam et al., 2013, pp7).

\subsection{Export in Developing Countries}

\section{Entrepreneurial strategy}

Entrepreneurial strategies increase productivity and address "unsatisfied market needs" (Webb et al., 2014, pp3). Webb et al. (2014) present historical cases to define an entrepreneurial strategy as novel processes, added value, intended expansion, opportunities for market information, and business strategies (product, price, technology, marketing, cost reduction and quality). Entrepreneurial strategy can manifest by four possible growth strategies, namely moving into new markets, introducing new products or services, increasing sale with existing products and services, and hiring more employees (Rostamkalaei \& Freel, 2016, pp9). This is consistent with the study by Bamiatzi \& Kirchmaier (2014, pp261) who "claim that high-growth firms pursue market expansion". In this study, we define entrepreneurial strategy as the intended expansion of a firm. Intended expansion, in particular, shows a firm's commitment to allocate resources to grow its production and move into new markets, which in turn increases a firm's size and/or turnover. This is why we argue that an entrepreneurial strategy positively impacts a firm's export performance:

H1 Entrepreneurial Strategy is positively related to export performance of NTAE SMEs in Ghana

\section{Innovation Capacity}

Perhaps, the earliest definition of innovation can be attributed to Schumpeter (1934) who suggested that innovation is a key driver for "economic growth, enhancing competitive advantage and stimulating firm productivity". Innovation enables firms to revitalise the value of assets they are endowed with (Schumpeter, 1942). Innovation is known as the "core renewal process" and "life blood" for a firm's survival and growth, creating value and competitive advantage (Zahra \& Covin, 1994, pp183; Bessant et al., 2005, pp1366). The ability of a firm to innovate is determined by its resources and capabilities (Barassa et al., 2016). Innovation is a way of bringing about organisational change and covers "new product or service, new process technology, new organization structure or administrative systems, or new plans or program pertaining to organization members" (Damanpour, 1996, pp694). This study adapts the definition of Damanpour (1996) focusing on innovation capacity in a firm's internal environment. There is some complementarity 
between innovation and export performance which positively impacts the growth and profitability of small firms (Golovko \& Valentini, 2011). The following hypothesis is drawn:

H2 Innovation capacity of Ghanaian NTAE SMEs is positively related to export performance.

\section{Supply Capacity}

The supply capacity (of a firm) is made up of size, asset endowments and various strategies adopted in its value chain. Supply capacity, as an internal condition of a firm, is affected by "location-related elements" such as "access to raw materials and other resources". "Supply conditions are fundamental in defining export potential" (Fugazza, 2004, pp3). In general, good internal conditions of a firm are needed for export performance. At country level, export performance is determined by foreign market access and supply capacity (Damijan, 2011). For a firm's value chain therefore, the upstream supply capacity requires effective stock management for continuous supply of inputs. This is because as an internal resource stocks have positive impact on profitability of the business through influencing customer satisfaction (Amoah-Mensah, 2013).

In this study, upstream supply capacity is defined as maintaining input supply capacity of a firm. Exporting firms that are better at managing the upstream supply capacity for inputs are considered to have a better understanding of the market, and, available options essential to obtain a smooth and steady export level. Upstream supply capacity is considered to have a positive influence on export performance. The following hypothesis is made:

H3 Upstream supply capacity of exporting Ghanaian NTAE SMEs is positively related to export performance.

The value chain activities downstream involve a strong market orientation towards buyers in foreign markets. It includes the established infrastructure for export storage and transportation to meet buyer demands. SMEs with a well organised downstream supply capacity towards buyers can benefit from their export market information and understanding of buyer needs and preferences (Akyol \& Akehurst, 2003) and respond much quicker to changing demands (Smith et al., 2007). Internal supply capacity is determined by "access to ports", "institutional quality" and "foreign market access", which positively impacts export performance (Redding \& Venables, 2004). In this study, downstream supply capacity is defined as a firm's ownership of storage facilities which is thought to have a positive influence on export performance. It is hypothesized as follows: 
H4 Downstream supply capacity of exporting Ghanaian NTAE SMEs is positively related to export performance.

Export knowledge

Export knowledge is necessary to facilitate entry into foreign markets (Okpara, 2010). Export knowledge includes the knowledge of export assistance available for potential exporters, awareness of export market benefits, knowledge of potential markets, availability of knowledgeable or trained staff for export markets, and knowledge of options for export market entry (Okpara, 2010; Suarez-Ortega, 2003). Having a better understanding of a foreign market contributes to the positioning of a firm's products in that market. Export knowledge helps a firm to "identify changes in products that will lead to greater acceptance and sales" (He et al., 2013, pp7). A firm's internationalisation may be endangered if knowledge of the foreign market is insufficient, as this will increase their probability of failure (Sui \& Baum, 2014). Export knowledge is therefore important to the success of the SME and export performance. It is hypothesized that:

H5 Export knowledge of NTAE SME management is positively related to export performance.

\section{International experience}

International experience is the experience gained outside the home country through career development or international assignments (Takeuchi et al., 2005). Successful international assignments occur where a manager overcomes cross-cultural barriers and completes the assignment (Caligiuri, 2000; Shaffer \& Harrison, 1998). International experience is acquired through current or past events and is determined by the "domain" (work or non-work) and cultural specificity either of which may or may not be work related (Takeuchi et al., 2005). International experience is described as the experience in selling to foreign markets and includes the factors that reflect a firm's exposure to foreign market environment (Reuber \& Fischer, 1997). SMEs with international experience resource tend to increase internationalisation because entrepreneurs (managers) returning to country of origin bring along transferable experiences. This ultimately has a positive impact on export performance (Filatotchev et al., 2009; Reuber \& Fischer, 1997). The lack of international experience poses challenges to internationalising SMEs (Thanos et al., 2017). The following hypothesis is drawn:

H6 International experience of NTAE SME management is positively related to export performance

The variables and hypotheses statements discussed are used in the conceptual model below. 
Figure 4.1 Conceptual Model: Relationship between the independent constructs and the dependent constructs of Export Performance

Independent Constructs

Dependent Constructs

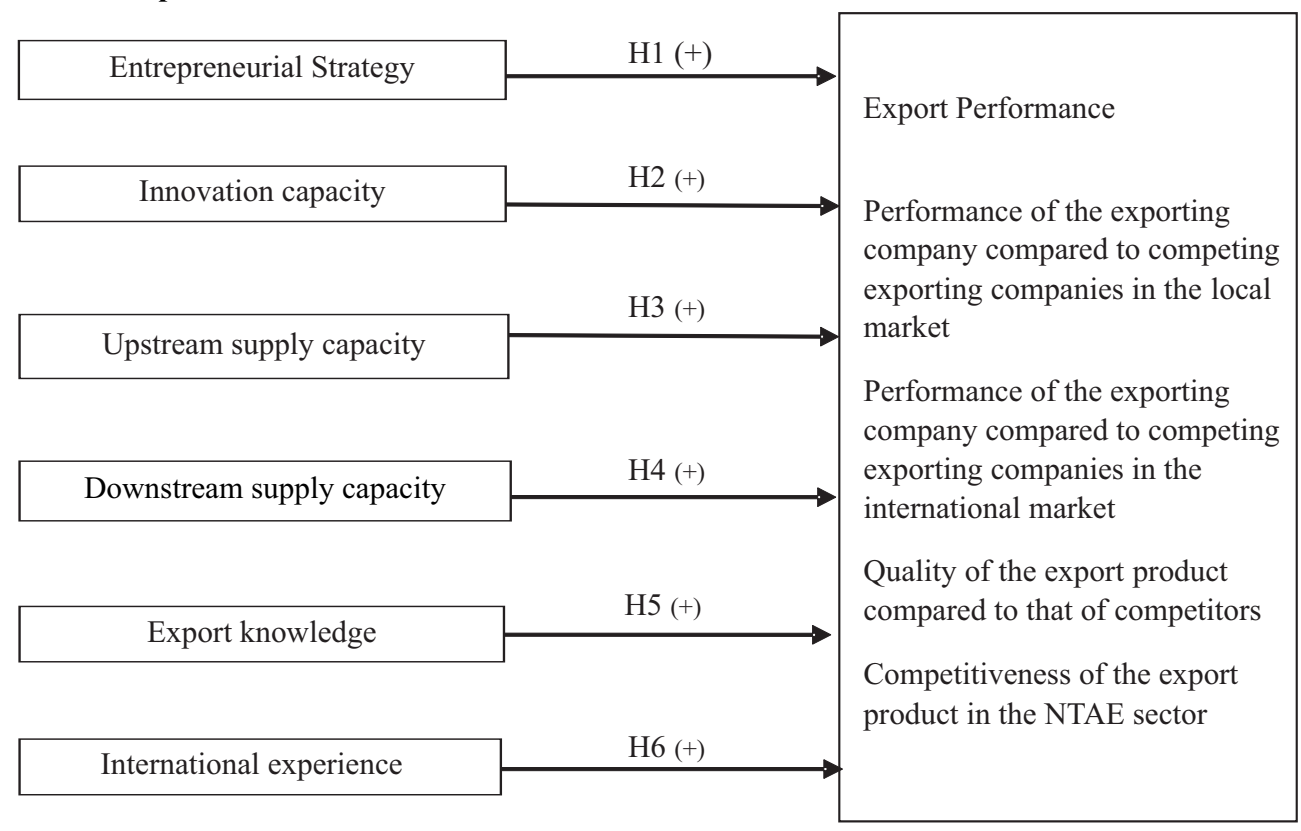

\subsection{Research Design}

\section{Context}

The context of the study is SME exporters in the NTAE sector. The focus on the NTAE sector is because of its importance to SubSaharan Africa (Ouma et al., 2013) and Ghana in particular. Ghana is a middle income country with a conducive business environment (Boso et al., 2016). All these reasons support a study on the characteristics of SMEs in the NTAE sector. Based on the recent referendum (in December 2018) increasing the number of regions in Ghana, the study covered 12 of the total of 16 regions, separated into 3 zones:

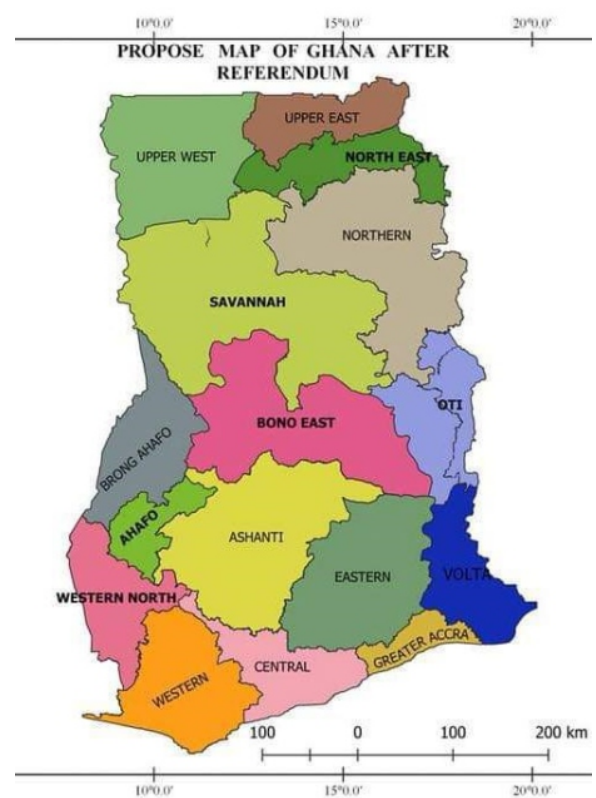

Figure 4.2 New Map of Ghana 2019 
1) Savannah zone: Upper West, Upper East, Savannah, Northern; 2) Forest zone: Bono, Brong Ahafo, Ashanti; 3) Coastal zone: Eastern, Volta, Western, Central and Greater Accra (see Figure 4.2).

The definition of SMEs used in this study is based on sales and/or employee size, that is, Micro: $\leq$ USD 10,000 / 1-5 employees; Small: USD 10,001 $\leq$ USD 100,000 / 6-29 employees; Medium: USD 100,001 < USD 250,000 / 30-99 employees. SMEs are also classified into various other identified firm categories: sole proprietor or single owner business; family-owned business; joint-partnerships; private limited liability companies; co-operatives; associations; and state-owned enterprises (Abban et al., 2013; Abor \& Quartey, 2010; Kayanula \& Quartey, 2000).

\section{Sample}

An assessment of relevant institutions to provide information on SMEs in the NTAE sector proved challenging as "there is no single public register of entrepreneurial firms in Ghana" (Adomako \& Danso, 2014, pp5). For this reason, an exploratory study of SME associations and related state institutions was undertaken with a list provided by GEPA. The exploratory study also provided the opportunity to pre-test survey instruments and make changes on the basis of the feedback before the main fieldwork. The pilot test was conducted in all the 3 zones on 10 SME cases to ensure face validity. To avoid duplication, the 10 SMEs used in the pilot study were excluded from the final dataset.

For the main fieldwork, the Federation of the Association of Ghanaian Exporters (FAGE) provided a list of relevant associations in the NTAE sector, which in addition to the database provided by the Ghana Export Promotion Authority (GEPA), the list from the Association of Ghana Industries (AGI), Sea Freight Pineapple Exporters of Ghana (SPEG), Vegetable Producers and Exporters Association of Ghana (VEPEAG), and that of other state institutions such as, Customs Division of the Ghana Revenue Authority (formerly Ghana Customs Excise and Preventive Service (GCEPS)), Ghana Statistical Service (GSS), and Bank of Ghana (BOG), enabled the identification of SMEs in the NTE sector. The consolidated list had over 800 SMEs, which was pruned to exclude: nonNTAE exporters (such as exporters of chemicals and metals), SMEs that had not exported in the preceding year, and repeated names of SMEs appearing in more than one list. Of the final list of NTAE SMEs based on the enhanced GEPA database, 483 non-traditional exporters were identified in Ghana, out of which 412 were in agriculture or agriculture related businesses. The 412 served as the sample population. 


\section{Data Collection}

A simple random sampling methodology was used to select 235 non-traditional agricultural exporters (NTAE) out of the 412. The selection reflected the spread of NTAE SMEs based on location. (This was similar to the case study (10 SME cases: 5 from coastal zone, 2 from forest zone and 3 from savannah zone) presented in Chapter 5. The details of the data collection approach for the case study is presented in Section 5.3. About $70 \%$ of NTAEs were found to be located in the coastal zone ${ }^{18}$ which accounts for $50 \%$ (on regional basis) of the country. Out of the 235 potential respondents, 152 participated in the survey. This represents a response rate of $65 \%$. The survey instrument (questionnaire) can be found in Appendix 6 on page138.

The survey was conducted in 2015 and 2016. The interviews were conducted with top management of the SMEs, that is CEO, Managing Director, Manager, Director, Officer, of each business. Trained interviewers were used to conduct face-to-face interviews. There were four experienced field assistants and two field supervisors who assisted in the field survey. The length of the questionnaire required repeated visits in a number of cases. Assurance of confidentiality and the ability of interviewers to clarify questions enhanced the reliability of the data. Most responses were on a 7 point 'Likert' scales from 1 (to a very low extent) to 7 (to a very high extent).

\subsection{Research methods}

\section{Measures}

The variables of our model are based on existing items which were used in similar studies that focused on measuring the performance of export companies and the resources of firms in general (see survey instrument, Appendix 6 on page 138). The items were measured using a questionnaire that included statements. The answer to each item reflects a selfassessment by the respondent, and, indicates the extent to which the respondent agrees or does not agree to the statement. The answers were measured by seven-point 'Likert' scales. Responses to the open-ended questions ${ }^{19}$ are used to support discussions on findings, and, forms the basis for some of the recommendations in this chapter and the concluding chapter 7 on page 111 .

\footnotetext{
${ }^{18}$ Coastal zone covers Western, Central, Greater Accra, Eastern and Volta regions. Forest zone covers Ashanti and Brong-Ahafo regions. Savannah zone covers Northern, Upper West and Upper East regions.

${ }^{19}$ The questions are Q71c and Q71d of the survey instrument. See Appendix 6 on page 138 and descriptives in Appendix 8 on page 161.
} 
- Dependent Variable

Export performance in this study was measured using four summative constructs on a seven-point 'Likert' scale (from "very poor/low" to "very good/high"). The summative constructs were derived from:

a) Company performance on the local market. This is measured by the rating of performance of each respondent company in comparison to competing export companies in the local market.

b) Company performance on international market. This is measured by the rating of performance of each respondent company in comparison to competing export companies in the international market.

c) Product quality. This is measured by the rating of the quality of each respondent's product compared to that of competitors. This measure identified quality as an indicator for sales demand. High product quality implies high sales and high export performance.

d) Product competitiveness. This is measured by how competitive each respondent's product(s) is in the NTAE sector. This measure identified competitiveness as an indicator for sales demand. High product competitiveness implies high sales and high export performance.

These measures are relevant within the context of NTAE sector and appropriate for this study, especially as no responses were provided on objective measures of export performance by which firms could be assessed. Please see Appendix 7 (on page157) for analysis of export performance.

The summative constructs were operationalized as follows:

i. ExpNatQualPerf2 - company performance compared to similar export companies in local market, product quality, and product competitiveness.

ii. ExpIntQualPerf3 - company performance compared to similar export companies in international market, product quality, and product competitiveness.

iii. ExpAllQualPerf4 - company performance in local market, company performance in international market, product quality, and product competitiveness.

- Independent variables

Entrepreneurial strategy was operationalized by five items: expansion of existing facilities, expansion to another location, expansion with more elaborate equipment, expansion in existing markets, and, adapt changes based on market information. 
Innovation capacity was operationalized by four items: owing to nature of environment bold wide-ranging acts are necessary to achieve firm's objective, new products/services, operating technologies or administrative techniques are the first to be introduced by the company (for company operations), CEO/MT have strong preference for high risk projects with chances of very high returns, and, company is first to introduce new products/services, administrative techniques or operating techniques (in the industry).

Upstream supply capacity was operationalised by four items: ensure reliability in supplies to the company, maintain minimum stock levels, provide for alternative sources of supply, and, make prices more competitive.

Downstream storage facilities was operationalized by two items: storage facilities are in place at harbor and/or airport, and, in the ships and/or planes. SMEs exporting nonprocessed products were highly dependent on storage facilities compared to SMEs that exported semi-processed and processed products.

Export knowledge was operationalized by five items: knowledge of market, knowledge of regulations of importing countries, knowledge of quotas/overseas barriers, knowledge of frequent changes in regulations of importing country, and, need for more learning.

International experience was operationalized by four items: CEO/Management team born and raised abroad, travelled abroad frequently, schooled abroad, and previously worked abroad.

\section{- Control Variables}

The statistical model included firm age and firm size as control variables. These variables were also used by Dana, Grandinetti, \& Mason (2016, pp612) because, firm's age (number of years) and size (total number of employees) were considered to minimize any spurious results. Firm age was measured by number of years of a company's operations. Firm size was measured by the total number of workers currently employed in the firm. This also included seasonal workers.

\subsection{Results/DataAnalysis}

\section{Sample Characteristics}

The profile of the NTAE SMEs is presented in Table 4.1. The T test results for the variables namely: location, audited financial statement, capital structure, and, company type (which were originally considered as control variables) were found to have no significant effects on export performance and most independent variables, and therefore excluded ${ }^{20}$.

\footnotetext{
${ }^{20}$ The same decision applied in our (study) context for other estimation parameters. Variables with composite reliability $<0.7$ were excluded.
} 
In addition, the reliability tests (Cronbach Alpha) for these excluded variables were low $(<0.7)$. The Levene's test for equality of variances $(\mathrm{p} \leq 0.05)$ was applied. Where the null hypothesis is rejected, the output for "equal variances not assumed" are correct. If not rejected, the results for "equal variances assumed" are correct. Appendix 1 (pp126-129) provides results for $\mathrm{T}$ tests which illustrates general lack of significance for these variables based on the model for the study.

Of the firms interviewed, $83 \%$ were located within the coastal belt of the country. About $7 \%$ and $10 \%$ were located in the forest and savannah zones respectively.

Table 4.1Company Characteristics (location, audits, and financial assets)

\begin{tabular}{|lcc|}
\hline Characteristics & Frequency & Percent \\
\hline Location of Business & & \\
Savannah & 15 & 9.87 \\
Forest & 11 & 7.24 \\
Coastal & 126 & 82.89 \\
Total & $\mathbf{1 5 2}$ & $\mathbf{1 0 0}$ \\
Ever Audited Financial Statement & & \\
Yes & 91 & 59.87 \\
No & 61 & 40.13 \\
Total & $\mathbf{1 5 2}$ & $\mathbf{1 0 0}$ \\
Company Capital Asset Finance & & \\
Equity & 79 & 51.97 \\
LT Debt-equity & 63 & 41.45 \\
ST Debt & 10 & 6.58 \\
\hline Total & $\mathbf{1 5 2}$ & $\mathbf{1 0 0}$ \\
\hline
\end{tabular}

Source: Field Survey (2015-2016)

Sixty percent of the respondents had audited financial statements. With respect to financing, about $52 \%$ of the companies used equity finance. Other forms of capital investment financing used were equity $51.97 \%$, long-term (LT) debt to equity $(41.45 \%)$ and short-term (ST) debt (6.58\%).

The vision of the SME CEOs was coded and categorised into five main thematic areas (Table 4.2). The table revealed that the majority of the CEOs had a vision to be leaders in fresh agricultural commodity exporting (42.8\%) or in supply of fresh agro and agrorelated products to shops abroad (34.2\%). 
Table 4.2 Vision of the SME CEOs

\begin{tabular}{|l|c|c|}
\hline Vision & Frequency & Percent \\
\hline $\begin{array}{l}\text { Commercialising goods (handicrafts, wood carvings, } \\
\text { artefacts) }\end{array}$ & 9 & 5.9 \\
\hline $\begin{array}{l}\text { Generating funds and creating employment through } \\
\text { exporting of agricultural commodities }\end{array}$ & 6 & 3.9 \\
\hline Leader in fresh agricultural commodity exporting in Ghana & 65 & 42.8 \\
\hline $\begin{array}{l}\text { Leader in supply of fresh agro and agro-related products to } \\
\text { shops }\end{array}$ & 52 & 34.2 \\
\hline $\begin{array}{l}\text { Leader in the production of good quality fabrics and } \\
\text { garments (textiles) for Ghana and abroad }\end{array}$ & 20 & 13.2 \\
\hline
\end{tabular}

Source: Field Survey (2015-2016)

Out of the total number of respondents, $79 \%$ were male and $21 \%$ were female. Fifty-seven percent of respondents had tertiary (first degree) education, $12 \%$ had post graduate or professional education, while the remaining respondents had secondary or basic education.

The respondents were working in their respective companies for an average of 10 years. On the average about $80 \%$ of the respondent SMEs relied on the national grid as source of energy supply. This, in effect, meant that SMEs' operations are highly affected by irregular power supply in Ghana. In total, about $48 \%$ of the SMEs exported non-processed agroproducts, $41 \%$ exported processed agro-products, and, the remaining $11 \%$ exported semiprocessed agro-products.

Non-processed agro products were pineapple, chilli pepper, 'baby' corn, sheanuts, lumber/timber, cashew nuts, green pepper, soyabean, green mango, green banana, green pawpaw, fish, garden eggs, cocoyam, okro, and soybean. Semi-processed products include dried fruits (mango, banana), orange concentrate, pineapple (juice, chopped), dried voacanga and/or griffonia seeds, shea butter, Voacanga/griffonia tea bags, dried orange/lemon peel, flowers. Processed products include clothing (garments and textiles), artefacts (carvings), baskets and other handicrafts (drums, masks), stools, shea - body oils/cream/lotions, lip balm, soap, canned foods - tuna, fruit, vegetables, pepper sauce, palm soup, melon soup, gari (grated, roasted cassava), palm oil, traditional footwear, cocoa products, processed wood, 'kente' cloth, 'fufu' flour (cassava, yam, plantain and maize) and 'banku' mix (dried fermented maize and cassava flour). 


\section{Data Description}

Partial least squares (PLS) structural equation modelling (PLS SEM) using SmartPLS 3.2 software was used to estimate our model and test the associated research hypotheses (Ringle et al., 2005). PLS SEM is an appropriate method in this context since it yields more stable estimators with small sample sizes than SEM, and, can also operate with indicators that do not follow a normal distribution (Wong, 2013; Henseler \& Fassott, 2010). The approach places a very flexible restriction concerning the distribution and population of the study (Haenlein \& Kaplan, 2004). It also has the possibility of providing a more reliable and accurate computation for moderating effects, because it accounts for error that is capable of reducing the possible relationship, as well as, the improvement of the validation of the theory (Helm et al., 2010; Henseler \& Fassott, 2010). In addition, PLS SEM is a components-based approach which models formative indicators that "form or cause the creation or change in latent variables" (Chin, 1998). The constructs were first analysed and checked for internal consistency (composite) reliability. The findings indicate composite reliability was not less than 0.851 , and, the convergent validity measured by the average variance extracted (AVE) was 0.589 minimum for all variables and is therefore acceptable (Wong, 2013). We also analysed the discriminant validity which was determined by the Fornell-Larcker (FL) criterion. For the FL criterion to be satisfied, the square root of the AVE should be greater than the correlation values amongst latent variables. The diagonal in Table 4.3, gives the square root of the AVE for each variable, and is calculated for as follows: $0.767=0.589^{\wedge} 0.5(0.589$ is the AVE). The findings indicate that the measures satisfy the criterion for discriminant validity.

On the non-diagonal you see the correlations of the constructs with the other constructs. According to the FL criterion, the values on the diagonal should be larger than the values in the respective columns. This shows that the correlations between the construct's underlying items are larger than the construct's correlations with other constructs. The construct is considered more internally coherent than are the relations of the construct with other constructs. It indicates that the construct really is unique (discriminative). The discriminant validity is good for all constructs (Hair et al., 2014; Wong, 2013).

Table 4.3 also gives the correlations between the variables. Some strong correlates were found between entrepreneurial strategy and interacting/joint innovation capacity and entrepreneurial strategy $(r=-0.437)$, innovation capacity and export knowledge $(r=$ $0.419)$, downstream supply capacity and innovation capacity $(r=0.422)$, upstream supply capacity and export performance $(r=0.442)$ and, export performance and export 
knowledge $(r=0.454)$, but these were considered not to pose a problem for the PLS SEM analyses.

Partial Least Squares Structural Equation Modelling analyses

The PLS SEM path modelling captures relationships of unobserved or latent variables and analyses path coefficients to avoid bias or inconsistency in parameter estimations for equations. The PLS SEM method is appropriate for "smaller size samples than recommended for covariate-based SEM methods" and reveals "associations that might not appear with standard regression or covariance-based SEM methods" (Lechner \& Gudmundsson, 2014). The results of the PLS SEM analyses are shown in Table 4.4. The standardised coefficient $(\beta)$ values are shown including the significance levels. The results were acceptable for the measurement model (outer model) since the composite scale reliability exceeded the recommended minimum of 0.70 (range 0.851 to 1.00 ), and, the cronbach alpha was above 0.7 for all variables except downstream supply capacity with 0.637. In addition, convergent validity (AVE) exceeded the minimum (0.50) in all cases (range 0.589 to 1.00) (Lechner \& Gudmundsson, 2014; Bagozzi \&Yi, 1988). 


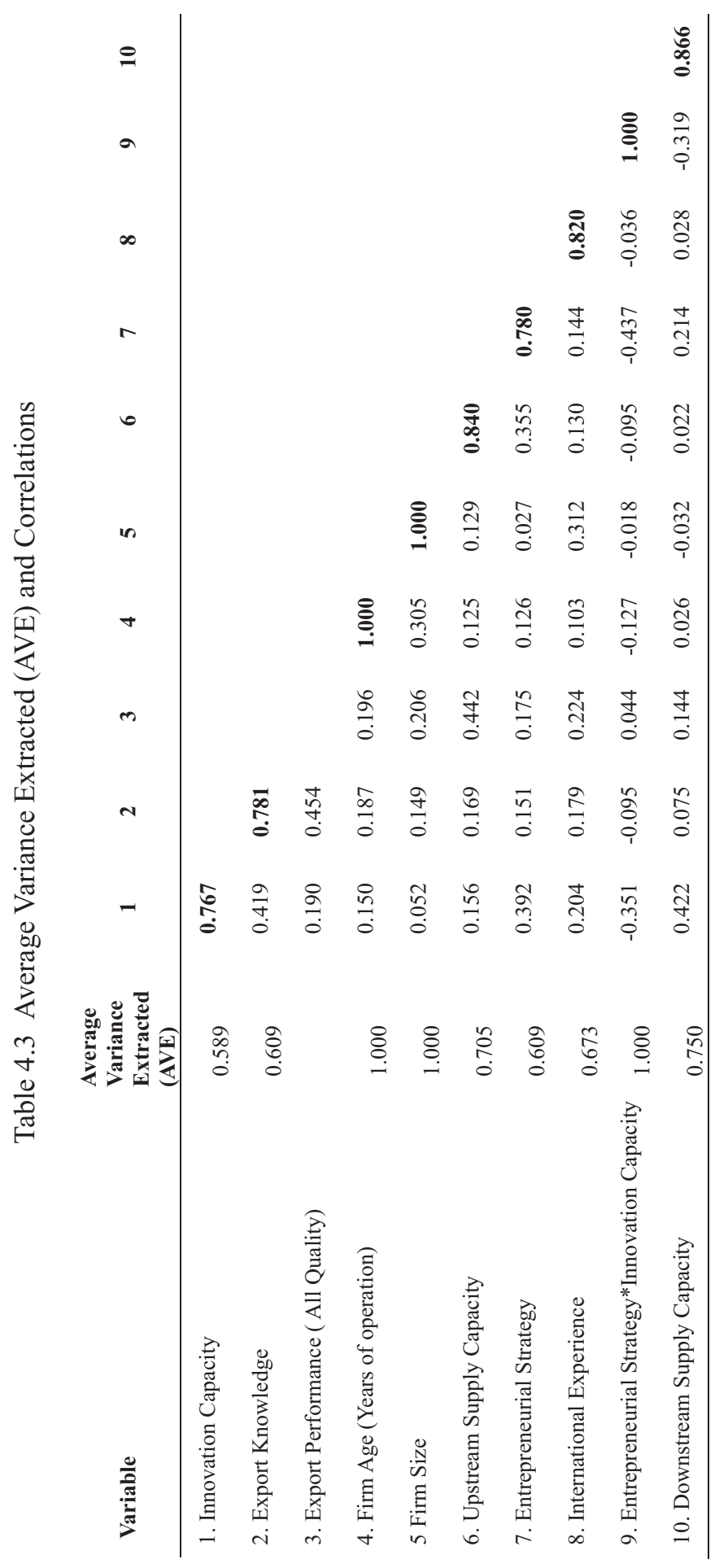


Table 4.4 PLS SEM estimates for factors that are linked to export performance of SMEs in Ghana

\begin{tabular}{|c|c|c|c|c|}
\hline & $\begin{array}{c}\text { MODEL 1 } \\
\text { Export National } \\
\text { Quality Performance } \\
2 \\
\end{array}$ & $\begin{array}{c}\text { MODEL 2 } \\
\text { Export International } \\
\text { Quality Performance } \\
3 \\
\end{array}$ & $\begin{array}{c}\text { MODEL } 3 \\
\text { Export All } \\
\text { Quality Performance } \\
4 \\
\end{array}$ & $\begin{array}{c}\text { Collinearity } \\
\text { Statistic }\end{array}$ \\
\hline Variables & Coef. & Coef. & Coef. & $\begin{array}{l}\text { Inner } \\
\text { VIF }\end{array}$ \\
\hline Firm Age & $0.139 *$ & $0.154 * *$ & 0.076 & 1.153 \\
\hline Firm Size & 0.060 & 0.056 & 0.062 & 1.229 \\
\hline International Experience & $0.176^{* *}$ & $0.216^{* * *}$ & 0.097 & 1.173 \\
\hline Entrepreneurial Strategy & 0.139 & 0.206 & 0.036 & 1.522 \\
\hline Innovation Capacity & $0.217 * *$ & 0.136 & -0.100 & 1.722 \\
\hline Upstream Supply Capacity & 0.122 & 0.145 & $0.376 * * *$ & 1.190 \\
\hline Downstream Supply Capacity & -0.013 & -0.094 & 0.195 & 1.293 \\
\hline Export Knowledge & 0.146 & $0.213^{* *}$ & $0.394 * * *$ & 1.287 \\
\hline $\begin{array}{l}\text { Entrepreneurial Strategy * } \\
\text { Innovation Capacity }\end{array}$ & $-0.315^{* *}$ & $0.372 * * *$ & 0.156 & 1.368 \\
\hline Observations & 152 & 152 & 152 & \\
\hline R-squared & 0.252 & 0316 & 0.408 & \\
\hline Adj. R-squared & 0.205 & 0.273 & 0.371 & \\
\hline
\end{tabular}

PLS SEM analysis was applied to test the hypotheses (Figure 4.1). Table 4.4 contains the coefficients $(\beta), \mathrm{R}^{2}$, the adjusted $\mathrm{R}^{2}$, and collinearity statistic. Multicollinearity was checked. For each of the predictor variables, the maximum variation inflation factor (VIF) was calculated and found to be below 5.0 (VIF $<1.73$ ). This indicates there were no serious multicollinearity problems. The test for endogeneity showed no endogeneity among the variables:

Ho : variables are exogenous.

Durbin (score) chi2 $(1)=2.7042 \quad(\mathrm{p}=0.1001)$
Wu-Hausman F $(1,134)=2.58285 \quad(\mathrm{p}=0.1104)$

The Durbin-Wu-Hausman test (DWH test) detects endogenous regressors (predictor or explanatory variables) in a regression model. It is a formal statistic for investigating whether the regressors are uncorrelated (exogenous) or correlated (endogenous) with the error terms (Hausman, 1978). Endogenous variables have values that are determined by other variables in the system. The DWH test makes use of the Two Stages Least Squares (2SLS) technique and an augmented LS regression. The check for endogeneity is done by comparing instrumental variable (IV) estimates to ordinary least squares (OLS) estimates. Having endogenous regressors in a model will cause ordinary least squares estimators to 
fail, as one of the assumptions of OLS is that there is no correlation between a predictor variable and the error term. The null hypothesis that there are endogenous regressors in a model is accepted if the p-value is small (less than 0.05), and rejected otherwise, meaning the variables are exogenous, as is the case in our study (Janot et al., 2016; Semadeni et al., 2014; Baum et al., 2003; Nakamura \& Nakamura, 1985). The Ramsey Regression Equation Specification Error Test (RESET) test was also applied to the model. It is a general specification test for a linear regression model. It tests whether non-linear combinations of the fitted values help explain the response variable. The idea behind the test is that if non-linear combinations of the explanatory variables have any power in explaining the response variable, the model is misspecified in the sense that the data generating process might be better approximated by a polynomial or another non-linear functional form. Also the results of the RESET test support no signs of an endogeneity problem (see Appendix 3, page134). The Ramsey RESET Test does not clearly distinguish between omitted variables and functional form misspecifications (which may occur if some important nonlinear relationships are not taken into account causing bias in the remaining parameter estimators) using RESET. However when combined with other tests, such as the DWH-test, the results strengthen the conclusion that endogeneity is not a problem in our model (Wooldridge, 1995; Thursby \& Schmidt, 1977; Kennedy, 1998).

The first model in Table 4.4 assesses the contribution of the variables on the export performance. Model 1 has an adjusted $\mathrm{R}^{2}$ of 0.205 . The first model shows that firm age measured by years of operation is statistically significant and positively related $(p<0.10)$ to export performance. The effect of the firm age remains stable for Model 2 with $p$ values at $p<0.05$ but is not significant for Model 3. Firm size has no statistically significant effect for any of the models. Innovation capacity and International experience have significant effects on export performance with $\mathrm{p}$ values each at $\mathrm{p}<0.05$ for Model 1. Although Entrepreneurial strategy has no effect on its own, the interaction of Entrepreneurial strategy and Innovation capacity has a significant joint inverse effect on export performance with $\mathrm{p}<0.05$. The result of this interaction suggests that for Model 1 , competing SMEs in the local market, do not have the same or similar positive impact on export performance as when compared with competing international exporting SMEs for Model 2. When all formative variables are included for export performance in Model 3 the interaction of entrepreneurial strategy and innovation capacity has no effect.

The second Model in Table 4.4 has an adjusted $\mathrm{R}^{2}$ of 0.273. Export knowledge has significant effect on export performance with $p<0.05$. International experience is significant with $\mathrm{p}<0.01$. There is a significant joint positive effect of Entrepreneurial 
strategy and Innovation capacity on export performance. This suggests that for Model 2, comparison with exporting companies on the international market has a positive influence. This is opposite for Model 1 when comparison is made with exporting companies on the local market. Model 3 was used in testing the study hypotheses. This is because all variables (formative) for export performance used in the study are captured, and the adjusted $\mathrm{R}^{2}$ is high.

The effect of Upstream Supply Capacity on export performance is formulated in Hypothesis 3 and is statistically significant $(\beta=.376 ; p<0.01)$. Hypothesis 3 is supported. Hypothesis 5 on Export Knowledge indicates significant effect on export performance $(\beta=.394 ; \mathrm{p}<0.01)$. Hypothesis 5 is therefore supported. Hypothesis 6 which reflects the role of international experience on export performance, has no effect. This hypothesis is therefore not supported. Hypothesis 1, focusing on an Entrepreneurial Strategy has no effect and is not supported. The role of Innovation Capacity is formulated by Hypothesis 2 and is not supported. Hypothesis 4, looking at Downstream Supply Capacity has no effect on export performance.

Analysis was conducted for interacting terms and effect on export performance. The result of interest was the joint effect of innovation capacity and entrepreneurial strategy which was found to come close to statistical significance at $1.04 \%$ for Model 3. This implies innovation capacity and entrepreneurial strategy may jointly improve export performance. On the basis of this result it can be assumed that the SME internal policies on innovation capacity and entrepreneurial strategy when properly coordinated will positively improve export performance of the SME.

\subsection{Conclusions and Recommendations}

This study focused on the relation between export performance of Ghanaian SMEs in the NTAE sector and internal capabilities of these SMEs. The results in our study show that the entrepreneurial strategy has no direct effect on the export performance. However, when we analyse the combination of entrepreneurial strategy with innovation capacity, it seems that the relative advantage of the combined entrepreneurial strategy and innovation capacity varies with the competitive position with national or international competitors. Innovation capacity is important for export firms when they compete with local SMEs. However, the effect is absent when compared to international export firms. The findings suggest that when the firms compete with local firms, higher levels of performance can be achieved when the firm has low levels of entrepreneurial strategy and low innovation capacity. When competing with international firms, the exporting firm could gain higher 
performance levels if they combine an entrepreneurial strategy with high innovation capacity. Also, export knowledge and the organization of the upstream supply chains will help them gain better performance while competing in international markets.

These findings may in part be the result of the financing options for expansion and innovation in Ghana. At least $50 \%$ of the SMEs in the study depended on equity finance where requirement of equity capital was small. Small enterprises could rely on microfinance institutions, credit unions, or, financial non-governmental organisations (FNGOs) to leverage some debt capital. However, the volume of capital available may not suffice for the venture to be undertaken due to restrictive conditions imposed by Bank of Ghana (BOG). As explained by the SMEs, these financial institutions cannot issue letters of credit (LCs). The SMEs, therefore, have to depend on other banks even though their interest rates may be higher. It is obvious the regular banks that can generate LCs, and, provide long term lump-sum capital, demand secured collateral which these SMEs cannot readily provide.

The higher levels of export performance may also be driven in part by better quality and competitive products. The innovations and better quality products could also be improved and sustained through legal protection mechanisms such as intellectual property (IP) registration. SMEs in Ghana appear unaware of such legal protection options. As a result, new innovations are easily picked up and copied by competitors. Carving out a niche for themselves through improved packaging, branding, trademarks, and designs could be improved with IP protection. There is the need to strengthen SME sub-sector collaborations for group exports through mandatory registrations of and with associations. This would enable better monitoring and regulation of the sub-sectors.

Currently, there is the perception that the ability of SMEs to mimic one another means any leads one SME may develop is short-lived, as other SMEs catch up fast through imitation. The effect may be the overall negative image that encapsulates them all and hampers international market penetration. With regards to organizing their business operations in the value chain, the results indicate that the upstream supply capacity have a significant effect on the export performance. It seems that organising the upstream supply capacity is important to ensure a reliable and stable flow of goods for export. It may be that the firms that can better manage their upstream supply capacity activities are showing higher export performance because they are more trustworthy to partner with. The findings indicate that the downstream supply capacity does not explain differences in export performance. It appears that these activities are less crucial. The export firms may have more alternatives 
when it comes to storage at harbour/airport location. It is largely true of exporting SMEs that they are concentrated on few international buyers. For this reason, developing franchise market as a strategy, linking the SMEs with multinational companies and large international buyers could generate multiple pay-offs in the value chain of the Ghanaian SMEs. This is because the multinationals or franchisors are likely to include support to their franchisees, to develop the same or similar value chains along their business concepts. What SMEs should consider in such ventures is to avoid "captive supply" scenarios, where only products of franchisors are produced without allowing or restricting alternative product lines to the franchisee. The role of export knowledge is also found to be important. Exporting firms that have more knowledge of the trade regulations abroad, and, the trade regulations to export in Ghana seem to be acquiring higher levels of export performance. This factor of export knowledge, knowing how to get the goods to foreign markets is often discussed as an important factor for export success in other countries (Okpara, 2010). Within the franchise market development proposed, SMEs could benefit from tacit knowledge build-up (anchor) from the established franchisor to enhance export knowledge. There may however be some genuine concerns about "crowding out" SMEs in the domestic market without the same or similar anchor. In addition, promoting SME participation in associations would help build absorptive capacities through avenues such as, knowledge share and outsourced arrangements. Relevant to our study findings is the significance for export knowledge. Knowing how to get the goods into foreign markets is essential for export firms in Ghana. 


\section{CHAPTER 5}

\section{Connecting the Dots: A Multiple Case Study of the Network Relationships of Small and Medium- Sized Enterprises (SMEs) in the Non Traditional Agricultural Export (NTAE) Sector of Ghana.}

\section{Chapter based on:}

Abban, R., Omta. S.W.F., Aheto, J. B., \& Scholten, V.E. (2013). Connecting the dots: A multiple case study of the network relationships of small and medium-sized enterprises (SMEs) in the non-traditional agricultural export (NTAE) sector of Ghana. African Journal of Economic and Management Studies, 4(1), pp 74-94.

Published: April 15, 2013. 


\section{CHAPTER 5}

\section{Connecting the Dots: A Multiple Case Study of the Network Relationships of Small and Medium-Sized Enterprises (SMEs) in the Non Traditional Agricultural Export (NTAE) Sector of Ghana.}

\subsection{Background}

The post-independence era in Ghana saw fluctuations in world producer prices for traditional exports such as cocoa, gold, timber, manganese and diamonds resulting in a shortfall in anticipated revenues. Governments therefore focused on the diversification of export products to include non-traditional exports (NTEs) in order to enhance the country's revenue base. Kuada (2000) suggests from existing literature that, successive Ghanaian governments have provided "macro policies and incentive packages" to boost exports over a 30 year period to 2000. In 2008, Kokutse reported that "impressive growth in exports from Ghana to the rest of the world has been witnessed over the past few years as more and more Ghanaians explore production in non-traditional sectors".

Indeed, NTE growth rate of which agricultural exports-NTAEs ${ }^{21}$ is a part, is impressive: $33 \%$ from 2005 to $2006,12 \%$ from 2006 to 2007 , and $22 \%$ from 2007 to 2008 . $^{22}$ NTE amounted to about US\$ 1.5 billion (total exports estimated at US $\$ 5.3$ billion), accounting for about $30 \%$ of total exports in 2008. The contribution of NTAE to NTE in particular is thought not to exceed $22 \%$ making NTAE contribution to total exports rather low. Small and medium sized enterprises (SMEs) ${ }^{23}$ are known to account for the bulk of NTE exports. The performance of SMEs falls short of expectation which might be further exaggerated by the shrinkage of global production due to the financial crisis (Cramer, Johnston \& Oya, 2009). The former Ghanaian Deputy Minister for Environment and Science, Agasika Agambila (2005) pointed at four factors that could have negatively affected the

\footnotetext{
${ }^{21}$ The non-traditional agricultural exports (NTAE) products include exotic fruits, vegetables, tubers, processed and semi-processed wood, apparel, rubber and agricultural products. Cocoa paste, canned tuna, veneer, cocoa butter, sheanut butter and pineapples are among the leading NTAE products. This differs from the traditional agricultural export products of Ghana such as cocoa, coffee, among others. Source: Bank of Ghana Annual Reports.

${ }^{22}$ Source http://bog.gov.gh/: Bank of Ghana Annual Reports 2005, 2006 and 2008.

${ }^{23}$ SMEs are defined in terms of assets/employees as follows: Micro: $\leq \$$ US10,000/1-5 employees; Small:\$US10,001 $\leq 100,000 / 6-29$ employees; Medium:\$US100,001 $\leq$ 250,000/30-99 employees. (Abor \& Quartey, 2010). For the purpose of this study, SMEs are also classified into various other identified firm categories, namely: Sole proprietor - one man business; family-owned business; jointpartnerships; private limited liability companies; co-operatives; associations; and state-owned enterprises.
} 
development of small scale industries in Ghana: management, capital, markets and government policy. Buatsi (2000, pp13) refers although there is a "network of institutions in place" to facilitate exports, exporters are still confronted with major constraints ranging from "accessing credit facilities, producing and developing high quality exportable products, marketing their products to international buyers, and going through shipment procedures." Within the broad area of export behaviour especially, the network relations (social capital) that the SME and its management use with upstream and downstream (international) supply chain partners has received little attention up to now.

The present chapter will fill up this gap by looking into the export (network) behaviour of NTAE SMEs. The literature presents contrasting views: for example Ibeh (2003) states that, "the sub-Saharan Africa is one particular region in which little systematic firm-level export behaviour research has been undertaken". Exporting SMEs in developing countries have "received little systematic attention from export behaviour researchers"(Ross 1989). These perceptions are challenged by recent work of some Ghanaian researchers including Mahmoud (2011); Hinson (2010); Engle, Dimitriadi, Gavidia, Schlaegel, Delanoe, Alvarado, He, Buame \& Wolf (2010); Nartey (2009); Hinson, Ofori, Kastner \& Mohammed (2008); Hinson \& Sorensen (2007); Kuada (2005); Hinson \& Abor (2005), Buatsi (2000) among others. Their focus has however been on non-traditional exports, SMEs, entrepreneurship, e-business, performance and marketing.

The objectives of the present study are to identify the types of SME networks that exist in the NTAE sector, and examine the interaction between the management attributes, the SME networks, the building of these networks, and ultimately the link with performance. This chapter is based on ten SMEs in the NTAE sector of Ghana. The research questions addressed are:

- What is the effect of human capital (management attributes and firm and employee capabilities) on the firm size of SMEs in the NTAE sector in Ghana? and

- Whichnetwork relationships (social capital) may lead to increased firm size of SMEs in the NTAE sector in Ghana?

The chapter is structured in four sections: a literature review discussing the concepts mentioned in the research model including physical, human and social capital, the business environment, supply chain complexity and performance; the research methodology (qualitative) such as the basis for sample selection, key questions administered, the variables identified, and, the indicators used. Thereafter the main 
findings are discussed and, finally, the conclusions are drawn and recommendations and management and policy implications are provided.

\subsection{Review of Relevant Studies and Research Model}

Various studies have found that the physical assets of a firm are influenced by the joint contribution of human capital and social capital (through networks). These include: Prahalad \& Hamel (1994) and Cole (2004) on core competencies of the corporation and the resource based view of the firm. Shrader \& Siegel (2007), assessing the role of human capital in firm growth, find that, "the fit between strategy and CEO and/or management team experience is a key determinant for the long-term performance of high-tech entrepreneurial ventures." Studies (by Ucbasaran, Westhead, \& Wright, 2008) exploring human capital approaches to entrepreneurship, relate management team inputs such as education, work and business experience, combined with managerial, technical and entrepreneurial capabilities, to performance outputs such as business opportunity, identification, and, pursuit.

Social capital has been described from a number of perspectives. Falk \& Harrison (1998) in answering the research question for their study, "What is the nature of the interactive productivity between the local networks in a community?", perceive social capital as "the networks, norms and trust which constitute the resources required for individuals, workplaces, groups, organizations and communities to strive for sustainable futures in a changing socio-economic environment." Studies (by Krause, Handfield, \& Tyler, 2007) investigating various dimensions of social capital, found that social capital could be linked to the firms' performance in terms of cost, quality, delivery, and flexibility improvements. The physical capital of a firm often referred to as physical or fixed assets include land, factories, and, equipment. In the empirical study of Tsai \& Wang (2008) physical capital was used as a proxy for firm size. In the present study, firm size is used as a proxy for (past) export performance, because it is very difficult in developing countries, such as Ghana, to get exact figures on actual performance in terms of sales volume, profit margins etc.

The research model for the present study is based on the core proposition that, if, there is an optimal mix of the SME's human, social, and physical capital (internal firm factors, or internal capabilities, see Chapter 4) with the contextual factors (such as institutions and supply chain complexity), this will lead to higher SME firm size. Figure 5.1 illustrates the research model, the different internal firm and contextual factors will be discussed below. 
Figure 5.1 Research Model

\section{Human capital}

- $\mathrm{CEO} / \mathrm{MT}$ attributes

- Education and experience

- Entrepreneurship

- Firm attributes

- Firm (export) experience

- Employee capabilities

\section{Social capital}

- Network structural embeddedness

- Density

- Complexity

- Network relational embeddedness

- Weak and strong ties

- Bridging and bonding ties

- Trust and contracts

\section{Physical capital}

Zones in Ghana

- Savannah, Forest and Coastal belt Institutions

- Ministries, financing companies, knowledge and technical org.

Supply chain complexity

- Upstream and downstream (export) complexity

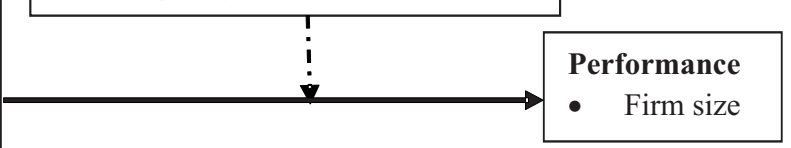

\section{Human capital}

- Chief Executive Officer/Management Team(CEO/MT) attributes: education and experience.

Dartey-Baah (2010) states that "capacity building should be a high policy priority and a key pillar in development". He further emphasized structured training for mobilising excess capacity for export. Welbourne \& Pardo-del-Val (2009) support the view of Arribas \& Vila (2007) stating that specific aspects of human capital relevant to the survival of a firm include, work experience and education level of the entrepreneur (cq. management team), something Oyelaran-Oyeyinka (2004) refers to as "non-formal learning". Oyelaran-Oyeyinka's study suggests that higher performance would be dependent on the skills and know-how of the entrepreneur (the SME CEO/MT). Education can be regarded as a knowledge tool that enhances the ability of the entrepreneur to capitalise on or exploit opportunities - a "knowledge corridor". (Casson \& Wadeson, 2007; Venkataraman, 1997; Shaver \& Scott, 1991). Rogerson (2000) (citing from the work of Levy \& Spiller, 1994) refers to findings which suggest that a firm that invests in the training of their staff members perform better than other firms (and can adapt to a changing business environment). This view is supported by other studies which found a positive impact of human capital on firm performance (Afenyadu, King, McGrath, Oketch, Rogerson \& Visser, 1999; King, \& McGrath, 1998). 
- Chief Executive Officer/Management Team(CEO/MT) attributes: entrepreneurship

Buame (2000) proposes an understanding of key success factors of an entrepreneur to include high achievement orientation, calculated risk taking, and opportunity exploitation. Entrepreneurship is considered to be "concerned with the discovery and exploitation of profitable opportunities" (Shane \& Venkataraman, 2000). In a social network context, entrepreneurship is the ability of the entrepreneur to engage in network relationships from which he reaps some form of benefit.

- Firm attributes: firm (export) experience

Research on firm experience has been conducted in a number of areas. One study (Shaver, Mitchell \& Yeung, 1997) identified experience gained from information spillovers as a determining factor for investment survival by foreign firms operating in a host country. Seringhaus \& Rosson (2001) find that firms with experience exhibiting at international trade fair perform better than firms without experience. Experience is therefore a contributory factor to the success of the firm.

- $\quad$ Firm attributes: employee capabilities

Employee capabilities are largely determined by management practices and are known to be influenced by education and training. An empirical model (used by Bontis \& Serenko, 2007) found that training, development and, job satisfaction were key factors, specifically, "job satisfaction in turn is affected by training and development, pay satisfaction, supervisor satisfaction, and job security." Kim \& Lee (2006) found that higher levels of employees' knowledge sharing abilities is influenced by social networks, performance-based reward systems, and employee usage of IT applications. Training opportunities therefore appear to be relevant for developing employee capabilities.

\section{Social capital}

- $\quad$ Network structural embeddedness: network density

Bhagavatula (2009) defining a dense network structure, suggests "...many members of the network know each other ... otherwise, it is considered sparse". Both he and Gulati (1998) refer to dense network structures as cohesive ties which allow actors to become a source of information about a partner's capabilities and reliability. Alternatively, sparse network structures can be described as networks in which few members know each other. Information in this type of networks is not common knowledge and there is no connection that binds actors. Granovetter (1983) refers to this as a "low density network". Sparse networks have the advantage that firms are 
facing a broader scope of information that may provide opportunities for the firm. In the present study social capital focuses on business/firm networks, and, does not include family and friend networks as is encompassed within the broader context of social capital. There were questions asked on family and friend networks but respondents failed or refused to provide any information, so unfortunately, these networks could not be included in the analyses.

- Network structural embeddedness: network complexity

Network complexity can be described by the number of actors that a firm has to connect. Newman (2003) describes a social network as "a set of people or groups of people with some pattern of contacts or interactions between them". The more patterns of contacts or frequency of interactions, the more complex the network. In simple network structures actors have not to relate to many other actors. In the export sector, complex network structures can be identified when firms export themselves and not through specialized traders. They need a large number of actors in their network to whom they have to communicate intensively, for instance, exporting agencies, shipping companies and international customers.

- Network relational embeddedness: weak and strong ties

Granovetter (1983) introduced the concepts of "weak and strong ties". Weak ties are networks in which the members are not closely connected. This assumes that the relationships are more formal and/or distant. Strong ties, however, are more socially networked and relations may be informal as with family and friends. Gulati (1988), (citing the work of Coleman, Katz \& Menzel, 1966) suggests that actors with strong ties have a common understanding as a result of shared opinions, and, socializing relations which determine the actions they take. According to Granovetter (1973), strong ties can be found more within groups than between groups, and, members may interact more frequently. Information is common knowledge and does not necessarily create opportunities. Weak ties are ties which can be found more between non-cohesive groups. Members of these groups are not necessarily known to each other and interactions are infrequent. Weak ties are considered to create opportunities by providing new information (Granovetter, 1983).

- Network relational embeddedness: bridging and bonding ties

Bridging ties enables a member of a network to access resources and opportunities in another network (Newman \& Newman, 2005; Granovetter, 1973). The actors within each of these networks develop bonding ties over time. According to Burt (1992) an 
entrepreneur that is the bridge between one network and the other is more likely to obtain new information. This view supports an earlier study by Leeds (1964) who focused on the political and economic development of the individual, and found, personal ties at each "promotional levels" serve as "springboards" projecting the individual to new and improved levels of performance. These "springboards" are bonding ties and may be found in what Long (2001) lists as "...family, kinship, compadrazgo (comradeship), politico-bureaucratic affiliations, commercial and industrial connections, and, recreational and educational bonds".

- Network relational embeddedness: trust and contracts

The position of trust in building social capital has been investigated in a number of studies. In one, the findings show that lack of trust brought about by income disparities among the members of a group, led to a breakdown in social capital and higher mortality rates (Kawachi, Kennedy, Lochner, \& Prothow-Stith, 1997). Woolthuis, Hillebrand, \& Nooteboom (2005) study found that trust and contracts are both substitutes and complements to each other. Using a case study methodology, Lyon (2000) investigated how trust developed among farmers, traders, and, agricultural input suppliers in Ghana. The main mechanisms were formal and informal networks which substituted for the formal legal institutions which are generally weak in developing countries such as Ghana.

\section{Physical capital}

In a study (by Javalgi, Lawson, Gross \& White, 1998) related to the propensity of firms to export, the firm characteristics variables examined were: "number of employees, total sales, years in business, international trade activity (exporter/non-exporter), and firm ownership". Other variables such as size, risk and debt have been used, as well (see Bougheas, Mizen \& Yalcin, 2006).

\section{Institutions}

The export related institutions found in Ghana are ministries, departments and agencies, banking and finance companies, and knowledge and technical organisations. The spread of these institutions in the country is disproportionate. For example, all the ministries are located in the capital and the majority of the banking and finance institutions and knowledge and technical organisations are headquartered in the capital, as well. These institutions operate in other areas of the country through branches and departments. The outreach, that is to say the ratio of branch or department location to area coverage is not 
proportionate across all the ten regions. For the study this makes it necessary to classify the regions into zones.

\section{Zones in Ghana}

The three main zones (GSS, 2001 ${ }^{24}$ ) in Ghana are:

Zone 1 (Savannah Belt) The Northern, Upper East and Upper West regions make up the savannah region of Ghana.

Zone 2 (Forest Belt) The Brong-Ahafo and Ashanti Regions are in the forest belt in the middle of Ghana.

Zone 3 (Coastal Belt) The Western, Central, Greater Accra, Eastern, and Volta Regions are classified as the coastal belt.

\section{Supply chain complexity}

- Upstream and downstream (export) complexity

Research (by Lambert \& Pohlen, 2001) indicates that there is an absence of widely accepted definitions of supply chain management and complexity. They proposed a framework that requires managing the interfaces with suppliers and buyers through supplier and customer relationship management. Christopher (2000) on one hand, focused on volatile markets compelling firms to review their supply chain processes. The key to survival of these firms in such uncertain environments is considered to be the degree of responsiveness of the supply chain. Milgate (2001) on the other hand, found that uncertainty hampered delivery performance. This was especially the case for firms competing internationally, "where the complexity of the supply chain must be managed within a global network". Similarly, McAdam \& McCormack (2001) present a qualitative study of the integration of supply chain management and business process management activities and concluded that there is little research evidence exploring integration of processes throughout the supply chain although the importance of supply chain communication is stressed by many researchers.

\section{Performance}

\section{- $\quad$ Firm size}

Firm size is known to influence export performance. Seringhaus (1993) describes export performance by "export share as a percentage of total sales". Julien \& Ramangalahy (2003) argue that, "the concept of export performance of SMEs is the

\footnotetext{
${ }^{24}$ Core Welfare Indicators Questionnaire Survey (CWIQ) 1997- Ghana Statistical Service, Ghana, 2001
} 
subject of much controversy" and, go on to suggest a number of measurement indicators from literature (see Bijmolt \& Zwart, 1994; Kaynak, 1992; Denis, 1990; Madsen, 1987; Kleinschmidt \& Ross, 1986) to include "export intensity (export sales as a percentage of total sales), growth rate of the export ratio, perception of export success/profitability, export profitability (the amount of profits or the perception of export profitability compared to domestic sales), export volume (the absolute value of exports, or exports as a percentage of total sales), export growth (the absolute or percentage value of export growth), and other indicators (such as perception of success, export variability and so forth)". In the present study, following earlier empirical studies (such as, Tsai \& Wang, 2008) labour in terms of total number of employees, is used as a proxy for firm size.

\subsection{Context and Research Methods}

The study context and sample is explained in more detail in Section 4.4 Research Design. The research approach involved the purposive selection of ten SMEs for the case study based on judgmental criteria of NTAE exporters. ${ }^{25}$ Five SMEs were selected from the coastal zone where a majority of SMEs are located, and, five SMEs were selected from the other zones: two SMEs from the forest zone and three SMEs from the savannah zone. This is consistent with the proportionate spread of the population of NTAE SMEs based on location. Information on the multiple case studies was obtained using a questionnaire containing a combination of open and closed questions, using 7-point Likert scales. The key questions administered can be found in Table 5.1. The questionnaire was administered using face-to-face interviews with the SME CEOs and/or managers to obtain primary data. Analyses are based on aggregated responses. General statements/conclusions are based on majority views of at least 7 NTAE SMEs providing the same/similar response.

Case study principles are applied throughout the fieldwork to include: multiple sources of evidence (triangulation), creating a case study database (report summaries), and, maintaining a chain of evidence-recordings/transcriptions (Yin, 2003). Reliability is assured by interviewing the CEOs of the SMEs, considering that they are the most knowledgeable persons regarding their business. Where possible the perceptions were triangulated by obtaining information from other sources. Experts from banks, microfinance institutions, and, knowledge institutions, were asked specific questions related to the answers and concerns raised by the SME CEOs before conclusions were drawn.

\footnotetext{
${ }^{25}$ All ten firms were selected from the total sample of exporting firms based on the list of NTAE-SMEs provided by the Ghana Export Promotion Authority (see Section 4.4 on page 46).
} 
To identify pattern matching, face-to-face interviews are conducted with identified members of the SME network (namely: the SME/umbrella associations, the public sector (government ministries, departments, and agencies, as well as institutions which draw government subsidies under the Consolidated Fund of Ghana), the institutional/technical sectors (the universities, technology and innovation centres), and, the SME departments of banks and micro-finance institutions) and, references made to secondary data to crosscheck information obtained from interviews with the SMEs. The research model presented in Figure 5.1 provides a clear overview of the variables that explain internal and external (contextual) fit and firm size.

Eisenhardt (1989) argues that, "a cross-case analysis involving four to ten case studies may provide a good basis for analytical generalization." These views support the selection of ten multiple case studies used for the present study. Explanation building based on the findings is used to support theory development. 


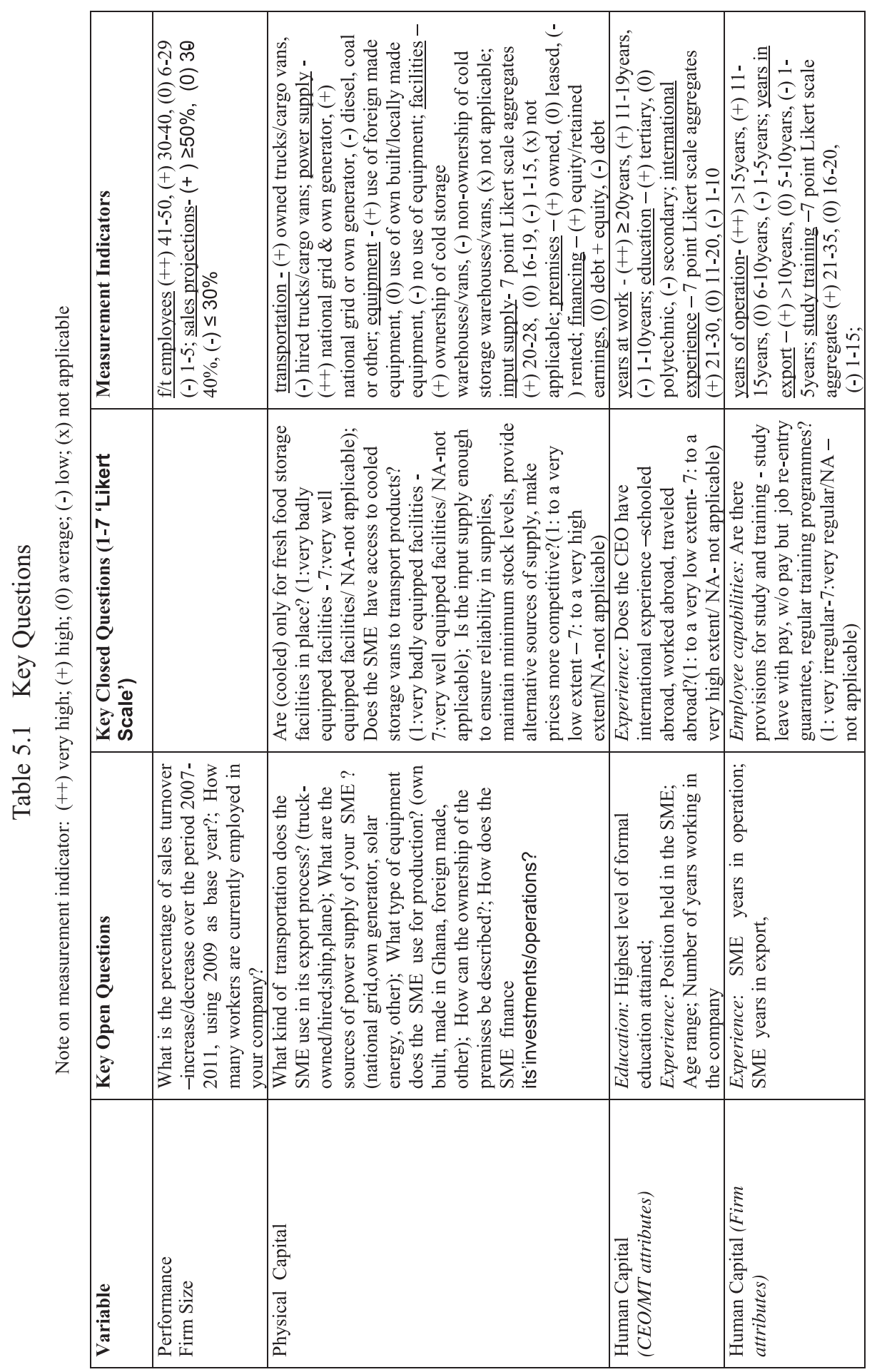




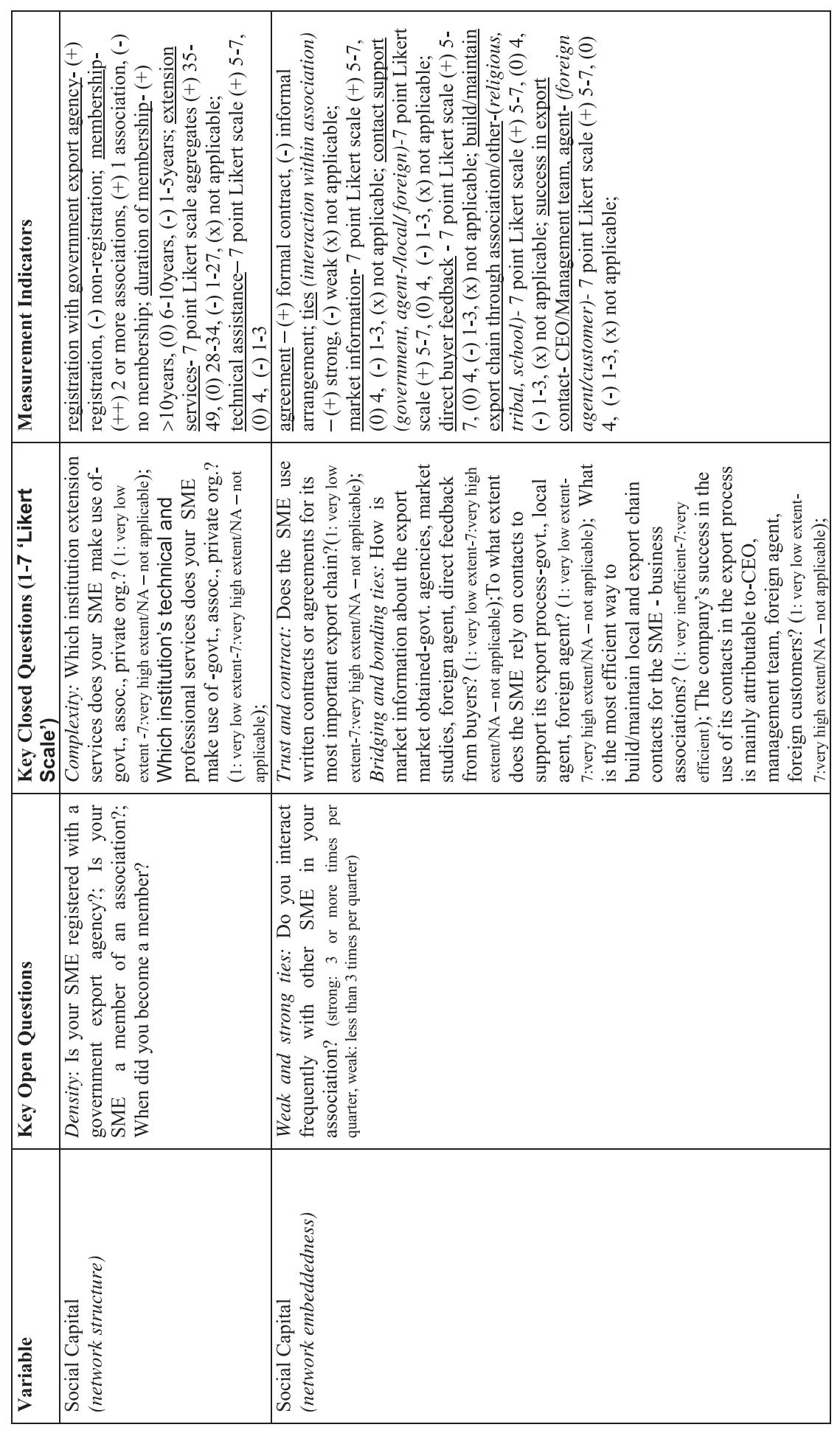




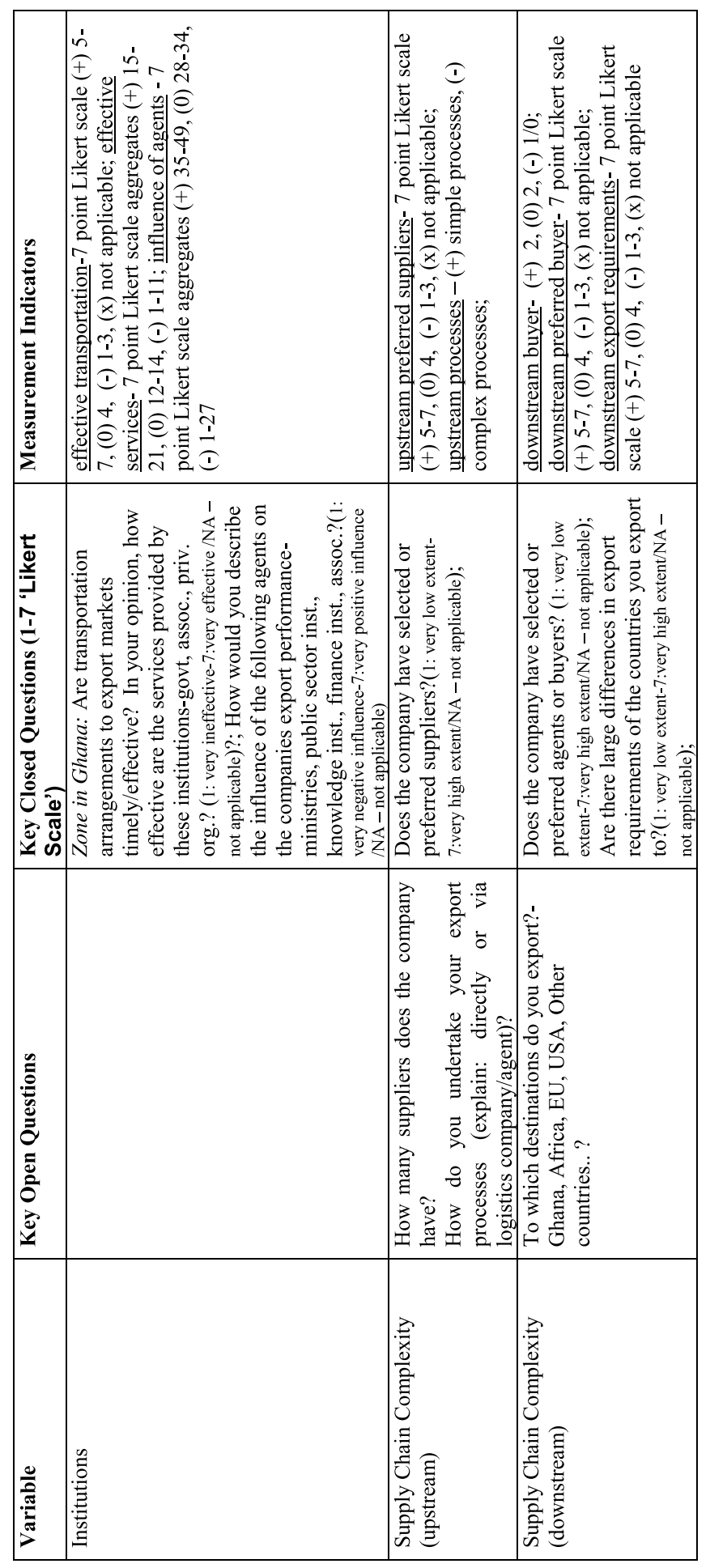




\subsection{Findings}

\section{General Aspects}

Most of top management were found to be predominantly male and of Christian belief. This is because most of the SMEs are located in the coastal zone which has more Christian followers compared to the Muslim north. The majority of CEO women are engaged more in trading than in exporting. Most of the SMEs have more employees contracted on a seasonal or periodic basis. For example one SME had an outgrower scheme ${ }^{26}$ arrangement with over 3,000 farmers. The SMEs themselves referred to full time staff as staff with a contract, working 40 hours per week (inclusive of breaks). All the SMEs in the processing sector made use of outsourcing. Outsourcing in almost all cases is limited to input supplies and/or logistics (transportation). Some firms made use of staff rotation in their work processes. Rotation in this feature is more a tool for process expediency than for staff development. The scheduled targets include quality control, deadlines/timelines, cost minimisation and stock control.

\section{Firm Size}

The number of full time employees has been used as a proxy for SME export performance. The more full time employees the SME contracts, the more likely that in-house tacit knowledge will be built up and preserved. This development is more likely to enhance the firm capacity and competitive edge. In addition, the potential growth rate was asked for, because the sales projections might give a clearer picture of the SMEs future performance. SMEs with a high sales projection are likely to take on more full time employees in order to meet and sustain targets, implying increased output, revenue and growth rates. For example, SME 1 anticipated increase in full time employees based on sales projections. In his words on sales projections, the CEO responded, "From 2006-2008, I would say there has been about an almost tenfold increase in volume. By 2010 we think we are going to increase by another 25\%. Then we hold it there, because we think that this is the volume that we can sell comfortably on the market and also process without finding ourselves with excess production."

\section{Physical Capital}

All medium sized firms made use of foreign equipment and were considered to be more innovative in their approach. Generally, small sized firms made more use of local

\footnotetext{
${ }^{26}$ Outgrower scheme normally takes the form of an agreement between the buyer and collective number of small farmers. The farmers may be provided with seedlings and other inputs and agree to farm according to specified requirements for a fee. The output is taken up by the buyer.
} 
equipment. They are considered equally enterprising though financially constrained. This is reflected in the fact that only the medium sized firms were capable of operating own generators (power supply) to facilitate production. A greater number of the SMEs relied on the (unreliable) national grid. The export product and nature of operation determined whether transportation, facilities and input supplies were relevant to the firm. Medium sized firms exporting fresh produce mostly owned cold storage facilities; though not all of them owned cooled transportation. Both small and medium sized firms that export fresh produce relied on input suppliers to supplement stocks. The medium sized firms had the advantage of organising vertically integrated supply chains reducing supply risks. Firms exporting processed products, such as clothing ${ }^{27}$, did not rely much on input suppliers since spot market purchases were more cost effective. The structure of the physical capital base influenced the performance of the firm. Most medium sized firms could export more frequently and had higher sales projections compared to small firms. However, entrepreneurial small firms showed a higher number of export destinations. Financing of most SMEs was through equity (retained earnings). SMEs used debt financing, this was mostly short term and was used to support their working capital. The SMEs concerned owned their own premises and could use it as collateral for debt financing. Debt financing however, is a disincentive for most SMEs due to the high cost and the lack of subsidies or other forms of debt relief. Small firms generally did not make use of debt financing, the credit requirements issued by the banking sector made the small sized firms either ineligible or debt unaffordable. For small sized firms finance constraints are generally managed by the ingenuity of the top management.

In the words of the CEO of SME 10: "It is not so that we began with exporting directly, we started small, selling to an exporting trader until the moment that we became financially strong enough through banking loans to export to the international buyers ourselves".

\section{Human Capital}

Tertiary level education of the CEO is a significant indicator for success of exporting SMEs, irrespective of location or sector. Up to tertiary level, training best explained firm performance. For SMEs whose CEOs did not have tertiary level education, years at work provide a better explanation for performance. In most cases, the number of years of firm export experience and the firm's years of operation show a direct relationship with the CEOs work experience and age. This is because in most instances the businesses were

\footnotetext{
${ }^{27}$ Clothing is also part of the NTAE sector (e.g. cotton) Figure 1.1 (pp5) and Appendix 5 (pp137) provide NTAE products/produce.
} 
started by the CEO. In almost all cases, firms with export experience of more than five years had at least two of the following features: the exporting SMEs had a top management with an age range from 45 to 55 years, the exporting SMEs were located in the coastal zone, and the exporting SMEs had been in operation for over 12 years. A possible explanation is that the CEOs were instrumental for the firm's export initiatives, consistent with the finding that most of the SME CEOs had international experience. This also implied that the CEOs showed special entrepreneurial skills enabling them to start their own export business. For example, the CEO of SME 10 said the following about his exporting firm: "So I started the business in 1997; before I registered the company in the year 2000." As he further explained this gave him the opportunity to understand the entire production export process before formally registering his firm. The CEO of SME 8 stated that: "I was in partnering in the business of purchasing, semi-processing and exporting botanical seeds ....... We have been in this business for about five to six years now .... It is only this year that we registered our company." Most CEOs of the medium sized firms have worked or are schooled abroad, whereas in the majority of small sized firms the CEOs have travelled abroad frequently. However, the CEOs of most SMEs did not place a premium on providing study and formal training to their employees, but a lot of time is spent on-the job training to meet the needs of the SMEs. The main capacity development here therefore comes from the entrepreneurial drive of the CEO, making use of their contact networks.

\section{Social Capital}

The majority of the exporting SMEs are members of an association or register with government export agencies and visit fairs and conferences to obtain relevant information, e.g. about importers and buyers. Associations typically work on knowledge building of their members through organizing specialized workshops, e.g. about quality standards in international markets. As a manager of an association mentions: "In Ghana we are encouraged to join product associations... we (the associations) are doing well, we are adapting ... Thanks to the help from various organizations including development agencies we can provide the technical assistance to SMEs to get the necessary certification done (of the Global Gap) ”. Medium sized firms as well as small sized firms with an association membership of more than 5 years appeared to have strong ties with the association. Interaction with the association is facilitated by technical services such as internet, mobile phones and special postal delivery. However, not all CEOs see advantage in joining an association or registering with government export agencies. These SMEs are either inexperienced, been in the exporting business for less than 3 years or do not feel the 
need, having a favourable long term buyer relationship with one or more importers. An indepth analysis of the SMEs (in-)formal buyer arrangement(s) may point at a possible "captive supply" scenario (Williamson, 1993). All SMEs make use of technical assistance, although the use of extension services is limited to the typical agricultural products. In general, SMEs in the coastal zone have an advantage because most of the export related technical institutions are located in this zone. The activities of these export related technical institutions are limited in terms of outreach (number of branches) in the forest and savannah zones. SMEs in the coastal zone tend to perform better than SMEs in the other two zones.

Medium sized firms appeared to have stronger bridging ties with international importers. They make extensive use of international trade fairs, conferences and exhibitions. They also conduct in-depth international market studies, but did not make much use of direct buyer feedback probably attributable to the spot market type of arrangements with the buyers. It was interesting to discover that the SMEs located in the forest zone are less able to profit from international ties, because they are sandwiched between the two other zones with most of the contact networks located in the coastal zone. Entrepreneurial SMEs, located in the savannah, take advantage of the proximity to the neighbouring regional export countries.

\section{Institutions}

Interestingly, in the light of the poor transportation infrastructure, the CEOs generally considered the transportation infrastructure as effective, because of the reliable transport arrangements that could be made, enabling timely delivery. The services provided by the export related institutions were generally considered as ineffective. E.g., in the eyes of the CEOs, the exporting risks could be considerably reduced by greater participation of banking and finance institutions. However, CEOs with the strongest bonding ties with the export related institutions showed the highest export level and the highest sales turnover.

\section{Supply Chain Complexity}

All SMEs face challenges in the upstream supply chain regarding reliability of delivery, quality of input supplies and input price. They all need to concern themselves to interact with suppliers to obtain the quality of input at the desired price, moving between alternative markets to select supplies, to arrange (cooled) transportation, and the right storage facilities. Most small sized firms that used preferred suppliers exported processed products and were located in the forest zone. A reason for this could be that there are more suppliers in the coastal zone. Medium sized firms showed a low preference for preferred 
suppliers in general. On the downstream side, directly exporting SMEs are confronted with governmental quality control requirements, certification issues, and the bureaucracy of customs inspections and checks. SMEs exporting via traders are also confronted with challenges, including, low prices offered by export agents, inability to (re-)negotiate competitive prices, or, captive export supply scenarios. In general, direct negotiation with the international importer/buyer is perceived to be more lucrative. For typically, the local export agent would like to push down the producer's price to maximise profits accruing to him. The complexity for the exporting SMEs may be referenced on whether the exporting arrangements are based on trust or contract. The issues that flow from this include to what extent the agreements are enforceable, how easy it is for the exporting SMEs to divert to alternative markets, and what costs are associated with entering these markets. Small sized firms generally showed a high preference for a preferred buyer. Interestingly, the medium sized firms did not have a high preference for a preferred buyer. As the CEO of SME1 indicated: "I have one major buyer who is doing (taking up) $60 \%$, the others $40 \%$ of my sales." The main reason for this was that the CEO of SME 1 had built up a reputation through its international contact network which made it easy for him to sell to other foreign buyers.

\subsection{Conclusions and Recommendations}

The results presented in this chapter are based on a purposive and judgmental sample of ten SMEs in the NTAE sector in Ghana. Notwithstanding, the triangulation of data by indepth interviews with key stakeholders (through interviews with banking and finance institutions, knowledge and technical institutions, and, government institutions) assured for the reliability of the data and validation of the responses made by the SME CEOs. The findings deserve some reservations in assuming a generalisation to all SMEs in the NTAE sector in Ghana, because of the limited number of 10 SMEs interviewed.

The findings are consistent with the literature (see section on literature review) which suggests both human and social capital are positively linked to firm performance. In this sense, human and social capital provides a store of wealth to the SMEs that they can draw upon to improve their performance. This can only be feasible where the SMEs contextual situation (institutions and supply chain complexity) is conducive. The core proposition of this study is that, if there is an optimal mix of the SME's human, social, and physical capital (internal firm factors) with the contextual factors (such as institutions and supply chain complexity), this will lead to higher SME firm size. The following will provide arguments to see if, and if so, to what extent, the proposition is valid by addressing the research questions. 
What is the effect of human capital (CEO/management attributes and firm attributes) on firm size of SMEs in the NTAE sector in Ghana?

There appears to be a positive relation between a high level of education of the CEO and firm size. The findings make for strong conclusion that, education in particular is pivotal in harnessing export opportunities available to the SME. Complete ownership of the firm seems to positively influence the SMEs performance, because it provides stability and frees the management to engage less lucrative investment arrangements. Small sized firms in the coastal zone that in general have complete ownership of premises, are therefore expected to be more likely to progress to medium sized firms, than the small sized firms in the other two zones that do not completely own premises.

Which network relationships (social capital) will lead to increased firm size of SMEs in the NTAE sector in Ghana?

It is key for exporting SMEs to be where the governmental export agencies and extension services are located or to strengthen their ties by increasing their interactions with the export institutions. This will facilitate the complex export processes, e.g. by providing information on export market trends, clearly important for SMEs exporting directly (not through traders). Especially for SMEs located in the forest zone, it is important to intensify their network relationships to improve their export opportunities, because most export institutions are located in the coastal zone, while the savannah zone has the northern border offering regional export opportunities. However, up to now, the costs associated with building and sustaining networks by the SMEs in the forest zone, with the institutions in the coastal zone, prohibits the building of strong ties. Membership of associations showed strengthened network ties with other exporting SMEs. Therefore, most of the CEOs who recognise the benefits of interaction participate in associations. Also the participation in international fairs and exhibitions can create new avenues, by, exchanging ideas and contact with new export opportunities. Network embeddedness showed both formal contracts and trust arrangements proved to be useful for the exporting SMEs. Interestingly, compared to the SMEs with informal contracts, the SMEs with formal international contracts were much more exploring the opportunities to enter alternative markets to spread exporting risks. The SMEs that relied on informal contracts were more "locked in" to one buyer in general. However in a number of cases the informal contract had the advantage that the SMEs could increase or decrease the frequency of export to this buyer. The management and policy implications will be addressed in more detail in the concluding chapter(7) on pages 111-122. 


\section{CHAPTER 6}

\section{Non-Traditional Agricultural Export Performance in Ghana. Exporting SMEs' Characteristics, Channel Choice and Institutions.}

\section{Chapter based on}

Abban, R., Velde van der, G., Omta, S.W.F., Aheto, J.B.K. \& Scholten, V. (2019). NonTraditional Agricultural Export Performance in Ghana. Exporting SMEs' Characteristics, Channel Choice and Institutions. Africa Journal of Management.

Submitted: May 29, 2019. 


\section{CHAPTER 6}

\section{Non-Traditional Agricultural Export Performance in Ghana. Exporting SMEs' Characteristics, Channel Choice and Institutions}

\subsection{Introduction}

The non-traditional agricultural export (NTAE) sector is increasingly important for African countries (Ouma et al., 2013). The start of the NTAE sector in Ghana can be traced back to the early 1980s, where declining export earnings from traditional exports (cocoa, minerals, and timber) led to government programmes aimed at resuscitating the export sector, and, diversifying the export base to include non-traditional exports (Buatsi, 2000). NTAEs include "exotic fruits, vegetables, tubers, processed and semi-processed wood, apparel, rubber and agricultural products, cocoa paste, canned tuna, veneer, cocoa butter, sheanut butter and pineapples" (Abban et al., 2013). In Ghana, the Ghana Export Promotion Authority (GEPA) 2018 statistics show that NTAEs grew from \$62.34 million in 1990 to about $\$ 2$ billion in 2016, an estimated increase of 3,210\%. Although some studies have been conducted on institutional support to SMEs, these studies used a small sample size, focused on case studies, value chain (Hinson, 2010; Tetteh, 1995) or on exporting SMEs and export performance (Boso et al., 2016). The focus on the NTAE sector is in part due to its high value products and governmental export diversification strategies focusing on this sector(Abban et al., 2018) with the aim of countering declining earnings from and dependence on traditional exports (Buatsi, 2000). Given the importance of NTAE and Ghanaian SMEs to development, this study seeks to extend the knowledge on SMEs in the NTAE sector focusing on their environment, and, on how institutions (services and finance) can support them to stay competitive in increasing globalizing export markets, and, the continuous introduction of new technologies (Ocloo et al., 2014). This is notwithstanding that Ghanaian NTAE SMEs face serious constraints, such as financing, insurance, enterprise level training, infrastructural support and appropriate incentives (Buatsi, 2000, pp13). These features are generally similar to constraints confronting Ghanaian SMEs such as poor availability of credit, lack of managerial skills and training, lack of equipment and technology, and, regulatory problems that limit their access to international markets. Given the important role of Ghanaian SMEs as the pillar for economic development; $90 \%$ of registered companies in Ghana are micro, small and medium enterprises (MSMEs), contributing to about $70 \%$ of gross domestic product and 85\% of employment (Abor \& Quartey, 2010; Mensah, 2004) it is even more pressing for Ghanaian institutions to support them. 
Exporting SMEs are affected by export market competition, (bad) image of the exporting country, and (lack of) information on export markets and regulations (Khattak et al., 2011). These points can be affected by the work of institutions that facilitate the growth of SMEs, and support export performance. Previous studies suggest that institutions can have both positive and negative effects on exporting SMEs (Yamoah et al., 2014). Institutional reforms, however, could make entrepreneurial endeavours of SMEs more successful (Manev et al., 2005) but could also result in problems that constrain their growth (Meyer \& Peng, 2005) and may even lead to their going out of business (Roxas et al., 2006). Services and finance institution reforms alone are of no effect without the requisite capacity of the SMEs to make use of them, so the focus should be more on building an appropriate institutional framework to support SMEs (Yamoah et al., 2014). Exporting SMEs may be hampered by a hostile regulatory environment, limited access to finance, but also by inadequate management and limited entrepreneurial skills (Zindiye et al., 2012, pp657). Hence, according to Korsakienè \& Tvaronavičienè (2012), both the internal environment (management and organisational characteristics such as international transactions experience, planning orientation, development of products for exports, researching overseas markets) and the external environment (which includes government assistance, cost issues and market activities of competitors in export markets) of exporting SMEs will either stimulate or act as a barrier to exporting SMEs.

Important exporting SME characteristics include years of experience, size, age, international experience, manager's characteristics, company status, previous export performance and nature or type of the product (Zaiem \& Sghidi, 2011; Maurel, 2009). International experience of the SME's CEO or export manager is a key driver of internationalisation influencing the ability and involvement of SMEs in exporting (Javagli $\&$ Todd, 2011). Export barriers are known to affect the internationalisation process of SMEs. This is determined in part by the extent of CEO's or export manager's export knowledge and knowledge of foreign market(s) (Okpara \& Koumbiadis, 2009). The entrepreneurial orientation of the CEOs or managers, as shown by their exporting initiatives and innovations has been found to be positively related to export performance (Okpara \& Koumbiadis, 2009; Imran et al., 2018). Also the networks of the CEO/export managers are relevant, since networks can reduce information asymmetry and provide the SMEs' CEOs opportunities to access or acquire information (Child \& Hsieh, 2013; Kontinen \& Ojala, 2011). 
Other SME characteristics that determine export performance include top management support, work autonomy, reward and reinforcement, time availability and flexible organisational boundaries that strengthen information flows internal and external to the organisation (Kuratko et al., 2014). The corporate governance mechanisms are important in supporting SMEs' internationalisation processes through the institution of appropriate structures and functions (Calabro' \& Mussolino, 2011). This is the same for operations and maintenance which are essential for production and improvement of process technologies (Wignaraja, 2001). Innovation in terms of product development and business outlook (technological leadership) is also considered relevant to internationalisation of SMEs. Product development is important in terms of improvement of existing products or introducing new products (Wignaraja, 2001). Business outlook is seen as a form of technological leadership because it requires varying skills for an "ambidextrous leadership which moves from transformational leadership towards more focused transactional leadership ${ }^{28,}$ (Love \& Ropper, 2015,pp30) for innovation and export.

Export channel (export mode) and institutional (services and finance) support are important to exporting. The export mode used in terms of cost options and resources is thought to be a determinant of SME export performance (Fernández-Olmos \& Díez-Vial, 2015; Roberts et al., 2012). Also institutional services that aid exporting SMEs, such as extension services, professional and technical support, and financing are equally important. Hessels \& Terjesen(2010, pp 208) explain that institutions have a "high degree of resilience" and are "composed of cultural-cognitive, normative, and regulative elements" which ultimately lead to stability and provide an anchor in the SMEs environment.

There is no single register or source that provides the list of all NTAE SMEs in Ghana. Similar to the study of Yamoah et al. (2014), this study made use of the directory of exporters provided by the Ghana Export Promotion Authority (GEPA) and list from other institutions (see Section 4.4 on page 46). The list showed $87 \%{ }^{29}$ of exporters were SMEs in the NTAE sector. Given the over $2000 \%$ increase in export volumes over 3 decades (GEPA 2018 reports), it could be expected that SMEs in the NTAE sector are flourishing. However, about $28 \%$ of the NTAE SMEs out of the GEPA list had either stopped

\footnotetext{
${ }^{28}$ Transformational and transactional leadership are polar opposites when it comes to the underlying theories of management and motivation. Transformational leaders focus on change within the organization, whereas transactional leaders focus on organization, supervision and group performance, as well.

${ }^{29} 87 \%$ of the exporters were NTAE exporters and the remaining $13 \%$ were NTE exporters.
} 
operating, exporting or were irregular exporters. Some of the reasons include: limited formal education or weak management skills, limited access to and use of new technologies, unavailable market information, lack of easy access to credit, (Ocloo et al., 2014), "resource limitations and a lack of experience in foreign operations", Boso et al. (2016, pp2). Hinson (2010, pp324) explains that in the non-traditional export (NTE ${ }^{30}$ ) sector of Ghana challenges faced by export firms include lack of training, lack of finance and equipment. Other studies, such as those of Buatsi (2002) and Abor \& Biekpe (2006) focused on limited access to finance, specifically from banks. Most studies have focused on the NTE sector in general. There appears neither to be much information on the NTAE sector, nor, the combination of factors determining SME characteristics, export mode, and, institutional (services and financial) arrangements of exporting SMEs in the NTAE sector of Ghana.

Given the rise in global importance of NTAEs, it is important to know which of the relevant factors determining these characteristics positively impacts export performance, and, ultimately SME growth and development. The study investigates this gap, providing insights into which factors in the (internal and external) environment positively impact performance of exporting SMEs in the NTAE sector. Factors that can lead to success or failure of exporting SMEs. These factors vary with the situational context (sector) and which ones positively impact SME export performance. With the increasing importance of the NTAE sector, predominated by SMEs, there is the need to investigate what works best for this sector, ultimately for economic growth and development. So the research question to be answered is: Which SME characteristic, export mode, and, institutions (services and finance) are positively related to export performance in the NTAE sector in

\section{Ghana?}

This paper is structured as follows: the theoretical background for the study is followed by an explanation of the conceptual model and hypotheses development. The research methodology explains data collection, data analysis, and results. The conclusion discusses the findings, policy implications, and identifies limitations to the study and recommendations for future research.

\footnotetext{
${ }^{30}$ The NTE sector differs from the NTAE sector because it includes not only agricultural products but also aluminum, metal, other manufactured articles, chemicals, iron and steel products, mineral products, machine and equipment.
} 


\subsection{The NTAE SME Sector in Ghana}

The start of the NTAE sector in Ghana can be traced back to the early 1980s, where declining export earnings from traditional exports (cocoa, minerals, and timber) led to government programmes aimed at resuscitating the export sector, and, diversifying export base to include non-traditional exports (Buatsi, 2000). Over a decade not much change was observed in the structure of exports as traditional exports still dominated $(85 \%)$ the foreign exchange earnings (Baah-Nuakoh et al., 1996). Since 1987 revenues increased from 27.963 to 159.660 US\$ million in 1996 (Buatsi, 2000). In the last decade, the NTE sector, dominated by SMEs, increased its exports from US\$ million 892.88 in 2006 to about US\$ billion 2.463 in 2016 (GEPA reports). There are no documentations to support whether or not the same SMEs recorded/registered in 2006 remained in business until 2016, whether there was any growth in these SMEs (micro to small, small to medium, medium to large), and, the trend in new entrants to the NTAE sector. These limitations in the data, peculiar to GEPA, are supplemented by data from other studies in the NTAE sector. For example, Kokutse (2008) indicates that there a more entrants into the NTE sector. Buatsi (2000) estimates that the NTE sector contributed about $15 \%$ of total exports in 1999. Further, Abban et al. (2013) suggest that the NTE sector accounted for $30 \%$ of total exports in 2008, and, NTAE comprised about $70 \%$ of the total NTE, making NTAEs contribution to total exports about 20.8\%. In 2017, BOG Annual report states that NTE revenue increased by $0.6 \%$ over 2016 . Total value of NTE amounted to US\$ billion 2.1 of which NTAE contributed about $64 \%$. The performance of the NTAE sector and the role of SMEs in this sector provide reasons to explore the NTAE SMEs in Ghana.

In the present study, the SME definition of Abor \& Quartey (2010), who describe micro, small and medium enterprises as follows: micro less than 5 workers, small 5 to 29 workers and medium 30 to 99 workers, is used. This definition is also supported by Teal (2002), Abban et al. (2013), and Yamoah et al. (2014). Abban et al. (2013, pp89) also define SMEs in terms of ownership structure to include "sole proprietor - one man business, familyowned business, joint-partnerships, private limited liability companies, co-operatives, associations, and, state-owned enterprises". For SMEs to be effective and achieve the desired levels of economic development would require a conducive business environment with institutions (services and finance) in the public sector. Public and private institutions are expected to provide an enhanced environment for SMEs by setting the policy framework and regulations. It is known that the different modes of regulations invariably impact the operations of an enterprise (Aryeetey \& Ahene, 2005). Aryeetey \& Ahene (2005) suggest that the private sector associations improve the operating environment of 
SMEs in Ghana. The institutional framework includes political, social and legal regulations/guidelines that facilitate production and distribution, and, to which businesses must comply for legitimacy and assistance (North, 1990). For example, institutions implementing incentive programmes in Ghana cannot be effective without the creation of an appropriate institutional framework (Kuada, 1993) that supports the idea that promotion alone is not sufficient for SME development (Buame, 1996). Yamoah (2014) suggests that providing incentive packages to SMEs or establishing support institutions alone is not enough for SME development in Ghana without considering the nature (operations) of those institutions. For NTEs it was found that the outreach of the institutions was a constraint, as most of the interviewed exporters were unaware of the institutional support available (Tetteh, 1995). Yamoah (2014) found that social support institutions were the most significant determinants of development of enterprises followed by regulatory institutions and structural support institutions. Incentive support institutions and government policy did not have much effect on enterprises.

In this study, attention is given to the internal characteristics of the NTAE SMEs and the institutional services and finance. The theoretical context draws on the RBV, network and SCM theories as discussed and explained in Section 1.5 on pages 9 to 11 .

\subsection{Conceptual Framework and Hypotheses}

Discussions on exporting SMEs in Ghana's NTE sector have mainly focused either on finance, access to credit or the role of institutions. Some of these studies include Kayanula \& Quartey (2000), Abor (2004), Aryeetey \& Ahene (2005), Abor et al. (2014), Yamoah et al. (2014), Oduro \& Matlay (2015). Few studies, such as that of Appiah et al. (2015), have looked at both institutional (external environment) and firm-level factors (internal environment) of exporting NTAE SMEs. This study seeks to extend the existing literature by providing insights into the internal and external environment of NTAE SMEs focusing on SME characteristics (including CEO/manager), export mode, institutional (services and finance) support related to export performance. Figure 6.1 illustrates the conceptual model for the study.

\section{- SME Characteristics}

\section{CE/Director}

-International experience

Sousa \& Tan (2015, pp86) define international experience as "the degree to which the firm's management has acquired overseas experience, professional foreign direct 
investment (FDI) experience, and training in international business". Earlier studies on international experience (Lages, Jap, \& Griffith, 2008; Sousa \& Bradley, 2008) support this definition. International experience equips managers with insights and an extensive knowledge base to better manage international operations (Herrmann \& Datta, 2006) and directly improves export performance. International experience is also positively related to learning/potential for learning (Love et al., 2015). It is argued that not all experiences have similar value, so the international experience of a manager may be beneficial where the firm is inexperienced (Coeurderoy \& Murray, 2008). In our study international experience is derived from the manager's exposure to an international context, either being born, raised or schooled abroad. It is this basis of international experience that aids the SME's export and international activities (Hultman, Katsikeas, \& Robson, 2011; Tsinopoulos, Lages, \& Sousa, 2014). International experience of managers' is largely beneficial to the firm as it provides export experience and international networks (Galati et al., 2014). Based on this discussion the following hypothesis is proposed:

H1 An NTAE SMEs international experience is positively related to export performance.

Figure 6.1 Conceptual Model

\begin{tabular}{|l|l|}
\hline $\begin{array}{l}\text { SME Characteristics } \\
\text { - CEO/Director } \\
\text {-International experience } \\
\text {-Export knowledge } \\
\text {-Intended expansion } \\
\text { (entrepreneurial orientation) } \\
\text {-Building social } \\
\text { networks }\end{array}$ \\
$\begin{array}{l}\text { - Corporate Governance } \\
\text { - Operations and Maintenance }\end{array}$ \\
$\begin{array}{l}\text { - Innovation } \\
\text {-Product development } \\
\text {-Business outlook }\end{array}$ \\
$\begin{array}{l}\text { Institutions (services and } \\
\text { finance) } \\
\text { - Export mode } \\
\text { - Extension services } \\
\text { - Professional and technical } \\
\text { support }\end{array}$ \\
\hline
\end{tabular}


-Export knowledge

Eriksson et al. (2015, pp9) discuss export knowledge in the form of a firm's internationalisation process. Export knowledge is experiential knowledge which includes foreign business knowledge ("knowledge of clients, the market and competitors") and foreign institutional knowledge ("knowledge of institutional frameworks, rules, norms and values"). Knowledge involves knowledge sharing of explicit knowledge, including all institutionalised knowledge, and tacit knowledge, based on face-to-face interactions (Wang \& Wang, 2012). Wang \& Wang (2012) suggest that effective knowledge sharing produces intermediate innovative outcomes, positively linked to firm performance. In addition managerial and commercial experiences are relevant attributes of export knowledge needed for export propensity, export intensity, and, export performance (Ganotakis \& Love, 2012). This was further explained to evolve from human capital gained through experience, business and technical education. Export knowledge is vital to SMEs to identify and realize opportunities in foreign markets and develop competitive capabilities for export performance (Nguyen et al., 2013). Following from these discussions in the literature, it is hypothesized that:

H2 Export knowledge of NTAE SMEs is positively related to exportperformance.

-Intended expansion (entrepreneurial attitude)

The intended export expansion of firms/SMEs is working through entrepreneurial strategy, internationalisation, or marketing capabilities. The aim of expansion of firms is to increase resources in an optimum way to positively impact export performance. The process requires incremental changes to the firms/SMEs operations, including strategy, structure and resources (Paul et al., 2017). Intended expansion is associated with enhancing the firms/SMEs capacity by developing its resource base. This provides the leverage to enter foreign markets (Sui \& Baum, 2014). The intended expansion of a firm underscores its option to expand its international scope (Rugman \& Oh, 2012). Intended expansion must be strategic to avoid adverse effects of expansion constraining resources. At the macro level, Cardoza et al. (2016) discuss international expansion of SMEs in the context of institutions (interventions and support) which seemingly has adverse effect on their internationalisation contrary to the positive effect at micro level. On the basis of these insights the following hypothesis is drawn:

H3 The intended expansion of NTAE SMEs is positively related to export performance. 
-Building social networks

From a social networking perspective, firms that cultivate and nurture strong ties with (inter)national partners gain access to network resources (Boso et al., 2013). Boso et al. (2013) further suggest that channel networking is a relational activity that builds on a firm's internal capabilities, which include, building social ties with supply chain partners. Strong networks enable innovation, acquisition of export market opportunities, and, have positive effects on export performance. Networks minimise the effect of informational barriers and cost of economic transactions (Ricci \& Trionfetti, 2011). Firms are more likely to export or export better when they "benefit from foreign networks (ownership and financial linkages), domestic networks (chamber of commerce, links to regulation), communication networks (E-mail, internet)" (Ricci \& Trionfetti, 2011, pp2). This is because network relationships are an important source of technological and market information (Fletcher \& Harris, 2011). Network relationships are built on trust and moral obligations, and facilitate learning (Fletcher \& Harris, 2011). In general, networks are favourably discussed in the literature, supporting export performance, which leads to the following hypothesis:

\section{H4 Social networks of NTAE SMEs are positively related to export performance.}

\section{Corporate governance}

Ansong \& Agyeman (2016) suggest that good corporate governance brings about quality and a good reputation leading to higher financial performance. Although there's no universally acceptable definition of corporate governance, it may be described as "a set of relationships between a company's board, management, its shareholders and the society within an institutional framework" (Mahmood, 2008, pp8). Mahmood (2008) further argues that good corporate governance ensures efficient allocation of resources, accountable stewardship, and promotes an institutional framework that leads to better performance. Claessens \& Yurtoglu (2013) discuss definitions of corporate governance and state that the term varies widely but falls in two categories: behavioural patterns of the firm related to measures of performance and a normative framework that links to rules and regulations. Other definitions such as Shleifer \& Vishny (1997, pp737) state that "corporate governance deals with the ways in which suppliers of finance to corporations assure themselves of getting a return on their investment", although this may be considered a narrow definition. Apadore \& Zainol (2014, pp160) indicate that corporate governance comprises two mechanisms. Internal corporate governance which focuses on the "priority of shareholders' interest, engaging with the board of directors to oversee top 
management" and "external corporate governance engaging on force and external regulations in order to control and oversee managers' behaviour". Studies (KyereboahColeman \& Biekpe, 2006; Abor \& Biekpe, 2007) on corporate governance and firm performance in the NTE sector in Ghana, found a positive relationship between board composition and ownership structure on performance of SMEs. The literature on corporate governance supports the idea that there will be a positive relationship with performance based on which the following hypothesize is developed:

H5 NTAE SMEs corporate governance is positively related to export performance.

\section{Operations and maintenance}

The literature has focused mostly on modern maintenance practices such as, total productive maintenance (TPM) as a way to reach organisational efficiency. The concept of total productive maintenance originated by Nakajima (1988) emphasizes improvement to effectiveness of equipment, and, maximising output. This is established by the smooth flow of equipment operations through routine maintenance tasks, training, planned maintenance and early maintenance management (Baglee \& Knowles, 2010). The literature generally suggests the success of maintenance culture in large organisations as opposed to SMEs (Percy \& Kobbacy, 1997; Wiklund \& Wiklund, 1999). The debate has been whether this is due largely to the absence of case studies on implementation of maintenance practices in SMEs or failure of majority of SMEs to run a maintenance strategy (Cooke, 2003). "Maintenance practices within SMEs are not dynamic or evolving, but are static and conditioned by the existence of barriers" because SMEs practiced more, a reactive maintenance strategy for survival (Baglee \& Knowles, 2010, pp300). Jain et al. (2015) suggest that SMEs could look to overall equipment effectiveness (OEE) and adopt mobile maintenance to improve equipment operation. These negative perceptions in the literature of an SMEs operation and maintenance lead to the following hypothesis:

H6 Equipment operation and maintenance in NTAE SMEs is negatively related to export performance.

\section{Innovation}

-Product development

Noke \& Hughes (2010) suggest that products may be developed along the value chain processes from raw material to final consumption where value added at each/any stage can give the firm competitive advantage. This is through better products or production 
practices, either of which yields higher prices or larger volumes. This line of reasoning is further extended by Terziovski (2010) who found that for manufacturing SMEs, entrepreneurial innovation making use of informal structures is most relevant to product development. Ebrahim et al. (2010) reviewed the literature on product development and observed that globalised competition placed increasing pressure on SMEs. This is to continuously innovate and, upgrade product quality in order to remain competitive. Nicholas et al. (2011) found that strategy was the most relevant dimension of new product development practices, because it ensured innovation and ultimately firm performance. Product development is the pillar of sustained competition as discussed in a number of studies, and, was found by Ardyan (2016) to have a positive and significant effect on SME performance. For this reason it is hypothesized that:

H7 NTAE SMEs product development is positively related to export performance.

-Business outlook (technology leadership)

Literature searches on business outlook mostly discuss it in terms of technology leadership having a positive effect on the performance of SMEs through fostering an innovation orientation (Rosenbusch et al., 2011, pp441). Rosenbusch et al. (2011) considered internal innovation processes, relying on the firm's own innovation resources, to be better suited for small businesses in a number of contexts. To this end, "SMEs adopting innovation strategy would provide the management direction and guidance necessary to ensure the correct focus on customer value" (Yan \& Chew, 2011, pp2397-98). In addition, business outlook ensures that the SMEs are more sustainable and competitive, and is considered positive when it reflects an improvement in executing a task or a marketing undertaking (Aziz \& Yassin, 2010). Business outlook adds to the structural capital of a firm, which positively impacts firm performance (Kamukama et al., 2011). The discussions in the literature show positive effect of business outlook in terms of technology leadership, which leads to the following hypothesis:

H8 Business outlook of NTAE SMEs is positively related to export performance.

\section{- Export Channels and Institutions (services and finance)}

\section{Export Mode}

The export mode of a firm depends largely on transactions cost in terms of how best to organise to make export operation more efficient (He et al., 2012). Export mode is either direct or indirect (through an intermediary/agent). Brouthers \& Hennart (2007) in reviewing the literature on market entry modes, suggest that asset specificity, information 
asymmetry, and market uncertainty, based on transaction cost analysis, are the driving factors for the choice of export mode. The firm determines this by assessing whether the net benefits of the export market exceed the fixed costs (Roberts et al., 2012). Export mode choice has also been explained by Fernández-Olmos \& Díez-Vial (2015) from the resource based view (RBV) approach. They argue that firms "establish their export channel (mode) to best exploit and develop their firm-specific resources" and protect from appropriation. Firms choose from direct or indirect export mode making use of intangible or tangible internal resources (Fernández-Olmos \& Díez-Vial, 2015, pp1014). This approach of selecting the appropriate mode based on the internal resource mix leads to better export performance. The following hypothesis is drawn:

\section{H9 NTAE SMEs exportmode is positively related to export performance.}

\section{Extension services}

Extension services are thought to be agriculture related and mostly undertaken by public sector institutions to strengthen the capacity of SMEs or small to medium scale farmers. Nkwe (2012, pp32) discusses extended extension services by the Ministry of Commerce and Industry "for small and medium business to urban areas, where the assistance will place special emphasis on export marketing, quality control and meeting delivery schedules". Extension services are delivering information inputs to farmers and include transfers of new knowledge, technology, skills development and advice from researchers to farmers (Aker, 2010; Anderson \& Feder, 2007). Extension services are described as systems that facilitate access by farmers, their partners, and market actors to knowledge, information, and technology through interactions with research and other relevant institutions (Faure et at., 2012). In this way, information asymmetry is generally reduced improving firm performance. Aker (2010) argues that measurement of the impact of agricultural extension services is difficult. The study of Buadi et al. (2013) on extension services in Ghana showed that these services declined in the last two decades of the $20^{\text {th }}$ century. At the turn of the $21^{\text {st }}$ century there was a peak in extension services due to an increase in government investments in the agricultural sector. Most support went to the traditional export products, such as cocoa, dominated by male farmers. Other food crops (especially non-export crops) dominated mostly by females, received less support. The focus did not include non-traditional agricultural exports. According to Buadi et al. (2013) extension services in Ghana have been provided mostly by government and also nongovernmental organizations (NGOs). The activities of the NGOs were an intervention to solve the market failure, due to inadequate availability and supply of governmental extension services. In Ghana, the government provides free and subsidized extension 
services to farmers although this is considered to be inadequate and untimely adversely affecting yield/harvest. Based on these discussions in the literature the following hypothesis is drawn:

H10 Extension services to NTAE SMEs is negatively related to export performance.

\section{Professional and technical support}

Professional and technical support is either intangible (talks and demonstrations, etc.) or tangible (assistance and technical services). They may be unpaid (public, common pool) or paid (private, toll) (Anderson \& Feder, 2007; Klerkx et al., 2006). Faure et al. (2012) define advisory services as "the actors involved in the advisory activity and the relationships they maintain with each other and with other external actors; and the methods that are used by advisory service actors to create knowledge and know-how in individual and/or collective learning processes". In our study, we look at tangible support including start-up, planting, harvesting and sales. The discussions in the literature lead to the following hypothesis:

H11 Professional and technical support to NTAE SMEs is positively related to export performance.

\section{Access to finance}

About $90 \%$ of SMEs in Ghana find access to finance a constraint due to limited access to capital markets, and, to poor support from government and traditional banks (Abor \& Biekpe, 2006). The lack of data however makes it difficult to access the financing gap, although microfinance institutions are perceived to be more supportive to SMEs than the traditional banks (Quaye et al., 2014). Generally, the nature of credit supply is such that "there will always be some borrowers whose demand for credit is not satisfied in full or include terms they consider inappropriate" (Quaye et al., 2014, pp341). Supply of finance is through equity or debt (capital structure) and this remains a relevant factor for SMEs who venture into the export market. The dynamics of the institutional environment appears to have generated repressive financial policies, adversely affecting the interest of traditional banks in supporting exporting SMEs. Also other factors, including the cost of monitoring as a result of information asymmetry, which drives up interest, negatively influence the loan conditions for SMEs (Abor et al., 2014). Mensah (2004) list a number of credit schemes for SMEs in Ghana but these funds are channelled through the traditional banks whose inherent policies and the weak institutional framework means that the same terms and conditions are applied as for regular loans. A difference may occur when the 
bank and the SME have a long term relationship (Abor et al., 2014). The analysis in the literature leads to the following hypothesis:

H12 NTAE SMEs access to financial resources is negatively related to export performance.

\section{- Export Performance}

Export performance can be viewed as "the outcome of the firm's export activities" (Abban et al., 2018, pp4). The literature provides for both subjective (relative performance, perceptions on performance) and objective (sales, profits) measures. Some studies have "found that subjective approaches were closely correlated with objective measures" (Aziz $\&$ Yassin 2010, pp157) and subjective measures can be used in research were objective data are unavailable (Greenlay, 1995; Dess \& Robinson, 1984). In operationalizing export performance we follow Boso et al. (2016) and Adu-Gyamfi \& Korneliussen (2013) where perception indicator(s) are used as a measure export performance. In a recent study in Ghana, export performance was measured by "new product success" and "overall export performance" determined by perceptions on the extent to which specified indicators were met using 'Likert' scales (Boso et al., 2016). Adu-Gyamfi \& Korneliussen (2013) in their study on antecedents of export performance in Ghana, measure export performance using satisfaction with export performance. Export performance is described as the ability of the exporting SME to offer goods and service of international standard, worth the global market price and obtaining appropriate returns on the resources used in producing them (Boansi, 2014).

\section{- Control Variables}

Firm size, the number of years of company operation, and number of years in export business were used as control variables in this study. This is consistent with other studies in Ghana on export performance, such as that of Boso et al., 2016. Similarly, firm size and age amongst other control variables were used by Adomako \& Danso (2014, pp6) because "control variables account for factors other than the theoretical constructs of interest that could explain variance in the dependent variable".

\subsection{Research Methods}

The Research Design for this study is extensively discussed in Chapter 4.4 and presents the study context, sample and data collection. The study questionnaire can be found in Appendix 6 (pp138). Responses to the open-ended questions ${ }^{31}$ are used to support

\footnotetext{
${ }^{31}$ The questions are Q71c and Q71d of the survey instrument. See descriptives in Appendix 8 pp 161
} 
discussions on findings and forms the basis for some of the recommendations in this chapter and in the concluding chapter 7 on page 111 . The $\mathrm{T}$ test results for the variables namely: location, audited financial statement, capital structure and company type (which were originally considered as control variables) showed general lack of significance for this study model. In addition the reliability test (Cronbach Alpha) for these variables were low $(<0.7)$ and they were therefore excluded ${ }^{32}$. Appendix 2 (pp130-133) provides results for $T$ tests for this study.

\section{Measurements}

Table 6.1a and 6.1b show the explanatory items for each variable, factor loadings, collinearity variance inflation factor (VIF), Cronbach alpha, mean, standard deviation, and, measurement scale.

\footnotetext{
${ }^{32}$ The same decision applied in our (study) context for other estimation parameters. Variables with composite reliability $<0.7$ were excluded.
} 
Table 6.1a Independent variables: items, factor loadings, VIF, Cronbach alpha, mean and standard deviations and measurement scales

\begin{tabular}{|c|c|c|c|c|c|c|}
\hline Variable & Items & $\begin{array}{l}\text { Factor } \\
\text { Loadings }\end{array}$ & $\begin{array}{l}\text { Collinea- } \\
\text { rity VIF }\end{array}$ & $\begin{array}{l}\text { Cronbach } \\
\text { Alpha } \\
\end{array}$ & $\begin{array}{l}\text { Mean } \\
\text { (SD) }\end{array}$ & $\begin{array}{l}\text { Measurement } \\
\text { Scale }\end{array}$ \\
\hline \multicolumn{7}{|c|}{ SME Characteristics } \\
\hline $\begin{array}{l}\text { International } \\
\text { experience }\end{array}$ & $\begin{array}{l}\text { - Born and raised abroad } \\
\text { - Schooled abroad } \\
\text { - Previously worked abroad }\end{array}$ & $\begin{array}{l}0.921 \\
0.909 \\
0.833\end{array}$ & $\begin{array}{l}2.846 \\
3.187 \\
1.805\end{array}$ & 0.867 & $\begin{array}{l}6.10 \\
(1.49)\end{array}$ & $\begin{array}{l}\text { 'Likert' scale } 1-7 \\
1 \text { - to a very low extent } \\
7 \text { - to a very high } \\
\text { extent }\end{array}$ \\
\hline $\begin{array}{l}\text { Export } \\
\text { knowledge }\end{array}$ & $\begin{array}{l}\text { Management's export knowledge is } \\
\text { constrained in areas such as: } \\
\text { - Knowledge of markets } \\
\text { - Knowledge of regulations } \\
\text { - Quotas/overseas barriers } \\
\text { - Frequent changes in regulations of } \\
\text { importing country } \\
\text { - Need for more more learning }\end{array}$ & $\begin{array}{l}0.823 \\
0.899 \\
0.799 \\
0.804 \\
0.651\end{array}$ & $\begin{array}{l}2.383 \\
3.826 \\
2.309 \\
2.028 \\
1.528\end{array}$ & 0.857 & $\begin{array}{l}4.01 \\
(1.45)\end{array}$ & $\begin{array}{l}\text { 'Likert' scale } 1-7 \\
\text { (Reverse coded) } \\
\text { 1- to a very low extent } \\
\text { 7- to a very high } \\
\text { extent }\end{array}$ \\
\hline $\begin{array}{l}\text { Intended } \\
\text { expansion } \\
\text { (entrepreneurial } \\
\text { attitude) }\end{array}$ & $\begin{array}{l}\text { - Expand its existing facilities } \\
\text { - Expand to another location } \\
\text { - Expand with more elaborate equipment } \\
\text { - Expand to new markets }\end{array}$ & $\begin{array}{l}0.903 \\
0.757 \\
0.951 \\
\mathbf{0 . 4 8 7}\end{array}$ & $\begin{array}{l}2.658 \\
1.849 \\
3.110 \\
1.453\end{array}$ & 0.846 & $\begin{array}{l}5.66 \\
(1.36)\end{array}$ & $\begin{array}{l}\text { 'Likert' scale } 1-7 \\
1 \text { - to a very low extent } \\
7 \text { - to a very high extent }\end{array}$ \\
\hline $\begin{array}{l}\text { Building social } \\
\text { networks }\end{array}$ & $\begin{array}{l}\text { The most efficient way to build/ maintain } \\
\text { local and export chain contacts for foreign } \\
\text { trade is through: } \\
\text { - Tribal affiliations } \\
\text { - Religious affiliations } \\
\text { - College or school alumni } \\
\text { - Government inititiatives }\end{array}$ & $\begin{array}{l}\mathbf{0 . 5 7 0} \\
0.617 \\
0.924 \\
0.604\end{array}$ & $\begin{array}{l}4.761 \\
\mathbf{5 . 4 0 7} \\
1.686 \\
1.089 \\
\end{array}$ & 0.746 & $\begin{array}{l}3.64 \\
(1.58)\end{array}$ & $\begin{array}{l}\text { 'Likert' scale } 1-7 \\
1 \text { - to a very low extent } \\
\text { 7- to a very high } \\
\text { extent }\end{array}$ \\
\hline $\begin{array}{l}\text { Corporate } \\
\text { governance }\end{array}$ & $\begin{array}{l}\text { - Processes allow for clear separation of } \\
\text { functions and checks and balances } \\
\text { - Clear reporting lines of communication } \\
\text { - Regulatory and monitoring requirements } \\
\text { are regularly met }\end{array}$ & $\begin{array}{l}0.851 \\
0.908 \\
0.854\end{array}$ & $\begin{array}{l}2.539 \\
2.923 \\
1.639\end{array}$ & 0.844 & $\begin{array}{l}5.20 \\
(1.44)\end{array}$ & $\begin{array}{l}\text { 'Likert' scale } 1-7 \\
1 \text { - to a very low extent } \\
7 \text { - to a very high } \\
\text { extent }\end{array}$ \\
\hline $\begin{array}{l}\text { Operations and } \\
\text { maintenance }\end{array}$ & $\begin{array}{l}\text { - Staff given on-the-job training in } \\
\text { equipment use } \\
\text { - Regular maintenance policy and schedule } \\
\text { in place }\end{array}$ & $\begin{array}{l}0.818 \\
0.895\end{array}$ & $\begin{array}{l}1.294 \\
1.294\end{array}$ & 0.646 & $\begin{array}{l}5.30 \\
(1.23)\end{array}$ & $\begin{array}{l}\text { 'Likert' scale } 1-7 \\
1 \text { - to a very low extent } \\
\text { 7- to a very high } \\
\text { extent }\end{array}$ \\
\hline $\begin{array}{l}\text { Product } \\
\text { development }\end{array}$ & $\begin{array}{l}\text { Introduction of new products /services is } \\
\text { best explained by: } \\
\text { - Strong marketing } \\
\text { - Emphasis on R\&D } \\
\text { - Technological leadership } \\
\text { - Innovation }\end{array}$ & $\begin{array}{l}\mathbf{0 . 4 8 1} \\
0.822 \\
0.821 \\
0.859 \\
\end{array}$ & $\begin{array}{l}1.204 \\
1.608 \\
1.658 \\
1.812 \\
\end{array}$ & 0.763 & $\begin{array}{l}5.40 \\
(1.42)\end{array}$ & $\begin{array}{l}\text { 'Likert' scale } 1-7 \\
1 \text { - to a very low extent } \\
7 \text { - to a very high } \\
\text { extent }\end{array}$ \\
\hline
\end{tabular}




\begin{tabular}{|c|c|c|c|c|c|c|}
\hline Variable & Items & $\begin{array}{l}\text { Factor } \\
\text { Loadings }\end{array}$ & $\begin{array}{l}\text { Collinea- } \\
\text { rity VIF }\end{array}$ & $\begin{array}{l}\text { Cronbach } \\
\text { Alpha }\end{array}$ & $\begin{array}{l}\text { Mean } \\
\text { (SD) }\end{array}$ & $\begin{array}{l}\text { Measurement } \\
\text { Scale }\end{array}$ \\
\hline $\begin{array}{l}\text { Business outlook } \\
\text { (technological } \\
\text { leadership) }\end{array}$ & $\begin{array}{l}\text { - New products/services, operating } \\
\text { technoligies or administrative techniques } \\
\text { are the first to be introduced by the } \\
\text { company } \\
\text { - New products/services, operating } \\
\text { technoligies or administrative } \\
\text { techniques are the first to be } \\
\text { introduced in the industry }\end{array}$ & 0.914 & 2.625 & 0.881 & $\begin{array}{l}4.71 \\
(2.08)\end{array}$ & $\begin{array}{l}\text { 'Likert' scale } 1-7 \\
1 \text { - to a very low } \\
\text { extent } \\
\text { 7- to a very high } \\
\text { extent }\end{array}$ \\
\hline \multicolumn{7}{|c|}{ Export Channels and Institutions (services and finance) } \\
\hline Export mode & $\begin{array}{l}\text { Export mode used: } \\
\text { - Final customer (buyer) } \\
\text { - No known customer (agent/logistics } \\
\text { company) }\end{array}$ & $\begin{array}{l}0.870 \\
0.862\end{array}$ & $\begin{array}{l}1.332 \\
1.332\end{array}$ & 0.666 & $\begin{array}{l}5.17 \\
(2.10)\end{array}$ & $\begin{array}{l}\text { 'Likert' scale } 1-7 \\
1 \text { - to a very low } \\
\text { extent } \\
7 \text { - to a very high } \\
\text { extent }\end{array}$ \\
\hline Extension service & $\begin{array}{l}\text { Do the extension services provide } \\
\text { assistance during: } \\
\text { - Start up } \\
\text { - Planting } \\
\text { - Harvesting } \\
\text { - Sales }\end{array}$ & $\begin{array}{l}0.905 \\
0.939 \\
0.800 \\
\mathbf{0 . 3 9 4}\end{array}$ & $\begin{array}{l}2.816 \\
3.156 \\
1.807 \\
1.139\end{array}$ & 0.787 & $\begin{array}{l}4.84 \\
(1.40)\end{array}$ & $\begin{array}{l}\text { 'Likert' scale } 1-7 \\
1 \text { - to a very low } \\
\text { extent } \\
7 \text { - to a very high } \\
\text { extent }\end{array}$ \\
\hline $\begin{array}{l}\text { Professional and } \\
\text { technical support }\end{array}$ & $\begin{array}{l}\text { Do the technical and professional services } \\
\text { provide assistance during: } \\
\text { - Planting } \\
\text { - Harvesting }\end{array}$ & $\begin{array}{l}0.939 \\
0.950\end{array}$ & $\begin{array}{l}2.605 \\
2.605\end{array}$ & 0.880 & $\begin{array}{l}4.84 \\
(1.49)\end{array}$ & $\begin{array}{l}\text { 'Likert' scale } 1-7 \\
1 \text { - to a very low } \\
\text { extent } \\
7 \text { - to a very high } \\
\text { extent }\end{array}$ \\
\hline $\begin{array}{l}\text { Access to } \\
\text { Finance }\end{array}$ & $\begin{array}{l}\text { How would you measure/ evaluate: } \\
\text { - Process of accessing financing } \\
\text { - Adequacy of amounts received } \\
\text { - Timing of financial resources } \\
\text { - Conditions attached to finances }\end{array}$ & $\begin{array}{l}0.799 \\
0.983 \\
0.815 \\
0.860\end{array}$ & $\begin{array}{l}4.202 \\
3.593 \\
\mathbf{5 . 7 6 0} \\
4.647\end{array}$ & 0.949 & $\begin{array}{l}3.06 \\
(1.65)\end{array}$ & $\begin{array}{l}\text { 'Likert' scale 1-7 } \\
1 \text { - very bad } \\
\text { 7- very good }\end{array}$ \\
\hline
\end{tabular}

Table 6.1b Dependent and control variables: items, mean and standard deviations and measurement scales

\begin{tabular}{|c|c|c|c|}
\hline Variable & Items & $\begin{array}{l}\text { Mean } \\
\text { (SD) }\end{array}$ & $\begin{array}{l}\text { Measurement } \\
\text { Scale }\end{array}$ \\
\hline \multirow[t]{4}{*}{$\begin{array}{l}\text { Dependent Variable } \\
\text { Export performance }^{33}\end{array}$} & $\begin{array}{l}\text { Rate quality of the export product } \\
\text { compared to that of competitors }\end{array}$ & \multirow{4}{*}{$\begin{array}{l}5.30 \\
(1.17)\end{array}$} & $\begin{array}{l}\text { 'Likert' scale 1-7 } \\
\text { 1- very low } \\
\text { 7- very high }\end{array}$ \\
\hline & $\begin{array}{l}\text { Rate competitiveness of the export product in the NTAE } \\
\text { sector }\end{array}$ & & $\begin{array}{l}\text { 'Likert' scale } 1-7 \\
1 \text { - very uncompetitive } \\
7 \text { - very competitive }\end{array}$ \\
\hline & $\begin{array}{l}\text { Rate performance of the exporting company compared } \\
\text { to competing exporting companies in the local } \\
\text { market }\end{array}$ & & $\begin{array}{l}\text { 'Likert' scale } 1-7 \\
1 \text { - very poor performance } \\
7 \text { - very good performance }\end{array}$ \\
\hline & $\begin{array}{l}\text { Rate performance of the exporting company compared } \\
\text { to competing exporting companies in the international } \\
\text { market }\end{array}$ & & $\begin{array}{l}\text { 'Likert' scale } 1-7 \\
1 \text { - very poor performance } \\
7 \text { - very good performance }\end{array}$ \\
\hline \multirow[t]{3}{*}{ Control Variables } & Firm age & $\begin{array}{l}12.69 \\
(9.73)\end{array}$ & $\begin{array}{l}\text { - Number of years of company } \\
\text { operation }\end{array}$ \\
\hline & Firm experience & $\begin{array}{l}10.69 \\
(8.62)\end{array}$ & - Number of years in export business \\
\hline & Firm size & $\begin{array}{l}98.34 \\
(304.18)\end{array}$ & - Number of employees \\
\hline
\end{tabular}

\footnotetext{
${ }^{33}$ Formative construct. See Appendix 7 on page 157
} 
Partial least squares structural equation modelling (PLS SEM) was used to analyse the data and considered appropriate from the literature for sample sizes between 100 and 200, because of better predictive values for latent variables (Wong, 2013). PLS SEM has been applied to even smaller sample sizes (Kock \& Hadaya, 2018; Hair et al., 2011) and proven to have an effective prediction of the population. As suggested by Goodhue et al. (2012), the PLS SEM also has an advantage with non-normal data which is often found in data used in behavioural research studies. All variables were measured on 7 point 'Likert' scales. The factor loadings were originally set at 0.6 for all the measures, although this was relaxed for variables that had a good Cronbach alpha. Most research assumes that an alpha level of 0.7 is good while above 0.6 is still considered adequate (Schmitt, 1996). The analysis for internal consistency/composite reliability show minimum value of 0.78 and convergent validity measured by the average variance extracted (AVE) ranged between 0.58 and 0.892 for all variables with the exception of 0.481 for "building social networks". The results are therefore consistent with the literature (Wong, 2013). Composite reliability above 0.6 is considered supportive of convergent validity (Adomako \& Danso, 2014).

The variable export performance was formative and the means/average of the different items were used to compute it (see Appendix 7 on page 157). For the independent variables the constructs were reflective which was also shown by the factor loadings and the measures for reliability and validity. The use of both formative and reflective measures is consistent with a majority of PLS SEM analyses found in literature (Ringle et al., 2012). Most exploratory research studies make use of both reflective and formative indicators, and it is considered appropriate for use in PLS SEM.

The means show how positively or negatively the respondents perceive the different constructs. The SD indicates the degree of closeness to the mean. A smaller SD suggests a smaller error or better prediction of the estimate (Winer, 1971). The constructs international experience, intended expansion (entrepreneurial attitude), operations and maintenance, corporate governance and form of channel show good results with means above 5.1, although form of channel has the highest SD of the constructs. In contrast, access to finance is regarded very negatively by the respondents with a mean of 3.06. The dependent variable export performance has a high mean of 5.3 and a low SD. The control variables firm age and firm experience show that the companies are on average 11 to 12 years in business. The firms are mostly medium sized companies with an average number of about 100 employees. The large SDs of the control variables reflect the wide variability of the firms in terms age, experience, and, number of employees. 
Table 6.2 presents the AVE and correlations. The Fornell-Larcker (FL) criterion was used to determine discriminant validity. The FL criterion is based on the AVE, (a measure of convergent validity) and "compares the AVE of each construct with the squared interconstruct correlations" (Hair et al., 2012, pp328). An acceptable AVE is considered to be 0.5 for convergent validity (Wong, 2013). To meet FL criterion, the square root of the AVE should be greater than the correlation values amongst latent variables. The findings indicate that the measures satisfy the criterion for discriminant validity. Although "building social networks" had an AVE of 0.481 this variable was included because results for reliability and other validity tests were strong. The values on the diagonal are all larger than the AVE values in the respective columns, showing that the constructs' correlations with other constructs is smaller than the correlation between the construct's underlying items. This proves the construct really is discriminative. The discriminant validity is good for all constructs. Some correlation was found between the variables: Business outlook and intended expansion $(r=0.438)$, business outlook and product development ( $r=$ $0.435)$, building social networks and international experience $(r=0.458)$, corporate governance and operations and maintenance $(r=0.489)$, corporate governance and export performance $(r=0.475)$, evaluation of financing sources and export knowledge $(r=$ $0.411)$, export mode and international experience $(r=0.462)$, and extension service and professional and technical support $(r=0.489)$. These correlations were not considered strong enough to pose a challenge to the PLS SEM analysis. 


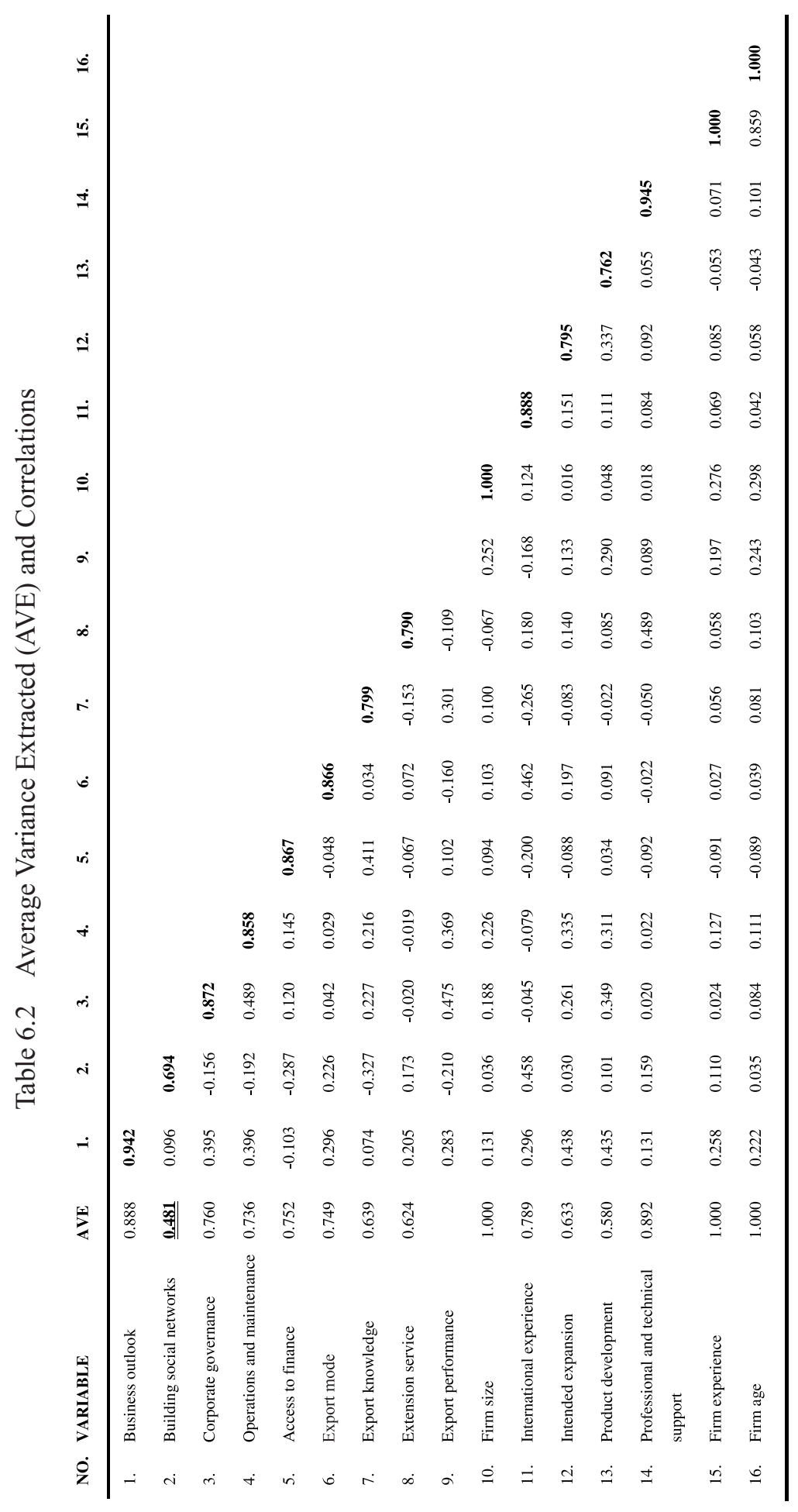




\subsection{Results/DataAnalysis}

Descriptives

SMEs in this study are defined in terms of number of employees. Following the study by Abor et al. (2014, pp100) SMEs are "micro firms if employing less than 6 persons; small firms if employing between 6 and 29 persons; and medium firms if employing between 30 and 99 persons". This definition is similar to other definitions in the literature on Ghanaian SMEs (Abban et al., 2013; Kayanula \& Quartey, 2000).

Table 6.3 Sample Characteristics (location, size, product type and CEO gender and education)

\begin{tabular}{|l|c|c|}
\hline Variable & Frequency & Percent \\
\hline Location & & \\
Savannah & 15 & 10 \\
Forest & 11 & 7 \\
Coastal & 126 & 83 \\
\hline Total & $\mathbf{1 5 2}$ & $\mathbf{1 0 0 . 0 0}$ \\
\hline Firm Size & & \\
Micro (1-5) & 44 & 29 \\
Small (6-29) & 62 & 41 \\
Medium (30-99) & 46 & 30 \\
\hline Total & $\mathbf{1 5 2}$ & $\mathbf{1 0 0}$ \\
\hline CEO/manager's gender & & \\
Male & 120 & 79 \\
Female & 32 & 21 \\
\hline Total & $\mathbf{1 5 2}$ & $\mathbf{1 0 0}$ \\
\hline CEO/manager's education & & \\
Basic/Secondary & 47 & 31 \\
Tertiary & 87 & 57 \\
Postgraduate/Professional & 18 & 12 \\
\hline Total & $\mathbf{1 5 2}$ & $\mathbf{1 0 0}$ \\
\hline Product Type & 62 & \\
Processed & 17 & $\mathbf{1 0 0}$ \\
Semi-processed & $\mathbf{1 5 2}$ & \\
Non-processed & & \\
\hline Total & & \\
\hline
\end{tabular}

Field survey 2015-2016 
The data in Table 6.3 shows that $41 \%$ of firms were small sized firms followed by $31 \%$ medium sized firms and $29 \%$ micro firms. Predominantly, firms (83\%) were located in the coastal zone. Of the remaining firms $7 \%$ were located in the forest zone and $10 \%$ in the savannah zone. This concentration of SMEs in the coastal zone is consistent with the findings of the pilot study (Abban et al., 2012). Sixty nine percent of SMECEO/managers had tertiary or postgraduate/professional education. By inference, institutional support by way of capacity building and incentivized training packages are required to support SMEs in export, because of the high proportion (31\%) of SMEs CEO/managers with basic or secondary education. The statistics also indicates that in the NTAE sector SMEs' $\mathrm{CEO} /$ managers are predominately males $(79 \%)$, whereas $48 \%$ of export products are nonprocessed with little or no value added, $11 \%$ are semi-processed, and, $41 \%$ processed products. Non-processed agro products include: pineapple, chilli pepper, 'baby' corn, sheanuts, lumber/timber, cashew nuts, green pepper, soyabean, green mango, green banana, green pawpaw, fish, garden eggs, cocoyam, okro, and soybean. Semi-processed products include: dried fruits (mango, banana), orange concentrate, pineapple (juice, chopped), dried voacanga and/or griffonia seeds, shea butter, voacanga/griffonia tea bags, dried orange/lemon peel, flowers. Processed products include: clothing (garments and textiles), artefacts (carvings), baskets and other handicrafts (drums, masks), stools, shea body oils/cream/lotions, lip balm, soap, canned foods - tuna, fruit, vegetables, pepper sauce, palm soup, melon soup, gari (grated, roasted cassava), palm oil, traditional footwear, cocoa products, processed wood, 'kente' cloth, 'fufu' flour (cassava, yam, plantain and maize) and 'banku' mix (dried fermented maize and cassava flour) (Abban et al., 2018, pp14).

\section{PLS-SEM}

Table 6.4a and 6.4b show the results for the outer models on SME characteristics and form of channel and institutions, respectively. The outer model measures the relationship between the latent variable and its indicators. The $\mathrm{p}$ values are an indication of the significance of, and, the confidence in the validity of the results. In general, the loadings and $\mathrm{p}$ values show that the variables are relevant and well explained. In tables $6.4 \mathrm{a}$ and $6.4 \mathrm{~b}$ only two variable items showed insignificant results, intended expansion- "expand to new markets" and extension service - "harvesting". These variable items were included because they are reflective indicators and provide some explanation for the variable. The result also does not impact the Cronbach alpha measure for the variable. The outer model results for export performance, firm size, firm age, and, firm experience showed significant results at the $99 \%$ level $(\mathrm{p}<0.01)$. 
Table 6.4a Outer Model: SME characteristics (including $\mathrm{p}$ values)

\begin{tabular}{|c|c|c|c|c|c|}
\hline Variable & Item & P Value & Variable & Item & P Value \\
\hline \multicolumn{6}{|c|}{ SME Characteristics $\quad * * * \mathrm{p}<0.01, * * \mathrm{p}<0.05, * \mathrm{p}<0.1$} \\
\hline $\begin{array}{l}\text { International } \\
\text { experience }\end{array}$ & $\begin{array}{l}\text { - Born and raised abroad } \\
\text { - Schooled abroad } \\
\text { - Previously worked abroad }\end{array}$ & $\begin{array}{l}* * * 0.000 \\
* * * 0.000 \\
* * * 0.000\end{array}$ & $\begin{array}{l}\text { Product } \\
\text { development }\end{array}$ & $\begin{array}{l}\text { Introduction of new } \\
\text { products /services is best } \\
\text { explained by: } \\
\text { - Strong marketing } \\
\text { - Emphasis on R\&D } \\
\text { - Technological } \\
\text { leadership } \\
\text { - Innovation }\end{array}$ & $\begin{array}{l}* * * 0.007 \\
* * * 0.000 \\
* * * 0.000 \\
* * * 0.000\end{array}$ \\
\hline $\begin{array}{l}\text { Intended } \\
\text { expansion }\end{array}$ & $\begin{array}{l}\text { - Expand its existing facilities } \\
\text { - Expand to another location } \\
\text { - Expand with more elaborate } \\
\text { equipment } \\
\text { - Expand to new markets }\end{array}$ & $\begin{array}{r}* * * 0.000 \\
* * * 0.001 \\
* * * 0.000 \\
\mathbf{0 . 1 2 0}\end{array}$ & Export knowledge & $\begin{array}{l}\text { Management export } \\
\text { knowledge is constrained } \\
\text { in areas such as: } \\
\text { - Knowledge of market } \\
\text { - Knowledge of } \\
\text { regulations } \\
\text { - Quotas/overseas barriers } \\
\text { - Frequent changes in } \\
\text { regulations of importing } \\
\text { country } \\
\text { - Need for more } \\
\text { more learning }\end{array}$ & $\begin{array}{l}* * * 0.000 \\
* * * 0.000 \\
* * * 0.000 \\
* * * 0.000 \\
* * * 0.000\end{array}$ \\
\hline $\begin{array}{l}\text { Corporate } \\
\text { governance }\end{array}$ & $\begin{array}{l}\text { - Processes allow for clear } \\
\text { Separation of functions and } \\
\text { checks and balances } \\
\text { - Clear reporting lines of } \\
\text { communication } \\
\text { - Regulatory and monitoring } \\
\text { requirements are regularly met }\end{array}$ & $\begin{array}{l}* * * 0.000 \\
* * * 0.000 \\
* * * 0.000\end{array}$ & $\begin{array}{l}\text { Building social } \\
\text { networks }\end{array}$ & $\begin{array}{l}\text { The most efficient way to } \\
\text { build/ maintain local and } \\
\text { export chain contacts for } \\
\text { foreign trade is through: } \\
\text { - Tribal affiliations } \\
\text { - Religious affiliations } \\
\text { - College or school } \\
\text { alumni } \\
\text { - Government } \\
\text { Inititiatives }\end{array}$ & $\begin{array}{r}* * * 0.000 \\
* * 0.036 \\
* 0.067 \\
\quad * 0.091 \\
\end{array}$ \\
\hline $\begin{array}{l}\text { Operations } \\
\text { and } \\
\text { maintenance }\end{array}$ & $\begin{array}{l}\text { - Staff given on-the-job training } \\
\text { in equipment use } \\
\text { - Regular maintenance policy } \\
\text { and schedule in place }\end{array}$ & $\begin{array}{l}* * * 0.000 \\
* * * 0.000\end{array}$ & & & \\
\hline $\begin{array}{l}\text { Business } \\
\text { outlook }\end{array}$ & $\begin{array}{l}\text { - New products/services, } \\
\text { operating technoligies or } \\
\text { administrative techniques are } \\
\text { the first to be introduced in the } \\
\text { company } \\
\text { - New products/services, } \\
\text { operating technoligies or } \\
\text { administrative techniques } \\
\text { are the first to be intro- } \\
\text { duced in the industry }\end{array}$ & $* * * 0.000$ & & & \\
\hline
\end{tabular}


Table 6.4b Outer model: Export mode and institutions (services and finance) (including $\mathrm{p}$ values)

\begin{tabular}{|c|c|c|c|c|c|}
\hline Variable & Item & P Value & Variable & Item & P Value \\
\hline \multicolumn{6}{|c|}{ Export Channels and Institutions (services and finance) $* * * p<0.01, * * p<0.05 * \mathrm{p}<0.1$} \\
\hline $\begin{array}{l}\text { Export } \\
\text { mode }\end{array}$ & $\begin{array}{l}\text { Export mode used: } \\
\text { - Final customer (buyer) } \\
\text { - No known customer } \\
\text { (agent/logistics company) }\end{array}$ & $\begin{array}{l}* * * 0.000 \\
* * * 0.000\end{array}$ & $\begin{array}{l}\text { Extension } \\
\text { service }\end{array}$ & $\begin{array}{l}\text { Do the extension } \\
\text { services provide } \\
\text { assistance during: } \\
\text { - Start up } \\
\text { - Planting } \\
\text { - Harvesting } \\
\text { - Sales }\end{array}$ & $\begin{array}{r}* * * 0.003 \\
* * * 0.001 \\
\mathbf{0 . 2 9 5} \\
* * * 0.003 \\
\end{array}$ \\
\hline $\begin{array}{l}\text { Access to } \\
\text { Finance }\end{array}$ & $\begin{array}{l}\text { How would you } \\
\text { measure/evaluate: } \\
\text { - Process of accessing } \\
\text { financing } \\
\text { - Adequacy of amounts } \\
\text { received } \\
\text { - Timing of financial } \\
\text { resources } \\
\text { - Conditions attached to } \\
\text { Finances }\end{array}$ & $\begin{array}{l}* * * 0.000 \\
* * * 0.000 \\
* * * 0.000 \\
* * * 0.000\end{array}$ & $\begin{array}{l}\text { Professional and } \\
\text { technical } \\
\text { support }\end{array}$ & $\begin{array}{l}\text { Do the technical and } \\
\text { professional services } \\
\text { provide assistance } \\
\text { during: } \\
\text { - Planting } \\
\text { - Harvesting }\end{array}$ & $\begin{array}{l}* * * 0.000 \\
* * * 0.000\end{array}$ \\
\hline
\end{tabular}

The inner model shows the recursive (path) relationship between the exogenous constructs. "The term exogenous is used to describe latent constructs that do not have any structural path relationships pointing at them" (Hair et al., 2011, pp141). The results for the inner model are shown in Table 6.5 indicating path coefficients and p values.

The model was tested for endogeneity. The results showed no endogeneity among the variables:

Ho : variables are exogenous.

$$
\begin{aligned}
& \text { Durbin (score) } \operatorname{chi} 2(1)=1.45042(\mathrm{p}=0.2285) \\
& \text { Wu-Hausman F }(1,128)=1.31158 \quad(\mathrm{p}=0.2542)
\end{aligned}
$$

The Durbin-Wu-Hausman test (DWH test) and Ramsey RESET test are discussed in Section 4.6 on page 50. The DWH test the null hypothesis that there are endogenous regressors in a model. It is accepted if the p-value is small (less than 0.05), and rejected otherwise, meaning the variables are exogenous, as is the case in our study. Also the results of the RESET test support the DWH test results showing no signs of an endogeneity problem (see Appendix 4, page 136). 
Table 6.5 PLS SEM estimates for the internal and external environmental factors related to export performance of NTAE SMEs in Ghana

\begin{tabular}{|c|c|c|c|}
\hline \multirow{3}{*}{$\begin{array}{l}\text { Variables } \\
\text { International experience }\end{array}$} & \multicolumn{3}{|c|}{$\begin{array}{c}\text { MODEL } \\
\text { Export } \\
\text { Performance }\end{array}$} \\
\hline & & Path Coef. & P Value \\
\hline & H1 (+) & -0.046 & 0.638 \\
\hline Export knowledge & $\mathrm{H} 2(+)$ & 0.167 & $* * 0.032$ \\
\hline Intended expansion & $\mathrm{H} 3(+)$ & -0.003 & 0.974 \\
\hline Building social networks & $\mathrm{H} 4(+)$ & -0.084 & $* * 0.020$ \\
\hline Corporate governance & $\mathrm{H} 5(+)$ & 0.265 & $* * * 0.000$ \\
\hline Operations and maintenance & H6(-) & 0.045 & 0.597 \\
\hline Product development & $\mathrm{H} 7(+)$ & 0.181 & $* * 0.020$ \\
\hline Business outlook & $\mathrm{H} 8(+)$ & 0.108 & 0.247 \\
\hline Export mode & $\mathrm{H} 9(+)$ & -0.192 & $* * 0.045$ \\
\hline Extension service & H10(-) & -0.154 & 0.132 \\
\hline Professional and technical support & $\mathrm{H} 11(+)$ & 0.134 & $* * 0.047$ \\
\hline Access to finance & H12(-) & -0.038 & 0.694 \\
\hline Firm size & & 0.124 & $* 0.099$ \\
\hline Firm experience & & -0.005 & 0.972 \\
\hline Firm age & & 0.165 & 0.263 \\
\hline
\end{tabular}

Observations

R-squared

Adj. R-squared

$* * * \mathrm{p}<0.01, * * \mathrm{p}<0.05, * \mathrm{p}<0.1$

0.364

Field Survey 2015-2016

Table 6.5 shows the PLS SEM results for the coefficients $(\beta), R^{2}$, and the adjusted $R^{2}$ and list the hypothesized relationships to export performance. The model made use of all 152 observations and had an $\mathrm{R}^{2}$ of 0.427 , and an adjusted $\mathrm{R}^{2}$ of 0.364 , which is high. Goodhue et al. (2012) suggest that for a sample size of 150 with a simple model the $\mathrm{R}^{2}$ should be above 0.27 , and the adjusted $\mathrm{R}^{2}$ above 0.25 . The model shows that, next to the control variable firm size, export knowledge $(\mathrm{H} 2+)$, corporate governance $(\mathrm{H} 5+)$, product development $(\mathrm{H} 7+)$ and professional and technical support $(\mathrm{H} 11+)$ are positively related to export performance, so these hypotheses are accepted. In contrast to this, the constructs, building 
social networks $(\mathrm{H} 4+)$ and export mode $(\mathrm{H} 9+)$ though significant, are negatively related to export performance, so these hypotheses are rejected. The other constructs in our model were not significantly related to export performance, so the related hypotheses are not supported.

\subsection{Conclusions and Recommendations}

This study explores NTAE SMEs and highlights some of the determinant factors in their (internal and external) environment which may impact their export performance. The study was based on 152 cases of NTAE SMEs in Ghana. The focus was on the SME characteristics, form of channels (export mode), and institutions (services and finance) related to export performance to answer the research question: Which $S M E$ characteristics, export mode and institutions (services and finance) will be positively related to export performance in the NTAE sector in Ghana?

The study shows that of the SME characteristics, corporate governance, product development, and export knowledge are positively related to export performance. Although building social networks was significant, it showed a negative relationship with export performance. A possible explanation may be that tribal and religious affiliations, contacts via college and school alumni, and, government initiatives are not the best way to find leads for export orders, and that, the time spent on building and maintaining these networks is detrimental to export performance. With respect to export channels (export mode) and institutions characteristics, professional and technical support showed a positive relationship with export performance. Export mode was another significant variable of interest that showed a negative relationship with export performance. The results for the means and SDs suggest that the $\mathrm{CEO} /$ managers perceive having a relatively high level of export knowledge, and, a very entrepreneurial attitude and apply good corporate governance in their companies. A look at the aspects that government can influence shows clearly that professional and technical support is important, but that it is not given enough attention in terms of policy interventions. Also access to finance (although not significantly related to export performance) could be improved, because it was very negatively evaluated.

\section{External environment}

The support to NTAE SMEs by actors such as government extension services and the financial sector showed no positive relationship with export performance. What this suggests is that the implementation of policy(s) and the policy framework of the public sector might still be weak. The private sector driven by associations might not be properly 
organised to harness knowledge sharing, and, to foster a positive competitive environment needed for firms seeking to internationalise.

It is sad to note that the $\mathrm{CEO} /$ managers in our study indicated that access to finance was a problem for most SMEs. Something that was also mentioned in a number of earlier studies (Abor, 2004; Aryeetey \& Ahene, 2005; Abor et al., 2014; Quaye et al., 2014) leading to NTAE SMEs stopping business, being irregular exporters, and new entrants coming in. However, Aryeetey \& Mckay (2007) state that government's monetary policy towards the NTAE sector has improved. Fortunately, our results also indicate that access to finance did not show a significant negative relationship with export performance.

In the literature, the export mode was mentioned as important, and, carefully selected in order to reduce transactions costs and improve returns (Fernández-Olmos \& Díez-Vial, 2015). However, in our study the export mode showed a negative relationship with export performance. The reason for this finding might be that in the case of Ghanaian NTAE SMEs the export mode is restricted. Most SMEs have to conform to the schedules of export carriers/freight forwarders to export their goods. Large export carriers or freight forwarders determine the market by the volume of exports they can transport from one hub to another. The seasonality of some horticultural products makes this an irregular market for them. Carriage by air freight is much more expensive and may lead to uncompetitive product prices. Government options to improve the situation include direct investments in shipping and air freight, tax rebates, concessions and access to finance for NTAE SMEs.

Professional and technical support showed a significant positive relationship with export performance. This is in line with the studies of Buadi et al. (2013) who suggests that the entrance of non-governmental organisations to provide support (because of governmental shortfall) has improved agricultural professional and technical support in Ghana. This factor is also related to private sector initiatives. Government could consider creating more incentives to the private sector to provide the essential services to NTAE SMEs. Consideration could also be given to public private partnerships to improve public sector services to NTAE SMEs.

\section{Internal environment}

The positive result for corporate governance proves that the organisation of the NTAE SMEs internal environment is very important to export performance. It shows that an ordered process in organising for exporting is important. It is interesting to notice that operations and maintenance was not significant. The literature provides ample support for 
a negative relationship for these variables, such as studies by Baglee \& Knowles (2010) and Cook (2003). The positive correlation between corporate governance and operations and maintenance might be an explanation that we did not find a negative relationship.

The innovation strategies of NTAE SMEs are reflected in the positive relation between product development and export performance. Successful NTAE SMEs show a drive to "go fishing" for new information, new trends and innovations of which they believe these would meet consumer expectations. No significant relationship was found for business outlook. This result was in line with that of Dierkes et al. (2012) who also found that business outlook (technology leadership) was not significantly related to export performance. The reason for this finding might be that Ghanaian SMEs tend to mimic each other, so the advantage of a new technology introduced by one SME might be short-lived as other SMEs catch up fast through imitation (Abban et al., 2018, pp20).

In contrast to earlier studies (Galati et al., 2014 and Buatsi, 2000), international experience is not significantly related to export performance. The result that knowledge of export markets is positively linked to export performance means that knowledge of export markets regulations, and, international consumer demands are clearly more important than the CEO/manager having lived or worked abroad. Successful SMEs clearly have know-how of the important export regulations and (changes in) international consumer preferences and apply this knowledge to their advantage. This is a clear improvement, for instance, in the early 2000s, the lack of knowledge of the change in consumer preferences for pineapples caused huge losses to pineapple exporters. They were caught off guard by the change in demand from smooth cayenne to MD2 by buyers mostly in EU markets. Lessons learnt from experiences such as this, have likely shaped the quest for export knowledge by NTAE SME exporters. 


\section{CHAPTER 7}

General Discussions and Conclusions 


\section{CHAPTER 7}

\section{General Discussions and Conclusions}

\subsection{Introduction}

In the introductory Chapter 1 and in Chapter 2, the importance of agriculture and agribusiness to Sub-Saharan Africa (SSA) is indicated in terms of foreign revenue generation. Exports of predominantly unprocessed agriculture produce/products have adverse effects on the development of micro, small and medium sized enterprises/farmers. This is largely because of the lower revenues obtained as compared to export of processed produce/products. It is especially important because agriculture accounts for about $50 \%$ of Africa's productive economic activities. It is therefore not surprising that African governments and development partners direct their attention at the entire agriculture chain (Babu et al., 2015) to include commercial agriculture and agribusiness. As a result, African Union (AU) member states established policies to promote agriculture and agribusiness, leading to diversification of the export base to include non-traditional agricultural exports (NTAEs). Given the assessment by the International Monetary Fund (IMF) of Ghana, as one of the fastest growing economies in Africa, and in support of the commitment of AU member states, including Ghana, there is an interest in exploring how SMEs in the NTAE sector of Ghana are performing. The background, study context, and theories applied are discussed extensively in these two chapters. This study is mainly based on the Resource Based View (RBV) of the firm, network (relationships) analysis and Supply Chain Management (SCM) (export linkages) as discussed in Section 1.5 (pp9). The RBV is used to better explain the firm's internal capabilities. The network relationships and SCM concepts are applied in discussing linkages, actors, and interactions in the upstream and downstream processes of the SME activities. The insights lead to a better understanding of the resources and or the factors that facilitate the NTAE SME internationalization process and ultimately export performance. It also illustrates developments in the agriculture and agribusiness environment with reference to the NTAE sector, and, how these developments support interventions/activities towards Ghana's Global Agenda 2030 and the sustainable development goals (SDGs).

Following the study by Buatsi (2000) the objective of this study is to identify the factors relating to the internal capabilities of NTAE SMEs, and, their network relationships that may affect their export performance. In this thesis, this is done in a number of ways. In Chapter 3 a case study of Ele Agbe, an NTAE SME in Ghana's shea sector, is used to better understand how Ghanaian SMEs operate and the challenges they are confronted with. 
Chapter 4 focuses on the internal capabilities of the NTAE SMEs based on a sample of 152 SMEs. Chapter 5, a multiple case study, focuses on the networks and linkages that NTAE SMEs form, as being relevant to how they build and maintain their (inter-) national supply chains, and, to get a better understanding of their role(s) in these chains. Ultimately, the combined effect of the SME characteristics and the business environment, is studied in Chapter 6, to get a better understanding of NTAE SME export performance. The theoretical underpinning of the different chapters is based on the Resource Based View (RBV), network theory, and, Supply Chain Management (SCM).

This chapter presents the discussion of the main findings and draws the conclusions of this study. The key results and findings are used to answer the research questions of the study in Section 7.2. The theoretical and methodological contributions are presented in Section 7.3. Section 7.4 presents the policy and managerial implications. The limitations and possibilities for further research are discussed in Section 7.6.

\subsection{Answers to the research questions}

The organisation of the thesis evolved from the central research question:

Within the theoretical context of the Resource Based View $(R B V)$, Supply Chain Management (SCM), and network theories, which characteristics (specifically internal capabilities, resources and network relationships) of NTAE SMEs and their business environment are positively related to their export performance?

To answer the central research question, there are three sub questions to be addressed. Which of the firms' internal capabilities are positively related to NTAE SME export performance?

Drawing on a sample of 152 firms in the NTAE sector of Ghana, Chapter 4 studied the internal capabilities of NTAE SMEs. The factors identified include the role of the entrepreneurial strategy, the innovation capacity, and, how they organise their value chain activities. They are considered especially important for export of agricultural products that are dependent on seasonal and storage conditions. The study covered not only the human capital of the SME CEO/management teams, but also their entrepreneurship, and, what could be done in the value chain in order to reach higher levels of export performance. It is also evident that sub-sector peculiarities exist, and, there are often lack of sub-sector drivers. However, entrepreneurial strategy and innovation capacity showed no significance. The interesting outcome is that export knowledge and upstream supply 
capacity alone are positively related to higher performance of NTAE SMEs' export performance. This is apparently an important asset for NTAE SMEs to help identify niche markets and gain competitive advantage internationally.

Previous studies on SME characteristics focused on strengthening the capacity at the firm level (Babu et al., 2015) although the human capital of the SME was often considered the limiting factor (due to lack of skills, training, low level of export knowledge) to the progress of the SME sector in Ghana (Konig et al., 2013). This study however has shown that human capital, measured by export knowledge of the $\mathrm{CEO} /$ management team is significantly related to export performance. As explained by the RBV it is also part of the core resources that make up the SMEs internal capabilities. Chapter 1 discusses the RBV and theoretical applications. In particular, the significance for export knowledge shows that knowing how to get the goods into foreign markets is essential for NTAE SMEs. The positive relationship of the upstream supply capacity with overall export performance implies that the best SMEs are capable (have more flexibility) of organizing their portfolio of upstream input supplies in order to meet buyer demands. The insignificant relationship of international experience and downstream supply capacity with export performance, is a point of concern, because it is important for exporting firms to be able to understand and answer the demands of their international buyers. Problems with storage facilities in the harbor or at the airport that compromise on quality standards are not good for NTAE SMEs export performance and could explain the "negatives" in terms of rejection of exported products for not meeting specifications or standards. A possible explanation for this could be that the NTAE SMEs do not have much control of storage facilities in Ghana, and the transportation conditions, negatively affecting export of products. This aspect of the value chain is also not easily vertically integrated because of the huge capital requirements, the lack of insurance, and, investment opportunities for improved coordination. In addition, insurance related to NTAEs is virtually non existent, expensive, and therefore not cost effective. The downstream chain processes could be better organized to improve exports of NTAEs.

What are the challenges that confront exporting NTAE SMEs and what could be done to improve the situation?

NTAE SMEs identified key challenges ${ }^{34}$ to their operations including: access to finance, infrastructure (transportations, road and warehousing), export processes (certification,

\footnotetext{
${ }^{34}$ See Appendix 8 pp 161 on descriptives for Q71c and Q71d of the main survey instrument on challenges facing NTAE SMEs and suggestions for improvement.
} 
handling/quality processes, clearance and payments), export education, research and development (training, market information, export regulations and requirements), subsector policies (absence of or poor implementation), ship and airline carriers (timing, schedules, frequency), agriculture insurance to include NTAEs among others. Specifically, when asked for the three most important challenges (Q 71c) the respondents mentioned: inadequate monetary interventions etc. (33\% of the respondents), poor/inadequate logistics, roads etc. (25\%) and poor/inadequate government policy, bureaucracy etc. (16\%). Their three main suggestions for areas of improvement (Q 71d) were: improving government macro policies $(35 \%)$, improving government financial policies (22\%), and, improving the export mode (17\%).

The most important challenge that NTAE SMEs identified is finance. The majority of the NTAE SMEs considered that the possibilities for obtaining finance to support export were poor. In general, the firm age (years in export) determined whether an NTAE SME could make successful applications for debt financing related to a more diversified portfolio and sustained operations. Access to finance has been and continues to be the bane for NTAE SMEs (Abor et al., 2014). This challenge is as a result of the perceived risk in lending to exporting SMEs because of uncertainty surrounding "chances of survival and success in exports" (Abor et al., 2014, pp102). One NTAE SME lamented that, even when finances are arranged, the banks are not timely in processing, and, money arrives well after the required time.

SMEs in the NTAE sector do not appear to invest much resources in training. Chapter 6 showed that as many as $66 \%$ of the SMEs interviewed did not invest in any form of training. As a result, their employees are skilled on the job (repeated tasks) but do not have deep insights in export markets. Technological adaptations, innovation, orientation to changes in market demand, or, regulations, are therefore rather slowly imbibed, if at all. Investing in employee training could be a way for NTAE SMEs to improve their performance. These investments in capacity building and innovation, from the RBV perspective, are believed to promote core competencies of the firm (Shafeey \& Trott, 2014). The absence, lack of, or limited training ultimately affects the SME resource base and internal capabilities.

Strengthening downstream supply linkages is another area that SMEs could focus on. This will ensure less interruptions in the agri supply chains as a result of poor handling or compromises on quality standards. Improved networks and chain coordination downstream is especially important for NTAEs. That is to say, the downstream supply 
linkages are important to the direction of exports which has mostly targeted the EU. Unfortunately, the export orders are seldom based on contracts which expose SMEs to risks (Abban et al., 2013) as exports are easily rejected. SMEs could fare better exporting added value (semi-processed and processed) products. Sub-regional markets could be further explored by SMEs, with government interventions (support) to reduce bottlenecks. The external environment (institutions/actors) operating in the downstream end of the NTAE SME supply chain are important to their performance and sustainability. SMEs could also consider improving social networks through participation in groups or associations with stronger monitoring and enforcement of agreed rules and regulations. This will lead to improvement in information flow and capacity building. Consideration could be given to the development of organised franchise markets that link SMEs with multinational companies or large buyers. From the perspectives on linkages for the small scale farmer/enterprise in Chapter 2, "stronger foreign networking for downstream processes to reduce transaction costs of production and marketing" and improved application of resources are required. This would improve the value chain as a result of better coordination of activities (Ricketts et al., 2014).

While government places effort in developing the NTAEs in general, equivalent efforts have not been channeled to sub-sector policies and export infrastructure. In Chapter 2, the findings on public policy for agriculture and agribusiness in Ghana suggests that these policies are "...not very effective in general". For example, until recently, the sheanut sector, discussed in Chapter 3, was unregulated and the activities of large foreign buyers distorted sheanut prices and truncated supply of sheanut to local exporters of shea products. Effective implementation of shea sector policies remains necessary to promote shea exports (Abban et al., 2014). In discussions in Chapter 5, exporters of medicinal seeds such as voacanga and griffonia have lamented the absence of a regulatory agency to enforce quality of these export products. This has to do with the moisture content of these products. The poor quality of the products supplied by a few exporters is often generalised to include/cover all exporters. Situations such as these, have significantly affected the subsectors exports. In the Chapters 1 and 6, it was mentioned that for the pineapple sector, the lack of investments in market research impacted SMEs who were caught unawares by the sudden shift in consumer demand from "smooth cayenne" to "MD2" pineapple varieties, which severely affected production. Kleeman et al. (2014, pp80) state that as a result of that "the market share of Ghanaian pineapple on the European market fell from $10.5 \%$ in 2003 to 5.2\% in 2006". Over-politicisation of government interventions make SMEs averse to seeking government support. It may likely be because a beneficiary in the term of 
one government is affected by exclusion (loss of opportunities) at the turn of another government. Government would be more helpful to promote and provide resources to agriculture and trade associations. This will encourage exporting SMEs to join the associations and build their capacities.

At the moment many NTAE SMEs do not have branded products that give them a competitive edge. Public-private sector initiatives with research institutions could help Ghana to strengthen the intellectual property (IP) framework to develop branded products that are internationally acceptable. Such initiatives could also help to expand the development of technology and innovation opportunities that are available to, and, affordable for exporting SMEs, while the NTAE SMEs themselves should place more emphasis on research to advance their innovation capacity.

What combination of the firm resources and network relationships are positively linked to NTAE SME performance?

Chapter 5 and 6 focus on network relationships among NTAE SMEs. Most of the SMEs network through associations. The associations are responsible for coordinating activities and information flow. In a few instances, such as the Sea Freight Pineapple Exporters of Ghana (SPEG), export orders are contracted on behalf of members whose only requirement is to supply. The relationship is built on trust as members are expected to ensure quality requirements. Members are well known to each other in a dense network structure within the association (Bhagavatula, 2009). For this reason a member breaching (aspects of) export contracts is easily identified and sanctioned. Other opportunities, such as donor sponsored technical assistance exist. Networking through associations can provide leverage to members by significantly reducing costs associated with downstream activities. The entrepreneurial strategies, innovation capacity, export knowledge and human capital measured by education are useful to network with associations. Firm size to a large extent determines the scope and depth of interaction with the association.

Other networks include government export agencies that provide information and facilitate participation in fairs and conferences, as platforms, to create exposure and market opportunities. Some of NTAE SMEs are reserved about involvement with government export agencies because of perceived political affiliations that used to be tagged to it in the past. In addition, there are no strict regulations for participation which enabled one time (or non-) exporters to make use of the events without any vision on continuity in the export business. In recent times, network structural embeddedness (network complexity) as explained by frequent interaction with government export 
agencies is thought to yield a positive pay off as export market opportunities are readily available or made known. NTAE SMEs investing in upstream supply capacity and physical capital (ownership of premises) are more resourced, and, could leverage the opportunities that come with network complexity downstream for competitive advantage. NTAE SMEs that invest in "technical services such as internet, mobile phones and special postal delivery" (Abban et al., 2013, pp85) could equally compete. Network relational embeddedness among the actors in the NTAE SME upstream supply chain shows stronger ties as opposed to weaker ties downstream. This is considered to be advantageous in terms of opportunities derived from new information (Granovetter, 1983).

The links to government extension services is generally limited to typical agricultural products. Professional and technical services are however linked to capacity building and training. Most trainings programmes organized by the association are (in house) for members, but with government export agencies, training programmes are publicly advertised. The interaction with these institutions are helpful for human capital development and could in part explain export knowledge. Following the RBV theory on firm resources, and based on this study, it is more the export knowledge acquired that seems to impact the NTAE SMEs export performance. Amongst the identified social network actors, the business associations prove most useful.

These discussions lead to answering the central research question:

Within the theoretical context of the Resource Based View $(R B V)$, Supply Chain Management (SCM), and network theories, which characteristics (specifically internal capabilities, resources and network relationships) of NTAE SMEs and their business environment are positively related to their export performance?

The RBV helps to specify the resources available to the SMEs to include human capital, physical capital, and, intangible resources. These resources contribute to the resource base that the NTAE SMEs have (internal capabilities) to leverage on in their networks with different actors in their supply chains. The network actors vary for the upstream and downstream ends of the supply chain, and to a large extent by the nature or type of network relationships. While firm size, years in operation, and, years in export are relevant to support the network relationships in the supply chain, it is the resource base that determines their long-term sustainability. Chapter 4 shows that the upstream supply capacity and export knowledge are especially important to optimize supply chain and 
networks and thereby export performance. From Chapter 6, it is very relevant to improve the network actors of NTAE SMEs related to export mode and institutions (services and finance). However, NTAE SMEs social networks (through religious and tribal affiliation and school alumni) had a significant negative effect on export performance. This suggests that putting a lot of effort in these types of networks could be a sub-optimal investment of resources. However, investments in the NTAE SMEs export knowledge, e.g. of export market regulations, lead to better compliance with regulatory requirements. Good corporate governance, innovation and use of professional and technical support are found to positively impact export performance. These insights contribute to a more detailed discussion in the next section, on theoretical and methodological contributions.

\subsection{Theoretical and methodological contributions}

Although there are challenges to export growth and difficulties for individual NTAE SME growth, arguably some NTAE SMEs are exporting more successfully than others. In this thesis this is analysed, using the theoretical insights of the Resource Based View (RBV), Network theory and Supply Chain Management (SCM). However these theories which are very relevant to a firms' internationalization process, have not been previously combined to study the export of NTAE SMEs in Ghana, and, to determine any novel developments arising out of such a study. These two theories (Network and SCM) are relied upon because the RBV mainly looks at the internal firm capabilities and does not address the external network structure of the SMEs. The theories are used in a combined framework to show the RBV focus on the firms' internal capabilities whereas the Network theory and SCM do not consider the internal capabilities of the firm. This is also similarly addressed by other authors such as Kwamega et al., 2018; Wanjiru \& Makori, 2016; Sarkis et al., 2011; Miles \& Snow, 2007. These studies however variously combined the RBV and networks with SCM, transaction cost economics, principal agent theory, property rights theory among others and in different and broader context of exporting SMEs. In this study, Network and SCM theories are combined with the RBV theory focusing on NTAE SMEs to build more theoretical insights related to the Ghanaian context.

The contextual factors of NTAE SMEs in developing countries, their internal capabilities, the logistic/chain and network characteristics, and the impact of (lack of) government support are often not addressed in the literature. This study discusses how these factors deriving from RBV on the one hand and network and SCM on the other, contribute to filling this gap. 
This thesis first introduces the general business environment of the NTAE sector within the context of Comprehensive Africa Agriculture Development Programme (CAADP) policy frameworks (for agriculture and agribusiness) of AU countries and a case study on the shea sector in the Chapters 2 and 3 . The case study describes the network arrangements in the upstream and downstream chain processes. For the upstream processes, forming trust and bonding ties are key to the network relationships. In the downstream processes bridging ties are useful to establish links and capitalize on opportunities with other networks. The findings support the literature on network trust, bridging and bonding ties (Granovetter, 1973; Kawachi et al., 1997; Lyon, 2000; Long, 2001). It also provides theoretical insights on networks in the shea subsector. There was a limitation by the company on how to strengthen the resource base in the absence of institutional support. Based on the RBV, a further study was conducted to better understand the internal capabilities of NTAE SMEs, and, the relationships with export performance which are provided in Chapter 4. The resources and internal capabilities of the firm described as tangible and intangible explain the extent they may be an aggregation of valuable, rare, inimitable and non-substitutable (VRIN) resources (Wernerfelt, 1984; Peteraf, 1993; Lin $\& \mathrm{Wu}, 2014)$. Further, productivity is enhanced by the availability of resources and capabilities and the way these are mobilized (Barney, 1991). The study makes use of a quantitative approach applying PLS SEM analysis. The results are robust and contribute to the literature on developing economies and which factors are likely to support internationalization of NTAE SMEs. Particularly, the findings show that upstream supply capacity and export knowledge are the key drivers of the NTAE SMEs internal capabilities. Chapter 5 uses network theory to discuss form and type of networks found in both the upstream and downstream parts of the agri supply chains. The form of networks found by the study are discussed to include structural: dense or sparse, complex or simple, and, relational: weak or strong, bridging or bonding (Granovetter, 1973, 1983; Gulatti, 1998; Long, 2001; Newman \& Newman, 2005). The case study approach provides more detailed insights in the nature of the networks in NTAE agri supply chains. Recent studies on SMEs in Ghana (Easmon et al., 2019; Abbey et al., 2016) discuss social capital in general and not specific to exporting NTAEs. The study shows that at different stages/phases of the agri supply chain the networks differ in form and type. For example, upstream network relations show dense networks, strong ties, and, trusted relationships; while downstream network relations are generally sparse and weak. Chapter 6 applies PLS SEM analysis and discusses the agri supply chain of NTAE SMEs in terms of resources and actors. Based on the RBV theory, the resources found to be most relevant to 
the NTAE SMEs varies when the downstream actors of the agri supply chain are included in the analysis, compared to the study on internal capabilities. The PLS SEM analysis makes an important contribution by providing more analytical precision in results and interpretation. Export knowledge is consistently identified as key resource driver of NTAE SMEs. The study contributes to the literature by applying the RBV, network, and, SCM theories. The product development, corporate governance, and institutional service (professional and technical support) are the resources identified. A key contribution of the study is that it shows how the dynamics of the resource, network and SCM interaction varies for the NTAE SME (in/external) environment and internationalisation process.

\subsection{Policy and managerial implications}

Within the AU context and SSA economies, the overarching policy implication is the importance of government commitment to agriculture and agribusiness targets. This has still not been achieved in terms of Comprehensive Africa Agriculture Development Programme (CAADP) implementation. It is envisaged that achieving this would create a positive enabling environment for the NTAE sector. Furthermore, developing sub-sector policies for NTAE will ensure that the peculiarities to each sector are addressed since prime issues vary per sector. The most direct investment options for governments include, roads, transportation, and, storage infrastructure. Also the creation/availability of credit facilities would immensely improve NTAE SME operations. This is especially so if risk is guaranteed (collateralized by government), and, interest rates have a fixed ceiling. More often than not, micro credit programmes and funds run directly by government have been perceived as too political and not sustainable.

To address challenges in the agri supply chain, the Ghanaian government could also consider providing export hubs in the forest and savannah zones, with the same facilities as those found in the coastal zone. This will ensure equitable spread of opportunities to NTAE SMEs. An alternative could be extending services through e-information, etraining and capacity building at reduced costs.

Working together with and through associations, government may encourage NTAE subsector drivers empowered to act as change agents through advocacy, collation of priority areas for intervention, advisory services for policy interventions, and, sub sector reports. Equipped and resourced regulatory agencies to enforce sub sector policies, certifications, and quality standards will help to improve acceptance of export products on the international markets. More importantly, extension services to agriculture would have to be improved in order to make the agri supply chains more effective. It was found in the 
study that the education level played a role for successful entrepreneurs. Capacity building and skills development programmes run by government export agencies (working with associations) should therefore investigate and fill up the training gaps of exporting NTAE SMEs.

For the NTAE SMEs themselves, there is a need to consider improving downstream supply capacity and networks with the help of associations and (multinational) companies. Cooperating within downstream networks could reduce the actual cost of downstream supply activities, and, spread any costs of risks, such as insurance for NTAEs. Coordination of downstream networks of NTAE SMEs will greatly help them align their resources strategically to exploit opportunities and improve export performance.

Entrepreneurial strategies could include not only intended expansion, but also bridging ties with other "sparse" networks which provide more opportunities. Enhancing innovation capacity by adaptations from new or novel information obtained through internet searches (websites of foreign buyers, retailers, chambers of commerce etc.) is an option to NTAE SMEs. This view is supported by Hinson (2011) who discusses the RBV in the context of NTE firms, and the competitive advantage derived from acquiring and managing information. In the views of the NTAE SMEs, the advantage of "technical services such as internet, mobile phones and special post especially delivery" (Abban et al., 2013, pp85) facilitated interaction with associations as well as other networks.

\subsection{Limitations and further research}

In general it can be said that, although it is a strong point of the thesis that it focuses on the views of NTAE CEOs working hard for the best performance of their export companies, the fact that opinions and impressions of CEOs are taken as an important source of information is also a limitation of the present study. For example, the studies presented in the chapters 4 and 6 measure (subjective) perceived export performance but not (objective) actual export performance. Although objective export performance data was asked, most respondents did not provide this information. The business owners who think that they perform well regarding their export knowledge and upstream supply capacity may also be more confident to say that they do better than other companies in terms of export. However, this does not necessarily mean that they do better than other companies in reality. Although subjective measures are widely used in the literature on export performance in developing countries, further research could use "triangulation" with other factors to indicate that what the owners say is true. For instance, experts may be asked to rank (part of) the companies in terms of export performance. If this correlates well 
support is provided for the idea that "subjective" export performance is indeed related to "objective" export performance.

Chapter 3 presents a case study on an NTAE SME in the shea sector. This is to highlight peculiarities of a sub sector and to support further empirical research. Although findings are not generalizable, they provide useful results to base our further research. In Chapter 5, the case study is based on a sample of ten SMEs in the NTAE sector in Ghana, and, makes use of data triangulation for reliability and validation of responses. The findings could not be generalized to all SMEs in the NTAE sector, but provides additional insights on networks in particular and which networks are likely to feature in different stages of the agri supply chain. Empirical analyses and a larger sample as presented in the Chapter 4 and 6 , further improves the generalizability of findings.

The results in the Chapter 4 and 6 are based on PLS SEM analysis. The study uses crosssectional data which might raise problems related to causality. Possible reverse effects of export performance influencing the independent variables can never be ruled out. Having a higher export performance, for example, motivates firms to channel more resources into the stability of their chain activities and into developing export knowledge. For this reason, the study models are tested for endogeneity and causality. The ' $T$ ' tests results (Appendices 1 and 2, pp126-133) suggests a general lack of significance for excluded control variables. Since there is significance for some of the independent variables, it is suggested that other analytical approaches may provide some interesting findings. It is however considered that the problems are limited because most of the NTAE SMEs are mature firms that do not change so much in their resources and strategic orientation. Also (unfortunately) the role of government has stayed same over the past few years. Costs limited the possibilities for conducting a longitudinal study that would help in providing more certainty about endogeneity and the direction of the relationships.

The study sample is categorised (non-processed, semi-processed and processed) as opposed to classified (horticultural products, oil seeds and nuts, dairy products etc.) making recommendations generic to the NTAE sector as a whole and not specific to subsectors. The reason that sub-sector peculiarities are not included is because of the absence of standardised sub-sector classifications. So, while the results are representative of the NTAE SME sector as a whole, it would be helpful for future studies to go more in-depth into the different sub-sectors. Also $83 \%$ of the sample cases were based in the coastal zone, 
which was a good representation of the number of exporting SMEs in the coastal versus the forest and savannah zones, but may have provided bias towards the NTAE SMEs inland.

Future research could use a longitudinal approach to support our cross-sectional data. This study could also capture a larger sample of non-traditional agricultural exporting SMEs in the forest and savannah zones and include different sub-sectors. 


\section{Appendices}

Appendix 1 T tests results (based on Chapter 4 statistical model) 126

Appendix 2 T tests results (based on Chapter 6 statistical model) 130

Appendix 3 Ramsey RESET Results (based on Table 4.3 statistical model) 134

Appendix 4 Ramsey RESET Results (based on Table 6.6 statistical model) 136

$\begin{array}{lll}\text { Appendix } 5 & \text { Trends of NTAE sub sectors 2007-2016 } & 137\end{array}$

$\begin{array}{lll}\text { Appendix } 6 & \text { SME Survey Questionnaire } & 138\end{array}$

$\begin{array}{lll}\text { Appendix } 7 & \text { Analysis on Export Performance } & 157\end{array}$

Appendix $8 \quad$ Descriptives of answers on questions Q71c and Q71d 161

Appendix 9 Recent Developments in Ghana's Shea Sector 163 


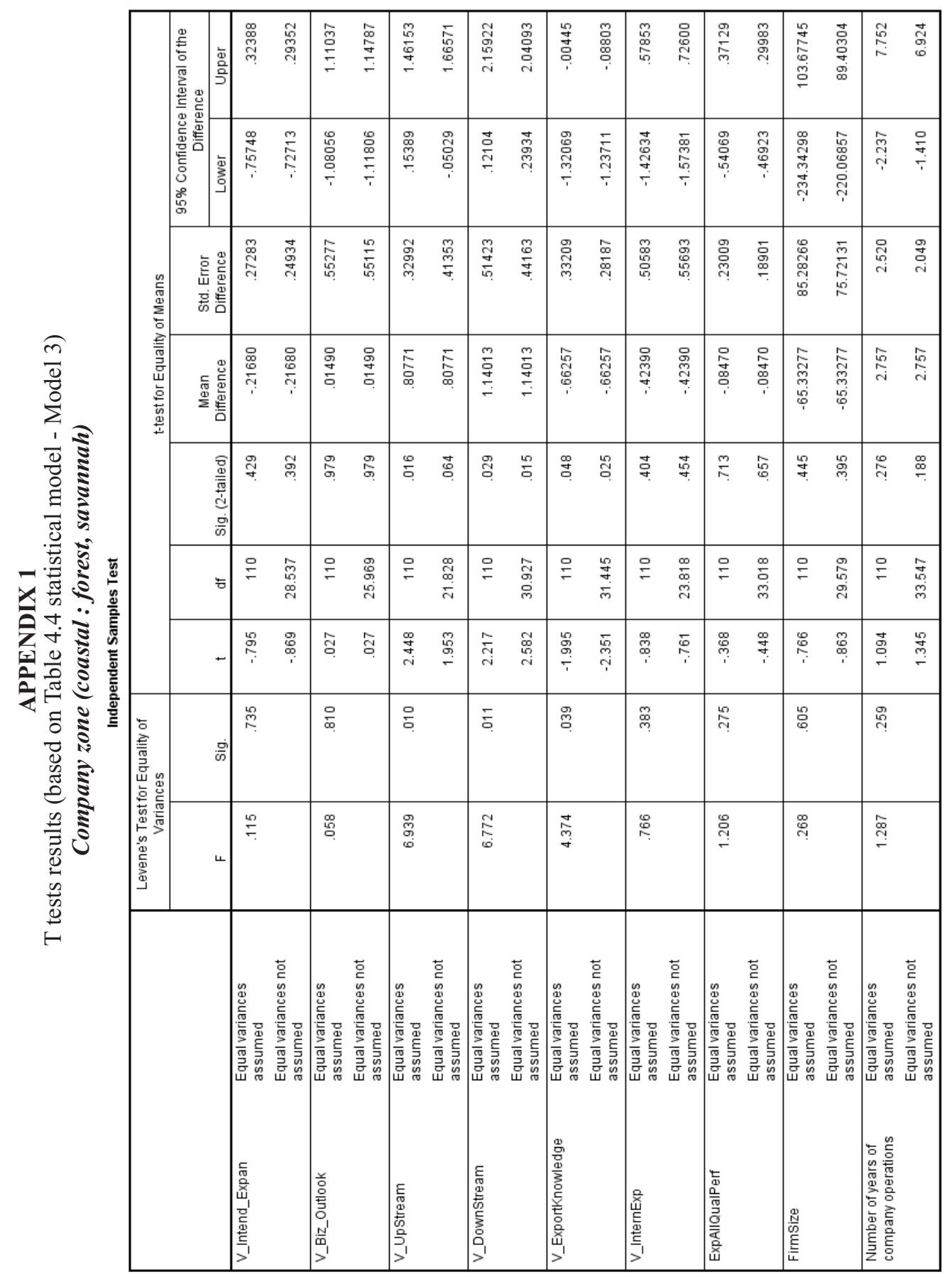




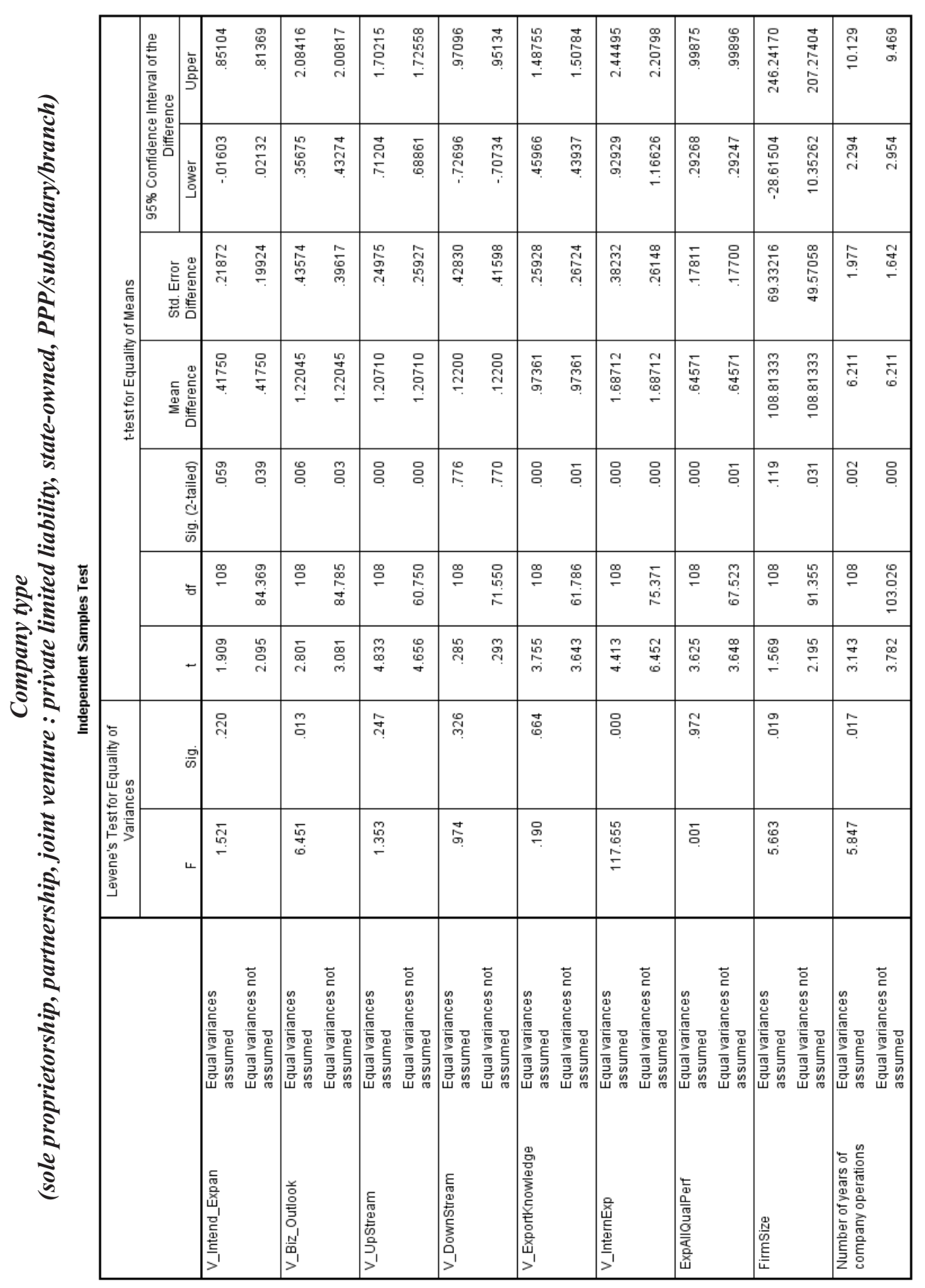




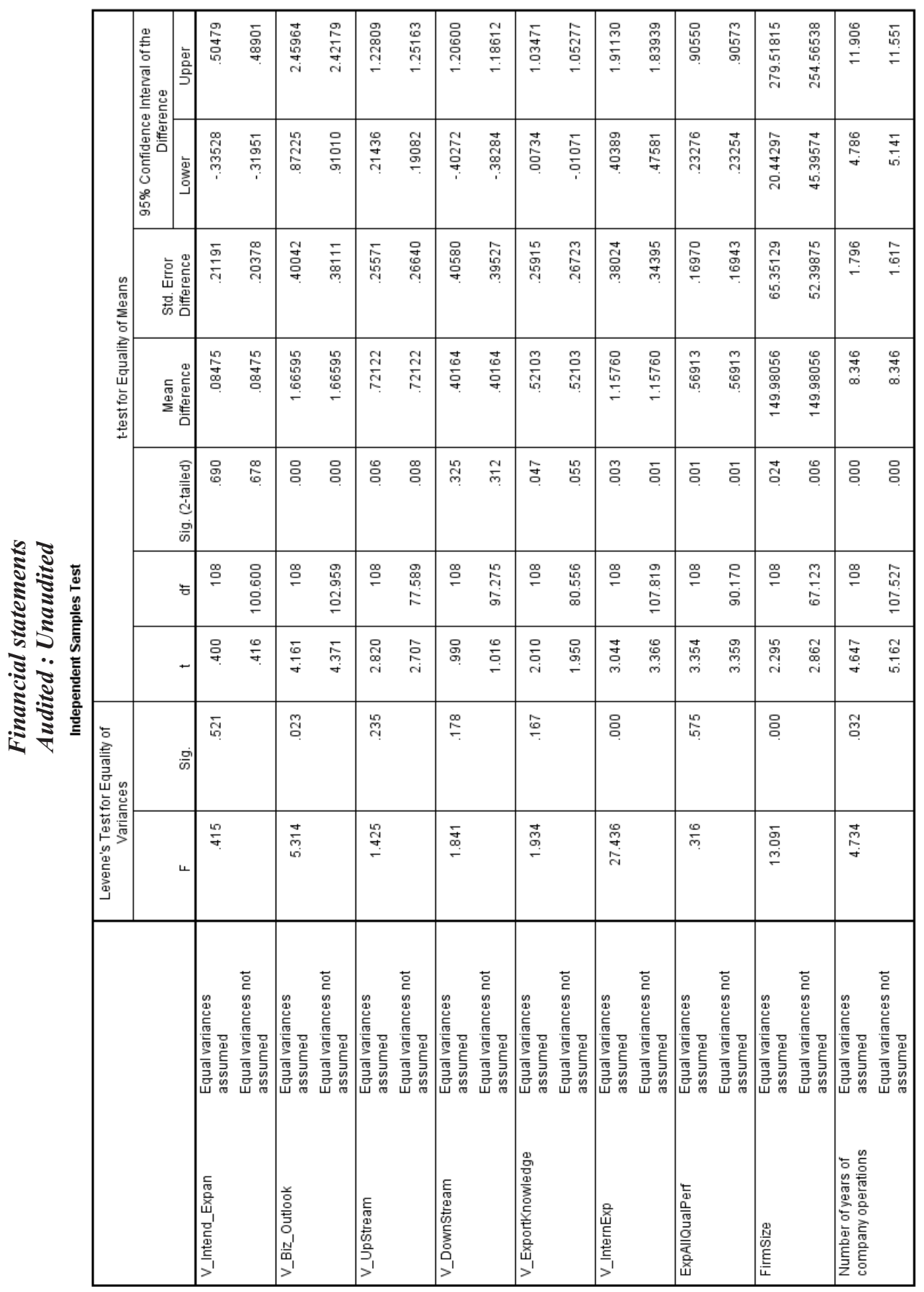




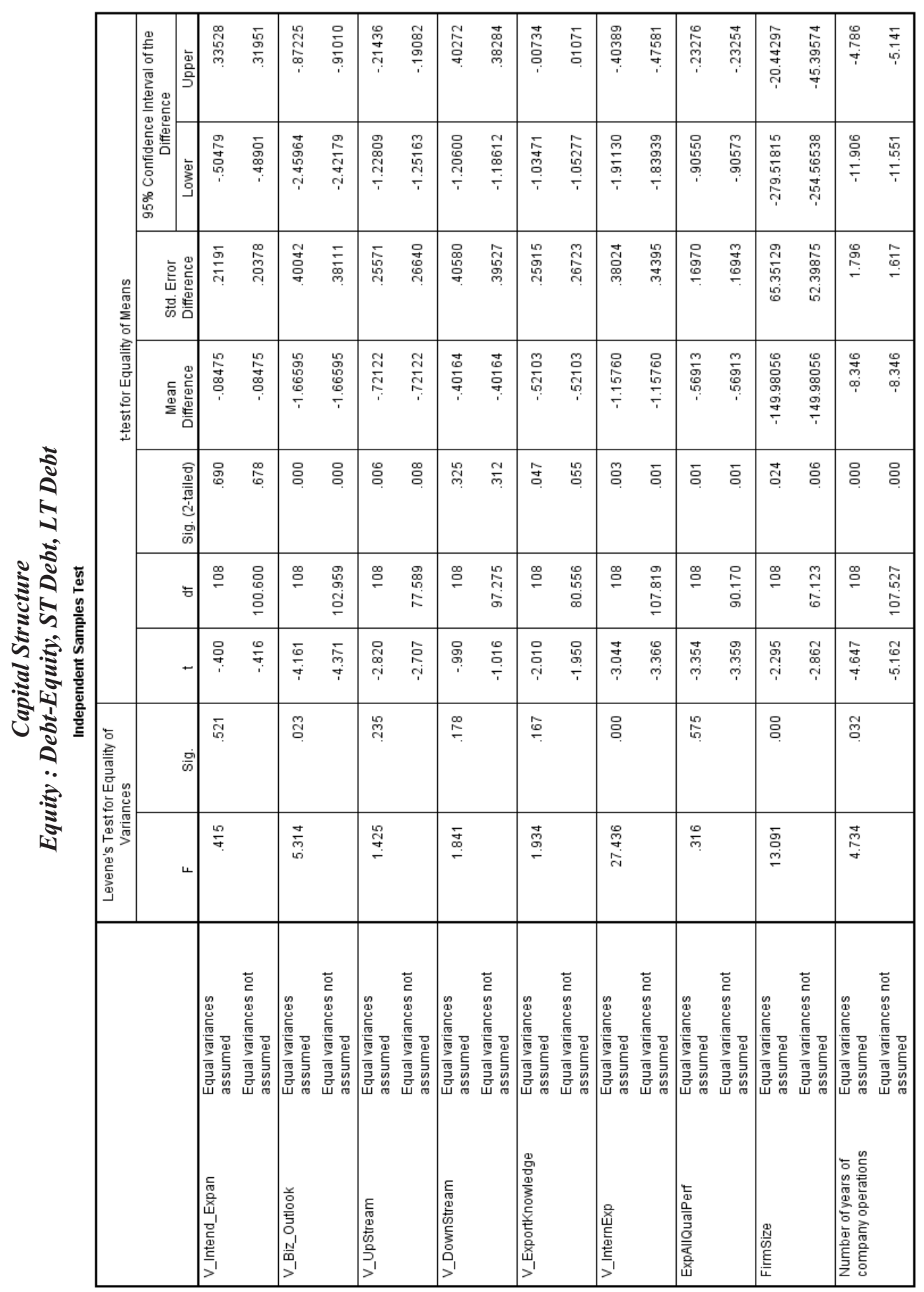


APPENDIX 2

T tests results (based on Table 6.5 statistical model)

Company zone

(coastal : forest, savannah)

\begin{tabular}{|c|c|c|c|c|c|c|c|c|c|c|}
\hline & & & Inde! & dent San & es Test & & & & & \\
\hline & & $\begin{array}{r}\text { Levene's Test } \\
\text { Varia }\end{array}$ & quality of & & & & t-test for Equality & $f$ Means & & \\
\hline & & & & & & & & Std. Error & $\begin{array}{r}95 \% \text { Confidenc } \\
\text { Differ }\end{array}$ & iterval of the \\
\hline & & $\mathrm{F}$ & Sig. & $\mathrm{t}$ & df & Sig. (2-tailed) & Difference & Difference & Lower & Upper \\
\hline W_Inter_exp & $\begin{array}{l}\text { Equal variances } \\
\text { assumed }\end{array}$ & 1.161 & .288 & .008 & 41 & .994 & .00975 & 1.20874 & -2.43134 & 2.45085 \\
\hline & $\begin{array}{l}\text { Equal variances not } \\
\text { assumed }\end{array}$ & & & .014 & 3.261 & .990 & .00975 & .69564 & -2.10709 & 2.12659 \\
\hline W_mgt_export_const & $\begin{array}{l}\text { Equal variances } \\
\text { assumed }\end{array}$ & 1.346 & .253 & .022 & 41 & .983 & .01452 & .67320 & -1.34502 & 1.37407 \\
\hline & $\begin{array}{l}\text { Equal variances not } \\
\text { assumed }\end{array}$ & & & .038 & 3.284 & .972 & .01452 & .38507 & -1.15317 & 1.18222 \\
\hline W_intend_expan & $\begin{array}{l}\text { Equal variances } \\
\text { assumed }\end{array}$ & 1.980 & .167 & -1.523 & 41 & .136 & -.89429 & .58729 & -2.08035 & .29177 \\
\hline & $\begin{array}{l}\text { Equal variances not } \\
\text { assumed }\end{array}$ & & & -.967 & 2.107 & .431 & -.89429 & .92461 & -4.68437 & 2.89579 \\
\hline W_biz_outiook & $\begin{array}{l}\text { Equal variances } \\
\text { assumed }\end{array}$ & .024 & .877 & -2.271 & 41 & .028 & -2.34924 & 1.03462 & -4.43871 & -.25978 \\
\hline & $\begin{array}{l}\text { Equal variances not } \\
\text { assumed }\end{array}$ & & & -2.541 & 2.405 & .105 & -2.34924 & .92457 & -5.74934 & 1.05085 \\
\hline W_buildingcontact_soc & $\begin{array}{l}\text { Equal variances } \\
\text { assumed }\end{array}$ & 4.205 & .047 & 1.143 & 41 & .260 & .62188 & .54424 & .47724 & 1.72099 \\
\hline & $\begin{array}{l}\text { Equal variances not } \\
\text { assumed }\end{array}$ & & & 3.754 & 26.384 & .001 & .62188 & .16565 & .28161 & .96214 \\
\hline W_corp_gover & $\begin{array}{l}\text { Equal variances } \\
\text { assumed }\end{array}$ & 1.277 & .265 & -1.586 & 41 & .120 & -1.53733 & .96912 & -3.49450 & .41984 \\
\hline & $\begin{array}{l}\text { Equal variances not } \\
\text { assumed }\end{array}$ & & & -2.394 & 2.855 & .101 & -1.53733 & .64211 & -3.64077 & .56612 \\
\hline W_equip_operat & $\begin{array}{l}\text { Equal variances } \\
\text { assumed }\end{array}$ & .008 & .931 & -1.041 & 41 & .304 & -1.17408 & 1.12741 & -3.45092 & 1.10277 \\
\hline & $\begin{array}{l}\text { Equal variances not } \\
\text { assumed }\end{array}$ & & & -1.025 & 2.299 & .401 & -1.17408 & 1.14515 & -5.53471 & 3.18656 \\
\hline W_prodt_devpmt & $\begin{array}{l}\text { Equal variances } \\
\text { assumed }\end{array}$ & .296 & .589 & -1.279 & 41 & .208 & -1.36599 & 1.06833 & -3.52353 & .79155 \\
\hline & $\begin{array}{l}\text { Equal variances not } \\
\text { assumed }\end{array}$ & & & .992 & 2.172 & .418 & -1.36599 & 1.37651 & -6.86079 & 4.12881 \\
\hline W_form_chan & $\begin{array}{l}\text { Equal variances } \\
\text { assumed }\end{array}$ & 4.009 & .052 & -1.408 & 41 & .167 & -.81995 & .58246 & -1.99625 & .35635 \\
\hline & $\begin{array}{l}\text { Equal variances not } \\
\text { assumed }\end{array}$ & & & -.800 & 2.082 & .505 & -.81995 & 1.02525 & -5.06887 & 3.42897 \\
\hline W_extservice & $\begin{array}{l}\text { Equal variances } \\
\text { assumed }\end{array}$ & 1.117 & .297 &. .552 & 41 & .584 &. .53623 & .97067 & -2.49655 & 1.42408 \\
\hline & $\begin{array}{l}\text { Equal variances not } \\
\text { assumed }\end{array}$ & & & -.382 & 2.131 & .737 & -.53623 & 1.40495 & -6.23839 & 5.16592 \\
\hline W_profservice & $\begin{array}{l}\text { Equal variances } \\
\text { assumed }\end{array}$ & .158 & .693 &. .979 & 41 & .333 & -1.37353 & 1.40349 & -4.20793 & 1.46087 \\
\hline & $\begin{array}{l}\text { Equal variances not } \\
\text { assumed }\end{array}$ & & & .705 & 2.145 & .550 & -1.37353 & 1.94880 & -9.23945 & 6.49239 \\
\hline W_access_fin & $\begin{array}{l}\text { Equal variances } \\
\text { assumed }\end{array}$ & .128 & .722 & -.688 & 41 & .495 & .48540 & .70546 & -1.91011 & .93930 \\
\hline & $\begin{array}{l}\text { Equal variances not } \\
\text { assumed }\end{array}$ & & & -.876 & 2.553 & .456 &. .48540 & .55439 & -2.43781 & 1.46700 \\
\hline ExpAllQualPerf & $\begin{array}{l}\text { Equal variances } \\
\text { assumed }\end{array}$ & 3.691 & .062 & -2.457 & 41 & .018 & -1.11111 & .45230 & -2.02455 & -.19767 \\
\hline & $\begin{array}{l}\text { Equal variances not } \\
\text { assumed }\end{array}$ & & & -6.724 & 9.097 & .000 & -1.11111 & .16524 & -1.48429 & -73793 \\
\hline Firmsize & $\begin{array}{l}\text { Equal variances } \\
\text { assumed }\end{array}$ & .305 & .584 & -.484 & 41 & .631 & -108.80833 & 224.80307 & -562.80734 & 345.19067 \\
\hline & $\begin{array}{l}\text { Equal variances not } \\
\text { assumed }\end{array}$ & & & -.571 & 2.460 & .616 & -108.80833 & 190.49476 & -797.67140 & 580.05473 \\
\hline $\begin{array}{l}\text { Number of years of } \\
\text { company operations }\end{array}$ & $\begin{array}{l}\text { Equal variances } \\
\text { assumed }\end{array}$ & .002 & .968 & -1.195 & 41 & .239 & -4.283 & 3.585 & -11.523 & 2.957 \\
\hline & $\begin{array}{l}\text { Equal variances not } \\
\text { assumed }\end{array}$ & & & -1.082 & 2.247 & .381 & -4.283 & 3.958 & -19.641 & 11.074 \\
\hline Number of years in export & $\begin{array}{l}\text { Equal variances } \\
\text { assumed }\end{array}$ & .081 & .778 & -1.429 & 41 & .161 & -5.167 & 3.617 & -12.471 & 2.137 \\
\hline & $\begin{array}{l}\text { Equal variances not } \\
\text { assumed }\end{array}$ & & & -1.333 & 2.264 & .301 & -5.167 & 3.875 & -20.107 & 9.773 \\
\hline
\end{tabular}




\section{Company type}

(sole proprietorship, partnership, joint venture : private limited liability, state-owned, PPP/subsidiary/branch)

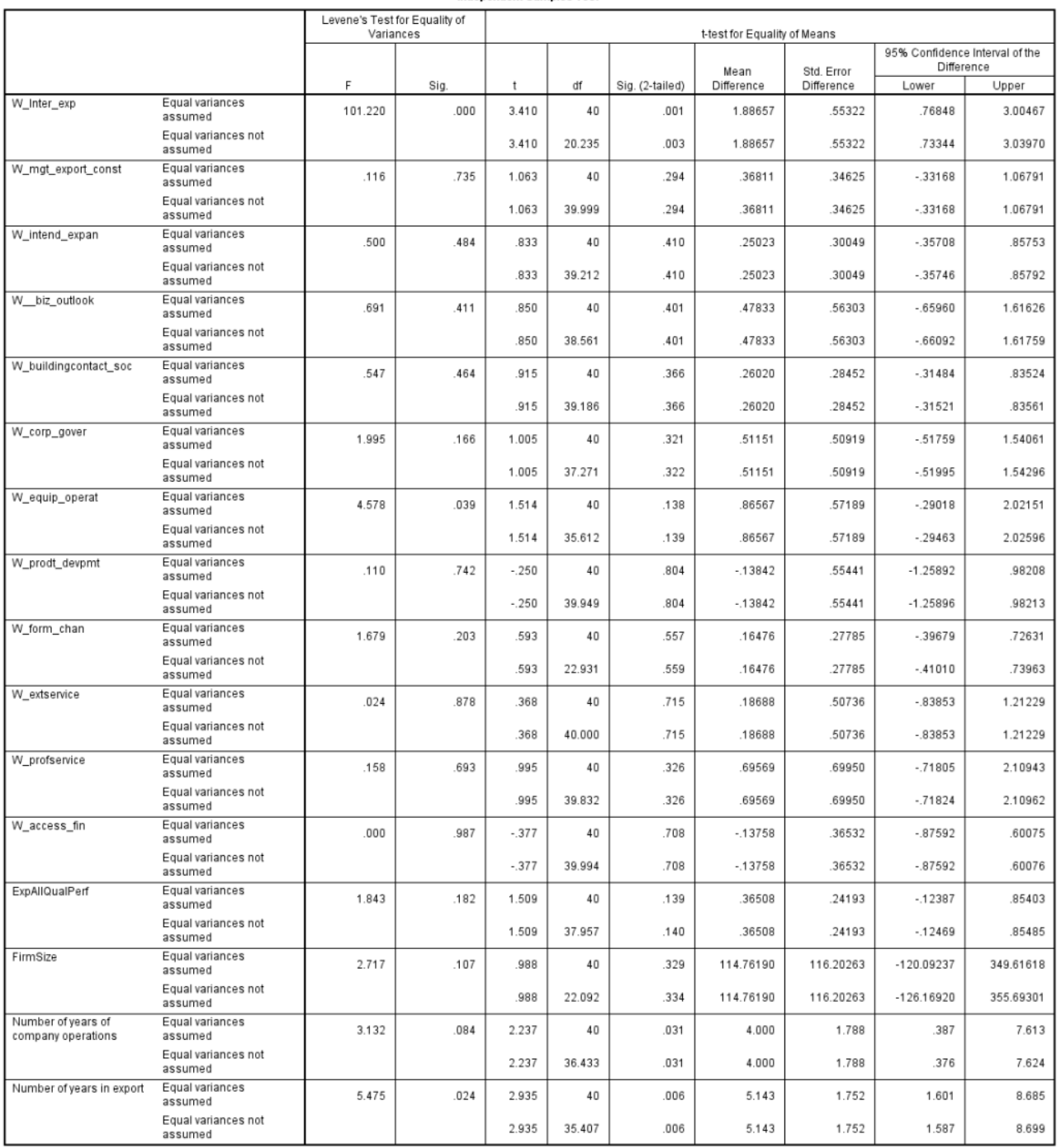


Financial statements

Audited : Unaudited

\begin{tabular}{|c|c|c|c|c|c|c|c|c|c|c|}
\hline \multicolumn{11}{|c|}{ Independent Samples Test } \\
\hline & & \multicolumn{2}{|c|}{$\begin{array}{l}\text { Levene's Test for Equality of } \\
\text { Variances }\end{array}$} & \multicolumn{7}{|c|}{ t-test for Equality of Means } \\
\hline & & \multirow[b]{2}{*}{$\mathrm{F}$} & \multirow[b]{2}{*}{ Sig. } & \multirow[b]{2}{*}{$t$} & \multirow[b]{2}{*}{ df } & \multirow[b]{2}{*}{ Sig. (2-tailed) } & \multirow{2}{*}{$\begin{array}{c}\text { Mean } \\
\text { Difference }\end{array}$} & \multirow{2}{*}{$\begin{array}{l}\text { Std. Error } \\
\text { Difference }\end{array}$} & \multicolumn{2}{|c|}{$\begin{array}{c}95 \% \text { Confidence Interval of the } \\
\text { Difference }\end{array}$} \\
\hline & & & & & & & & & Lower & Upper \\
\hline \multirow[t]{2}{*}{ W_Inter_exp } & $\begin{array}{l}\text { Equal variances } \\
\text { assumed }\end{array}$ & \multirow[t]{2}{*}{7.207} & \multirow[t]{2}{*}{.010} & \multirow{2}{*}{$\begin{array}{l}1.441 \\
1.404\end{array}$} & \multirow{2}{*}{$\begin{array}{r}41 \\
32.870\end{array}$} & \multirow[t]{2}{*}{.157} & \multirow{2}{*}{$\begin{array}{l}.86805 \\
.86805\end{array}$} & \multirow{2}{*}{$\begin{array}{l}.60230 \\
.61818\end{array}$} & \multirow{2}{*}{$\begin{array}{r}-34832 \\
-38983\end{array}$} & \multirow{2}{*}{$\begin{array}{l}2.08442 \\
2.12593\end{array}$} \\
\hline & $\begin{array}{l}\text { Equal variances not } \\
\text { assumed }\end{array}$ & & & & & & & & & \\
\hline \multirow[t]{2}{*}{ W_mgt_export_const } & $\begin{array}{l}\text { Equal variances } \\
\text { assumed }\end{array}$ & \multirow[t]{2}{*}{1.324} & \multirow[t]{2}{*}{.257} & \multirow{2}{*}{$\begin{array}{l}1.707 \\
1.696\end{array}$} & \multirow{2}{*}{$\begin{array}{r}41 \\
38.871\end{array}$} & .095 & .56712 & .33224 & -.10385 & 1.23809 \\
\hline & $\begin{array}{l}\text { Equal variances not } \\
\text { assumed }\end{array}$ & & & & & .098 & .56712 & .33442 & -.10937 & 1.24361 \\
\hline W_intend_expan & $\begin{array}{l}\text { Equal variances } \\
\text { assumed }\end{array}$ & .125 & .725 & 1.342 & 41 & .187 & .40489 & .30177 & -.20455 & 1.01433 \\
\hline & $\begin{array}{l}\text { Equal variances not } \\
\text { assumed }\end{array}$ & & & 1.344 & 40.413 & .186 & .40489 & .30128 & -20383 & 1.01361 \\
\hline W_biz_outiook & $\begin{array}{l}\text { Equal variances } \\
\text { assumed }\end{array}$ & 2.557 & .117 & 1.819 & 41 & .076 & .98129 & .53933 & -10791 & 2.07048 \\
\hline & $\begin{array}{l}\text { Equal variances not } \\
\text { assumed }\end{array}$ & & & 1.765 & 31.319 & .087 & .98129 & .55601 & -.15224 & 2.11482 \\
\hline W_buildingcontact_soc & $\begin{array}{l}\text { Equal variances } \\
\text { assumed }\end{array}$ & .473 & .496 & .501 & 41 & .619 & .14096 & .28150 &. .42755 & .70947 \\
\hline & $\begin{array}{l}\text { Equal variances not } \\
\text { assumed }\end{array}$ & & & .495 & 37.686 & .623 & .14096 & .28465 & .43543 & .71736 \\
\hline W_corp_gover & $\begin{array}{l}\text { Equal variances } \\
\text { assumed }\end{array}$ & .439 & .512 & 2.759 & 41 & .009 & 1.29192 & .46833 & .34611 & 2.23773 \\
\hline & $\begin{array}{l}\text { Equal variances not } \\
\text { assumed }\end{array}$ & & & 2.803 & 40.716 & .008 & 1.29192 & .46090 & .36092 & 2.22292 \\
\hline W_equip_operat & $\begin{array}{l}\text { Equal variances } \\
\text { assumed }\end{array}$ & 4.935 & .032 & 2.474 & 41 & .018 & 1.34648 & .54418 & .24750 & 2.44547 \\
\hline & $\begin{array}{l}\text { Equal variances not } \\
\text { assumed }\end{array}$ & & & 2.549 & 37.899 & .015 & 1.34648 & .52817 & .27716 & 2.41581 \\
\hline W_prodt_devpmt & $\begin{array}{l}\text { Equal variances } \\
\text { assumed }\end{array}$ & 4.979 & .031 & 2.340 & 41 & .024 & 1.22294 & .52262 & .16748 & 2.27839 \\
\hline & $\begin{array}{l}\text { Equal variances not } \\
\text { assumed }\end{array}$ & & & 2.291 & 34.527 & .028 & 1.22294 & .53381 & .13871 & 2.30717 \\
\hline W_form_chan & $\begin{array}{l}\text { Equal variances } \\
\text { assumed }\end{array}$ & 10.936 & .002 & -1.596 & 41 & 118 & .47161 & .29556 & -1.06850 & .12528 \\
\hline & $\begin{array}{l}\text { Equal variances not } \\
\text { assumed }\end{array}$ & & & -1.714 & 22.000 & .101 & -.47161 & .27517 & -1.04228 & .09906 \\
\hline W_extservice & $\begin{array}{l}\text { Equal variances } \\
\text { assumed }\end{array}$ & .435 & .513 & 1.351 & 41 & .184 & .65757 & .48690 & -.32575 & 1.64090 \\
\hline & $\begin{array}{l}\text { Equal variances not } \\
\text { assumed }\end{array}$ & & & 1.346 & 39.526 & .186 & .65757 & .48865 & .33039 & 1.64554 \\
\hline W_profservice & $\begin{array}{l}\text { Equal variances } \\
\text { assumed }\end{array}$ & .819 & .371 & .086 & 41 & .932 & .06223 & .72510 & -1.40213 & 1.52659 \\
\hline & $\begin{array}{l}\text { Equal variances not } \\
\text { assumed }\end{array}$ & & & .087 & 40.985 & .931 & .06223 & .71873 & -1.38930 & 1.51375 \\
\hline W_access_fin & $\begin{array}{l}\text { Equal variances } \\
\text { assumed }\end{array}$ & 6.895 & .012 & .917 & 41 & .364 & -.32903 & .35873 & -1.05349 & .39544 \\
\hline & $\begin{array}{l}\text { Equal variances not } \\
\text { assumed }\end{array}$ & & & .878 & 26.941 & .388 & -.32903 & .37460 & -1.09772 & .43967 \\
\hline ExpAllQualPerf & $\begin{array}{l}\text { Equal variances } \\
\text { assumed }\end{array}$ & .896 & .349 & 3.880 & 41 & .000 & .82101 & .21162 & .39364 & 1.24839 \\
\hline & $\begin{array}{l}\text { Equal variances not } \\
\text { assumed }\end{array}$ & & & 3.809 & 35.460 & .001 & .82101 & .21554 & .38364 & 1.25839 \\
\hline FirmSize & $\begin{array}{l}\text { Equal variances } \\
\text { assumed }\end{array}$ & 6.753 & .013 & 1.427 & 41 & .161 & 160.37826 & 112.38949 & -66.59692 & 387.35344 \\
\hline & $\begin{array}{l}\text { Equal variances not } \\
\text { assumed }\end{array}$ & & & 1.329 & 19.091 & .200 & 160.37826 & 120.69756 & -92.16311 & 412.91964 \\
\hline $\begin{array}{l}\text { Number of years of } \\
\text { company operations }\end{array}$ & $\begin{array}{l}\text { Equal variances } \\
\text { assumed }\end{array}$ & .398 & .531 & 2.794 & 41 & .008 & 4.770 & 1.707 & 1.322 & 8.217 \\
\hline & $\begin{array}{l}\text { Equal variances not } \\
\text { assumed }\end{array}$ & & & 2.780 & 39.257 & .008 & 4.770 & 1.716 & 1.300 & 8.239 \\
\hline Number of years in export & $\begin{array}{l}\text { Equal variances } \\
\text { assumed }\end{array}$ & 3.043 & .089 & 3.471 & 41 & .001 & 5.776 & 1.664 & 2.416 & 9.136 \\
\hline & $\begin{array}{l}\text { Equal variances not } \\
\text { assumed }\end{array}$ & & & 3.418 & 36.407 & .002 & 5.776 & 1.690 & 2.351 & 9.202 \\
\hline
\end{tabular}




\section{Capital Structure}

Equity : Debt-Equity, ST Debt, LT Debt

\begin{tabular}{|c|c|c|c|c|c|c|c|c|c|c|}
\hline & & & Inde! & ndent Sar & les Test & & & & & \\
\hline & & $\begin{array}{r}\text { Levene's Test } \\
\text { Varia }\end{array}$ & Equality of & & & & t-test for Equalit & $f$ Means & & \\
\hline & & & & & & & & & $\begin{array}{r}95 \% \text { Confidenc } \\
\text { Differ }\end{array}$ & $\begin{array}{l}\text { terval of the } \\
\text { e }\end{array}$ \\
\hline & & $\mathrm{F}$ & Sig. & $t$ & df & Sig. (2-tailed) & Difference & Difference & Lower & Upper \\
\hline W_Inter_exp & $\begin{array}{l}\text { Equal variances } \\
\text { assumed }\end{array}$ & 3.927 & .054 &. .787 & 40 & .436 & -.46309 & .58878 & -1.65306 & .72688 \\
\hline & $\begin{array}{l}\text { Equal variances not } \\
\text { assumed }\end{array}$ & & & -.894 & 39.768 & .377 & -46309 & .51823 & -1.51066 & .58448 \\
\hline W_mgt_export_const & $\begin{array}{l}\text { Equal variances } \\
\text { assumed }\end{array}$ & .595 & .445 &. .551 & 40 & .585 & -.18945 & .34377 & .88422 & .50533 \\
\hline & $\begin{array}{l}\text { Equal variances not } \\
\text { assumed }\end{array}$ & & & .526 & 27.355 & .603 & -.18945 & .35998 & .92762 & .54873 \\
\hline W_intend_expan & $\begin{array}{l}\text { Equal variances } \\
\text { assumed }\end{array}$ & .004 & .950 & 1.680 & 40 & .101 & .52552 & .31286 & -.10680 & 1.15784 \\
\hline & $\begin{array}{l}\text { Equal variances not } \\
\text { assumed }\end{array}$ & & & 1.707 & 33.567 & .097 & .52552 & .30779 & -.10028 & 1.15132 \\
\hline W_biz_outlook & $\begin{array}{l}\text { Equal variances } \\
\text { assumed }\end{array}$ & 8.652 & .005 & 1.991 & 40 & .053 & 1.03679 & .52085 & -.01588 & 2.08946 \\
\hline & $\begin{array}{l}\text { Equal variances not } \\
\text { assumed }\end{array}$ & & & 1.719 & 19.770 & .101 & 1.03679 & .60312 & -.22224 & 2.29583 \\
\hline W_buildingcontact_soc & $\begin{array}{l}\text { Equal variances } \\
\text { assumed }\end{array}$ & 2.220 & .144 & 1.081 & 40 & .286 & .31534 & .29176 & -.27433 & .90502 \\
\hline & $\begin{array}{l}\text { Equal variances not } \\
\text { assumed }\end{array}$ & & & .990 & 23.791 & .332 & .31534 & .31852 & -34236 & .97305 \\
\hline W_corp_gover & $\begin{array}{l}\text { Equal variances } \\
\text { assumed }\end{array}$ & 3.257 & .079 & .889 & 40 & .379 & .46279 & .52063 & -.58943 & 1.51501 \\
\hline & $\begin{array}{l}\text { Equal variances not } \\
\text { assumed }\end{array}$ & & & .820 & 24.312 & .420 & .46279 & .56466 & -.70182 & 1.62740 \\
\hline W_equip_operat & $\begin{array}{l}\text { Equal variances } \\
\text { assumed }\end{array}$ & .194 & .662 & .403 & 40 & .689 & .23988 & .59536 & -.96338 & 1.44313 \\
\hline & $\begin{array}{l}\text { Equal variances not } \\
\text { assumed }\end{array}$ & & & .395 & 29.986 & .695 & .23988 & .60668 & -99915 & 1.47890 \\
\hline W_prodt_devpmt & $\begin{array}{l}\text { Equal variances } \\
\text { assumed }\end{array}$ & 4.195 & .047 & 1.263 & 40 & .214 & .69926 & .55347 & -.41934 & 1.81787 \\
\hline & $\begin{array}{l}\text { Equal variances not } \\
\text { assumed }\end{array}$ & & & 1.191 & 26.188 & .244 & .69926 & .58711 & .50713 & 1.90565 \\
\hline W_form_chan & $\begin{array}{l}\text { Equal variances } \\
\text { assumed }\end{array}$ & .002 & .961 & .067 & 40 & .947 & .02159 & .32021 & .62559 & .66876 \\
\hline & $\begin{array}{l}\text { Equal variances not } \\
\text { assumed }\end{array}$ & & & .073 & 38.745 & .942 & .02159 & .29701 &. .57929 & .62247 \\
\hline W_extservice & $\begin{array}{l}\text { Equal variances } \\
\text { assumed }\end{array}$ & 1.028 & .317 & 2.519 & 40 & .016 & 1.21689 & .48318 & .24036 & 2.19342 \\
\hline & $\begin{array}{l}\text { Equal variances not } \\
\text { assumed }\end{array}$ & & & 2.444 & 28.886 & .021 & 1.21689 & .49788 & .19843 & 2.23535 \\
\hline W_profservice & $\begin{array}{l}\text { Equal variances } \\
\text { assumed }\end{array}$ & .020 & .887 & 2.371 & 40 & .023 & 1.67601 & .70681 & .24749 & 3.10454 \\
\hline & $\begin{array}{l}\text { Equal variances not } \\
\text { assumed }\end{array}$ & & & 2.312 & 29.343 & .028 & 1.67601 & .72493 & .19411 & 3.15792 \\
\hline W_access_fin & $\begin{array}{l}\text { Equal variances } \\
\text { assumed }\end{array}$ & .213 & .647 & -1.395 & 40 & .171 & -.48886 & .35049 & -1.19724 & .21951 \\
\hline & $\begin{array}{l}\text { Equal variances not } \\
\text { assumed }\end{array}$ & & & -1.435 & 34.773 & .160 & -48886 & .34070 & -1.18068 & .20296 \\
\hline ExpAllQualPerf & $\begin{array}{l}\text { Equal variances } \\
\text { assumed }\end{array}$ & .730 & .398 & .021 & 40 & .984 & .00481 & .23372 & -47718 & .46757 \\
\hline & $\begin{array}{l}\text { Equal variances not } \\
\text { assumed }\end{array}$ & & & .020 & 26.947 & .985 & .00481 & .24584 & .50927 & .49966 \\
\hline FirmSize & $\begin{array}{l}\text { Equal variances } \\
\text { assumed }\end{array}$ & 8.889 & .005 & 1.677 & 40 & .101 & 47.37500 & 28.25594 & -9.73239 & 104.48239 \\
\hline & $\begin{array}{l}\text { Equal variances not } \\
\text { assumed }\end{array}$ & & & 1.328 & 15.655 & .203 & 47.37500 & 35.66175 & -28.36021 & 123.11021 \\
\hline $\begin{array}{l}\text { Number of years of } \\
\text { company operations }\end{array}$ & $\begin{array}{l}\text { Equal variances } \\
\text { assumed }\end{array}$ & .272 & .605 & .301 & 40 & .765 & .587 & 1.949 & -3.352 & 4.525 \\
\hline & $\begin{array}{l}\text { Equal variances not } \\
\text { assumed }\end{array}$ & & & .308 & 34.297 & .760 & .587 & 1.903 & -3.281 & 4.454 \\
\hline Number of years in export & $\begin{array}{l}\text { Equal variances } \\
\text { assumed }\end{array}$ & .189 & .666 & .041 & 40 & .967 & .082 & 1.974 & -4.072 & 3.908 \\
\hline & $\begin{array}{l}\text { Equal variances not } \\
\text { assumed }\end{array}$ & & & .042 & 33.139 & .967 & .082 & 1.950 & -4.049 & 3.886 \\
\hline
\end{tabular}




\section{APPENDIX 3}

\section{Ramsey RESET Test Results}

Table 4.3 (Model 3)

\section{Export Performance}

Firm Size, Firm Age, International Experience, Export Knowledge, Downstream Supply Capacity, Upstream Supply Capacity, Innovation Capacity, Entrepreneurial Strategy

\begin{tabular}{|c|c|c|c|c|c|c|}
\hline Source & SS & df & MS & $\begin{array}{l}\text { Number of obs } \\
\mathrm{F}(8,143)\end{array}$ & $\begin{array}{l}= \\
=\end{array}$ & $\begin{array}{l}152 \\
7.09\end{array}$ \\
\hline Model | & 31.999252 & 8 & 3.9999065 & Prob $>F$ & $=$ & 0.0000 \\
\hline Residual| & 80.6783795 & 143 & .564184472 & R-squared & $=$ & 0.2840 \\
\hline Total & 12.677632 & 151 & .746209481 & $\begin{array}{l}\text { Adj R-squared } \\
\text { Root MSE }\end{array}$ & $\begin{array}{l}= \\
=\end{array}$ & $\begin{array}{l}0.2439 \\
.75112\end{array}$ \\
\hline
\end{tabular}

\begin{tabular}{l|llllll} 
Export Performance & Coef. & Std. Err. & $\mathrm{t}$ & $\mathrm{P}>\mathrm{t} \mid$ & {$[95 \%$ Conf. Interval] } \\
\hline Firm Size & .0002816 & .0002279 & 1.24 & 0.219 & -.0001688 & .0007319 \\
International Experience & .048506 & .0318422 & 1.52 & 0.130 & -.0144361 & .1114482 \\
Export Knowledge & .1746415 & .0499174 & 3.50 & 0.001 & .0759702 & .2733127 \\
Downstream Supply Capacity & -.0092651 & .0325008 & -0.29 & 0.776 & -.0735091 & .054979 \\
Upstream Supply Capacity & .148926 & .0493938 & 3.02 & 0.003 & .0512896 & .2465624 \\
Innovation Capacity & .0349821 & .0301711 & 1.16 & 0.248 & -.024657 & .0946211 \\
Entrepreneurial Strategy & -.0621684 & .0568 & -1.09 & 0.276 & -.1744446 & .0501078 \\
Firm Age & .0113716 & .0068766 & 1.65 & 0.100 & -.0022214 & .0249646 \\
Entrepreneurial Strategy * & 4.093521 & .310523 & 13.18 & 0.000 & 3.479713 & 4.707329 \\
Innovation Capacity & & & & & &
\end{tabular}

Ramsey RESET test using powers of the fitted values of Export Performance

Ho: model has no omitted variables

$$
\begin{aligned}
& \mathrm{F}(3,140)=0.73 \\
& \text { Prob }>\mathrm{F}=0.5372
\end{aligned}
$$

Ramsey RESET test using powers of the independent variables Ho: model has no omitted variables

$$
\begin{aligned}
& \mathrm{F}(24,119)=1.38 \\
& \mathrm{Prob}>\mathrm{F}=0.1301
\end{aligned}
$$

The Ramsey RESET test is applied to all forms of models (log, quadratic, linear, etc.) and determines whether or not the functional form of the model has any misspecification, causality (reverse relationship/effect) between dependent and independent variables or endogeneity occasioned by the X variable correlated with the error term exists. Ramsey RESET test was conducted on the study model and the results for the F statistic was

\footnotetext{
${ }^{19}$ The OLS model estimators are considered to be biased and inconsistent when a relevant variable is omitted. If the omitted variable is a function of an explanatory variable in the model then functional form misspecification arises. The misspecification therefore occurs when the relationship between the observed explanatory variable(s) and dependent variable is not properly accounted for.
} 
significant $(\mathrm{p} \leq 0.05 \%)$ for the dependent variable, export performance: Prob $>\mathrm{F}=0.5372$ and for the independent variables: Prob $>F=0.1301$ where the Ho: model has no omitted variables. This means there are neither endogeneity biases nor model misspecifications (causality) issues related to the study model. 


\section{APPENDIX 4 \\ Ramsey RESET Test Results}

\section{Table 6.5}

\section{Export Performance}

Firm Size, Firm Age, Firm Experience, International Experience, Export Knowledge, Intended Expansion, Building social networks, Corporate governance, Operations and maintenance, Product development, Business outlook, Form of channels, Extension service, Professional and technical support, Access to finance

\begin{tabular}{|c|c|c|c|c|c|c|c|c|}
\hline Source | & SS & df & MS & & & Num & er of obs & $\begin{array}{l}=152 \\
=517\end{array}$ \\
\hline Model & 40.8978245 & 15 & 2.726521 & & & Prob & $>\mathrm{F}$ & 0.0000 \\
\hline Residual| & 71.7798071 & 136 & .527792 & & & $\mathrm{R}-\mathrm{sc}$ & ared & 0.3630 \\
\hline Total & 112.677632 & 151 & .7462094 & & & Roo & MSE & .72649 \\
\hline Export $\mathrm{P}$ & rformance & & Coef. & Std. Err. & $\mathrm{t}$ & $P>|t|$ & {$[95 \%$ Con } & nf. Interval] \\
\hline Internationa & experience & & .0218053 & .0319369 & 0.68 & 0.496 & -.0413519 & .0849625 \\
\hline Export know & ledge & & .1178848 & .0564273 & 2.09 & 0.039 & .0062964 & .2294732 \\
\hline Intended ex] & ansion & & .0044111 & .0638808 & 0.07 & 0.945 & -.1219171 & .1307392 \\
\hline Business ou & ook & & .0310702 & .026701 & 1.16 & 0.247 & -.0217327 & .0838732 \\
\hline Building soc & al networks & & -.0578144 & .0758338 & -0.76 & 0.447 & -.2077804 & .0921516 \\
\hline Corporate g & vernance & & .1501618 & .061809 & 2.43 & 0.016 & .0279307 & .2723928 \\
\hline Operations a & d maintenance & & -.0104974 & .0431517 & -0.24 & 0.808 & -.0958326 & .0748378 \\
\hline Product dev & lopment & & .0694498 & .0526179 & 1.32 & 0.189 & -.0346054 & .173505 \\
\hline Form of cha & nels & & -.038027 & .0684176 & -0.56 & 0.579 & -.173327 & .0972729 \\
\hline Extension se & vice & & -.0740912 & .0577435 & -1.28 & 0.202 & -.1882824 & .0401001 \\
\hline Professional & and technical suppor & & .0330452 & .0360634 & 0.92 & 0.361 & -.0382725 & .1043628 \\
\hline Access to fir & ance & & .0210122 & .0407426 & 0.52 & 0.607 & -.0595587 & .1015831 \\
\hline Firm size & & & .0003106 & .0002353 & 1.32 & 0.189 & -.0001546 & .0007759 \\
\hline Firm age & & & .0140365 & .0124892 & 1.12 & 0.263 & -.0106616 & .0387346 \\
\hline Firm experie & & & -.007754 & .0139124 & -0.56 & 0.578 & -.0352665 & .0197585 \\
\hline
\end{tabular}

Ramsey RESET test using powers of the fitted values of Export Performance Ho: model has no omitted variables

$$
\begin{array}{ll}
\mathrm{F}(3,133)= & 0.21 \\
\text { Prob }>\mathrm{F}= & 0.8888
\end{array}
$$

Ramsey RESET test using powers of the independent variables Ho: model has no omitted variables

$$
\begin{array}{ll}
\mathrm{F}(45,91)= & 1.27 \\
\text { Prob }>\mathrm{F}= & 0.1706
\end{array}
$$

The results for the F statistic was significant $(\mathrm{p} \leq 0.05 \%)$ for the dependent variable, export performance: Prob $>\mathrm{F}=0.8888$ and for the independent variables: Prob $>\mathrm{F}=0.1706$ where the Ho: model has no omitted variables. This means there are neither endogeneity biases nor model misspecifications (causality) issues related to the study model. 


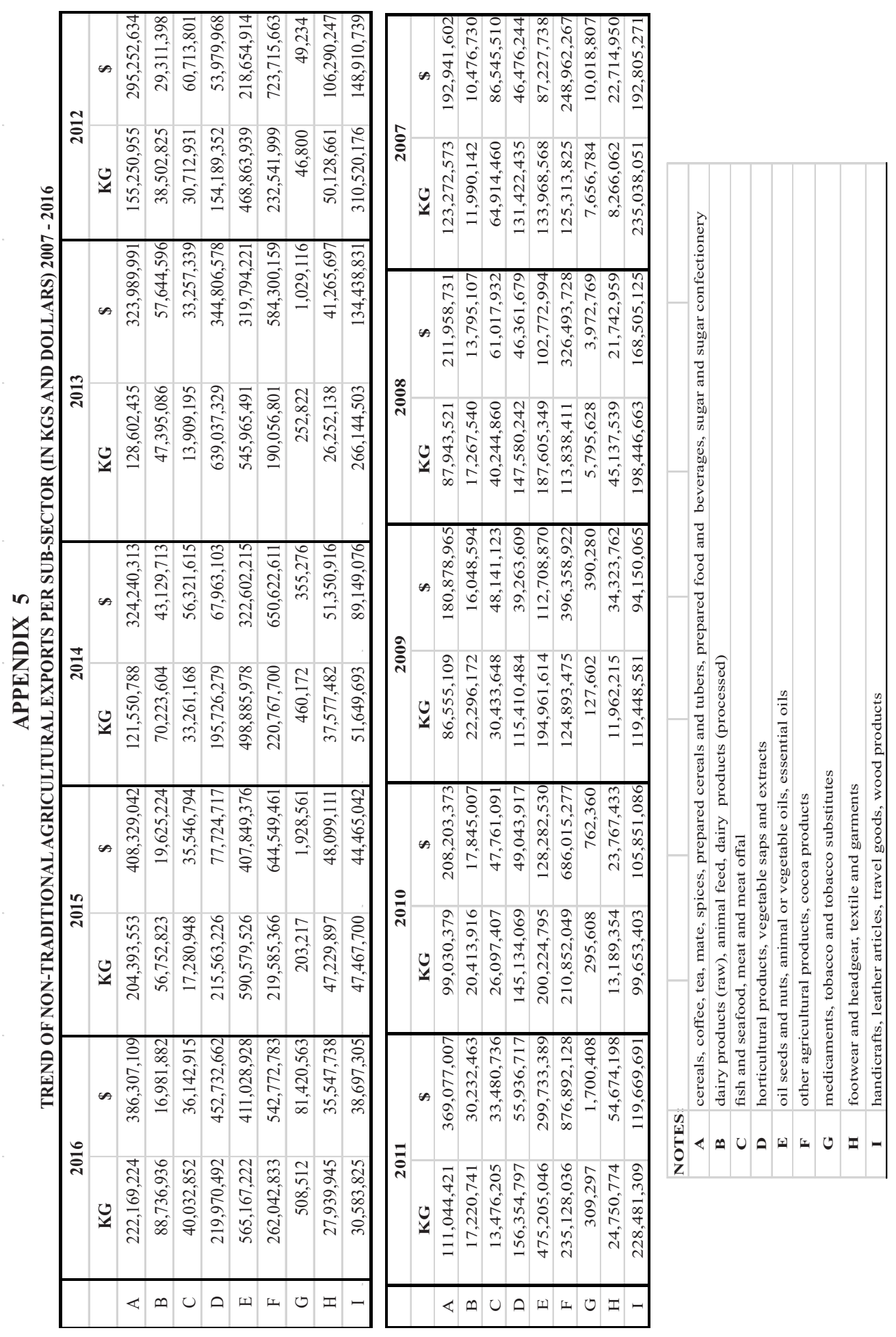




\section{APPENDIX 6 \\ SME CHARACTERISTICS}

\section{Company Data}

1. Name of company

2a. Address (actual location) of your business

2b. Zone (Savannah, Forest, Coastal)

3. Company type: (please tick )

Sole Proprietorship

Partnership.

Joint Venture

(with family/other)

(with foreign partner)

Private Limited Liability

State-Owned PPP (your \%).

Subsidiary

Branch

Where is the headquarters of the company?

4. Number of years of company operations:

5. Number of years in export business:

\section{Bio Data of Respondent}

6a. Name of respondent

6b. Sex:

male:

female:

7. Position held in the company:

8. Date of birth: (dd/mm/yy )

Your age range: (please tick)

(36-40)

under $20 \ldots . .$.

(20-25)

$(56-60)$

over 60

$(46-50) \ldots \ldots . .$.

(41-45)

Founder (if different from respondent)

9a. Who is the founder (name)

9b. Date of birth ( $\mathrm{dd} / \mathrm{mm} / \mathrm{yy})$ (if known) Age range (if known)

10. What is the vision of the company:

Founding:

Current:

11. Is there a succession plan? Yes/No

please circle and explain

\section{Education \& Experience of Respondent}

12a. Number of years working in the institution:

12b. Number of years of export experience in industry/product: 
13. Highest level of formal education attained: (please tick $\checkmark$ )

No formal education

Primary

Middle School/JSS/SSS/Secondary (including O/A level/ Vocational/Technical)

Tertiary/(Higher)Education (Teacher's certificate, Nursing, Polytechnic, University) ...

Post-graduate degree (Master; $\mathrm{PhD}$ )

Professional Certificate:

Other (Please specify):

14. Non-formal Export Training:

Please tick $(\checkmark)$ appropriate number from 1 - to a very low extent; 2 - to a low extent; 3 - to a somewhat low extent; 4 - to an average extent; 5 - to a somewhat high extent; 6 - to a high extent; 7- to a very high extent; NA- not applicable

\begin{tabular}{|c|c|c|c|c|c|c|c|c|}
\hline & $\mathrm{CEO} / \mathrm{MT}^{1}$ international experience was acquired through having.. & 12 & 3 & 4 & 5 & & & \\
\hline a. & .... been born and raised abroad & $\square \square$ & $\square$ & $\square$ & $\square$ & & $\square$ & $\square$ \\
\hline b. & ... traveled abroad frequently & $\square \square$ & $\square$ & $\square$ & $\square$ & $\square$ & $\square$ & $\square$ \\
\hline c. & .... schooled abroad & $\square \square$ & $\square$ & $\square$ & $\square$ & $\square$ & $\square$ & $\square$ \\
\hline d. & .... previously worked abroad & $\square \square$ & $\square$ & $\square$ & $\square$ & $\square$ & $\square$ & $\square$ \\
\hline e. & .... been involved in export trade to abroad & $\square \square$ & $\square$ & $\square$ & $\square$ & $\square$ & $\square$ & $\square$ \\
\hline f. & .... been involved in export trade abroad with prior employer & $\square \square$ & $\square$ & $\square$ & $\square$ & $\square$ & $\square$ & $\square$ \\
\hline g. & .... other (please specify)........................................ & $\square \square$ & $\square$ & $\square$ & $\square$ & $\square$ & $\square$ & $\square$ \\
\hline
\end{tabular}

15. Religion: (please tick $\checkmark$ )

Catholic..... Orthodox Protestant ..... Pentecostal/Charismatic ...... Baptist ...

Other Christian ...... Muslim ...... Traditionalist ...... No declared religion.......

Other(please specify)

16. International experience:

Please tick $(\checkmark)$ appropriate number from 1 - to a very low extent; 2 - to a low extent; 3to a somewhat low extent; 4- to an average extent; 5 - to a somewhat high extent; 6 to a high extent; 7- to a very high extent; NA- not applicable

Entrepreneurship (strategy, culture \& capabilities)

\section{Strategy}

17. Number of production locations in Ghana

18. Number of agents in a. Ghana

b. other countries

(input suppliers/export agents) (sales/marketing agents) 
19. Intended expansion, work processes and added value:

Please tick $(\checkmark)$ appropriate number from 1 - to a very low extent; 2 - to a low extent; 3 - to a somewhat low extent; 4 - to an average extent; 5 - to a somewhat high extent; 6 - to a high extent; 7- to a very high extent; NA- not applicable

\begin{tabular}{|c|c|c|c|c|c|c|c|c|}
\hline & Too what extent does your company:... & 12 & 3 & 4 & 5 & 6 & & NA \\
\hline a. & $\begin{array}{l}\text {... add value (such as packaging and labelling) to its products } \\
\text { before export? }\end{array}$ & $\square \square$ & $\square$ & $\square$ & & & & $\square$ \\
\hline b. & .... want to expand its existing facilities? & $\square \square$ & $\square$ & $\square$ & $\square$ & $\square$ & & $\square$ \\
\hline c. & .... want to expand to another location? & $\square \square$ & $\square$ & $\square$ & $\square$ & $\square$ & $\square$ & $\square$ \\
\hline d. & .... want to expand with more elaborate equipment? & $\square \quad \square$ & $\square$ & $\square$ & $\square$ & $\square$ & $\square$ & $\square$ \\
\hline e. & .... want to expand in existing markets? & $\square \square$ & $\square$ & $\square$ & $\square$ & $\square$ & $\square$ & $\square$ \\
\hline f. & .... want to expand to new markets? & $\square \square$ & $\square$ & $\square$ & $\square$ & $\square$ & & $\square$ \\
\hline g. & .... want to expand in other ways...... & $\square \square$ & $\square$ & $\square$ & $\square$ & $\square$ & $\square$ & $\square$ \\
\hline h. & .... rely on strategy provided by CEO/MT? & $\square \square$ & $\square$ & $\square$ & $\square$ & $\square$ & $\square$ & $\square$ \\
\hline i. & .... involve staff in decision-making that affects them? & $\square \square$ & $\square$ & $\square$ & $\square$ & $\square$ & $\square$ & $\square$ \\
\hline j. & .... adapt changes based on market information? & $\square \square$ & $\square$ & $\square$ & $\square$ & $\square$ & ப & $\square$ \\
\hline $\mathrm{k}$. & .... other (please specify). & $\square \quad \square$ & $\square$ & $\square$ & $\square$ & $\square$ & $\square$ & $\square$ \\
\hline
\end{tabular}

20. Sources of market information:

Please tick $(\checkmark)$ appropriate number from 1 - to a very low extent; 2 - to a low extent; 3 - to a somewhat low extent; 4 - to an average extent; 5 - to a somewhat high extent; 6 - to a high extent; 7- to a very high extent; NA- not applicable

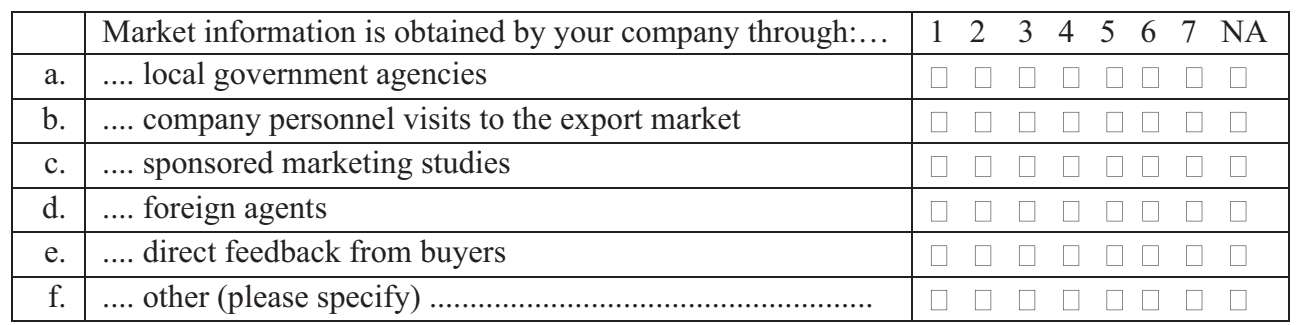

21. Forms of strategy adopted by the business:

Please tick $(\checkmark)$ appropriate number from 1 - to a very low extent; 2 - to a low extent; 3 - to a somewhat low extent; 4 - to an average extent; 5 - to a somewhat high extent; 6 - to a high extent; 7- to a very high extent; NA- not applicable 


\begin{tabular}{|c|c|c|c|c|c|c|c|c|c|}
\hline & The forms of business strategy adopted include:... & & 2 & 3 & 4 & 5 & 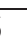 & & NA \\
\hline a. & .... product differentiation & $\square$ & $\square$ & $\square$ & $\square$ & $\square$ & & & $\square$ \\
\hline b. & .... pricing & $\square$ & $\square$ & $\square$ & $\square$ & $\square$ & 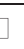 & & $\square$ \\
\hline c. & .... cost reduction & $\square$ & $\square$ & $\square$ & $\square$ & $\square$ & $\square$ & & $\square$ \\
\hline d. & .... use of up to date technology & $\square$ & $\square$ & $\square$ & $\square$ & $\square$ & $\square$ & $\square$ & $\square$ \\
\hline e. & .... marketing & $\square$ & $\square$ & $\square$ & $\square$ & & ] & & $\square$ \\
\hline f. & .... quality processes (from source to finish) & & & & & & & & \\
\hline g. & 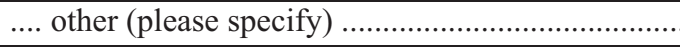 & $\square$ & $\square$ & $\square$ & $\square$ & $\square$ & - & $\square$ & $\square$ \\
\hline
\end{tabular}

\section{Culture}

22(a) Has your financial statement ever been audited? Please tick $(\checkmark)$

$$
\text { Yes .... No .... If No move to Q23 }
$$

22(b) Financial statements:

Please tick $(\checkmark)$ appropriate number from 1- not at all; 2- very unlikely; 3- somewhat unlikely; 4- on the average; 5-somewhat likely; 6-likely; 7-very likely

\begin{tabular}{|c|c|c|c|c|c|c|c|c|}
\hline & Over what period is your financial statement audited and certified: & 12 & 3 & 4 & 5 & 6 & & NA \\
\hline a. & $0-3$ months & $\square \square$ & $\square$ & $\square$ & $\square$ & $\square$ & $\square$ & $\square$ \\
\hline b. & 4-5 months & $\square \square$ & $\square$ & $\square$ & $\square$ & $\square$ & & $\square$ \\
\hline c. & 7-9 months & $\square \square$ & $\square$ & $\square$ & $\square$ & $\square$ & & $\square$ \\
\hline d. & 10-12 months & $\square \square$ & $\square$ & $\square$ & $\square$ & $\square$ & & $\square$ \\
\hline e. & 13-15 months & $\square \square$ & $\square$ & $\square$ & $\square$ & $\checkmark$ & & $\square$ \\
\hline f. & $>15$ months & $\square \quad \square$ & $\square$ & $\square$ & $\square$ & $\square$ & $\square$ & $\square$ \\
\hline
\end{tabular}

23. Work processes:

Please tick $(\checkmark)$ appropriate number from 1 - to a very low extent; 2 - to a low extent; 3 - to a somewhat low extent; 4 - to an average extent; 5 - to a somewhat high extent; 6 - to a high extent; 7- to a very high extent; NA- not applicable

\begin{tabular}{|c|c|c|c|c|c|c|c|}
\hline & Work processes are carried out as follows... & 123 & 34 & 5 & 6 & & NA \\
\hline a. & ...... centralized in a hierarchical structure & $\square \square \square$ & $\square \square$ & & $\square$ & $\square$ & $\square$ \\
\hline b. & ...... carried out in teams in a relatively flat structure & $\square \square \square$ & $\square$ & $\square$ & $\square$ & $\square$ & $\square$ \\
\hline c. & ...... employees work in all areas as the need arises & $\square \square \square$ & $\square \square$ & $\square$ & $\square$ & $\square$ & $\square$ \\
\hline d. & ...... aspects of the work process is outsourced/contracted out & $\square \square$ & $\square \square$ & & $\square$ & $\square$ & $\square$ \\
\hline e. & ..... other (please indicate) ............................. & $\square \square \square$ & $\square \square$ & & $\square$ & $\square$ & $\square$ \\
\hline
\end{tabular}

24. Corporate governance structures:

Please tick $(\checkmark)$ appropriate number from 1 - to a very low extent; 2 - to a low extent; 3 - to a somewhat low extent; 4 - to an average extent; 5 - to a somewhat high extent; 6 - to a high extent; 7 - to a very high extent; NA- not applicable 


\begin{tabular}{|c|c|c|c|c|c|c|c|c|}
\hline & The governance structures in place at the company involve:... & 12 & 3 & 4 & 5 & & & \\
\hline a. & $\begin{array}{l}\text {...the institution's processes allow for clear separation of } \\
\text { functions and checks and balances }\end{array}$ & $\square \square$ & $\square$ & $\square$ & & $\square$ & & $\square$ \\
\hline b. & ....there are clear reporting lines of communication & $\square \square$ & $\square$ & $\square$ & & a & & $\square$ \\
\hline c. & ....regulatory and monitoring requirements are regularly met & $\square \square$ & $\square$ & $\square$ & & 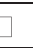 & & $\square$ \\
\hline d. & .... board of directors and strong internal controls & $\square \square$ & $\square$ & $\square$ & & & & $\square$ \\
\hline e. & ..... other ............................ & $\square \square$ & $\square$ & $\square$ & & $\square$ & & $\square$ \\
\hline
\end{tabular}

\section{Equipment Operation and Maintenance:}

Please tick $(\checkmark)$ appropriate number from 1 - to a very low extent; 2 - to a low extent; 3 - to a somewhat low extent; 4- to an average extent; 5 - to a somewhat high extent; 6 - to a high extent; 7- to a very high extent; NA- not applicable

\begin{tabular}{|c|c|c|c|c|c|c|c|c|}
\hline & The company's equipment is operated and maintained through.. & 12 & 3 & & & & & NA \\
\hline a. & ... staff given on-the-job training in equipment use & $\square \square$ & $\square$ & $\square$ & & & & $\square$ \\
\hline b. & ... regular maintenance policy and schedule in place & $\square \square$ & $\square$ & $\square$ & & & & $\square$ \\
\hline c. & ... manufacturers' providing local service guarantees & $\square \square$ & $\square$ & $\square$ & & & & $\square$ \\
\hline d. & ... local mechanics and maintenance crew contracted on a need basis & $\square \square$ & $\square$ & $\square$ & & & & $\square$ \\
\hline e. & .... other (please indicate) ..................... & $\square \square$ & $\square$ & $\square$ & & & & $\square$ \\
\hline
\end{tabular}

\section{Business Culture:}

Please tick $(\checkmark)$ appropriate number from 1 - to a very low extent; 2 - to a low extent; 3 - to a somewhat low extent; 4 - to an average extent; 5 - to a somewhat high extent; 6 - to a high extent; 7- to a very high extent; NA- not applicable

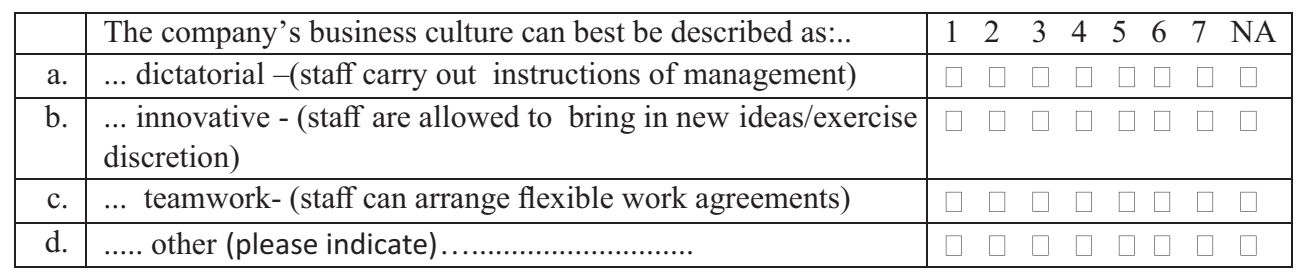

27. Business Outlook:

Please tick $(\checkmark)$ appropriate number from 1 - to a very low extent; 2 - to a low extent; 3 - to a somewhat low extent; 4- to an average extent; 5 - to a somewhat high extent; 6 - to a high extent; 7- to a very high extent; NA- not applicable 


\begin{tabular}{|c|c|c|}
\hline & The company' business outllook is such that..... & $\begin{array}{llllllll}1 & 2 & 3 & 4 & 5 & 6 & 7 & \text { NA }\end{array}$ \\
\hline a. & ...competitive clashes with other businesses are avoided... & \\
\hline b. & $\begin{array}{l}\text {... owing to nature of environment bold wide-ranging acts are } \\
\text { necessary to achieve the firm's objectives.... }\end{array}$ & \\
\hline c. & $\begin{array}{l}\ldots \text { new products/services, operating technoligies or administrative } \\
\text { techniques are the first to be introduced by the company.... }\end{array}$ & \\
\hline d. & $\begin{array}{l}\text {... CEO/MT have strong preference for high risk projects with } \\
\text { chances of very high returns...... }\end{array}$ & \\
\hline e. & $\begin{array}{l}\text {...we are first to introduce new products/services, administrative } \\
\text { techniques or operating techniques }\end{array}$ & \\
\hline f. & ..... other (please indicate) & \\
\hline
\end{tabular}

28(a) How many new products/services have been introduced in the past five years by your company?

28(b) Product Development:

Please tick $(\checkmark)$ appropriate number from 1 - to a very low extent; 2 - to a low extent; 3 - to a somewhat low extent; 4 - to an average extent; 5 - to a somewhat high extent; 6 - to a high extent; 7- to a very high extent; NA- not applicable

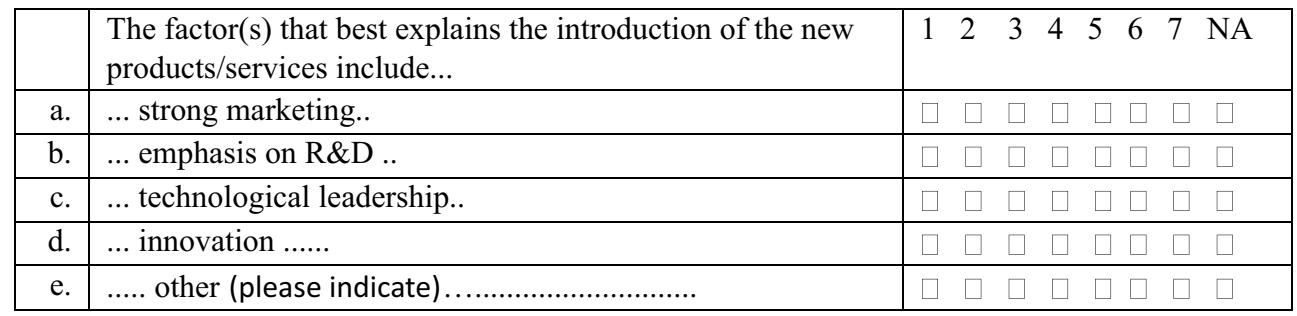

\section{Capabilities}

\section{Cost Drivers:}

Please tick $(\checkmark)$ appropriate number from 1- to a very low extent; 2 - to a low extent; 3 - to some low extent; 4 - to an average extent; 5 - to some high extent; 6 - to a high extent; 7 to a very high extent; $\mathrm{NA}$ - not applicable

\begin{tabular}{|r|l|l|l|}
\hline & To what extent do/does ...... & $1 \quad 2 \quad 3 \quad 4 \quad 5 \quad 6 \quad 7 \quad$ NA \\
\hline a. & ... location make a difference to costs or processes? & $\square \quad \square \quad \square \quad \square \square \square \square$ \\
\hline b. & ... the product make a difference to costs or processes? & $\square \square \quad \square \quad \square \square \square \square$ \\
\hline c. & $\begin{array}{l}\text {... you incur large costs to meet the quality standards of the } \\
\text { countries you export to? }\end{array}$ & $\square \quad \square \quad \square \square \square \square$ \\
\hline
\end{tabular}

30. Training:

Please tick $(\checkmark)$ appropriate number from 1- very irregular; 2- irregular; 3- somewhat irregular; 4- averagely; 5 - somewhat regular; 6 - regular; 7- very regular; NA - not applicable 


\begin{tabular}{|c|c|c|c|c|c|c|c|c|c|}
\hline & Are there training policies instituted by the company such as .... & & 2 & & & & & & NA \\
\hline a. & ... study leave with pay & $\square$ & $\square$ & $\square$ & ( & & & & $\square$ \\
\hline b. & ... study leave without pay but with job re-entry guarantee & $\square$ & $\square$ & $\square$ & $\square$ & $\square$ & & ] & $\square$ \\
\hline c. & ... study leave without pay and without job re-entry guarantee & $\square$ & $\square$ & $\square$ & $\square$ & & 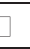 & & $\square$ \\
\hline d. & ... regular training programmes & $\square$ & $\square$ & $\square$ & $\square$ & & $\checkmark$ & & $\square$ \\
\hline e. & ... training is provided on a need basis & $\square$ & $\square$ & $\square$ & $\square$ & $\square$ & & ] & $\square$ \\
\hline f. & ... training need results from performance evaluation & $\square$ & $\square$ & $\square$ & $\square$ & $\square$ & & & $\square$ \\
\hline g. & 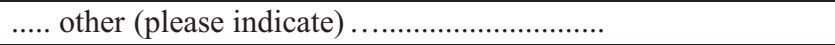 & $\square$ & $\square$ & $\square$ & $\square$ & $\square$ & & & $\square$ \\
\hline
\end{tabular}

31. Input Supply:

Please tick $(\checkmark)$ appropriate number from 1 - to a very low extent; 2 - to a low extent; 3 - to a somewhat low extent; 4 - to an average extent; 5 - to a somewhat high extent; 6 - to a high extent; 7- to a very high extent; NA - not applicable

\begin{tabular}{|c|c|c|c|c|c|}
\hline & Input supply is used to ......... & 12 & 3 & 4 & 5 \\
\hline a. & .... ensure reliability in supplies to the company & $\square \quad \square$ & $\square$ & $\square$ & $\square$ \\
\hline b. & .... maintain minimum stock levels & $\square \quad \square$ & $\square$ & $\square$ & $\square$ \\
\hline c. & .... provide for alternative sources of supply & $\square \square$ & $\square$ & $\square$ & \\
\hline d. & .... make prices more competitive & $\square \quad \square$ & $\square$ & $\square$ & $\square$ \\
\hline e. & ..... other (please indicate).. & $\square \square$ & $\square$ & $\square$ & $\square$ \\
\hline
\end{tabular}

\section{Management's Export Constraints:}

Please tick $(\checkmark)$ appropriate number from 1 - to a very low extent; 2 - to a low extent; 3 - to a somewhat low extent; 4 - to an average extent; 5 - to a somewhat high extent; 6 - to a high extent; 7- to a very high extent; NA- not applicable

\begin{tabular}{|c|c|c|c|c|c|c|c|c|}
\hline & Management is constrained in export in areas such as .... & 12 & 3 & 4 & 5 & 6 & 71 & \\
\hline a. & ... lack of time... & $\square \square$ & $\square$ & $\square$ & & $\square$ & $\square$ & $\square$ \\
\hline b. & ...cost/financing of activities... & $\square \square$ & $\square$ & $\square$ & & $\square$ & $\square$ & $\square$ \\
\hline c. & ... lack of qualified personnel.. & $\square \square$ & $\square$ & $\square$ & & $\square$ & $\square$ & $\square$ \\
\hline d. & ... satisfying demand.. & $\square \quad \square$ & $\square$ & $\square$ & & $\square$ & $\square$ & $\square$ \\
\hline e. & ... strong competition.. & $\square \quad \square$ & $\square$ & $\square$ & & $\square$ & $\square$ & $\square$ \\
\hline f. & ... knowledge of market.. & $\square \quad \square$ & $\square$ & $\square$ & & $\square$ & $\square$ & $\square$ \\
\hline g. & ... knowledge of regulations... & $\square \square$ & $\square$ & $\square$ & & $\square$ & $\square$ & $\square$ \\
\hline h. & ... quotas/overseas barriers... & $\square \quad \square$ & $\square$ & $\square$ & & $\square$ & $\square$ & $\square$ \\
\hline i. & ... frequent changes in regulations of importing country.. & $\square \square$ & $\square$ & $\square$ & $\square$ & $\square$ & $\square$ & $\square$ \\
\hline $\mathrm{j}$. & $\ldots$ need for more more learning... & $\square \square$ & $\square$ & $\square$ & $\square$ & $\square$ & $\square$ & $\square$ \\
\hline $\mathrm{k}$. & 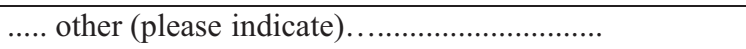 & $\square \square$ & $\square$ & $\square$ & & $\square$ & $\square$ & $\square$ \\
\hline
\end{tabular}




\section{Physical Capital}

33. How does the company finance its capital investments (Long term-LT investment, machinery and equipment)? Please tick $(\checkmark)$

Equity.......... LT Debt-Equity

LT Debt

ST Debt

34. Sources of Finance:

Please tick $(\checkmark)$ appropriate number from 1 - to a very low extent; 2 - to a low extent; 3 - to a somewhat low extent; 4 - to an average extent; 5 - to a somewhat high extent; 6 - to a high extent; 7- to a very high extent; NA - not applicable

\begin{tabular}{|c|c|c|c|c|c|c|c|c|}
\hline & The providers/sources of your finance include:... & 12 & 3 & 4 & 5 & 6 & & NA \\
\hline a. & ...friends & $\square \square$ & $\square$ & $\square$ & $\square$ & $\square$ & $\square$ & $\square$ \\
\hline b. & ...family & $\square \square$ & $\square$ & $\square$ & $\square$ & $\square$ & $\square$ & $\square$ \\
\hline c. & ...business associates/partners & $\square \square$ & $\square$ & $\square$ & $\square$ & $\square$ & $\square$ & $\square$ \\
\hline d. & ...banks and other finance institutions & $\square \square$ & $\square$ & $\square$ & $\square$ & $\square$ & $\square$ & $\square$ \\
\hline e. & 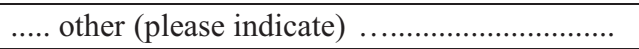 & $\square \quad \square$ & $\square$ & $\square$ & $\square$ & $\square$ & $\square$ & $\square$ \\
\hline
\end{tabular}

35. Evaluation of financing sources:

Please tick $(\checkmark)$ appropriate number from 1- very bad; 2- bad; 3- somewhat bad; 4average; 5-somewhat good; 6-good; 7-very good; NA-not applicable

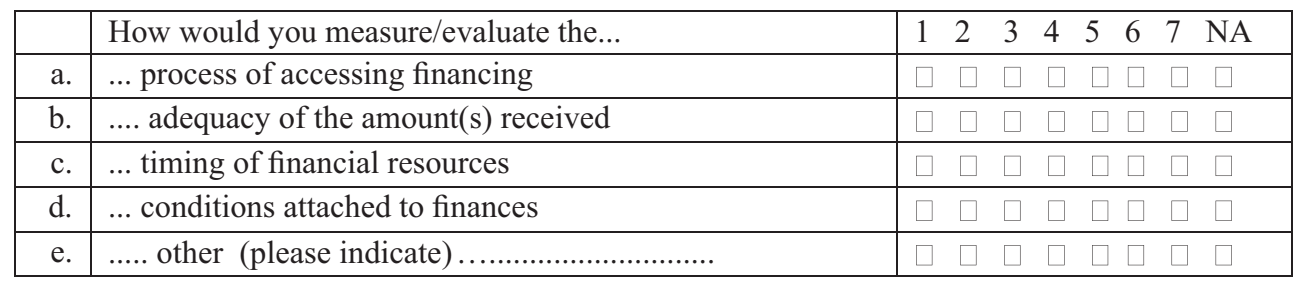

36. What is the breakdown of the sources of the types of equipment the company uses for its operations?
a. own built equipment

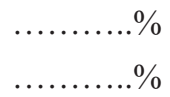
b. equipment built in Ghana $\%$
c. imported (foreign made) equipment ..$\%$
d. others (please indicate) 
37. How can the ownership of the operating premises of the company be described/ categorised?
a. complete ownership of the property
b. rental of the property
c. lease of the property
d. other
(please indicate)

.................\%
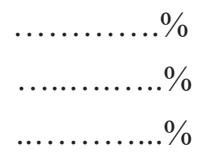

TOTAL

38. Company's storage facilities:

Please tick $(\checkmark)$ appropriate number from 1- very badly equipped facilities; 2- badly equipped facilities; 3- somewhat badly equipped facilities; 4- averagely equipped facilities; 5 - somewhat well equipped facilities; 6 - well equipped facilities; 7- very well equipped facilities; NA-not applicable

\begin{tabular}{|c|c|c|c|c|c|c|c|c|}
\hline & Storage facilities are in place .... & 12 & & & & 6 & & \\
\hline a. & ...on factory site (specify type: fresh food, dry food, other ..........) & $\square \square$ & $\square$ & $\square$ & $\square$ & $\square$ & & $\square$ \\
\hline b. & ...on warehouse site (specify type: fresh food, dry food, other .....) & $\square \square$ & $\square$ & $\square$ & $\square$ & $\square$ & & $\square$ \\
\hline c. & $\begin{array}{l}\text {....at strategic transit (harbour/airport) points (specify type: fresh } \\
\text { food, dry food, other ..........) }\end{array}$ & $\square \square$ & & $\square$ & & $\square$ & & $\square$ \\
\hline d. & ... in transit (ship/plane) (specify type: fresh food, dry food, other ...) & $\square \square$ & & & & $\square$ & & $\square$ \\
\hline
\end{tabular}

39. Ownership of Storage Facilities:

Please tick $(\checkmark)$ appropriate number from 1 - to a very low extent; 2 - to a low extent; 3 - to a somewhat low extent; 4 - to an average extent; 5 - to a somewhat high extent; 6 - to a high extent; 7- to a very high extent; NA - not applicable

\begin{tabular}{|c|c|c|c|c|c|c|c|c|c|c|c|c|c|c|c|c|}
\hline & Your st orage facilities is owned by:... & \multicolumn{7}{|c|}{ On site } & \multicolumn{8}{|c|}{ At transit point } \\
\hline a. & ... the company & 12 & 3 & 4 & 5 & 6 & 7 & NA & & 2 & 3 & 4 & 56 & 6 & 7 & NA \\
\hline b. & $\ldots$ a third party & $\square \square$ & $\square$ & $\square$ & $\square$ & $\square$ & $\square$ & & & $\square$ & $\square$ & ( & & $\square$ & $\square$ & $\square$ \\
\hline c. & ... a government agency & $\square \square$ & $\square$ & $\square$ & $\square$ & $\square$ & $\square$ & $\square$ & & $\square$ & $\square$ & $\square$ & & $\square$ & $\square$ & $\square$ \\
\hline d. & ... a business network & $\square \square$ & $\square$ & $\square$ & $\square$ & $\square$ & $\square$ & & & $\square$ & $\square$ & $\square$ & $\square$ & $\square$ & $\square$ & $\square$ \\
\hline e. & ..... other (please indicate) ................. & $\square \square$ & $\square$ & $\square$ & & $\square$ & $\square$ & $\square$ & & $\square$ & $\square$ & $\square$ & $\square$ & $\square$ & $\square$ & $\square$ \\
\hline
\end{tabular}

40. Availability of storage vans:

Please tick $(\checkmark)$ appropriate number from 1- very badly equipped facilities; 2- badly equipped facilities; 3-somewhat badly equipped facilities; 4- averagely equipped facilities; 5 - somewhat well equipped facilities; 6 - well equipped facilities;

7- very well equipped facilities; NA-not applicable

\begin{tabular}{|r|l|lll|}
\hline & Storage vans are available/accessible from .... & $1 \quad 2 \quad 3 \quad 4 \quad 5 \quad 6 \quad 7$ NA \\
\hline a. & ...farm to site (specify type: fresh food, dry food, other ..........) & $\square \quad \square \quad \square \quad \square \quad \square \quad \square \quad \square$ \\
\hline b. & ... site to export (specify type: fresh food, dry food, other ...........) & $\square \quad \square \quad \square \quad \square \quad \square \quad \square \quad \square$ \\
\hline
\end{tabular}


41. Ownership of storage vans:

Please tick $(\checkmark)$ appropriate number from 1 - to a very low extent; 2 - to a low extent; 3 - to a somewhat low extent; 4 - to an average extent; 5 - to a somewhat high extent; 6 - to a high extent; 7- to a very high extent; NA - not applicable

\begin{tabular}{|c|c|c|c|c|c|c|c|c|c|c|c|c|c|c|c|c|}
\hline & The storage vans you use is owned by... & \multicolumn{7}{|c|}{ Farm to site } & \multicolumn{8}{|c|}{ Site to export } \\
\hline a. & ... the company & 12 & 3 & 4 & 5 & 6 & 7 & NA & & 2 & 3 & 4 & 5 & 6 & 7 & NA \\
\hline b. & ... a third party (logistic company) & $\square \square$ & $\square$ & $\square$ & $\square$ & $\square$ & & & ¿ & $\square$ & $\square$ & $\square$ & $\square$ & $\square$ & $\square$ & $\square$ \\
\hline c. & ... a government agency & $\square \quad \square$ & $\square$ & $\square$ & & $\square$ & $\square$ & $\square$ & ¿ & $\square$ & $\square$ & $\square$ & $\square$ & $\square$ & $\square$ & $\square$ \\
\hline d. & ... a business network & $\square \quad \square$ & $\square$ & $\square$ & & $\square$ & $\square$ & $\square$ & ¿ & $\square$ & $\square$ & $\square$ & $\square$ & $\square$ & $\square$ & $\square$ \\
\hline e. & ..... other (please indicate). & $\square \square$ & $\square$ & $\square$ & & $\square$ & $\square$ & $\square$ & $\square$ & $\square$ & $\square$ & $\square$ & & $\square$ & $\square$ & $\square$ \\
\hline
\end{tabular}

42. What are the sources of power supply (in terms of relative costs) of your company?
a. Electricity Company of Ghana

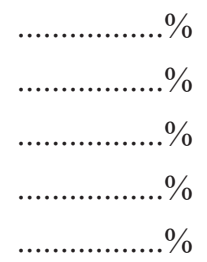
b. Own Generator
c. Own Solar Energy
d. Firewood
e. Other: (please indicate)
$\%$

TOTAL

\section{PRODUCT AND CHAIN CHARACTERISTICS}

Product please state and tick $(\checkmark)$ as appropriate

\begin{tabular}{|l|l|l|l|l|}
\hline 43. & Main products & $\begin{array}{l}\text { Non-processed } \\
\text { Product only }\end{array}$ & $\begin{array}{l}\text { Semi-processed } \\
\text { Product }\end{array}$ & $\begin{array}{l}\text { Processed } \\
\text { Product only }\end{array}$ \\
\hline a. & & & & \\
\hline b. & & & & \\
\hline c. & & & & \\
\hline
\end{tabular}

44. To what extent would you describe your export products as perishable?

Please tick $(\checkmark)$ appropriate number from 1 - to a very low extent; 2 - to a low extent; 3 - to a somewhat low extent; 4 - to an average extent; 5 - to a somewhat high extent; 6 - to a high extent; 7- to a very high extent

$$
1 \square 2 \square 3 \square 4 \square 5 \square 6 \square 7 \square
$$

45. Channels of export utlised:

Please tick $(\checkmark)$ appropriate number from 1- to a very low extent; 2 - to a low extent; 3 - to a somewhat low extent; 4 - to an average extent; 5 - to a somewhat high extent; 6 - to a high extent; 7- to a very high extent 


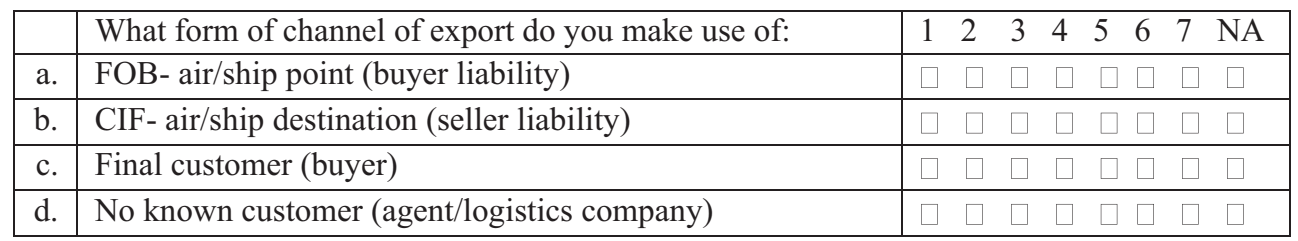

Social Capital - Network Density, Weak and Strong ties, Bridging and Bonding ties

46. Degree of Reliance on Contacts:

Please tick $(\checkmark)$ appropriate number from 1 - to a very low extent; 2 - to a low extent; 3 - to a somewhat low extent; 4 - to an average extent; 5 - to a somewhat high extent; 6 - to a high extent; 7- to a very high extent; NA- not applicable

\begin{tabular}{|c|c|c|c|c|c|c|c|c|c|}
\hline & $\begin{array}{l}\text { The contacts that the company relies on to support its export } \\
\text { process are:............ }\end{array}$ & & 2 & 3 & 4 & 5 & & & NA \\
\hline a. & ... CEO/Management team & $\square$ & $\square$ & $\square$ & $\square$ & & & & $\square$ \\
\hline b. & ...Embassies/High Commisions & $\square$ & $\square$ & $\square$ & $\square$ & & & & $\square$ \\
\hline b. & ...Ghanaian government agencies & $\square$ & $\square$ & $\square$ & $\square$ & & & & $\square$ \\
\hline c. & ... local export agents (non-governmental) & $\square$ & $\square$ & $\square$ & $\square$ & $\square$ & $\square$ & & $\square$ \\
\hline d. & ... foreign agents (non-governmental) & $\square$ & $\square$ & $\square$ & $\square$ & & $\square$ & & $\square$ \\
\hline e. & ... international partner/customer & $\square$ & $\square$ & $\square$ & $\square$ & & $\square$ & & $\square$ \\
\hline f. & ... companies within association & $\square$ & $\square$ & $\square$ & $\square$ & & 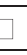 & & $\square$ \\
\hline g. & ...companies outside association & $\square$ & $\square$ & $\square$ & $\square$ & $\square$ & & $\square$ & \\
\hline h. & 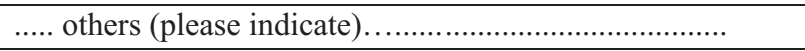 & $\square$ & $\square$ & $\square$ & $\square$ & & & $\square$ & \\
\hline
\end{tabular}

47. Building/Maintaining contacts:

Please tick $(\checkmark)$ appropriate number from 1- very inefficient; 2- inefficient; 3- somewhat inefficient 4- average; 5 - somewhat efficient; 6-efficient; 7- very efficient; NA- not applicable.

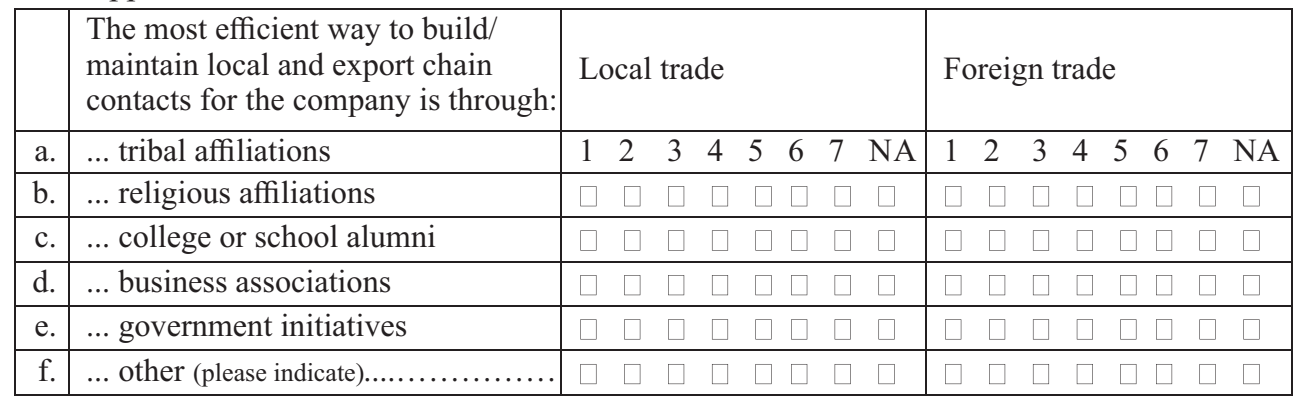

48a. Is your company a member of an association? Yes ...... No....... Please tick $(\checkmark)$

(If No, move to Q49)

48b. Which association(s) is your company a member of?

i.

ii.

iii. 
48c. When did your company join/register with this association?

48d. For how many years has your company been a member of this association?

48e. What are the main activities of the association(s)?

i.

ii.

iii.

48f. How would you describe the frequency of your company's interactions with the association?

Please tick $(\checkmark)$ appropriate number from 1- very irregular; 2- irregular; 3- somewhat irregular; 4-average; 5-somewhat regular; 6-regular; 7-very regular

$$
1 \square 2 \square 3 \square 4 \square 5 \square 6 \square 7 \square
$$

48g. What services or benefits have you received from the association in the past?

i.

ii.

iii.

48h. To what extent are the services or benefits useful to your organisation?

Please tick $(\checkmark)$ appropriate number from 1- to a very low extent; 2 - to a low extent; 3 - to some low extent; 4- to an average extent; 5 - to some high extent; 6 - to a high extent; 7 to a very high extent

49a. Do you regularly use export information provided by the Ghana Export Promotion Authority (GEPA)? Yes...... No....... Please tick $(\checkmark)$

If No, move to $49 \mathrm{~d}$.

49b. To what extent do you use/rely on information from the GEPA?

Please tick $(\checkmark)$ appropriate number from 1 - to a very low extent; 2- to a low extent; 3 - to a somewhat low extent; 4- to an average extent; 5 - to a somewhat high extent; 6 - to a high extent; 7- to a very high extent

$$
1 \square 2 \square 3 \square 4 \square 5 \square 6 \square 7 \square
$$

49c Is the information you get from the GEPA normally relevant? (addresses concern and is timely) $\quad$ Yes............ Please tick $(\checkmark)$

49d. Do you need the information from the GEPA? Yes...... No........ Please tick $(\checkmark)$ If No, move to Q50

49e. How cooperative is the staff of the GEPCin your dealings with it?

Please tick $(\checkmark)$ appropriate number from 1- very uncooperative; 2- uncooperative; 3somewhat uncooperative; 4- average; 5 - somewhat cooperative; 6 - cooperative; 7very cooperative

$$
1 \square 2 \square 3 \square 4 \square 5 \square 6 \square \quad 7 \square
$$


49f. Which information from the GEPC is/would be/has been most valuable/helpful to your organisation?

e.g.: information on the export process, information on marketing, etc.

49g. Who are the specific individuals/officers in the GEPC who are/would be/have been of most help to you? Please list

i.

ii.

iii.

\section{$\underline{\text { Social Capital - Network trust and contract }}$}

50. Does the company use written contracts or agreements for its most important export chain/deals?

Please tick $(\checkmark)$ appropriate number from 1- not at all; 2 - to a very low extent; 3 - to a low extent; 4- cannot determine; 5 - to an average extent; 6 - to a high extent; 7 - to a very high extent; NA- not applicable

$$
1 \square 2 \square 3 \square \quad 4 \square 5 \square 6 \square 7 \square \mathrm{NA} \square
$$

51. Is the company faced with other unwritten requirements to ensure the performance of these contracts or agreements?

Please tick $(\checkmark)$ appropriate number from 1- not at all; 2- to a very low extent; 3- to a low extent 4 - cannot determine; 5 - to an average extent; 6 - to a high extent; 7 - to a very high extent; NA- not applicable

$$
1 \square 2 \square 3 \square \quad 4 \square 5 \square 6 \square 7 \square \mathrm{NA} \square
$$

Please explain:

\section{Social Capital - Network Diversity, Integration and Complexity,}

52. How much percentage (\%) of your products go to the following destinations:

Ghana

USA

Africa

EU

Asia

Oceania

Latin America

(please indicate)

TOTAL

$$
\begin{aligned}
& \ldots \ldots \% \% \\
& \ldots \ldots . \% \% \\
& \ldots \ldots . \% \text { countries: } \\
& \ldots \ldots . \% \text { countries: } \\
& \ldots \ldots . \% \text { countries: } \\
& \ldots \ldots . . \\
& \ldots \ldots \% \text { countries: } \\
& \ldots \ldots \% \text { countries: }
\end{aligned}
$$


53. Frequency to export destinations:

Please tick $(\checkmark)$ appropriate number from 1- very irregular; 2- irregular; 3- somewhat irregular; 4- average; 5 - somewhat regular; 6 - regular; 7- very regular ; NA-not applicable

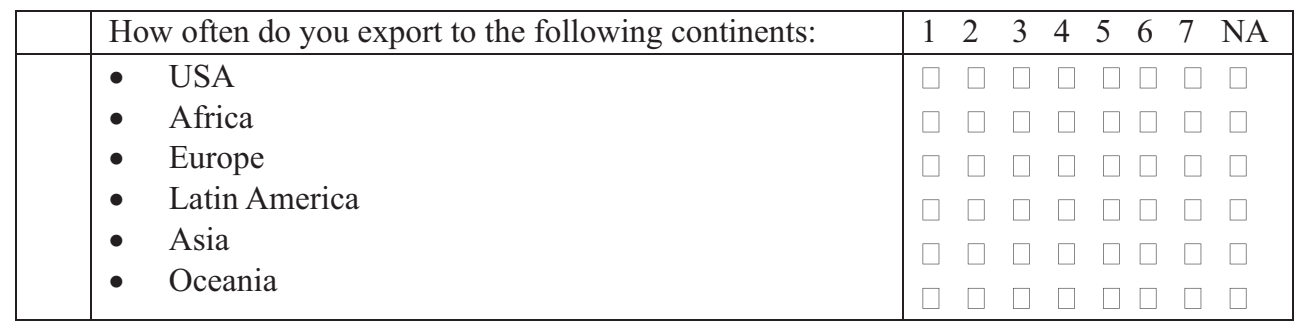

54a. To what extent does the company have a large number of suppliers?

Please tick $(\checkmark)$ appropriate number from 1 - to a very low extent; 2 - to a low extent; 3 - to a somewhat low extent; 4- to an average extent; 5 - to a somewhat high extent; 6 - to a high extent; 7- to a very high extent; NA- not applicable

$$
1 \square \quad 2 \square 3 \square \quad 4 \square \quad 5 \square \quad 6 \square 7 \square \mathrm{NA} \square
$$

54b. How many suppliers does the company have?

54c. To what extent does the company have selected or preferred suppliers?

Please tick $(\checkmark)$ appropriate number from 1 - to a very low extent; 2 - to a low extent; 3 - to a somewhat low extent; 4 - to an average extent; 5 - to a somewhat high extent; 6 - to a high extent; 7- to a very high extent; NA- not applicable

$$
1 \square \quad 2 \square 3 \square 4 \square 5 \square 6 \square 7 \square \mathrm{NA} \square
$$

55a. Does the company have selected or preferred agents or buyers?

Please tick $(\checkmark)$ appropriate number from 1 - to a very low extent; 2 - to a low extent; 3 - to a somewhat low extent; 4 - to an average extent; 5 - to a somewhat high extent; 6 - to a high extent; 7- to a very high extent; NA- not applicable

$$
1 \square \quad 2 \square 3 \square 4 \square \quad 5 \square \quad 6 \square \quad 7 \square \quad \mathrm{NA} \square
$$

55b. How many preferred agents or buyers does the company have?

56. Marketing of Export Products:

Please tick $(\checkmark)$ appropriate number from 1 - to a very low extent; 2 - to a low extent; 3 - to a somewhat low extent; 4 - to an average extent; 5 - to a somewhat high extent; 6 - to a high extent; 7- to a very high extent; NA- not applicable 


\begin{tabular}{|c|c|c|c|c|c|c|c|c|}
\hline & $\begin{array}{l}\text { Marketing (excluding advertising) of export products is done } \\
\text { by or through...... }\end{array}$ & 12 & 3 & & & & & NA \\
\hline a. & ... local government agencies & $\square \square$ & $\square$ & $\square$ & & & & $\square$ \\
\hline b. & ... contract outsourcing to agents in foreign countries & $\square \square$ & $\square$ & $\square$ & & & $\square$ & $\square$ \\
\hline c. & ... reliance on international network ties of management team & $\square \square$ & $\square$ & $\square$ & & & 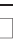 & $\square$ \\
\hline d. & $\begin{array}{l}\text {... using an incentive structure to reward customers who bring } \\
\text { in export orders }\end{array}$ & $\square \square$ & $\square$ & $\square$ & & & & $\square$ \\
\hline e. & 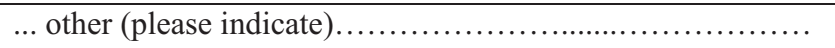 & $\square \square$ & $\square$ & & & & & $\square$ \\
\hline
\end{tabular}

57(a). To what extent are transportation arrangements to export markets timely?

Please tick $(\checkmark)$ appropriate number from 1 - to a very low extent; 2 - to a low extent; 3 - to a somewhat low extent; 4 - to an average extent; 5 - to a somewhat high extent; 6 - to a high extent; 7- to a very high extent; NA- not applicable

$$
1 \square 2 \square 3 \square \quad 4 \square \quad 5 \square 6 \square \quad 7 \square \quad \mathrm{NA} \square
$$

57(b). To what extent are transportation arrangements to export markets cost effective?

Please tick $(\checkmark)$ appropriate number from 1- to a very low extent; 2 - to a low extent; 3 - to a somewhat low extent; 4 - to an average extent; 5 - to a somewhat high extent; 6 - to a high extent; 7- to a very high extent; NA- not applicable

$$
1 \square \quad 2 \square 3 \square \quad 4 \square 5 \square 6 \square 7 \square \quad \mathrm{NA} \square
$$

58. Are there major differences in export requirements of the countries you export to?

Please tick $(\checkmark)$ appropriate number from 1 - to a very low extent; 2 - to a low extent; 3 - to a somewhat low extent; 4 - to an average extent; 5 - to a somewhat high extent; 6 - to a high extent; 7- to a very high extent

$$
1 \square \quad 2 \square \quad 3 \square \quad 4 \square \quad 5 \square \quad 6 \square \quad 7 \square \mathrm{NA} \square
$$

59a. Are there legal constrains on exports to specific destinations? Yes No

Please tick $(\checkmark)$ If No move to Q60.

59b. Please list three key contrains.

i .

ii.

iii.

\section{INSTITUTIONS}

\section{Proxies}

60. Does the company make use of extension services? Yes

No

Please tick $(\checkmark)$ If No move to Q62.

61. Extension Service and Timing:

Please tick $(\checkmark)$ appropriate number from 1 - to a very low extent; 2 - to a low extent; 3 - to a somewhat low extent; 4 - to an average extent; 5 - to a somewhat high extent; 6 - to a high extent; 7 - to a very high extent 


\begin{tabular}{|c|c|c|c|c|c|c|c|c|}
\hline & & 12 & 3 & 4 & 56 & & 1 & $\mathrm{NA}$ \\
\hline a. & $\begin{array}{l}\text { Which institutional extension services does your company } \\
\text { make use of? } \\
\text { i. the government } \\
\text { ii. the association } \\
\text { iii. private organizations }\end{array}$ & $\begin{array}{l}\square \square \\
\square \quad \square \\
\square \square\end{array}$ & $\begin{array}{l}\square \\
\square \\
\square\end{array}$ & $\begin{array}{l}\square \\
\square \\
\square \\
\end{array}$ & $\begin{array}{l}\square[ \\
\square \square \\
\square \square\end{array}$ & & $\begin{array}{l}\square \\
\square\end{array}$ & $\begin{array}{l}\square \\
\square \\
\square \\
\end{array}$ \\
\hline b. & $\begin{array}{l}\text { Do the extension services provide assistance during : } \\
\text { i. start up } \\
\text { ii. planting } \\
\text { iii. harvesting } \\
\text { iv. post-harvest } \\
\text { v. sales } \\
\text { vi. other (please indicate) }\end{array}$ & $\begin{array}{l}\square \\
\square \quad \square \\
\square \quad \square \\
\square \quad \square \\
\square \quad \square \\
\square \quad \square\end{array}$ & $\begin{array}{l}\square \\
\square \\
\square \\
\square \\
\square \\
\square\end{array}$ & $\begin{array}{l}\square \\
\square \\
\square \\
\square \\
\square \\
\square\end{array}$ & $\begin{array}{l}\square \\
\square \square \\
\square \square \\
\square \square \\
\square \square \\
\square \square\end{array}$ & & $\square$ & $\begin{array}{l}\square \\
\square \\
\square \\
\square \\
\square\end{array}$ \\
\hline
\end{tabular}

62. Does the company make use of technical and professional services?

Yes....... No........ Please tick $(\checkmark)$ If No, move to Q64.

63. Use of technical and professional services:

Please tick $(\checkmark)$ appropriate number from 1 - to a very low extent; 2 - to a low extent; 3 - to a somewhat low extent; 4 - to an average extent; 5 - to a somewhat high extent; 6 - to a high extent; 7- to a very high extent

\begin{tabular}{|c|c|c|c|c|c|c|c|c|}
\hline & & 12 & 3 & 4 & 5 & 6 & 7 & $\mathrm{NA}$ \\
\hline a. & $\begin{array}{l}\text { Which institution's technical and professional services does your } \\
\text { company make use of? } \\
\text { i. the government } \\
\text { ii. the association } \\
\text { iii. private organizations }\end{array}$ & $\begin{array}{l}\square \square \\
\square \quad \square \\
\square \quad \square\end{array}$ & $\begin{array}{l}\square \\
\square\end{array}$ & $\begin{array}{l}\square \\
\square \\
\square\end{array}$ & & $\begin{array}{l}\square \\
\square \\
\square\end{array}$ & $\begin{array}{l}\square \\
\square\end{array}$ & $\begin{array}{l}\square \\
\square \\
\square\end{array}$ \\
\hline b. & $\begin{array}{l}\text { Do the technical and professional services provide assistance during: } \\
\text { i. } \text { : planting } \\
\text { ii. harvesting } \\
\text { iii. } \\
\text { iv. other (please indicate) }\end{array}$ & $\begin{array}{l}\square \square \\
\square \square \\
\square \square \\
\square \square\end{array}$ & $\begin{array}{l}\square \\
\square \\
\square \\
\square\end{array}$ & & & $\begin{array}{l}\square \\
\square \\
\square \\
\square\end{array}$ & $\begin{array}{l}\square \\
\square \\
\square\end{array}$ & $\begin{array}{l}\square \\
\square \\
\square \\
\square\end{array}$ \\
\hline
\end{tabular}

64. Effectiveness of services provided:

Please tick $(\checkmark)$ appropriate number from 1- very ineffective; 2- ineffective; 3- somewhat ineffective; 4- average; 5 - somewhat effective; 6 -effective; 7- very effective; NA-not applicable (effective=frequency)

\begin{tabular}{|l|l|l|l|}
\hline In your opinion, how effective are the services provided by: & 1 2 3 4 5 6 7 NA \\
\hline a. the government & $\square \square \square \square \square \square \square \square$ \\
b. the association & $\square \square \square \square \square \square \square \square$ \\
c. private organizations & $\square \square \square \square \square \square \square \square$ \\
\hline
\end{tabular}

65(a) Influence on Company's Export Performance:

Please tick $(\checkmark)$ appropriate number from 1- very negative influence; 2- negative influence 3- somewhat negative influence; 4- average;5 - somewhat positive influence; 6 positive influence; 7- very positive influence; NA - not applicable 


\begin{tabular}{|c|c|c|c|c|c|c|c|}
\hline \multirow{2}{*}{$\begin{array}{l}\text { The influence of the following agents on the companies export } \\
\text { performance can be described as being: }\end{array}$} & 1 & \multicolumn{6}{|c|}{$\begin{array}{llllllll}1 & 2 & 3 & 4 & 5 & 6 & 7 & \mathrm{NA}\end{array}$} \\
\hline & & & & & & & \\
\hline 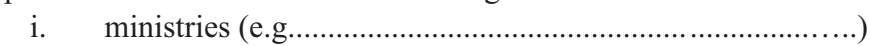 & $\square \square$ & $\square$ & $\square$ & & $\square$ & $\square$ & $\square$ \\
\hline 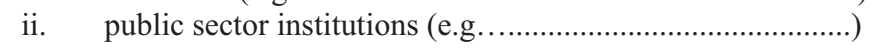 & $\square \square$ & $\square$ & $\square$ & & $\square$ & $\square$ & $\square$ \\
\hline 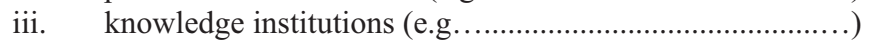 & $\square \square$ & $\square$ & $\square$ & & $\square$ & $\square$ & $\square$ \\
\hline 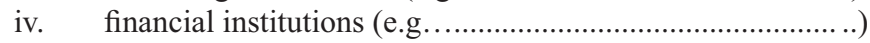 & $\square \square$ & $\square$ & $\square$ & & $\square$ & $\square$ & $\square$ \\
\hline 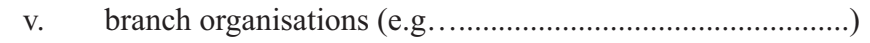 & $\square \square$ & $\square$ & $\square$ & & 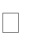 & ( & $\square$ \\
\hline 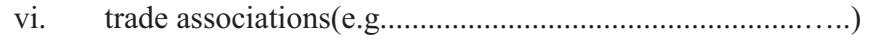 & $\square \square$ & $\square$ & $\square$ & & & & $\square$ \\
\hline 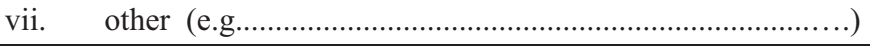 & $\square \square$ & $\square$ & $\square$ & & & & $\square$ \\
\hline
\end{tabular}

65(b) Influence of Selected Institutional Factors on Company's Export Performance:

Please tick $(\checkmark)$ appropriate number from 1- very negative influence; 2- negative influence

3- somewhat negative influence; 4- average; 5 - somewhat positive influence; 6 positive influence; 7 - very positive influence; NA-not applicable

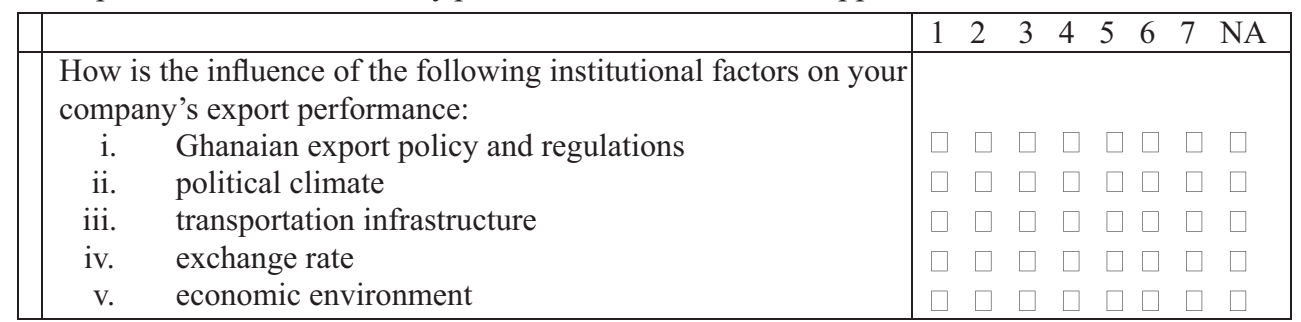

65(c). Influence of Selected Institutional Services on Company's Export Performance:

Please tick $(\checkmark)$ appropriate number from 1 - very negative influence; 2- negative influence

3- somewhat negative influence; 4- average; 5 - somewhat positive influence; 6 positive influence; 7 - very positive influence; NA-not applicable

\begin{tabular}{|c|c|c|c|c|c|c|c|}
\hline & 12 & 3 & 4 & 5 & & & \\
\hline $\begin{array}{l}\text { How is the influence of the services provided by the banking/ } \\
\text { finance sector on your company's export performance: } \\
\begin{aligned} \text { i. } & \text { outreach/branches } \\
\text { ii. } & \text { credit facilities } \\
\text { iii. } & \text { monitoring of contracts } \\
\text { iv. } & \text { other (please indicate) ............................................................ }\end{aligned}\end{array}$ & $\begin{array}{l}\square \quad \square \\
\square \quad \square \\
\square \quad \square \\
\square \quad \square\end{array}$ & $\begin{array}{l}\square \\
\square \\
\square \\
\square \\
\square\end{array}$ & $\begin{array}{l}\square \\
\square \\
\square \\
\square\end{array}$ & $\begin{array}{l}\square \\
\square \\
\square \\
\square\end{array}$ & $\begin{array}{l}\square \\
\square \\
\square\end{array}$ & $\begin{array}{l}\square \\
\square \\
\square\end{array}$ & $\begin{array}{l}\square \\
\square \\
\square \\
\square\end{array}$ \\
\hline
\end{tabular}

\section{FIRM PERFORMANCE}

66. What is the amount of your sales/turnover over the period 2011-2015? (GH $\phi)$

$20112012 \quad 2013 \quad 2015$ (projected)

67a. What is the number of staff over the period 2011-2015?

$20112012 \quad 2014 \quad 2015$ (projected)


67b. How many of the following category of workers are currently employed in your company?

Top level.

Senior/Middle level

Junior/Lower level

Workers.

Workers

Other

(full-time)

(casual)

(national service/attachment)

68a. How much profit (after tax) is/was realised in the following years $\mathrm{GH} \phi$ ?

2011

2012

2013

2014

2015(projected)

.

.........

............

............

68b. What is/was operating costs plus cost of goods sold over the following years?

$20112012 \quad 2014 \quad 2015$ (projected)

69. How competitive is/are your products in the NTAE sector?

Please tick $(\checkmark)$ appropriate number from 1- very uncompetitive; 2- uncompetitive; 3somewhat uncompetitive; 4- average; 5- somewhat competitive; 6- competitive; 7-very competitive

$$
1 \square \quad 2 \square \quad 3 \square \quad 4 \square 5 \square \quad 6 \square 7 \square
$$

70. How would you describe the quality of your product?

Please tick $(\checkmark)$ appropriate number from 1- very low; 2- low; 3- somewhat low; 4average; 5-somewhat high; 6- high; 7-very high

$$
1 \square \quad 2 \square \quad 3 \square \quad 4 \square \quad 5 \square 6 \square 7 \square
$$

\section{EXPORT PERFORMANCE}

71a. How would you rate the performance of your company in comparison with competing companies in the local market?

Please tick $(\checkmark)$ appropriate number from 1- very poor performance; 2- poor performance; 3- somewhat poor performance; 4- average; 5- somewhat good performance; 6-good performance; 7-very good performance

$$
1 \square 2 \square \quad 3 \square \quad 4 \square \quad 5 \square \quad 6 \square \quad 7 \square
$$

71b. How would you rate the performance of your company in comparison with competing companies in the international market?

Please tick $(\checkmark)$ appropriate number from 1- very poor performance; 2 - poor performance; 3-somewhat poor performance; 4- average; 5- somewhat good performance; 6-good performance; 7-very good performance

$$
1 \square \quad 2 \square \quad 3 \square \quad 4 \square \quad 5 \square \quad 6 \square \quad 7 \square
$$


71c. What are the top three (3) biggest export challenges faced by SMEs in the NTAE sector? Please list.

i.

ii.

iii.

71d What top three (3) suggestions do you have to improve the NTAE sector?

Please list

i.

ii.

iii.

72. Improvements in the SME-NTAE Sector.

Please tick $(\checkmark)$ appropriate number from 1 - to a very low extent; 2 - to a low extent; 3 - to a somewhat low extent; 4 - to an average extent; 5 - to a somewhat high extent; 6 - to a high extent; 7 - to a very high extent

\begin{tabular}{|l|l|llll|}
\hline & $1 \quad 2 \quad 3 \quad 4 \quad 5 \quad 6 \quad 7 \quad$ NA \\
\hline & In your opinion has there been an improvement in the & & & & \\
NTAE SME sector with respect to: & & & & \\
a. average market growth rate & $\square \quad \square \quad \square \quad \square \quad \square \quad \square \quad \square$ \\
b. number competing firms & $\square \quad \square \quad \square \quad \square \quad \square \quad \square$ \\
\hline
\end{tabular}




\section{APPENDIX 7}

\section{Analyses on Export Performance}

Table 1 Descriptive statistics

\begin{tabular}{|l|c|c|c|c|c|}
\hline Item & $* \mathrm{Q}$ & Min. & Max. & Mean & $\begin{array}{c}\text { Std. } \\
\text { Deviation }\end{array}$ \\
\hline $\begin{array}{l}\text { How competitive is/are your products in the NTAE } \\
\text { sector? }\end{array}$ & 69 & 2 & 7 & 5.39 & 1.110 \\
$\begin{array}{l}\text { How would you describe the quality of your products? } \\
\text { How would you rate the performance of your } \\
\text { company in comparison with competing companies in } \\
\text { the local market? }\end{array}$ & 70 & 3 & 7 & 5.91 & .996 \\
$\begin{array}{l}\text { How would you rate the performance of your } \\
\text { company in comparison with competing companies in } \\
\text { the international market? } \\
\text { Valid N (listwise) }=152\end{array}$ & $71 \mathrm{~b}$ & 1 & 7 & 4.68 & 1.369 \\
\hline
\end{tabular}

Table 2 Cronbach Alpha Results

\begin{tabular}{|l|l|l|l|}
\hline Item & Measure & CA & $\mathrm{N}$ \\
\hline ExpPerformance & Q71a Q71b & .674 & 152 \\
ExpNatQualPerf & Q69 Q70 Q71a & .720 & 152 \\
ExpIntQualPerf & Q69 Q70 Q71b & .568 & 152 \\
ExpA11QualPerf & Q69 Q70 Q71a Q71b & .709 & 152 \\
\hline
\end{tabular}

Table 1 provides the descriptive statistics of the 'Likert' scale questions measuring Export performance. Table 2 provides the Cronbach Alpha of the different measures for Export performance. The construct used in the final analysis (ExpAllQualPerf) had a Cronbach Alpha above 0.7 (0.709). For the robustness tests presented in the Tables 3 and 4 the independent variables (predictors) were first weighted by their respective score (factor loading) and summated. The summated values for the constructs were used for the regression in SPSS. The regression was done for each of the formative construct measures of the dependent variable. Table 3 shows to what extent each of the formative construct measures is explained by the $\mathrm{R}$ square and Adjusted R square in Table 4.6. Below Table 3 the computations are presented. 
Table 3 Test for robustness of formative construct measures - Regression results Analysis based on Chapter 4 (Table 4.4)

\begin{tabular}{|l|c|c|c|}
\hline Item & Question & R Square & $\begin{array}{c}\text { Adjusted R } \\
\text { Square }\end{array}$ \\
\hline $\begin{array}{l}\text { How competitive is/are your products in the NTAE sector? } \\
\text { How would you describe the quality of your products? }\end{array}$ & 69 & .167 & .099 \\
$\begin{array}{l}\text { How would you rate the performance of your company in } \\
\text { comparison with competing companies in the local market? }\end{array}$ & $71 \mathrm{a}$ & .287 & .221 \\
$\begin{array}{l}\text { How would you rate the performance of your company in } \\
\text { comparison with competing companies in the international } \\
\text { market? }\end{array}$ & $71 \mathrm{~b}$ & .394 & .345 \\
\hline
\end{tabular}

Computation of the independent variables in Table 4.6:

Entrepreneurial strategy

Intend_Expan $=\left(0.771 * \mathrm{R} \_\right.$intend_expan_19b $+.660 * \mathrm{R} \_$intend_expan_19c +

$0.826 * \mathrm{R} \_$intend_expan_19d $+0.635 * \mathrm{R}$ _intend_expan_19f) 4.

Innovation capacity

Biz_Outlook $=\left(0.668 * \mathrm{R} \_\right.$biz_outlook_27b $+0.872 * \mathrm{R} \_$biz_outlook_27c $+0.753 *$

R_biz_outlook_27d+0.882*R_biz_outlook_27e )/ 4 .

Upstream supply capacity

UpStream $=\left(0.744 * \mathrm{R} \_\right.$input_supply_31a $+0.841 * \mathrm{R} \_$input_supply_31b +

$0.816 * \mathrm{R}$ input_supply_31c $+0.704 * \mathrm{R}$ _input_supply_31d)/ 4 .

Downstream supply capacity (Q38 storage facilities)

DownStream $=\left(0.824 * \mathrm{R} \_\right.$DownStrSTTrans $+0.898 * \mathrm{R} \_$DownStrTrans $) / 2$.

International experience

InternExp $=\left(0.852 * \mathrm{R} \_\right.$inter_exp_16a $+0.758 * \mathrm{R} \_$inter_exp_16b $+0.882 * \mathrm{R}$ _inter_exp_16c $+0.897 * \mathrm{R}$ inter_exp_16d)/ 4 . 
Table 4 shows to what extent each of the formative construct measures is explained by the $\mathrm{R}$ square and Adjusted R square in Table 6.5. Below Table 4 the computations are presented.

Table 4 Test for robustness of formative construct measures - Regression results Analysis based on Chapter 6 (Table 6.5)

\begin{tabular}{|l|c|c|c|}
\hline Item & Question & R Square & $\begin{array}{c}\text { Adjusted R } \\
\text { Square }\end{array}$ \\
\hline $\begin{array}{l}\text { How competitive is/are your products in the NTAE sector? } \\
\text { How would you describe the quality of your products? }\end{array}$ & 69 & .412 & .128 \\
$\begin{array}{l}\text { How would you rate the performance of your company in } \\
\text { comparison with competing companies in the local market? }\end{array}$ & $71 \mathrm{a}$ & .417 & .251 \\
$\begin{array}{l}\text { How would you rate the performance of your company in } \\
\text { comparison with competing companies in the international } \\
\text { market? }\end{array}$ & $71 \mathrm{~b}$ & .598 & .403 \\
\hline
\end{tabular}

Computation of the independent variables in Table 6.5:

International experience

Inter_exp $=\left(0.921 * \mathrm{R} \_\right.$inter_exp_16a $+0.909 * \mathrm{R}$ _inter_exp_16c $+0.833 *$

R_inter_exp_16d)/3.

Export knowledge (reverse coded)

Mgt_export_const $=\left(\mathrm{RX}\right.$ _mgt_export_const_32 $\mathrm{f}^{*} 0.823+$

RX_mgt_export_const_32g*0.899+RX_mgt_export_const_32h*0.799+

RX_mgt_export_const_32i*0.804 + RX_mgt_export_const_32j*0.651)/5.

Intended expansion

Intend_expan $=\left(\mathrm{R}\right.$ _intend_expan_19b*0.903 $+\mathrm{R} \_$intend_expan_19c*0.757 +

R_intend_expan_19d*0.951 + R_intend_expan_19f*0.487)/4.

Business outlook (technological leadership)

Biz_outlook=( R_biz_outlook_27c*0.914 + R_biz_outlook_27e*0.970)/2.

Building social networks

Buildingcontact_soc $=\left(\mathrm{R} \_\right.$buildingcontact_tribal_foriegn_47aa*0.570 +

R_buildingcontact_religious_foriegn_47bb*0.617+

R_buildingcontact_college_foriegn_47cc*0.924+

R_buildingcontact_govt_foreign_47ee*0.604)/4. 
Corporate governance

Corp_gover $=($ R_corp_gover_24a*0.851 + R_corp_gover_24b*0.908 +

R_corp_gover_24c*0.854)/3.

Operations and maintenance

Equip_operat $=($ R_equip_operat_25a*0.818 + R_equip_operat_25b*0.895)/2.

Product development

Prodt_devpmt $=($ R_prodt_devpmt_28ba*0.481 + R_prodt_devpmt_28bb*0.822 +

$\mathrm{R} \_$prodt_devpmt_28bc*0.821 + R_prodt_devpmt_28bd*0.859)/4.

Export mode

Form_chan $=($ R_exportutlised_finalcustomer_45c*0.870+

R_exportutlised_knowncustomer_45d*0.862)/2.

Extension service

Extservice $=($ R_assistance_extservice_startup_61bi*0.905 +

R_assistance_extservice_planting_61bii*0.939+

R_assistance_extservice_harvesting_61biii*0.800+

R_assistance_extservice_sales_61bv*0.394)/4.

Professional and technical support

Profservice $=($ R_assistance_profservice_planting_63bi*0.939+

R_assistance_profservice_harvesting_63bii*0.950)/2.

Access to finance

Access_fin $=($ R_evaluate_finance_source_35a*0.799 +

R_evaluate_finance_source_35b*0.983 + R_evaluate_finance_source_35c*0.815+

R_evaluate_finance_source_35d*0.860)/4.

Reference: Pavel, A., Tsipi, H., Hanan, M. \& Nava, P. (2009). Validating Formative Partial Least Squares (PLS) Models: Methodological Review and Empirical Illustration. ICIS 2009 Proceedings, 193. http://aisel.aisnet.org/icis2009/193 


\section{APPENDIX 8}

Descriptives of answers on questions Q71c and Q71d

71c. What are the top three biggest export challenges faced by SMEs in the NTAE sector?

\begin{tabular}{|c|c|c|c|}
\hline & Frequency & Percentage & $\begin{array}{l}\text { Cumulative } \\
\text { Percentage }\end{array}$ \\
\hline No answer given & 10 & 6.6 & 6.6 \\
\hline $\begin{array}{l}\text { Poor/inadequate government } \\
\text { policy and government } \\
\text { interventions, much bureaucracy }\end{array}$ & 25 & 16.4 & 23.0 \\
\hline $\begin{array}{l}\text { Poor/inadequate logistics, roads, } \\
\text { transport, storage facilities }\end{array}$ & 38 & 25.0 & 48.0 \\
\hline $\begin{array}{l}\text { Inadequate monetary } \\
\text { interventions- finance, interest } \\
\text { rate, loans }\end{array}$ & 52 & 34.2 & 82.2 \\
\hline $\begin{array}{l}\text { Poor marketing of products, } \\
\text { packaging, knowledge of export } \\
\text { market requirements, rules etc. }\end{array}$ & 9 & 5.9 & 88.2 \\
\hline $\begin{array}{l}\text { Poor/absent services, utilities, } \\
\text { institutional services, poor } \\
\text { handling affecting quality of } \\
\text { products etc. }\end{array}$ & 18 & 11.8 & 100.0 \\
\hline Total & 152 & 100.0 & \\
\hline
\end{tabular}


71d What are the top three suggestions you have to improve the NTAE sector?

\begin{tabular}{|l|c|c|c|}
\hline & Frequency & Percentage & $\begin{array}{c}\text { Cumulative } \\
\text { Percentage }\end{array}$ \\
\hline $\begin{array}{l}\text { No answer given } \\
\text { Improve govt. macro policies, sub-sector } \\
\text { policies, institutional policies, promoting } \\
\text { private sector initiatives, PPP programs }\end{array}$ & 53 & 34.9 & 9.9 \\
$\begin{array}{l}\text { Improve export mode, expansion of } \\
\text { harbor and services, improve }\end{array}$ & 26 & 17.1 & 61.8 \\
$\begin{array}{l}\text { infrastructure } \\
\text { Improve/implement govt. policy on } \\
\text { finance, bank policy, insurance for agric., } \\
\text { PPPs, financing initiatives }\end{array}$ & 33 & 21.7 & 83.6 \\
$\begin{array}{l}\text { Improve networking through associations, } \\
\text { provision of real time information on } \\
\text { trade regulations, protection of }\end{array}$ & 11 & 7.2 & 90.8 \\
intellectual property & 152 & 100.0 & \\
$\begin{array}{l}\text { Improve training and make it affordable, } \\
\text { improve utility services, prof. services, } \\
\text { place competent personnel in charge of } \\
\text { govt. inst. } \\
\text { Total }\end{array}$ & 14 & 9.2 & \\
\hline
\end{tabular}




\section{APPENDIX 9}

\section{Recent Developments in Ghana's Shea Sector}

The Ghana Tree Crop Development Authority Bill was passed in Parliament on December 2, 2019. The Bill now awaits Presidential assent to be passed into law. This achievement was a collaboration between government and stakeholders in the tree crops industry. The Ghana Tree Crop Development Authority (GTCDA) Bill seeks to regulate the tree crop sectors of cashew, oil palm, shea, rubber, mango and coconut.

Currently, the Ghana Cocoa Board (COCOBOD) has the mandate to regulate shea marketing and export through vetting and approving license applications of private buyers and exporters. Shea is known as an ingredient in natural lines of cosmetics, food and confectionery industries with significant increases in global demand since 2000. This positions shea as a leading nontraditional export commodity although about $52 \%$ of total shea production is also not collected in Ghana. Shea development is considered a potential in meeting the sustainable development goal especially on poverty alleviation among rural women in the savannah zone in Ghana. Although the Cocoa Research Institute of Ghana (CRIG) established a station at Bole in 1976 to carry out research into shea, none of the key policies and strategies for developing the agricultural sector included shea.

The first Shea Development Strategy (SHEDS) was developed as a national strategy document for 2015 to 2030 to serve as a roadmap for sustainable growth and development of shea. The objectives are in three thematic areas: i) research, extension, plantation development and conservation, ii) strategic stakeholder partnerships, iii) products development, marketing and quality standards. The constraints identified for the shea sector in the strategy document include: poor research extension, weak collaboration, coordination and information sharing. The document also identified lack of interventions, duplication of efforts, poor organization of producers and weak advocacy as constraints. The enabling environment is weak because SMEs dominating the shea sector have weak entrepreneurial competence and access to credit facilities and financial support pose a challenge. Further inadequate infrastructure such as motorable roads, electricity and telecommunication facilities in shea growing areas has led to the under development of the shea sector.

Sources:

1. Shea Unit, COCOBOD (September 2015). Shea Development Strategy 2015-2030. Unpublished.

2. PN Africa (December 5, 2019). Legislative Alert. www.parliamentafrica.com 


\section{Summary}




\section{Summary}

Primary agriculture and agribusiness are considered vital to the economies of Sub Saharan Africa (SSA) countries. However, contribution of Africa's agricultural exports to world trade is less than $15 \%$ which is limited, given Africa's vast amount of arable land and resources. The main agricultural features of SSA economies are small farm holdings, dependent on rain fed agriculture, and working on a small portion of arable land. Agricultural produce (until the 1970s) were traditional exports, horticultural produce and high value cash crops including: cocoa, tea, coffee, cotton, oranges, and, timber. With agriculture employing close to $60 \%$ of the work force in Africa (majority classified as rural poor) and contributing averagely $30 \%$ of gross domestic product, the foreign revenues generated could not stimulate development. This is associated with the fact that African economies do not control world market prices, not much investments went into agriculture, and exports had little added value. Two strategic interventions stand out namely: improving the agriculture, and agribusiness environment, and, diversification of export portfolios. African economies given the earlier status quo did not have possibilities to leverage or exploit opportunities to their advantage. So, it comes as no surprise that Africa's agriculture and agribusiness is receiving increasing attention from governments, international partners, and donors, for the agri supply chains. In the last three decades, African Union (AU) member states have sought to reverse the status quo and improve interventions by commitment to more effective agriculture and agribusiness policies (CAADP targets). African governments have embarked on export diversification (programmes/strategies) primarily nontraditional exports including agricultural exports. Ghana is no exception, and in 2017, Ghana was listed in World Development Indicators as one of the best performing countries in Africa (30 percentage points away from the frontier- best performing country, New Zealand). In 2019, the International Monetary Fund (IMF) discussing the fastest growing SSA economies (per GDP growth \%) stated Ghana (7.6\%) as one of the top three, behind Ethiopia (8.5\%) and Rwanda (7.8\%). In spite of these positive statistics, Ghana has not met all CAADP targets. It is a general perception that AU and state level policies on agriculture and agribusiness are not properly aligned to positively impact agri supply chains and non-traditional agricultural exports. The thesis explored this misalignment, focusing on NTAE SMEs in Ghana, their characteristics, environment and export performance. It is considered that the findings will contribute relevant information to support Ghana's Global Agenda 2030 and the sustainable development goals (SDGs).

This thesis addresses the following central research question and sub-questions. Within the theoretical context of the Resource Based View (RBV), Supply Chain Management (SCM), and network theories, which characteristics (specifically internal capabilities, resources and network relationships) of NTAE SMEs and their business environment are positively related to 
their export performance? The sub-questions to be addressed are:

1. Which of the firms' internal capabilities are most relevant to NTAE SME export performance?

2. What are the challenges that confront exporting NTAE SMEs and what could be done to improve the situation?

3. What combination of the firm resources and network relationships are positively linked to NTAE SME performance?

\section{Overview of Agriculture and Agribusines in Sub Saharan Africa}

Chapter 2 provides an overview of agriculture and agribusiness in Africa with reference to the Comprehensive Africa Agriculture Development Programme (CAADP). The CAADP is a classic initiative indicating what the different AU member states committed themselves to do in order to improve Africa's agriculture and agribusiness. The study in Chapter 2 investigates the viewpoints of 11 respondents (government officials, experts and professionals, who were AU member representatives) from Tanzania, Mali, Mozambique, Kenya and Ghana on different factors related to agriculture in their respective countries. The objective is to assess whether external factors (public policy, financing, political wherewithal and creating partnership opportunities for small scale farmer/enterprises) would support agriculture and agribusiness. The viewpoints of the respondents are interpreted as an appreciation of the importance of creating an enabling environment for agriculture and agribusiness. It is found that for public policy, the "macro" state level policy is not adequately aligned with "micro" agri supply chain factors. This explains some of the issues emanating from further studies in Chapters 5 and 6 which suggest the upstream network linkages are poor between NTAE SMEs and extension services. Further the downstream network coordination is equally poor as either the certification processes/controls are not effective enough, export regulations are not strictly adhered to, leading loss of export market (reject of goods). The weak institutional support also means that the NTAE SMEs cannot build capacity to strengthen their resource base. The state policy either does not address critical issues at micro level, policy formulation, and, implementation is not participatory enough, or policy does not include agribusiness/value added interventions. Again this may very well be reflected by the view of one respondent (Case 5) that "there are no explicit policy provisions on agribusiness in the broader agriculture policy and that the agriculture policy was not very effective in general". In one case the policy is considered effective because of the positive developmental impact on small scale farmers, creating downstream opportunities to reach modern markets through public-private partnerships. Agribusiness financing is perceived to be inadequate, with urgings for more government prioritization to support this. Perceptions on government commitment to agribusiness development is used as a measure of partnerships opportunities. This indicator on 
agribusiness exceeded agriculture in only two cases reflecting more attention to agriculture and less focus on value addition through agribusiness. Linkages for small scale farmers or agri enterprises are effective in cases where substantial investments have been made in this or where tourism is encouraged. It is concluded that an improved economic environment with policies addressing the different phases of agri supply chains would be beneficial to all the 5 cases/countries.

Ele Agbe-Example of a Non-Traditional Agricultural Exports (NTAE) SME in Ghana's shea sector.

Chapter 3 presents a case study on Ele Agbe, an SME operating in the downstream end of Ghana's shea supply chain. The company is studied based on a face-to-face semi-structured interview with the CEO. The shea sector is an NTAE sub-sector which is experiencing increasing demand for shea, for use in skin and hair products. This gives Ele Agbe good market opportunity(s). The SME has developed trade secret for its product lines for competitive edge. This also means the company is required to build its capacity, to continuously innovate and safeguard its knowledge build up. Through this the resource base is developed along the VRIN concept of RBV. However Ele Agbe is confronted with the challenge of operating in an unregulated sector (no policy/framework) resulting in gaps in the shea supply chain. Ele Agbe has the intention of expanding export markets through its business networks. The SME is constrained because it funds its operations through equity financing. The export knowledge and international experience is driven by the CEO who has 18 years of work experience in exporting. Although governance structures are weak, the SME meets all regulatory and certification requirements for its operations. The company is important for rural poor women to be employed as shea pickers. Upstream, the network relational embeddedness is strong, based on trust and strong bonds. Ele Agbe has exploited network links with established buyers who advertise its products on their website, in this way it can profit from e-platforms. In terms of networks, the structural embeddedness with institutions is sparse. The company has not registered with any of the shea associations nor with government export agencies. The CEO is more concerned about the absence of a national sector policy for shea and lack of a shea regulator. These seriously affect chain operations and increase costs of coordination of activities. This case study showed that government facilitating micro credit lines for access to finance by NTAE SMEs, such as Ele Agbe, improving the NTAE environment with sub-sector policies, and strengthening the intellectual property (IP) framework to encourage IP registrations would help to improve the performance of NTAEs.

\section{Internal Capabilities and Export Performance of NTAE SMEs in Ghana}

Chapter 4 discusses the internal capabilities (human and physical capital, social and management team networks) of NTAE SMEs which are considered to positively impact export 
performance. The ability of NTAE SMEs to succeed in exporting is thought to be based on their internal capabilities - the human capital (export knowledge), and the organization of the value chain activities (upstream supply capacity). The study uses cross-sectional data from a sample of 152 NTAE SMEs located in the coastal, forest and savannah zones of Ghana. Eighty three percent $(83 \%)$ of the cases are located in the coastal zone. Partial Least Squares Structural Equation Modelling (PLS SEM) analyses is applied. PLS SEM is appropriate for smaller sample sizes and reveals associations that may not reflect in standard regression or covariancebased SEM methods. The results suggest that when competing internationally, the NTAE SMEs could gain higher performance levels if they combine export knowledge with upstream supply capacity. Export knowledge and good organization of the upstream supply capacity in chain relations will help NTAE SMEs to gain better performance when competing in international markets. The result about the importance of building upstream supply chain relations is not surprising and suggests that the best SMEs, such as Ele Agbe in Chapter 2, are able to integrate their upstream chain activities better than the average SMEs. The positive impact of export knowledge on exporting shows that knowing how to get your goods into foreign markets is essential for exporting NTAE SMEs. This supports the argument that downstream chain networks and resources need to be properly aligned and strengthened. The findings based on the export performance measures show that NTAE SMEs fare well with low levels of entrepreneurial strategy and innovation capacity when competing locally but will need higher levels of entrepreneurial strategy and innovation capacity when competing internationally. From an RBV perspective, NTAE SMEs will have to build resources to strengthen entrepreneurial strategy and innovation capacity. Implications of the study suggest that NTAE SMEs could improve their social networks through building groups or associations for export. These groups or associations are considered to undertake strong monitoring and enforcement of rules. It is concluded that focusing on added value products, organising franchise markets with links to multinational companies or large buyers, and diversification of export markets can be helpful strategies for exporting NTAE SMEs.

\section{Connecting the dots: A multiple case study of the network relations of NTAE SMEs in Ghana}

Based on network theory, Chapter 5 discusses the optimal mix of internal firm factors (or internal capabilities, human and physical capital, social and management team networks) and contextual factors (such as institutions and supply chain complexity) for export performance. The objective is to identify which combination of internal firm factors will lead to higher performance in terms of firm size given different contextual factors. The CEOs and managers of ten SMEs in the NTAE sector are interviewed face-to-face based on a structured questionnaire containing both open and closed ended questions. The findings suggest that performance is highest for those SMEs where the CEO has received tertiary level education and has export experience for over five years, exports directly (no use of traders/agents), makes 
extensive use of Ghana's export institutions, uses export contracts and is a member of an SME association. In general the NTAE SMEs face more challenges in their downstream than in their upstream processes. The type of export product is a determinant factor for downstream costs. The network relations in the upstream processes are mostly based on relational embeddedness, that is, on trust (unwritten agreements) which has led to strong bonds over time. The strong upstream relationships could be used by the SMEs to obtain bridging ties with other networks. The scenario downstream is a little different. The networks are dense for NTAE SMEs who belong to an association and sparse for those who do not. Although the agri supply chains upstream are not that complex, location is thought to influence the number of actors that the NTAE SME may have to connect to for export. Policy makers can use these findings to fine tune their policy based on the different locations (coastal, forest and savannah zones) of SMEs.

\section{NTAE performance in Ghana. Exporting SMEs' Characteristics, Export Mode and Institutions}

Chapter 6 investigates the combination of factors including SME characteristics, export mode and institutional (services and financial) arrangements of exporting SMEs in the NTAE sector to identify the factors that positively impact export performance and ultimately SME growth and development. The study applied PLS SEM analysis on the 152 cases discussed in Chapter 4 in the NTAE sector in Ghana. The findings suggest export knowledge, corporate governance, product development, and professional and technical support are positively related to export performance. Interestingly, building social networks (except being a member of associations/groups) is negatively related to export performance. A possible explanation might be that networks based on tribal and religious affiliations, contacts via college and school alumni and government initiatives are not the best way to find leads for export orders. The time spent on building and maintaining these networks is detrimental to export performance. Also export mode is negatively related to export performance. The reason for this finding might be that in the case of Ghanaian NTAE SMEs the export mode is restricted. Most SMEs have to conform to the schedules of export carriers/freight forwarders to export their goods. Extension services and access to finance are not significantly related to export performance. These suggest that in the upstream chain operations and activities, institutional networks and coordination are poor. In relation to agri supply chains this finding is disturbing as it indicates that micro and macro level policies are misaligned.

The study sample was categorised (non-processed, semi-processed and processed) as opposed to classification (horticultural products, oil seeds and nuts, dairy products etc.) making recommendations generic to the NTAE sector as a whole and not specific to sub-sectors. The results of this study will help shape and focus prioritization of policy interventions in the NTAE SME sector. Some policy intervention could include, encouraging public private partnerships 
where government shortfalls in NTAE support are identified. There is the need to create and make more incentives available to private sector actors in agri supply chains in order to strengthen their resource base and internal capacities, so that more services can be provided. Government interventions leading to coordinated arrangements with international carriers/transporters could improve the limited transport options available locally to NTAE SMEs. 


\section{REFERENCES}




\section{REFERENCES}

Abban, R., Aheto, J.B.K., Omta, S.W.F. \& Scholten, V.E. (Forthcoming). Some Perspectives on Agriculture and Agribusiness in Sub-Saharan Africa. International Journal of Technology and Entrepreneurship.

Abban, R., Scholten V., Velde van der, G., Omta, (Onno) S.W.F. \& Aheto, J.B. (2018). Internal Capabilities and Export Performance of SMEs in Ghana's Non-Traditional Agricultural Export Sector. Journal of Management \& Entrepreneurship, 12(3), pp1-29.

Abban, R., Omta, (Onno) S.W.F., Aheto, J.B., \& Scholten, V.E. (2014). Ele Agbe in search of a new light in Ghana's shea sector. International Food and Agribusiness Management Review, 17(sp. issue B), pp63-68.

Abban, R., Omta. S.W.F., Aheto, J. B., \& Scholten, V. E. (2013). Connecting the dots: A multiple case study of the network relationships of small and medium-sized enterprises (SMEs) in the non-traditional agricultural export (NTAE) sector of Ghana. African Journal of Economic and Management Studies, 4(1), pp74-94.

Abor J., Agbloyor E.K., \& Kuipo, R. (2014). Bank finance and export activities of small and medium enterprises. Review of Development Finance, 4(2), pp97-103.

Abor, J. \& Quartey, P. (2010). Issues in SME development in Ghana and South Africa. International Research Journal of Finance and Economics, 39(6), pp218-228.

Abor, J., \& Biekpe, N. (2007). Corporate governance, ownership structure and performance of SMEs in Ghana: Implications for financing opportunities. Corporate Governance, 7(3), pp288-300.

Abor, J. \& Biekpe, N. (2006). Small business financing initiatives in Ghana. Problems and Perspectives in Management, 4(3), pp69-77.

Abor J. (2004). Internationalisation and financing options of Ghanaian SMEs. Acta Commercii, 4, pp60-72.

Acquaah, M. \& Agyapong, A., (2015). The relationship between competitive strategy and firm performance in micro and small businesses in Ghana: The moderating role of managerial and marketing capabilities. Africa Journal of Management, 1(2), pp172-193.

Adenle, A. A., Azadi, H. \& Manning, L. (2017). The era of sustainable agricultural development in Africa: Understanding the benefits and constraints. Food Reviews International.pp1-52 DOI: 10.1080/87559129.2017.1300913

Adomako, S. \& Danso, A. (2014). Financial Literacy and Firm performance: The moderating role of financial capital availability and resource flexibility. International Journal of Management \& Organizational Studies, 3(4), pp1-15.

Adu-Gyamfi, N. \& Korneliussen, T. (2013). Antecedents of export performance: the case of an emerging market. International Journal of Emerging Markets, 8(4), pp354-372. 
Afenyadu, D., King, K., McGrath, S., Oketch, H., Rogerson, C. \& Visser, K. (1999). Learning to Compete: Education, Training \& Enterprise in Ghana, Kenya \& South Africa Education Research Paper No. 42.

Affognon, H., Mutungi, C., Sanginga, P., Borgemeister, C. (2015). Unpacking postharvest losses in Sub-Saharan Africa: a meta-analysis. World Development, 66, pp49-68.

African Union Commission-AUC (2019). The CAADP Biennial Review - Measuring Progress and Keeping Accountability in Agriculture.

Agambila, Agasika. 2005. Speech delivered at Roundtable, in Accra, Ghana on the theme, 'Research as key to development of SMEs', Network Herald ed., July 8. Other media sources quoted: GNA, BBC, CNN and Reuters.

Aker, J.C. (2010). Dial -“A” for Agriculture: Using Information and Communication Technologies for Agricultural Extension in Developing countries. Conference Agriculture for Development-Revisited, University of California at Berkeley, pp1-2.

Akomea, S. Y., Sørensen, O. J., and Amponsah-Efah, K. (2014). Export drivers and barriers: Evidence from Ghanaian pharmaceutical manufacturing firms. Global Journal of Business, 8(2), pp81-96.

Akyol, A. \& Akehurst, G. (2003). An investigation of export performance variations related to corporate export market orientation. European Business Review, 15(1), pp5-19.

Amanor, K.S., \& Chichava, S. (2016). South-south cooperation, agribusiness, and African agricultural development: Brazil and China in Ghana and Mozambique. World Development, 81, pp13-23.

Amoah-Mensah. A. (2013). Strategic resources and performance of rural SMEs. International Journal of Business and Social Research, 3(4), pp106-119.

Amoako, I.O. \& Matlay, H. (2015). Norms and trust-shaping relationships among foodexporting SMEs in Ghana. Entrepreneurship and Innovation, 16(2), pp123-134.

Anderson, J. R. \& Feder,G. (2007). Handbook of Agricultural Economics. Agricultural Extension, 3,pp2343-2378.

Ansong, A. \& Agyemang, O.S. (2016). Firm reputation and financial performance of SMEs: the Ghanaian perspective. EuroMedJ. Management, 1(3), pp237-251.

Apadore, K. \& Zainol Binti, S.S. (2014). Determinants of Corporate Governance and Corporate Performance among Consumer Product Industry in Malaysia: A Theoretical Model. International Journal of Academic Research in Accounting, Finance and Management Sciences, 4(2), pp159-165.

Appiah, K., Selassie, H., \& Burnley, R. (2015). Determinants of SME international competitiveness: a case of Ghanaian horticultural exporters. The Business and Management Review, 6(3), pp191-204.

Ardyan, E. (2016). Market Sensing Capability and SMEs Performance: The Mediating Role of Product Innovativeness Success. Business \& Economics Review, 25(2), pp79-97. 
Armstrong, C. E. \& Shimizu, K. (2007). A review of approaches to empirical research on the resource-based view of the firm. Journal of Management, 33(6), pp959-986.

Arribas I. \& Vila J.E. 2007. Human capital determinants of the survival of entrepreneurial service firms in Spain. International Entrepreneurship Management Journal, 3(3), pp309-322. doi:10.1007/s11365-007-0038-z.

Aryeetey, E \& McKay, A. (2007). Ghana: The Challenge of Translating Sustained Growth into Poverty Reduction. pp147-168. In: Besley, T. \& Cord, L.J. (eds) Delivering on the Promise of Pro-poor Growth. Insights and Lessons from Country Experiences. Palgrave Macmillan and the World Bank.

Aryeetey, E., \& Ahene, A. (2005). Changing regulatory environment for small-medium size enterprises and their performance in Ghana. CRC Working Paper No. 30594, Centre on Regulation and Competition (CRC).

Axelsson, B. \& Easton, G. (2016). Industrial networks: a new view of reality. New York: Routledge

Aziz, N.A. \& Yassin, N.M. (2010). How Will Market Orientation and External Environment Influence the Performance among SMEs in the Agro-Food Sector in Malaysia? International Business Research, 3(3), pp154-164.

Baah-Nuakoh, A., Jebuni, C.D., Oduro, A. D. \& Asante,Y. (1996). Exporting Manufactures from Ghana. Overseas Development Institute, London.

Babu, S.C., Manvatkar, R., \& Kolavalli, S. (2015). Strengthening Capacity for Agribusiness Development and Management in Sub-Saharan Africa. Africa Journal of Management, 2(1), pp1-30. DOI: 10.1080/23322373.2015.1112714

Baglee, D \& Knowles, M. (2010). Maintenance strategy development within SMEs: the development of an integrated approach. Control and Cybernetics, 39(1).

Bagozzi, R. P., \& Yi, Y. (1988). On the evaluation of structural equation models. Journal of the Academy of Marketing Science, 16(1), pp74-94.

Bamiatzi, V. C. \& Kirchmaier, T. (2014). Strategies for superior performance under adverse conditions: A focus on small and medium-sized high-growth firms. International Small Business Journal, 32(3), pp259-284.

Bank of Ghana (BOG) Annual Reports 2005-2017: Source http://bog.gov.gh/.

Barasa, L., Knoben, J., Vermeulen, P., Kimuyu, P., and Kinyanjui, B. (2017). Institutions, resources and innovation in East Africa: A firm level approach. Research Policy, 46(1), pp280-291.

Barney, J.B. (2001). Is the Resource-Based "View" a useful perspective for strategic management research? Yes. Academy of Management Review, 26(1), pp41-56.

Barney, J. (1991). Firm resources and sustained competitive advantage. Journal of Management, 17(1), pp99-120.

Bates, R. H. (2005). Markets and States in Tropical Africa, The Political Basis of Agricultural Policies. University of California Press, Berkeley CA. 
Baum, C. F., Schaffer, M. E. \& Stillman, S. (2003). Instrumental variables and GMM:

Estimation and testing. Stata Journal 3, pp1-31.

Becker, G. S. (1964). Human capital, New York: Columbia Univ. Press (for National Bureau of Economic Research)

Bessant, J., Lamming, R., Noke, H., and Phillips, W. (2005). Managing innovation beyond the steady state. Technovation, 25(12), pp1366-76.

Bhagavatula S. (2009). Weaving Social Networks -Performance of small rural firms in India as an outcome of entrepreneurs' social and human capital. (PhD Dissertation), Vrije University, The Netherlands.

Bijman, J., Omta, S.W.F., Trienkens, J.H., Wijnands, J.H.M., \& Wubben, E.F.M. (2006). International agri-food chains and networks. Management and organization. Wageningen Academic Publishers, Wagengingen

Bijmolt, T.H.A. \& Zwart, P.S. (1994). The impact of internal factors on the export success of Dutch small and medium-sized firms. Journal of Small Business Management, 32(2), pp69-83.

Boansi, D., Lokonon, B.O. K. \& Appah, J. (2014). Determinants of Agricultural Export Trade: Case of Fresh Pineapple Exports from Ghana. British Journal of Economics, Management \& Trade, 4(11), pp1736-1754.

Bontis, N. \& Serenko, A. (2007). The moderating role of human capital management practices on employee capabilities. Journal of Knowledge Management, 11(3), pp31 - 51.

Boso, N., Oghazi, P., Cadogan, J.W., \& Story, V.M. (2016). Entrepreneurial and MarketOriented activities, financial capital, environment turbulence, and export performance in an emerging economy. Journal of Small Business Strategy, 26 (1), pp1-24.

Boso, N., Story, V. M., Cadogan, J.M., Micevski, M. \& Kadić-Maglajlić, S. (2013). Firm Innovativeness and Export Performance: Environmental, Networking, and Structural Contingencies. Journal of International Marketing, 21(4), pp62-87.

Bougheas, S., Mizen, P. \& Yalcin, C. (2006). Access to external finance: Theory and evidence on the impact of monetary policy and firm-specific characteristics. Journal of Banking \& Finance, 30(1), pp199-227.

Brown, T.E., Davidsson, P., \& Wiklund, J. (2001). An operationalization of Stevenson's conceptualization of entrepreneurship as opportunity based behavior. Strategic Management Journal, 22(10), pp953-68.

Brouthers, K. D., \& Hennart, J. F. (2007). Boundaries of the firm: Insights from international entry mode research. Journal of Management, 33, pp395-425.

Buadi, D.K., Anaman, K.A. \& Kwarteng, J.A. (2013). Farmers' perceptions of the quality of extension services provided by non-governmental organisations in two municipalities in the Central Region of Ghana. Agricultural Systems, 120, pp20-26 
Buame S. (2003). Entrepreneurship and International business Strategy. An insight into the key success factors of the Exporting Entrepreneurs in Ghana. Journal of Management Studies, 15(1), pp34-51.

Buame S. (1996). Entrepreneurship: A contextualization of international marketing activities and some observations. Studies in Development, 16, pp28-42.

Buatsi, S.N. (2002). Financing non-traditional exporters in Ghana. Journal of Business and Industrial Marketing, 17(6), pp501-522.

Buatsi, S. N. (2000). Perceived Risk and the Pre-Export Behaviour of Firms: A Conceptual Model. The Journal of Management Studies, 15(1), pp10-33.

Burt, R. (1992). Structural Holes: The Social Structure of Competition. Harvard University Press: Cambridge, Massachusetts.

Calabro, A. \& Mussolino, D. (2011). How do boards of directors contribute to family SME

export intensity? The role of formal and informal governance mechanisms. Journal of Management and Governance.pp1-41. DOI 10.1007/s10997-011-9180-7

Caligiuri, P. M. (2000). The big five personality characteristics as predictors of expatriate's desire to terminate the assignment and supervisor-rated performance. Personnel Psychology, 53, pp67-88.

Carland J.C., Carland, J.W., \& Stewart, W.H. (2015). Seeing what's not there: The enigma of entrepreneurship. Journal of Small Business Strategy, 7(1), pp1-20.

Cardoza, G., Fornes, G., Farber, V., Duarte, R. G., \& Gutierrez, J. R. (2015). Barriers and public policies affecting the international expansion of Latin American SMEs: Evidence from Brazil, Colombia, and Peru. Journal of Business Research, 69(6), pp2030-2039.

Casson, M., \& Wadeson, N. (2007). The discovery of opportunities: Extending the economic theory of the entrepreneur. Small Business Economics 28, pp285-300

Chandra, K \& Kumar, S. (2000). Supply chain management in theory and practice: a passing fad or a fundamental change? Industrial Management \& Data System, 100(3), pp100113

Child, J., Hsieh, L., Elbanna, S., Karmowska, J., Marinova, S., Puthusserry, P. \& Zhang, Y. (2017). SME international business models: the role of context and experience. Journal of World Business, 52(5), pp664-679.

Chin, T.A., Tat, H. H. \& Sulaiman, Z. (2015). Green supply chain management, environmental collaboration and sustainability performance. Procedia CIRP 26, pp695-699. https://doi.org/10.1016/j.procir.2014.07.035

Chin, W.W. (1998). Issues and Opinion on Structural Equation Modeling. Management Information Systems Quarterly, 22(1), pp1-14.

Child, J., \& Hsieh, L. (2013). Decision mode, information and network attachment in the internationalization of SMEs: A configurational and contingency analysis. Birmingham Business School, Discussion Paper Series, pp1-39. 
Christopher, M. (2011). Logistics and supply chain management $4^{\text {th }}$ Ed., UK: Pearsons Education Ltd.

Christopher, M. (2000). The Agile Supply Chain: Competing in Volatile Markets. Industrial Marketing Management, 29(1), pp37-44.

Chung, H.F.L., Ding, Z. \& Ma, X. (2019). Organisational learning and export performance of emerging market entrepreneurial firms: The roles of RBV mechanism and decisionmaking approach. European Journal of Marketing, pp1-22. https://doi.org/10.1108/EJM-08-2017-0496

Claessens, S. \& Yurtog $`$ lu, B.B. (2013). Corporate governance in emerging markets: a survey. Emerging Markets Review, 15, pp1-33.

Coeurduroy, R. \& Murray, G.C. (2008). Institutional environments and the location decisions of start-ups: evidence from the first international market entries of new technologybased firms. Journal of International Business Studies, 39, pp625-646.

Cole, G. (2004). Management Theory and Practice. $6^{\text {th }}$ Ed., Thomson Learning, UK.

Coleman, J.S., Katz, E. \& Menzel, H. (1966). Medical innovation: A diffusion study. NY. Free Press.

Cooke, F.L. (2003). Plant Maintenance strategy: evidence from four British manufacturing firms. International Journal of Quality \& Reliability Management, 9 (3), pp239-249.

Core Welfare Indicators Questionnaire Survey (CWIQ) 1997 (2001)- Ghana Statistical Service.

Costa e Silva, S., Pacheco, E., Meneses, R., \& Brito, C. (2012). The Importance of SecondHand Knowledge in the Revised Uppsala Model: Can European Textiles Producers Export to China? Journal of Global Marketing, 25(3), pp141-160

Cramer, C., Johnston, D. \& Oya, C. (2009). Africa and the Credit Crunch: From Crisis to Opportunity? African Affairs, 108/433, pp643-654.

Damanpour, F. (1996). Organizational complexity and innovation: developing and testing multiple contingency models. Management Science, 42(5), pp693-716.

Damijan, J.P., Rojec, M. \& Ferjančič, M. (2011). The growing export performance of transition economies: EU market access versus supply capacity factors. PANOECONOMICUS, 4, pp489-509.

Dana, L-P, Grandinetti, R., \& Mason, M.C. (2016). International entrepreneurship, export planning and export performance: evidence from a sample of winemaking SMEs. International Journal of Entrepreneurship and Small Business, 29(4), pp602-626.

DaSilva, C.M. \& Trkman, P. (2014). Business model: what it is and what it is not. Long Range Planning, 47, pp379-389.

Demil, B., Lecocq, X., Ricart, J.E. \& Zott, C. (2015). Introduction to the SEJ special issue on business models: Business models within the domain of strategic entrepreneurship. Strategic Entrepreneurship Journal, 9, pp1-11. 
Denis, J.E. (1990). Une synthèse de la recherche sur le comportement des firmes à l'exportation. Working Paper 90-15, University of Ottawa.

Dess, G.G. \& Robinson, R.B. (1984). Measuring Organizational Performance in the Absence of Objective Measures: The Case of the Privately Held Firm and Conglomerate Business Unit. Strategic Management Journal, 5 (3), pp265-73.

Devaux, A, Torero, M., Donovan, J., \& Horton, D. (2018). Agricultural innovation and inclusive value-chain development: a review. Journal of Agribusiness in Developing and Emerging Economies, 8(1), pp99-123. DOI:10.1108/JADEE-06-2017-0065

Dierkes M., Erner, C., Langer, T. \& Norden, L. (2013). Business credit information sparing and default risk of private firms. Journal of Banking \& Finance 37, pp2867-2878.

Dinham, B. \& Hines, C. (1984). Agribusiness in Africa. A study of the impact of big business on Africa's food and agricultural production. Africa World Press, USA

Dolan, C. \& Humphrey, J. (2000). Governance and Trade in Fresh Vegetables: The Impact of UK Supermarkets on the African Horticulture Industry. Journal of Development Studies, 37(2), pp147-76.

Donovan, J., Franzel, S., Cunhja, M., Gyau, A. \& Mithofer, D. (2015). Guides for value chain development: a comparative review. Journal of Agribusiness in Developing and Emerging Economies, 5(1), pp2-23.

Ebrahim, N.A., Ahmed, S. \& Taha, Z. (2010). SMEs; Virtual research and development (R\&D) teams and new product development: A literature review. International Journal of the Physical Sciences, 5(7), pp916-930.

Ecker, O. (2018). Agricultural transformation and food and nutrition security in Ghana: Does farm production diversity (still) matter for household dietary diversity? Food policy, 79, pp271-282.

Eisenhardt, K. M. (1989). Building Theories from Case Study Research. The Academy of Management Review, 14(4), pp532-550.

Eriksson, K., Johanson, J., Majkgård, A. \& Sharma, D.D. (2015). Experiential Knowledge and Cost in the Internationalization Process. In: Forsgren, M., Holm, U. \& Johanson, J. (eds) Knowledge, Networks and Power. Palgrave Macmillan, London.

Fainshmidt, S., Pezeshkan, A., Frazier, M. L., Nair, A., \& Markowski, E. (2016). Dynamic capabilities and organizational performance: A meta-analytic evaluation and extension. Journal of Management Studies, 53(8), pp1348-1380. DOI:10.1111/joms.12213

Falk, I. \& Harrison, L. (1998). Indicators of social capital: social capital as the product of local interactive learning processes. CRLRA discussion paper series B1, University of Tasmania, 18.

Faure G., Desjeux Y. \& Gasselin, P. (2012). New challenges in agricultural advisory services from a research perspective: a literature review, synthesis and research agenda. Journal of Agricultural Education and Extension, 18(5), pp461-492. 
Fernández-Olmos, M. \& Díez-Vial, I. (2015). Intangible Resources, Export Channel and Performance: Is there any fit? Journal of Business Economics and Management, 16(5), pp1013-1033.

Filatotchev, I., Liu, X., Buck, T., \& Wright, M. (2009). The export orientation and export performance of high-technology SMEs in emerging markets: The effects of knowledge transfer by returnee entrepreneurs. Journal of International Business Studies, 40(6), pp1005-1021. DOI:10.1057/jibs.2008.105

Fletcher, M. \& Harris, S. (2011). Knowledge acquisition for the internationalization of the smaller firm: content and sources. International Business Review, 21, pp631-647.

Food and Agricultural Organisation (FAO) (2004). The market for non-traditional agricultural exports. FAO Commodities and Trade Technical Paper.

Fugazza, M. (2004). Export performance and its determinants: Supply and demand Constraints. Policy Issues in International Trade and Commodities Study Series, UNCTAD, 26, pp1-53.

Galati,A., Crescimanno, M., Rossi, M., Farruggia, D. \& Tinervia, S. (2014). The determinants affecting the internationalization of the Italian SMEs producing sparkling wines: an empirical study on the RBV of the firms. International Journal of Globalisation and Small Business, 6(2), pp100-118.

Ganotakis, P. \& Love, J.H. (2012a). Export propensity, export intensity and firm performance: The role of the entrepreneurial founding team. Journal of International Business Studies, 43, pp693-718.

Gashi, P., Hashi, I. \& Pugh, G. (2014). Export behaviour of SMEs in transition countries. Small Business Economics, 42(2), pp407-435. DOI:10.1007/s11187-013-9487

Gerrefi, G. \& Fernandez-Stark, K. (2016). Global value chain analysis: A primer. $2^{\text {nd }}$ ED. UK, Duke CGGC.

Golovko, E. \& Valentini, G. (2011). Exploring the complementarity between innovation and export for SMEs' growth. Journal of International Business Studies, 42, pp362-380.

Goodhue, D.L., Lewis, W. \& Thompson, R. (2012). Does PLS have advantages for small sample size or non-normal data? MIS Quarterly, 36(3), Appendices A1-A16.

Granovetter, M. (1983). The Strength of Weak Ties: A network theory revisited. Sociological Theory, 1, pp201-233.

Granovetter, M. (1973). The strength of weak ties. American Journal of Sociology, 78, pp1360- 1380 .

Greenley, G.E. (1995). Market Orientation and Firm Performance: Empirical Evidence from UK Companies. British Journal of Management, 6(1), pp1-13.

Gulati, R. (1988). Alliances and Networks. Strategic Management Journal, 19, pp293 - 317.

Haenlein, M., \& Kaplan, A. M. (2004). A beginner's guide to partial least squares analysis. Understanding Statistics, 3, pp283-297. 
Hakansson, H. (2015). Industrial Technological Development (Routledge Revivals): A Network Approach. Routledge

Hakansson, H. \& Snehota, I. (1995). Developing relationships in business networks. Routledge London.

Hair Jr., J. F., Sarstedt, M., Hopkins, L. \& Kuppelwieser, V.G. (2014). Partial least squares structural equation modeling (PLS-SEM) An emerging tool in business research. European Business Review, 26(2), pp106-121.

Hair, J.F., Sarstedt, M., Ringle, C.M. \& Mena, J.A. (2012). An assessment of the use of partial least squares structural equation modeling in marketing research. Journal of the Academy of Marketing Science, 40(3), pp414-433.

Hair, J. F., Ringle, C. M. \& Sarstedt, M. (2011). PLS-SEM: Indeed a silver bullet. Journal of Marketing Theory and Practice, 19(2), pp139-151.

Hair. J., Anderson. R., Tatham. R. \& Black. W. (1995). Multivariate data analysis with readings. $4^{\text {th }}$ ED., NJ: Prentice Hall. Englewood Cliffs.

Hamel, G. \& Prahalad, C.K. (1994). Competing for Future. Havard Business School Press, Boston, Massachusetts.

Handayati, Y., Simatupang, T.M. \& Perdana, T. (2015). Agri-food supply chain coordination: the state-of-the-art and recent developments. Logistics Research, 8(1), pp1-15.

Hausman, J. A., (1977). Errors in Variables in Simultaneous Equation Models. Journal of Econometrics, 5 (3), pp389-401.

Hausman, J.A., (1978). Specification tests in econometrics. Econometrica, 46, pp1251-1271.

Hausman, J. A., (1983). Specification and Estimation of Simultaneous Equation Models.

Chapter 7 in Handbook of Econometrics, 1, eds. Z. Griliches and M.D.Intriligator, North Holland.

He, X., Brouthers, K. D. \& Filatotchev, I. (2012). Resource-Based and Institutional Perspectives on Export Channel Selection and Export Performance. Journal of Management, 39(1), pp27-47.

Heiss, G. (2017). Influencing factors and the effect of organizational capabilities on internationalization strategies for German SMEs in the MedTech industry. Management Studies, 5(4), pp263-277. DOI: 10.17265/2328-2185/2017.04.001

Helm, S., Eggert, A., \& Garnefled, I. (2010) Modelling the Impact Corporate Reputation on Customer Satisfaction and Loyalty Using Partial Least Squares. In V. Esposito Vinzi, W. W. Chin, J. Henseler, \& H. Wang. (Eds.) Handbook of Partial Least Squares: Concepts, Methods and Applications, 2, pp515-534. Heidelberg, Germany: Springer.

Henseler, J., \& Fassott, G. (2010). Testing moderating effects in PLS path models: An illustration of available procedures. In V. Esposito Vinzi, W. W. Chin, J. Henseler, \& H. Wang (Eds.), Handbook of Partial Least Squares: Concepts, Methods and Applications, 2, pp713-735. Springer Handbooks of Computational Statistics Series. Springer, Heidelberg, Dordrecht, London, New York. 
Herbig, P.A., Pulambo, F. \& Golden, J.E. (1995). The Evolution of Economic Development: A Case Study of East Asia. Journal of Asia-Pacific Business, 1(1).

Herrmann, P. \& Datta, D.K. (2006). CEO Experiences: Effects on the Choice of FDI Entry Mode. Journal of Management Studies, 43(4), pp755-78.

Hessels, J. \& Terjesen, S. (2010). Resource dependency and institutional theory perspectives on direct and indirect export choices. Small Business Economics 34, pp203-220.

Hinson, R. (2010). The value chain and e-business in exporting: Case studies from Ghana's non-traditional export (NTE) sector. Telematics and Informatics, 27, pp323-340.

Hinson, R., Ofori. D., Kastner, A. \& Mohammed, M. (2008). Market orientation and export performance: a Ghanaian study. African Journal of Business and Economic Research, $3(2 \& 3)$, pp.62-91.

Hinson, R. \& Sorensen, O. J. (2007). E-Business Triggers: An Exploratory Study of Ghanaian Nontraditional Exporters (NTEs). Journal of Electronic Commerce in Organisations, 5(4), pp55-69.

Hoopes, D. G., Madsen, T. L. \& Walker, G. (2003). Why is there a resource-based view? Toward a theory of competitive heterogeneity. Strategic Management Journal, 24(10), pp889-902.

Hugos, M. (2018). Essentials of Supply Chain Management. $4^{\text {th }}$ Ed. John Wiley \& Sons Inc., USA

Hult, G.T.M., Ketchen, D.J. \& Arrfelt, M. (2007). Strategic supply chain management: improving performance through a culture of competitiveness and knowledge development. Strategic Management Journal, 28(10), pp1035.

Hultman, M., Katsikeas, C. S., \& Robson, M. J. (2011). Export promotion strategy and performance: The role of international experience. Journal of International Marketing, 19, pp17-39.

Ibeh, K.I.N. (2003). On the Internal Drivers of Export Performance among Nigerian Firms: Empirical Findings and Implications. Management Decision, 41(3), pp217-225.

International Monetary Fund (IMF) (2019). In: Business News March 1, 2019 : https://www.ghanaweb.com/GhanaHomePage/business/Ghana-4th-fastest-growingeconomy-in-Africa-IMF-727331

Imrana, M., Azelin Aziz binti, A., Abdul Hamid binti, N.S., Shabbir, M.S., Rabia Salman, R. \& Jian, Z. (2018). The mediating role of total quality management between entrepreneurial orientation and SMEs export performance. Management Science Letters, 8, pp519-532

Jain, A., Bhatti, R.S. \& Singh, H. (2015). OEE enhancement in SMEs through mobile maintenance: a TPM concept. International Journal of Quality and Reliability Management, 32(5), pp503-516.

Jalali, S.H. (2012). The explanation of relationship between strategic orientation and export performance. The Journal of Commerce, 4(1), pp40-47. 
Janot, A., Vandanjon, P.O. \& Gautier, M. (2016). A revised Durbin-Wu-Hausman test for industrial robot identification. Control Engineering Practice, Elsevier, 48, pp52-62.

Javalgi, R.G. \& Todd, P.R. (2011). Entrepreneurial orientation, management commitment, and human capital: The internationalization of SMEs in India. Journal of Business Research, 64(9), pp1004-1010.

Javalgi, R. G., Lawson, D., Gross, A., C. \& White, S. D. (1998). Firm characteristics and export propensity: a comparison of manufacturers and manufacturing-based service providers. International Business Review, pp521-534.

Johanson, J. \& Mattsson, L.-G. (2015). Internationalisation in industrial systems-a network approach. Knowledge, Networks and Power. UK, Springer pp111-132.

Johanson, J. \& Mattsson, L.-G. (1987). Interorganizational relations in industrial systems: a network approach compared with the transaction-cost approach. International Studies of Management \& Organization, pp34-48.

Julien, P-A \& Ramangalahy, C. (2003). Competitive Strategy and Performance of Exporting SMEs: An Empirical Investigation of the Impact of Their Export Information Search and Competencies. Entrepreneurship Theory and Practice, pp227-245.

Kamukama, N., Ahiauzu, A. \& Ntayi, J.M. (2011). Competitive advantage: mediator of intellectual capital and performance. Journal of Intellectual Capital, 12(1), pp152-64.

Kawachi, I, Kennedy, B.P., Lochner, K. \& Prothow-Stith, D. (1997). Social capital, income inequality, and mortality. American Journal of Public Health, 87(9), pp1491-1498.

Kayanula, D. \& Quartey, P. (2000). The policy environment for promoting small and mediumsized enterprises in Ghana and Malawi. Finance and Development Research Programme, Working Paper Series, 15, University of Manchester, pp1-29.

Kaynak, E. (1992). A cross regional comparison of export performance of firms in two Canadian regions. Management International Review, 32(2), pp163-180.

Kennedy, P. (1998). A Guide to Econometrics, MIT Press

Khalefa, M. (2018). Internationalisation and performance of small and medium enterprises in the wood and furniture in Damietta Governante, Egypt. (PhD Dissertation), University of Birmingham, United Kingdom.

Khattak, J.K., Arslan, M. \& Umair, M. (2011). SMEs' export problems in Pakistan. Journal of Business Management and Economics, 2(5), pp192-199.

Kim, S. \& Lee, H. (2006). The Impact of Organizational Context and Information Technology on Employee Knowledge-Sharing Capabilities, Public Administration Review, 66(3), pp370-385.

King, K. \& McGrath, S. (1998). Rethinking small enterprise development: between poverty and growth. University of Edinburgh.

Kiss, A.N., Danis, W.M. \& Cavusgil, S.T. (2012). International entrepreneurship research in emerging economies: A critical review and research agenda. Journal of Business Venturing, 27, pp266-290. 
Kleemann, L., Abdulai, A., \& Buss, M. (2014). Certification and access to export markets: Adoption and return on investment of organic-certified pineapple farming in Ghana. WorldDevelopment, 64(12), pp79-92.

Kleinschmidt, E.J. \& Ross, R.E. (1986). Export performance and foreign market information: Relations for small high-technology firms. Journal of Small Business and Entrepreneurship, 4(1), pp14-25.

Kock, N \& Hadaya, P. (2018). Minimum sample size estimation in PLS-SEM: The inverse square root and gamma-exponential methods. Information Systems Journal, 28, pp227261.

Kokutse, F. (2008). Non-Traditional Exports Booming. IPS. Internet source: http://ipsnews.net/news.asp?idnews $=42880$.

Konig, G., da Silva, C. A., \& Mhlanga, N. (2013). Enabling environments for agribusiness and agro-industries development: Regional and country perspectives. Rome, Italy: Food and Agriculture Organization of the United Nations.

Kontinen, T., \& Ojala,A. (2011). Network ties in the international opportunity recognition of family SMEs. International Business Review, 20(4), pp440-453.

Korsakienè, R. \& Tvaronavičienė, M. (2012). The Internationalisation of SMEs: An Integrative Approach. Journal of Business Economics and Management, 13(2), pp294-307.

Krause, D. R., Handfield, R. B. \& Tyler, B. B. (2007). The relationships between supplier development, commitment, social capital accumulation and performance improvement. Journal of Operations Management, 25(2), pp528-545.

Kuada, J. (2005). Internationalisation and Enterprise Development in Ghana. Adonis \& Abbey Publishers Ltd.

Kuada, J. (1993). Knowledge acquisition and the internationalisation process of firms. Working Paper Series, Centre for International Studies, Aalborg University.

Kungwansupaphan, C., \& Siengthai, S. (2014). Exploring entrepreneurs' human capital components and effects on learning orientation in early internationalizing firms. International Entrepreneurship and Management Journal, 10(3), pp561-587.

Kuratko, D.F., Hornsby, J.S., \& Covin, J.G. (2014). Diagnosing a firm's internal environment for corporate entrepreneurship. Business Horizons, 57, pp37-47.

Kwamega, M., Li, D. \& Abrokwah, E. (2018). Supply chain management practices and agribusiness firms' performance: Mediating role of supply chain integration. South African Journal of Business Management, 49(1), pp317. https://doi.org/10.4102/ sajbm.v49i1.317

Kyereboah-Coleman, A. \& Biekpe, N. (2006). The relationship between board size, board composition, CEO duality and firm performance: evidence from Ghana. Corporate Ownership and Control, 4(2), pp114-22. 
Lages, L. F, Jap, S.D. \& Griffith, D.A. (2008). The Role of Past Performance in Export Ventures: A Short-Term Reactive Approach. Journal of International Business Studies, 39(2), pp304-25.

Lambert, D. M. \& Pohlen, Terrance L. (2001). Supply Chain Metrics. International Journal of Logistics Management, 12(1), pp1 - 19.

Lechner, C. \& Gudmundsson, S. V. (2014). Entrepreneurial orientation, firm strategy and small firm performance. International Small Business Journal, 32(1), pp36-60.

Leeds, A. (1964). Brazilian careers and social structure: an evolutionary model and case history. 66, American Anthropologist 1321

Levy, B. \& Spiller, P.T. (1994). The Institutional Foundations of Regulatory Commitment: A Comparative Analysis of Telecommunications Regulation. Journal of Law, Economics and, Organisations, 10, pp201-246.

Li, S., Subba, R. S., Ragu-Nathan, T.S. \& Ragu-Nathan B. (2005). Development and validation of a measurement instrument for studying supply chain management practices. Journal of Operations Management, 23, pp618-641.

Lin, Y. \& Wu, L. (2014). Exploring the role of dynamic capabilities in firm performance under the resource-based view framework. Journal of Business Research, 67(3), pp407-413.

Liñán, F., Paul, J., \& Fayolle, A. (2019). SMEs and entrepreneurship in the era of globalization: advances and theoretical approaches. Small Business Economics, pp1-9.

Livingston, G., Schonberger, S., \& Delaney, S. (2011). Sub-Saharan Africa: The state of smallholders in 664 agriculture. In IFAD Conference on New Directions for Smallholder Agriculture. Rome.pp1-32.

Long, N. (2001). Development sociology: actor perspectives. London, Routledge.

Love, J.H. \& Roper, S. (2015). SME innovation, exporting and growth: A review of existing evidence. International Small Business Journal, 33(1) pp28-48.

Lozano, R., Carpenter, A., \& Huisingh, D. (2014). A review of 'theories of the firm' and their contributions to Corporate Sustainability. Journal of Cleaner Production. DOI:10.1016/j.jclepro.2014.05.007

Lyon, F. (2000). Trust, Networks and Norms: The Creation of Social Capital in Agricultural Economies in Ghana. World Development, 28(4), pp663-681.

Madsen, T.K. (1987). Empirical export performance studies. Advances in International Marketing, 2(2), pp178-198.

Mahmood, S. (2008). Corporate Governance and Business Ethics for SMEs in Developing Countries: Challenges and Way Forward. Paper presented at the International Society of Business, Economics, and Ethics World Congress. 15-18 July 2008. Cape Town, South Africa.

Mahmoud, M.A. (2011). Market Orientation and Business Performance among SMEs in Ghana. International Business Research, 4(1), pp241-251.

Makri, K., Theodosiou, M. \& Katsikea, E. (2017). An empirical investigation of the 
antecedents and performance outcomes of export innovativeness. International Business Review, 26, pp628-639.

Manev, I.M.,Yan, A. \& Manolova, T. (2005). Toward a model of governance and legality in transforming economies: Empirical evidence from China. Thunderbird International Business Review, 47(3), pp313-334.

Maurel, C. (2009). Determinants of Export Performance in SMEs: The Case of the French Wine Industry. International Journal of Wine Business Research, 21(2), pp118-142.

McAdam, R. \& McCormack, D. (2001). Integrating business processes for global alignment and supply chain management. Business Process Management Journal, 7(2), pp113 130.

Mensah, S. (2004). A review of SME Financing Schemes in Ghana. UNIDO Regional

Workshop of Financing Small and Medium Scale Enterprises, Accra, Ghana, (15-16 March 2004), pp1-20.

Meyer, K.E. \& Peng, M.W. (2005). Probing theoretically into Central and Eastern Europe: transactions, resources, and institutions. Journal of International Business Studies, 36, pp600-621.

Miles, R.E. and Snow, C.C. (2007). Organization Theory and Supply Chain Management: An Evolving Research Perspective. Journal of Operations Management, (25), pp459-463.

Milgate, M. (2001). Supply chain complexity and delivery performance: an international exploratory study. Supply Chain Management: An International Journal, 6(3), pp106118.

Mitgwe, B. (2006). Theoretical milestones in international business: The journey to international entrepreneurship theory. Journal of International Entrepreneurship, 4, pp5-25.

Nakajima, S. (1988). Introduction to Total Productive Maintenance (TPM). Productivity Press, Cambridge (translated into English from the original text published by the Japan Institute for Plant Maintenance, Tokyo, Japan, 1984).

Nakamura, A. \& Nakamura, M. (1985). On the Performance of Tests by WU and by Hausman for detecting the Ordinary Least Squares Bias Problem. Journal of Econometrics, 29, pp213-227.

New Partnerships for Africa's Development-NEPAD (2012). www.nepad.org/filedownload/download/public/117408

Newman, L. L. \& Newman D.A. (2005). Network structure, diversity, and proactive resilience building: a response to Tompkins and Adger. Ecology and Society 10(1): r2.

Newman, M.E.J. (2003). The Structure and Function of Complex Networks. SIAM Review.

Ngo, V. D., Janssen, F., Leonidou, L.C. \& Christodoulides, P. (2016). Domestic institutional attributes as drivers of export performance in an emerging and transition economy. Journal of Business Research, 69(8), pp2911-2922.

Nguyen, T. V., Le, N.T.B. \& Bryant, S.E. (2013). Sub-National Institutions, Firm Strategies, 
and Firm Performance: A Multilevel Study of Private Manufacturing Firms in Vietnam. Journal of World Business, 48(1), pp68-76.

Nicholas, J., Ledwith, A. \& Perks, H. (2011). New product development best practice in SME and large organisations: theory vs practice. European Journal of Innovation Management, 14(2), pp227-251.

Nkwe, N. (2012). Role of SMEs in Botswana. American International Journal of Contemporary Research, 2(8), pp29-37.

Noke, H. \& Hughes, M. (2010). Climbing the value chain: strategies to create a new product development capability in mature SMEs. International Journal of Operations and Production Management, 30(2), pp132-154.

North, D.C. (1990). Institutions, Institutional Change and Economic Performance. Cambridge University Press.

Ocloo, C.E., Akaba,S., \& Worwui-Brown, D.K. (2014). Globalization and Competitiveness: Challenges of Small and Medium Enterprises (SMEs) in Accra, Ghana. International Journal of Business and Social Science, 5(4), pp287-296.

Okpara, J.O. (2010). Strategic export orientation and internationalization barriers: Evidence from SMEs in a developing economy. Journal of International Business and Cultural Studies, 4, pp1-10.

Okpara, J. O., \& Koumbiadis, N. J. (2009). Strategic export orientation and internationalization barriers: evidence from SMEs in a developing economy. Journal of International Business and Cultural Studies, 1, pp1-10.

Onetti, A., Zucchella, A., Jones, M.V. \& McDougall-Covin, P.P. (2012). Internationalization, innovation and entrepreneurship: Business models for new technology-based firms. Journal of Management and Governance, 16, pp337-368.

Oppong, M., Owiredu, A., \& Churchill, R. Q. (2014). Micro and small scale enterprises development in Ghana. European Journal of Accounting Auditing and Finance Research, 2(6), pp84-97.

Ouma, S., Boeckler, M. \& Lindner, P. (2013). Extending the margins of marketization: Frontier regions and the making of agro-export markets in northern Ghana. Geoforum, 48, pp225-235.

Oyelaran-Oyeyinka, B. (2004). Human Capital and Systems of Innovation in African Development. African Development Review.

Paul, J., Parthasarathy, S. \& Gupta, P. (2017). Exporting challenges of SMEs: A review and future research agenda. Journal of World Business, 52, pp327-342.

Pavel, A., Tsipi, H., Hanan, M., \& Nava, P. (2009). Validating Formative Partial Least Squares (PLS) Models: Methodological Review and Empirical Illustration. International Conference on Information Systems (ICIS) Proceedings, pp193.

Percy, D. \& Kobbacy, B. (1997). Setting preventive maintenance schedules when data are 
sparse. International Journal of Production Economics, 51, pp223-234.

Peteraf, M.A. (1993). The cornerstones of competitive advantage: A resource-based view. Strategic Management Journal, 14(3), pp179-191.

Porter, M.E. (1985). Competitive advantage, NY: The Free Press.

Prahalad, C.K. \& Hamel, G. (1990). Core Competencies of the Corporation. Havard Business Review, pp1-15.

Quartey, P., Turkson, E., Abor, J.Y., Iddrisu, A.M. (2017). Financing the growth of SMEs in Africa: What are the contraints to SME financing within ECOWAS? Review of Development Finance, 7(1), pp18-28.

Quaye, I., Abrokwah, E., Sarbah, A. \& Osei, J.Y. (2014). Bridging the SME Financing Gap in Ghana: The Role of Microfinance Institutions. Open Journal of Business and Management, 2, pp339-353.

Redding, S. \& Venables, A.J. (2004). Geography and export performance: External market access and internal supply capacity. In Challenges to globalization: Analyzing the economics, National Bureau of Economic Research, Working Paper 9637, pp95-130.

Reuber, R. A. \& Fischer, E. (1997). The Influence of the management team's international experience on the internationalization behaviors of SMEs. Journal of International Business Studies, 28(4), pp807-825.

Reyes, P.M., Worthington, W.J. \& Collins, J.D. (2015). Knowledge management enterprise and RFID systems: Adoption to supply chain performance. Management Research Review, 38(1), pp44-66. https://doi.org/10.1108/MRR-01-2013-0011

Ricci, L.A. \& Trionfetti, F (2011). Productivity, networks, and export performance: evidence from a cross-country firm dataset. GREQAM, HALArchives-Ouvertes.fr.

Ricketts, K., Turvey, C. \& Gomez, M. (2014). Value chain approaches to development: smallholder farmer perceptions of risk and benefits across three cocoa chains in Ghana. Journal of Agribusiness in Developing and Emerging Economies, 4(1), pp2-22.

Ringle, C.M., Wende, S. \& Will, A. (2005). SmartPLS 2, SmartPLS, Hamburg

Ringle, C.M., Sarstedt, M. \& Straub, D.W. (2012). A Critical Look at the Use of PLS-SEM in MIS Quarterly. MIS Quarterly, 36(1) ppiii-xiv.

Roberts, M.J., Xu, Y.D., Fan, X. \& Zhang, S. (2012). A Structural Model of Demand, Cost, and Export Market Selection for Chinese Footwear Producers. NBER Working Paper Series.

Roepstorff, T. M. \& Wiggins, S. (2011). New global realities governing agribusiness. In Agribusiness for Africa's prosperity. UNIDO

Rogerson, C. M. (2000). Successful SMEs in South Africa: the case of clothing producers in the Witwatersrand. Development Southern Africa, 17(5), pp687-716.

Rosenbusch, N., Brinckmann, J. \& Bausch, A. (2011). Is innovation always beneficial? A meta-analysis of the relationship between innovation and performance in SMEs. Journal of Business Venturing, 26(4), pp441-457.

Ross, A. (1989). No respect: intellectuals \& popular culture. Routledge. 
Rostamkalaei, A. \& Freel, M. (2016). The cost of growth: small firms and the pricing of bank loans. Small Business Economics, 46(2), pp255-272. DOI: 10.1007/s11187-015-9681-X

Roxas, H. B., Ashill, N. \& Victorio A. (2006). An institutional view of local entrepreneurial climate, Journal of Asia Entrepreneurship and Sustainability, 3(1), pp1-17.

Rugman, A.M., \& Oh, C.H. (2012). Why the home region matters: location and regional multinationals. British Journal of Management, 24(4), pp463-479.

Sanchez, R. (2008). A scientific critique of the resource-base view (RBV) in strategy theory, with competence-based remedies for the RBV's conceptual deficiencies and logic problems. In R. Sanchez (Ed.): Fundamental issues in competence theory development (Research in competence-based management) (4), pp3-78. Emerald Group Publishing Limited.

Sarkis, J., Zhu, Q., Lai, K.-H., (2011). An organizational theoretic review of green supply chain management literature. International Journal of Production Economics, 130, pp1-15.

Schaffnit-Chatterjee, C. (2014). Agricultural value chains in sub Saharan Africa: From a development challenges to a business opportunity. Deutsche Bank Research, April 2014.

Schmitt, N. (1996). Uses and abuses of coefficient alpha. Psychological assessment, 8, pp350353.

Schumpeter, J. A. (1934). The theory of economic development; an inquiry into profits, capital, credit, interest, and the business cycle. Cambridge, MA: Harvard University Press.

Semadeni, M., Withers, M. C. \& Certo, S.T. (2014).The Perils of Endogeneity and Instrumental Variables in Strategy Research: Understanding through Simulations. Strategic Management Journal, 35, pp1070-1079

Seoudi, I. (2009). The resource-capability-competence perspective in strategic management: A reappraisal of the epistemological \& theoretical foundations. Published PhD Thesis, Department of Economics, School of Graduate Studies, Case Western Reserve University.

Seringhaus, Rolf F.H. \& Rosson, Philip J. (2001). Firm Experience and International Trade Fairs. Journal of Marketing Management, 17 (7 \& 8), pp877-901.

Seringhaus, R. (1993). Comparative marketing behaviour of Canadian and Austrian high-tech exporters. Management International Review, 33(3), pp247-268.

Shafeey, T. E., \& Trott, P. (2014). Resource-based competition: Three schools of thought and thirteen criticisms. European Business Review, 26, pp122-148. doi:10.1108/EBR-072013-0096

Shaffer, M. A. \& Harrison, D. A. (1998). Expatriates' psychological withdrawal from international assignments: Work, non-work, and family influences. Personnel Psychology, 51, pp87-118.

Shane, S. \& Venkataraman, S. (2000). The Promise of Enterpreneurship as a Field of Research. The Academy of Management Review, 25(1), pp217-226.

Shaver, J. M., Mitchell, W. \& Yeung, B. (1997). The effect of own-firm and other-firm 
experience on foreign direct investment survival in the United States, 1987-92. Strategic Management Journal, 18(10), pp811-824.

Shaver, K.G \& Scott, 1.R. (1991). The promise of entrepreneurship as a field of research. Academy of Management Review, 25(1), pp217-226.

Sheahan, M. \& Barrett, C.B. (2017). Ten striking facts about agricultural input use in SubSaharan Africa. Food Policy, 67, pp12-25

Shleifer A. \& Vishny, R. (1997). A survey of corporate governance. Journal of Finance, 52, pp737-783

Shrader, R. \& Siegel, D. S. (2007). Assessing the Relationship between Human Capital and Firm Performance: Evidence from Technology-Based New Ventures. Entrepreneurship Theory and Practice, 6, pp893-908.

Shukla, M. \& Jharkharia, S. (2013). Agri-fresh produce supply chain management: a state-ofthe-art literature review. International Journal of Operations \& Production Management, 33(2), pp1-61. DOI:10.1108/01443571311295608

Sibomana, M. S., Workneh, T.S. \& Audain, K. (2016). A review of postharvest handling and losses in the fresh tomato supply chain: a focus on Sub-Saharan Africa. Food Security, 8, pp389-404. DOI:10.1007/S12571-016-0562-1.

Smith, B.D., Pitta, D. A. \& Richardson, L. (2007). A Comparison of the market orientation of Chinese and US Firms. International Business \& Economics Research Journal, 6(12), pp25-38

Sousa, M.P.C. \& Tan, Q. (2015). Exit from a Foreign Market: Do Poor Performance, Strategic Fit, Cultural Distance, and International Experience Matter? Journal of International Marketing, 23(4), pp84-100.

Sousa, C.M.P. \& Bradley, F. (2006). Cultural Distance and Psychic Distance: Two Peas in a Pod? Journal of International Marketing, 14(1), pp49-70.

Sraha, G., Raman Sharma, R., \& Crick, D. (2017). Ghanaian exporters' international experience and performance: the mediating role of export commitment. Journal of Strategic Marketing, 25(4), pp353-365.

Stam, W., Arzlanian, S. \& Elfring, T. (2013). Social capital of entrepreneurs and small firm performance: A meta-analysis of contextual and methodological moderators. Journal of Business Venturing, 1(2), pp1-22.

Suarez-Ortega, S. (2003). Export Barriers: Insights from small and medium-sized firms. International Small Business Journal, 21(4), pp403-419.

Sui, S., \& Baum, M. (2014). Internationalization strategy, firm resources and the survival of SMEs in the export market. Journal of International Business Studies, 45(7), pp821-841. DOI:10.1057/jibs.2014.11

Takeuchi, R., Tesluk, P.E., Yun, S., \& Lepak, D.P. (2005). An Integrative View of International Experience. Academy of Management Journal, 48(1), pp85-100.

Tan, K.C. (2002). Supply chain management: practices, concerns, and performance issues. 
Journal of Supply Chain Management, 38(1), pp42-53.

Teal, F.(2002). Background Information On Use Of Dataset: Regional Project On Enterprise Development (RPED) Ghana Manufacturing Sector Survey Waves I-V (1992-98). Centre for the Study of African Economies, Institute of Economics and Statistics, University of Oxford.

Terjesen, S., Hessels, J. \& Li, D. (2016). Comparative international entrepreneurship. A review and research agenda. Journal of Management, 42, pp299-344.

Terziovski, M. (2010). Innovation Practice and its Performance Implications in Small and Medium Enterprises (SMEs) in the Manufacturing Sector: A Resource-Based View. Strategic Management Journal. 31(8), pp892-902.

Tetteh, D.O. (1995). Institutional support for non-traditional exports in Ghana. Unpublished MBA Thesis, University of Ghana, School of Administration, Accra, Ghana.

Thanos, I.C., Dimitratos, P. \& Sapouna, P. (2017). The implications of international entrepreneurial orientation, politicization and hostility upon SME international performance. International Small Business Journal, 35(4), pp495-515. DOI: $10.1177 / 0266242616641749$.

Thursby, J. G. \& Schmidt, P. (1977). Some Properties of Tests for Specification Error in a Linear Regression Model. Journal of the American Statistical Association, 72, pp635-641.

Tsai, K-H \& Wang, J-C. (2008). External technology acquisition and firm performance: A longitudinal study. Journal of Business Venturing, 23(1), pp91-112.

Tsinopoulos, C., Lages, L.F. \& Sousa, C.M.P. (2014). Export Experience Counts: Exploring Its Effect on Product Design Change. R\&D Management, 44(5), pp450-65.

Ucbasaran, D., Westhead, P. \& Wright, M. (2008). Opportunity Identification and Pursuit: Does an Entrepreneur's Human Capital Matter? Small Business Economics, 30(2), pp153-173.

United Nations Communications Group (UNCG) \& Civil Society Organisations (CSOs) Platform Ghana (2017). The Sustainable Development Goals in Ghana. Why they matter \& how we can help. Publication sheet.

https://www.undp.org/content/dam/unct/ghana/docs/SDGs/UNCT-GH-SDGs-inGhana-Avocacy-Messages-2017.pdf

Van Ittersum, M. K., Van Bussel, L. G. J., Wolf, J., Grassini, P., Van Wart, J., Guilpart, N., Claessens, L., de Groot, H., Wiebe, K., Mason-D'Croz, D., Yang, H., Boogaard, H., Van Oort, P.A.J., Van Loon, M.P., Saito, K., Adimo, O., Adjei-Nsiah, S., Agali, A., Bala, A., Chikowo, R., Kaizzi, K., Kouressy, M., Makoi, J.H.J.R., Ouattara, K., Tesfaye, K., Cassman, K.G. (2016). Can sub-Saharan Africa feed itself? Proceedings of the National Academy of Sciences of the United States of America, 113, pp14964-14969.

Van Rooyen, C.J. (2014). Towards 2050: Trends and scenarios for African agribusiness. 
International Food and Agribusiness Management Review, 17(1), pp19-39.

Venkataraman, S. (1997). The distinctive domain of entrepreneurship research: an editor's perspective. In Advances in Entrepreneurship, Firm Emergence, and Growth. J. Katz, R. Brouckhaus, EDS. JAI Press, Greenwhich, CT.

Wang, Z \& Wang, N. (2012). Knowledge sharing, innovation and firm performance. Expert Systems with Applications, 39, pp8899-8908.

Wanjiru, M. \& Makori, M. 2016. Role of traceability in Kenya's Credence Export Goals: From the perspective of new institutional economics and supply chain management frameworks. Vilakshan, XIMB Journal of Management, 13(1).

Webb, J.W., Ireland, R.D. \& Ketchen Jnr., D.J. (2014). Toward a Greater understanding of entrepreneurship and strategy in the informal economy. Strategic Entrepreneurship Journal, 8, pp1-15.

Welbourne, T.M. \& Pardo-del-Val, M. (2009). Relational Capital: Strategic Advantage for Small and Medium-Size Enterprises (SMEs) through Negotiation and Collaboration. Group Decision and Negotiation, 18(5), pp483-497. DOI 10.1007/s10726-008-9138-6

Wernerfelt, B. (1984). A resource-based view of the firm. Strategic Management Journal, 5, pp171-180.

Whitfield, L. (2011c). Political Challenges to Developing Non-Traditional Exports in Ghana: The Case of Horticulture Exports. DIIS Working Paper 2011:29 (Copenhagen: Danish Institute for International Studies).

Wignaraja, G. (2001). Firm Size, Technological Capabilities and Market-Oriented Policies in Mauritius. UNU/INTECH Discussion Papers. pp7-41.

Wiklund, H. \& Wiklund, P. (1999). A collaboration concept for TQM implementation in small and medium sized enterprises. International Journal of Applied Quality Management, 2 (1), pp101-115.

Willer, H. \& Lernoud J. Julia (Eds.) (2017). The World of Organic Agriculture. Statistics and Emerging Trends 2017. Research Institute of Organic Agriculture (FiBL), Frick, and IFOAM - Organics International, Bonn. Version 1.3.

Williamson, O.E (1993). Calculativeness, Trust, and Economic Organization. Journal of Law and Economics.

Winer, B.J. (1971). Statistical Principles in Experimental Design, $2^{\text {nd }}$ Ed. NY. McGraw-Hill.

Wolff, J.A. \& Pett, T.L. (2000). Internationalization of small firms: An examination of export competitive patterns, firm size, and export performance. Journal of Small Business Management, 38(2), pp34-47.

Wong, K.K.-K. (2013). Partial Least Squares Structural Equation Modeling (PLS-SEM) Techniques Using SmartPLS. Marketing Bulletin, 24(1), pp1-32.

Wooldridge, J. M. (2002). Introductory Econometrics: A Modern Approach, Southwestern.

Woolthuis, R.K., Hillebrand, B. \& Nooteboom, B. (2005). Trust, Contract and Relationship 
Development. Organization Studies, 26(6), pp813-840.

DOI: $10.1177 / 0170840605054594$

World Development Report (WDR), 2008: Agribusiness for development. Focus D.

Yamin, M. \& Kurt, Y. (2018). Revisiting the Uppsala internationalization model: Social network theory and overcoming the liability of outsidership. International Marketing Review, 35(1), pp2-17.

Yamoah E.E., Arthur, S. \& Abdullai I. (2014). Institutional Framework for Promoting Small and Medium Scale Enterprises in Ghana: Perspective of Entrepreneurs. Australian Journal of Business and Management Research, 3(10), pp28-45.

Yan, S. \& Chew, D.A.S. (2011). An investigation of marketing strategy, business environment and performance of construction SMEs in China. African Journal of Business Management, 5(6), pp2396-2405

Yeboah, M. A. (2014). Analysis of entrepreneurship: How does culture influence risk taking in SMEs in the Sekondi-Takoradi Metropolis, Ghana? American International Journal of Contemporary Research, 4, pp131-140.

Yin, R. K. (2003). Case Study Research: Design and Methods. Applied Social Research Methods Series, Sage Publications, 3 Ed., 5.

Zaiem, I \& Zghidi, A.B.Y. (2011). Product Adaptation Strategy and Export Performance: The Impacts of the Internal Firm Characteristics and Business Segment. Contemporary Management Research, 7(4), pp291-312.

Zahra, S.A. \& Covin, J.G. (1994). The financial implications of fit between competitive strategy and innovation types and sources. The Journal of High Technology Management Research, 5(2), pp183-211.

Zindiye, S., Chiliya, N. \& Masocha, R. (2012). The impact of Government and other Institutions' support on the Performance of Small and Medium Enterprises in the Manufacturing Sector in Harare, Zimbabwe. International Journal of Management and Economic Research, 3(6), pp655-667.

Zou, S. \& Stan, S. (1998). The determinants of export performance: a review of the empirical literature between 1987 and 1997. International Marketing Review, 15(5), pp333 
PhD Candidate: RITA ABBAN

Registration No.: 680522-003-070

Group/Department: Management Studies

COMPLETED TRAINING AND SUPERVISION PLAN

\begin{tabular}{|c|c|c|c|c|c|}
\hline No & Name of the course & Department/Institute & $\begin{array}{l}\text { Estimated } \\
\text { costs }(€)\end{array}$ & Year & $\begin{array}{c}\text { ECTS } \\
(=28 \mathrm{hrs})\end{array}$ \\
\hline \multicolumn{6}{|c|}{ I. General part } \\
\hline 1 & $\begin{array}{l}\text { Corporate Governance and } \\
\text { Economic Performance }\end{array}$ & $\begin{array}{l}\text { University of Oslo } \\
\text { Oslo, Norway }\end{array}$ & $\mathrm{n} / \mathrm{a}$ & 1997 & 3 \\
\hline 2 & Corporate Governance & Institute of Directors, Ghana & $\mathrm{n} / \mathrm{a}$ & 2000 & 1 \\
\hline 3 & $\begin{array}{l}\text { Science, the Press and the General Public: } \\
\text { Communication and Interaction }\end{array}$ & $\begin{array}{l}\text { Wageningen Graduate Schools } \\
\text { (WGS) }\end{array}$ & 150 & $2009, \mathrm{P} 4$ & 1 \\
\hline 4 & $\begin{array}{l}\text { Techniques for writing and } \\
\text { presenting a scientific paper }\end{array}$ & $\begin{array}{l}\text { Wageningen Graduate Schools } \\
\text { (WGS) }\end{array}$ & 230 & $2010, \mathrm{P} 2$ & 1.2 \\
\hline 5 & Research Proposal & Social Sciences-MST & $\mathrm{n} / \mathrm{a}$ & $2008, \mathrm{P} 2$ & 6 \\
\hline \multirow[t]{2}{*}{6} & Information Literacy PhD and EndNote Introduction & WUR Library & 130 & $2009, \mathrm{P} 3$ & 0.6 \\
\hline & Subtotal part I (min. 3-4 ECTS) & & & & 12.8 \\
\hline \multicolumn{6}{|c|}{ II. Mansholt-specific part } \\
\hline 7 & Mansholt Introduction course & Mansholt Graduate School & 150 & $2009, \mathrm{P} 4$ & 1.5 \\
\hline 8 & Mansholt Multidisciplinary Seminar & Mansholt Graduate School & $\mathrm{n} / \mathrm{a}$ & $2009, \mathrm{P} 4$ & 1 \\
\hline 9 & $\begin{array}{l}\text { Connecting the Dots: A Case Study of Network } \\
\text { Relationships of Small and Medium-Sized Enterprises } \\
\text { (SMEs) in the Non Traditional Agricultural Export } \\
\text { (NTAE) Sector of Ghana. }\end{array}$ & PhD Day - May 26, 2010 & $\mathrm{n} / \mathrm{a}$ & $2010, \mathrm{P} 5$ & 1 \\
\hline 10 & $\begin{array}{l}\text { Perceptions of Development Partners how to improve } \\
\text { Ghana's Agribusiness Sector }\end{array}$ & PhD Day - May 10, 2012 & $\mathrm{n} / \mathrm{a}$ & $2012, \mathrm{P} 5$ & 1 \\
\hline 11 & $\begin{array}{l}\text { Perceptions on Agriculture and Agribusiness in Ghana- } \\
\text { Civil Society Organisations (CSOs) }\end{array}$ & $\begin{array}{l}\text { Africa Green Revolution } \\
\text { Forum, Tanzania Sept 26-28 }\end{array}$ & $\mathrm{n} / \mathrm{a}$ & 2012 & 1 \\
\hline 12 & $\begin{array}{l}\text { Agribusiness: A key determinant of overall economic } \\
\text { growth and poverty reduction in Africa }\end{array}$ & $\begin{array}{l}\text { World Association of Small } \\
\text { and Medium Enterprises } \\
\text { International Conference, } \\
\text { Ghana Nov 7-11 }\end{array}$ & $\mathrm{n} / \mathrm{a}$ & 2012 & 1 \\
\hline 13 & $\begin{array}{l}\text { Some Perspectives on Agriculture and Agribusiness } \\
\text { in Sub-Saharan Africa }\end{array}$ & $\begin{array}{l}\text { International Conference on } \\
\text { Education, Technology and } \\
\text { Entrepreneurship, Ghana Sept } \\
11-12\end{array}$ & $\mathrm{n} / \mathrm{a}$ & 2019 & 1 \\
\hline & Subtotal part II (min.4 ECTS) & & & & 7.5 \\
\hline \multicolumn{6}{|c|}{ III. Discipline-specific part } \\
\hline & Organisation of Agribusiness & BEC 31306 & $\mathrm{n} / \mathrm{a}$ & $2009, \mathrm{P} 2$ & 6 \\
\hline 15 & Technology Innovation \& Strategy & MST 30306 & $\mathrm{n} / \mathrm{a}$ & $2009, \mathrm{P} 4$ & 6 \\
\hline 16 & $\begin{array}{l}\text { The Economic Institutions of Agriculture, Food and } \\
\text { Rural Areas: Institutional Dynamics, Organizations } \\
\text { and Governance }\end{array}$ & MGS & 275 & $2009, \mathrm{P} 4$ & 1.5 \\
\hline 17 & Advanced Supply Chain Management & ORL 31306 & $\mathrm{n} / \mathrm{a}$ & $2009, \mathrm{P} 4$ & 6 \\
\hline 18 & $\begin{array}{l}\text { Method, Techniques and Data Analysis of Field } \\
\text { Research }\end{array}$ & RDS 33306 & $\mathrm{n} / \mathrm{a}$ & $2009, \mathrm{P} 5$ & 6 \\
\hline \multirow[t]{2}{*}{19} & Institutions, Knowledge and Information & NOVA PhD Certificate & $\mathrm{n} / \mathrm{a}$ & $27 / 7 / 10$ & 6 \\
\hline & Subtotal part III (min. 15-18 ECTS) & & & & 31.5 \\
\hline \multicolumn{6}{|c|}{$\begin{array}{l}\text { IV. Teaching and supervising activities (optional) } \\
\text { Courses of interest: }\end{array}$} \\
\hline 20 & Course A Corporate Financial Management & MST20806 & & $2008, \mathrm{P} 2$ & 1 \\
\hline \multirow[t]{3}{*}{21} & Course B Financial Business Management & MST22806 & & $2009, \mathrm{P} 4$ & 1 \\
\hline & Subtotal part IV (max 4 ECTS) & & & & 2 \\
\hline & & TOTAL & \multicolumn{2}{|c|}{ (min. 30 ECTS) } & 53.8 \\
\hline
\end{tabular}




\section{Funding}

The $\mathrm{PhD}$ programme including training, study, fieldwork and research was funded by the PhD student, Rita Abban.

Funding from the following sources towards $\mathrm{PhD}$ thesis printing are acknowledged: the Business Management and Organisation - BMO ( formerly Management Studies - MST). Social Sciences Group, Wageningen University, and, the Council for Scientific and Industrial Research, Ghana.

Funding from Nana Awuah-Darko Ampem II to support PhD defense is also acknowledged. 


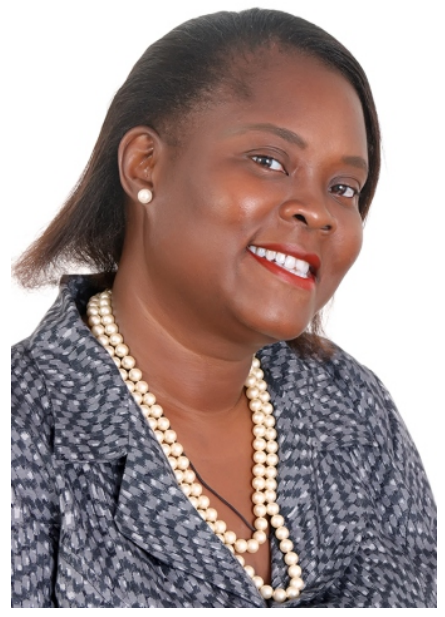

\section{About the Author}

Rita Abban was born in Accra, Ghana on May 22, 1968. She hails from the Western Region (Axim and Sekondi) and is an Akan. Rita completed her G.C.E. O' and A' levels from Achimota school in 1985 and 1987 respectively. She obtained a diploma in French from Alliance Francaise in Accra in 1988 and later proceeded to obtain her BCom degree and Diploma in Education from the University of Cape-Coast in 1992. In 1997, she graduated from the Norwegian School of Management (BI) in Sandvika, Norway with an Msc. in Financial Economics. She obtained a Doctoral Certificate in Corporate Governance and Economic Performance from the University of Oslo in 1997. She completed the Maastricht School of Management MPhil programme in December 2007 and entered the PhD programme of Wageningen University in October 2008 with the Management Studies Group, Wageningen School of Social Sciences (WASS). She has obtained a number of certificates in corporate governance, intellectual property, and financial management.

Rita has worked in various capacities (and also as a consultant, technical advisor) with international and national institutions including the World Bank Group, the Ministry for Private Sector Development (MPSD), State Enterprises Commission, Ghana Institute of Management and Public Administration (GIMPA), Danish International Development Agency (DANIDA), Ernst \& Young, and currently with the Council for Scientific and Industrial Research. She has worked as a lecturer at the Wisconsin University College, Ghana, Methodist University Ghana and visiting lecturer to Central University College, Ghana. Her teaching work extended to Wageningen University where she was an assistant lecturer on the Corporate Financial Management and Financial Business Management courses. As part of her $\mathrm{PhD}$ programme, she had opportunity to present papers at various international conferences and workshops and has also published her works.

Rita Abban's research is on Firm Characteristics, Business Environment, and Performance of Non-Traditional Agricultural SME Exporters in Ghana.

Rita may be reached at rabban22@gmail.com and on +233 244968415; +233 263374732. 


\title{
Cover Design
}

Anne-Marie Abban-Demitrus

\author{
Cover Layout \\ Eric Sam \\ Printing \\ CSIR-INSTI, Accra Ghana \\ CRita Abban, 2019
}




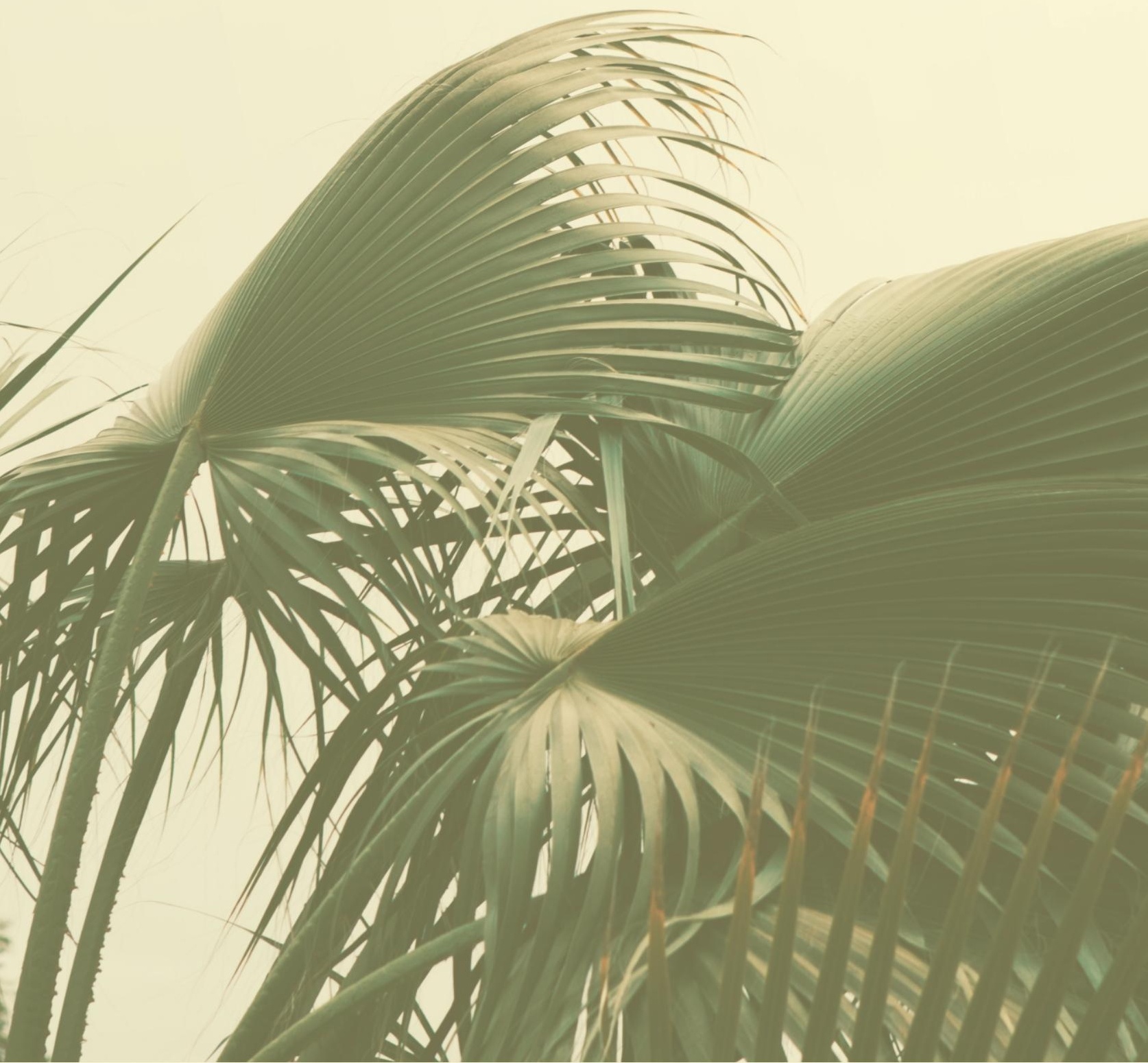

